Slavistische Beiträge · Band 423

(eBook - Digi20-Retro)

Claudia Böhler

Das Russisch-Deutsche Wörterbuch

von Iwan Pawlowsky

Eine metalexikographische Analyse

Verlag Otto Sagner München - Berlin - Washington D.C.

Digitalisiert im Rahmen der Kooperation mit dem DFG-Projekt „Digi20“

der Bayerischen Staatsbibliothek, München. OCR-Bearbeitung und Erstellung des eBooks durch den Verlag Otto Sagner:

http://verlag.kubon-sagner.de

( $)$ bei Verlag Otto Sagner. Eine Verwertung oder Weitergabe der Texte und Abbildungen, insbesondere durch Vervielfältigung, ist ohne vorherige schriftliche Genehmigung des Verlages unzulässig.

«Verlag Otto Sagner» ist ein Imprint der Kubon \& Sagner GmbH. 


\title{
SLAVISTISCHE BEITRÄGE
}

\author{
Herausgegeben von \\ Peter Rehder
}

\author{
Beirat: \\ Tilman Berger • Walter Breu • Johanna Renate Döring-Smirnov \\ Walter Koschmal • Ulrich Schweier • Miloš Sedmidubský • Klaus Steinke
}

BAND 423

\section{VERLAG OTTO SAGNER MÜNCIIEN 2003}


Claudia Böhler

Das russisch-deutsche Wörterbuch von Iwan Pawlowsky

- eine metalexikographische Analyse -

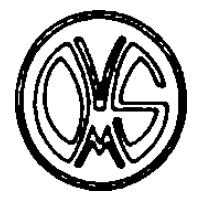

VERLAG OTTO SAGNER MÜNCHEN 2003 
ISBN 3-87690-854-X

(1) Verlag Otto Sagner, München 2003 Abteilung der Firma Kubon \& Sagner

D-80328 München

Gedruckt auf alterungsbeständigem Papier 


\section{Vorwort}

Die vorliegende Arbeit wurde im August 2002 vom Fachbereich Slavische Philologie der Philosophischen Fakultät der Georg-August-Universität in Göttingen als Dissertation angenommen. Ich danke meinem Doktorvater Herm Prof. Dr. Werner Lehfeldt, der Forschung und Lehre in meinen Augen beispielhaft verbindet, dafür dass er mich so hervorragend betreut und mit Interesse das Entstehen der Arbeit begleitet hat. Frau Prof. Dr. Monika Wingender, die seit 2001 an der Justus-Liebig-Universität in Gießen tätig ist, stellte sich als Zweitgutachterin zur Verfügung, dafür gilt auch ihr mein herzlicher Dank. Ebenfalls danken möchte ich Herrn Dr. Volker Bockholt, der nicht nur bei der teilweise schwierigen Suche nach Literatur eine wertvolle Hilfe war.

Außerdem danke ich der Studienstiftung des Deutschen Volkes. deren großzügige finanzielle Förderung mir den Luxus ermöglicht hat, mich voll und ganz auf meine wissenschaftliche Arbeit zu konzentrieren.

Ohne die Unterstützung. Ermunterung und Fürsprache meiner Familie und meiner Freunde hätte diese Arbeit nicht entstehen können, deshalb Euch allen an dieser Stelle ein herzliches Dankeschön!

Braunschweig, im Juni 2003

Claudia Böhler 


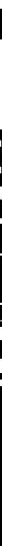

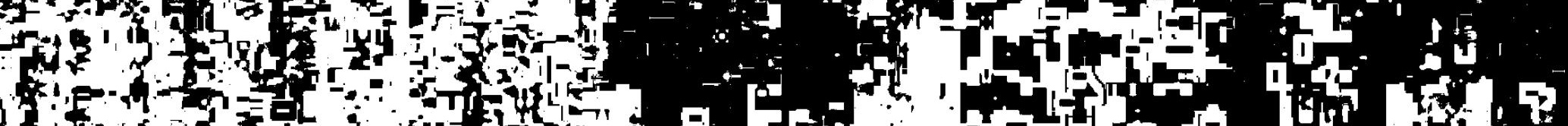

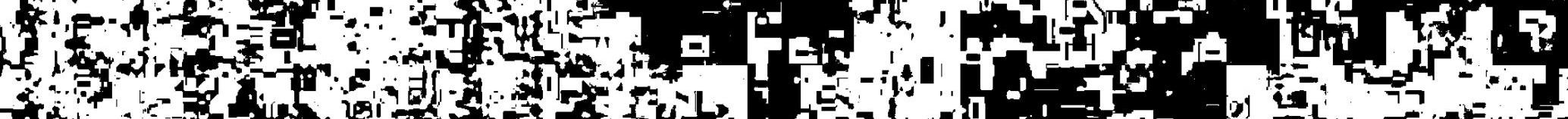

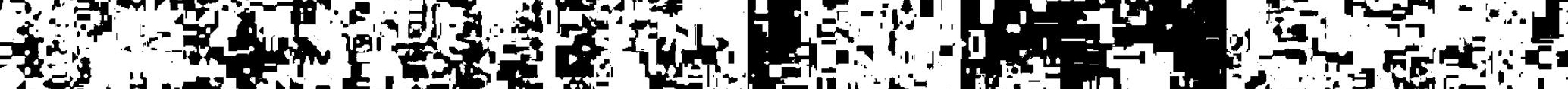

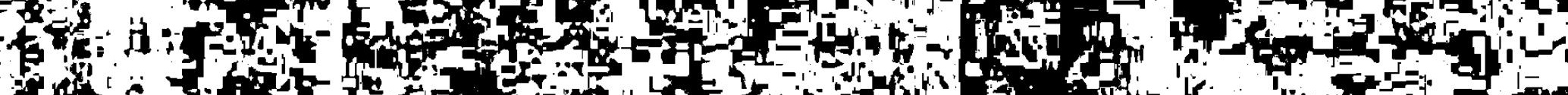

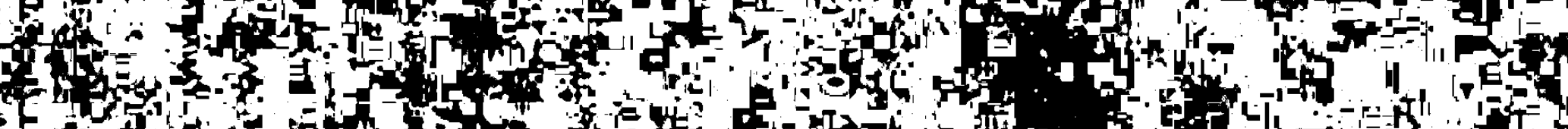

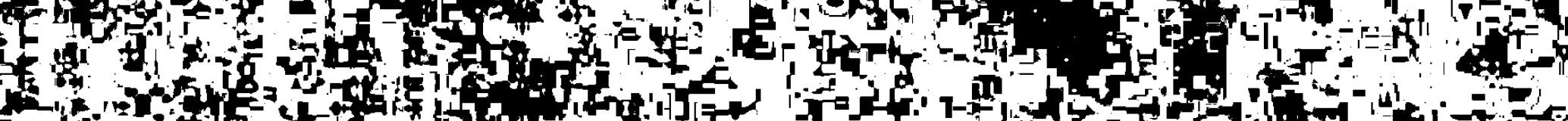

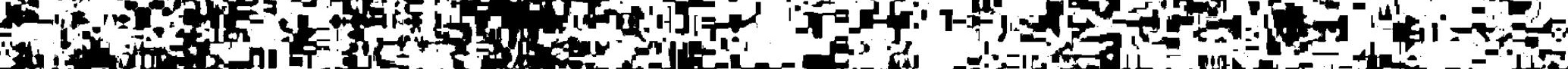

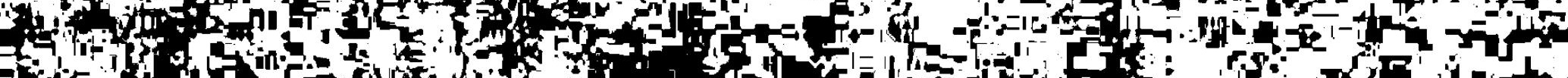

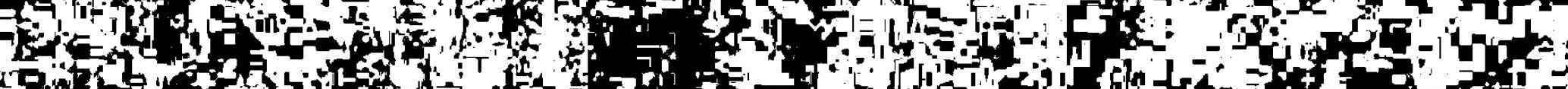

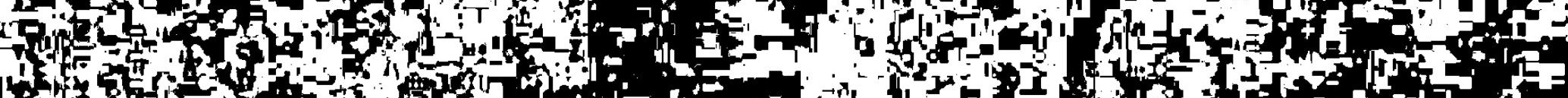

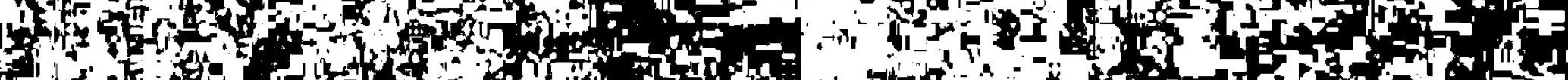

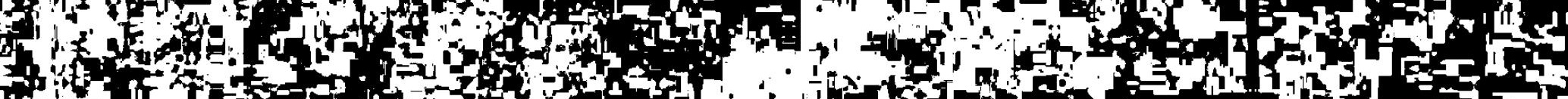

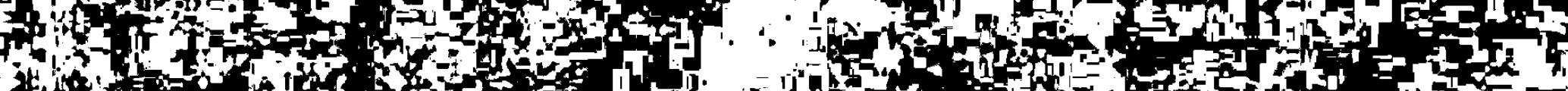

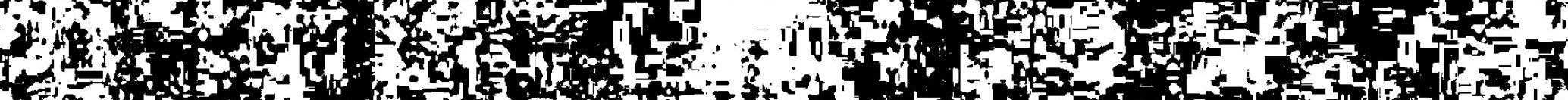

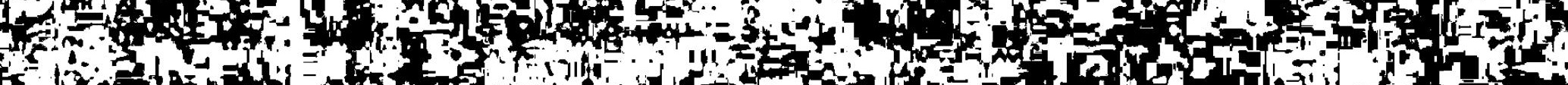
How

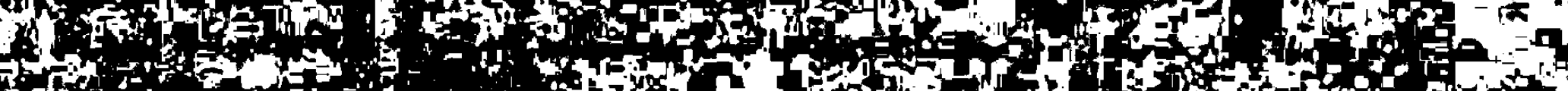

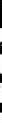

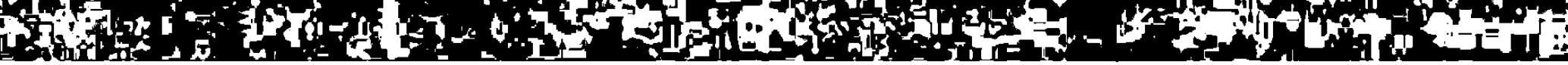




\section{INHALTSVERZEICHNIS}

EINLEITUNG.

I FORSCHUNGSSTAND

1.1 KURZE GESCHICHTE DER RUSSISCHEN LEXIKOGRAPHIE .......................................................4

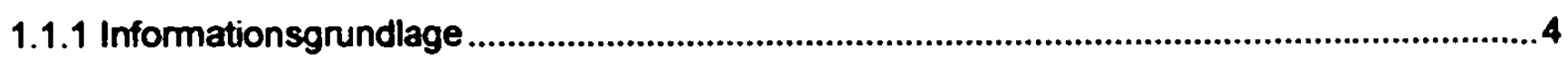

1.1.2 Die Anfänge der russischen Wörterbuchschreıbung .....................................................4

1.1.3 Die russische Lexikographie im 18. Jahrhundert ...........................................................6

1.1.4 Die russische Lexikographie im 19. Jahrhundert ...........................................................7

1.1.5 Die russische Lexikographie im 20. Jahmundert ..........................................................10

1.2 KURZE GESCHICHTE DER RUSSISCH+DEUTSCHEN LEXIKOGRAPHIE .............................................12

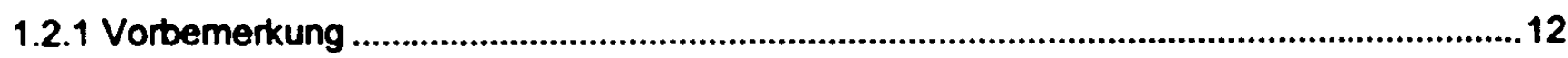

1.2.2 Der Beginn der russisch-deutschen Lexikographie: Gesprächsbücher.............................14

1.2.3 Erster Aufschwung der russisch-deutschen Lexikographie im 18. Jahmundert................ 19

1.2.4 Die zweisprachige Lexikographie russisch-deutsch im 19. Jahthundert...........................24

1.2.5 Die zweisprachige Lexikographie Deutsch-Russisch im 20. Jahmundert: Ein breites

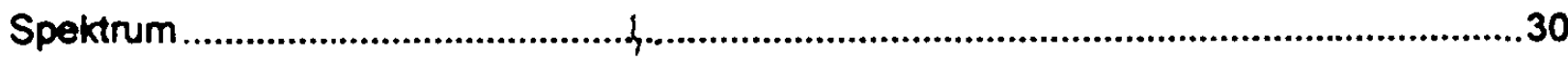

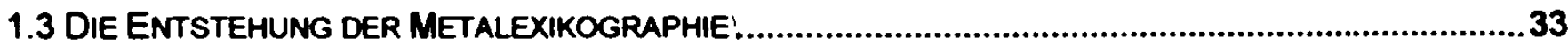

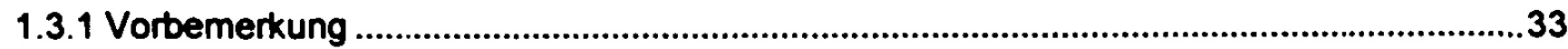

1.3.2 Der Aufschwung der Metalexikographie um die Mitte des 20. Jahmunderts.....................34

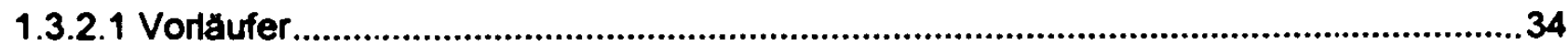

1.3.2.2 Die Entwicklung der Metalexikographie zu einer wissenschaftichen Disziplin.............35

1.3.2.2.1 Die angelsächsische Metalexikographie .........................................................35

1.3.2.2.2 Die franzðsische Metalexikographie.................................................................36

1.3.2.2.3 Die deutsche Metalexikographie ......................................................................37

1.3.2.2.4 Die russische Metalexikographie.......................................................................37

1.3.2.2.5 Die bilinguale Metalexikographie ....................................................................39

1.3.2.2.6 Metalexikographische Gesellschaften und Zeitschriften......................................40

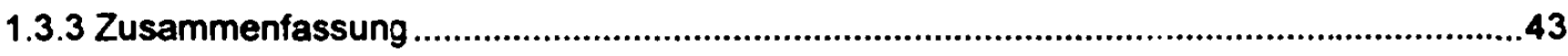

1.4 EINORDNUNG DER ARBEIT IN DEN KONTEXT DER METALEXIKOGRAPHIE ......................................44

2 DAS PAWLOWSKYSCHE WÖRTERBUCH: LEBEN UND WERK DER AUTOREN UND DER VERLEGER

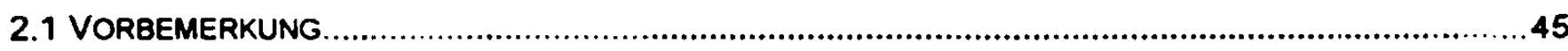

2.2 DER BEGRÜNDER DES WORTERBUCHES: I. JA. PAWLOWSKY ....................................................45

2.3 DIE NACHFOLgER PAWLOWSKYS: I. NIKOLIC UNO N. ASMUSS ...............................................47 


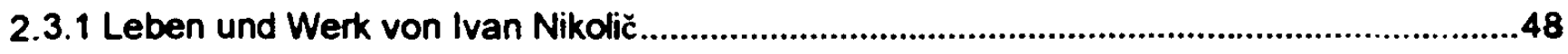

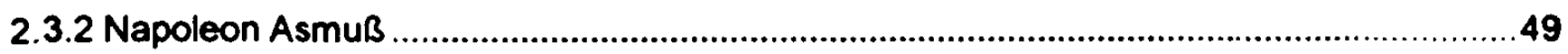

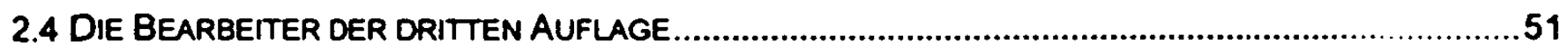

2.4.1 Die Bearbeiter der dritten Auflage des deutsch-russischen Wörterbuches: Otto Stahl, Oskar

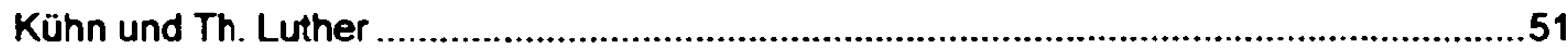

2.4.2 Die Bearbeiter der dritten Auflage des russisch-deutschen Wörterbuches .......................52

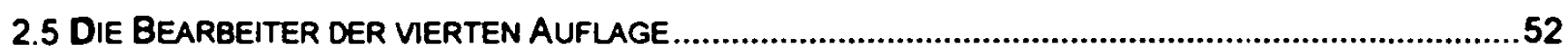

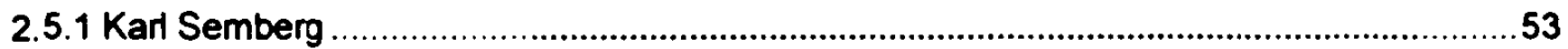

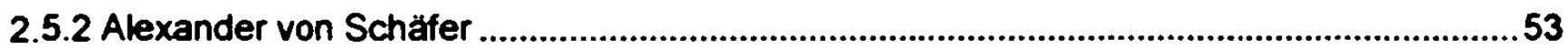

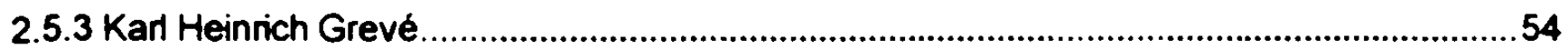

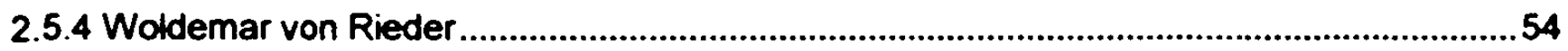

2.6 Die VERLEGER Des WORTERBUCHES: NikOLAJ GEORG KYMMEL UND NiKOLAJ KYMMEL.................55

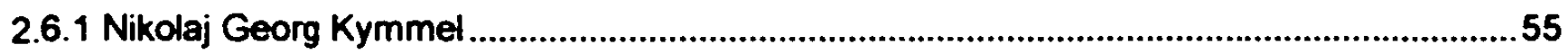

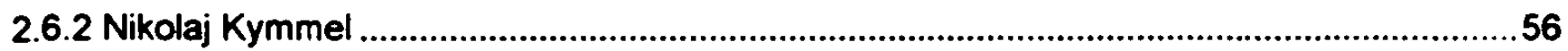

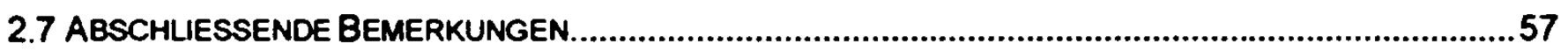

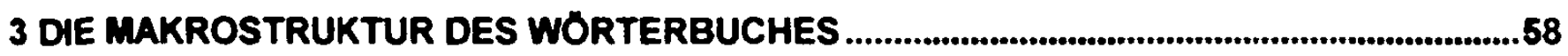

3.1 Die PUBLIKATIONSGESCHICHTE DES WORTERBUCHES .........................................................58

3.1.1 Die erste Auflage des Wörterbuches ........................................................................58

3.1.2 Die zweite Auflage des Wörterbuches .......................................................................59

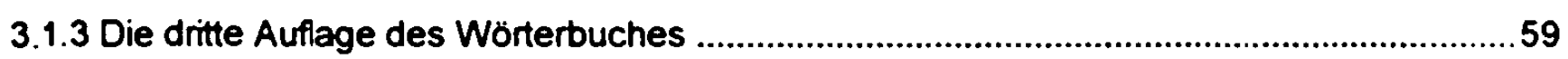

3.1.4 Die vierte Auflage des Wörterbuches........................................................................60

3.1.5 Die photomechanischen Nachdrucke durch das Zentralantiquariat in Leipzig .................60

3.2 DIE MAKROSTRUKUR DES RUSSISCH+DEUTSCHEN TEILS DES WORTERBUCHES..............................60

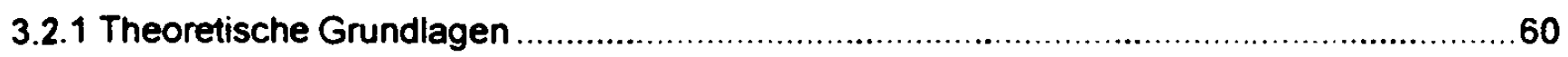

3.2.2 Die Makrostruktur der ersten Auflage des russisch-deutschen Wörterbuches..................62

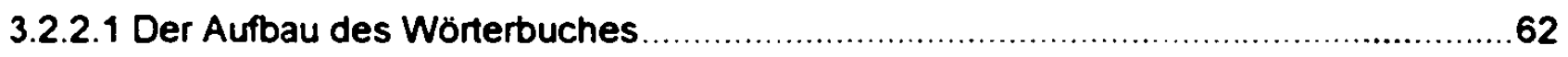

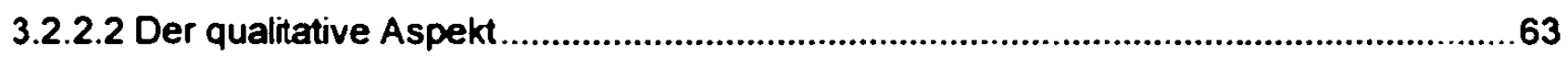

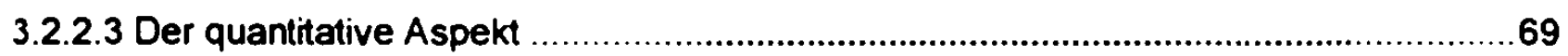

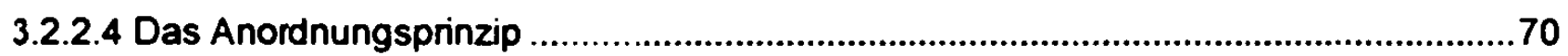

3.2.3 Die Makrostruktur der zweiten Auflage des russisch-deutschen Wörterbuches................72

3.2.3.1 Der Aufbau des Wörterbuches ..............................................................................72

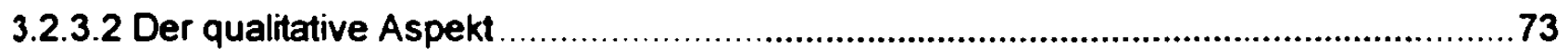

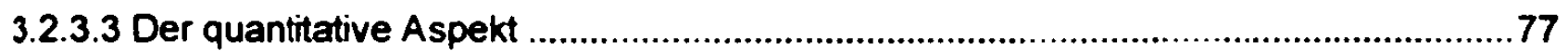

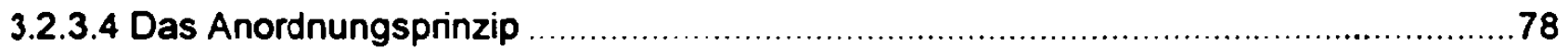

3.24 Die Makrostruktur der dritten Auflage des russisch-deutschen Wörterbuches .................80

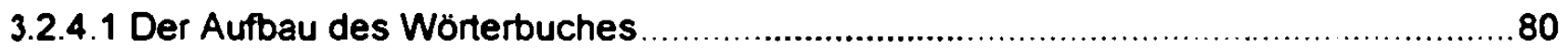


3.2.4.2 Der qualitative Aspekt 80

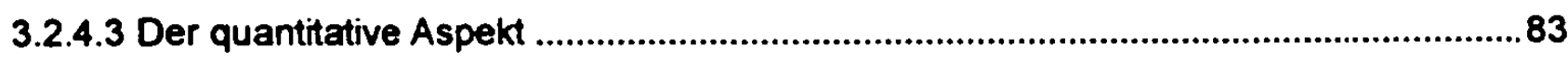

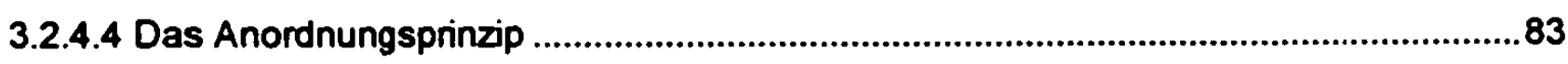

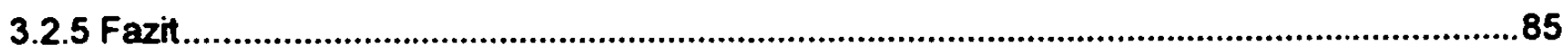

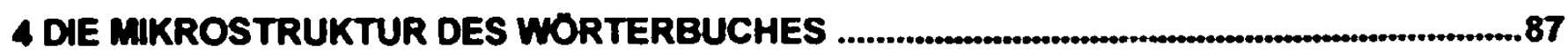

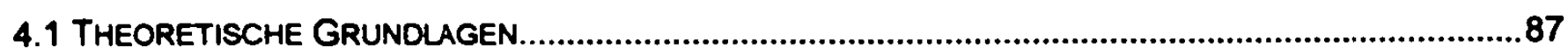

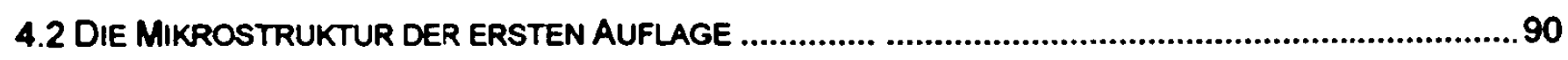

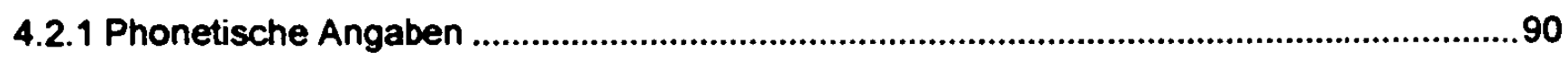

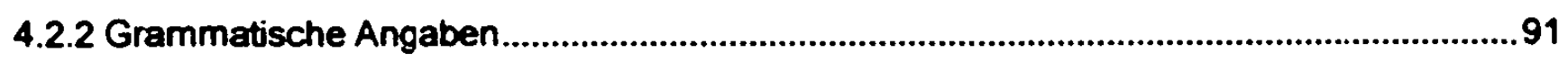

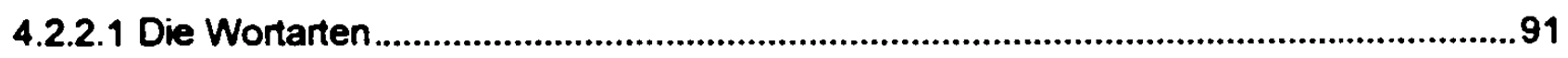

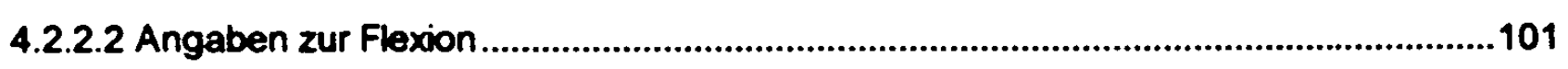

4.2.2.3 Bewertung der grammatischen Angaben .............................................................103

4.2.3 Diasystematische Markienungen ..............................................................................103

4.2.3.1 Die diatechnischen Markierungen .......................................................................104

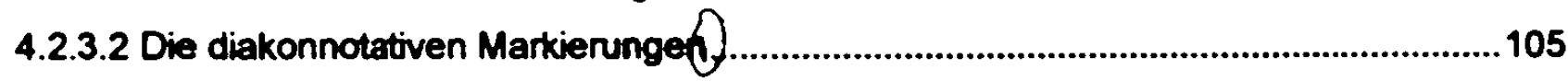

4.2.3.3 Die diachronischen Markierungen ........................................................................106

4.2.3.4 Die diastratischen Markierungen .........................................................................106

4.2.3.5 Die diatopischen Markierungen ........................................................................107

4.2.3.6 Diaintegrative Markierungen................................................................................108

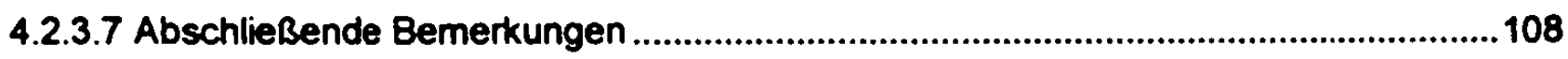

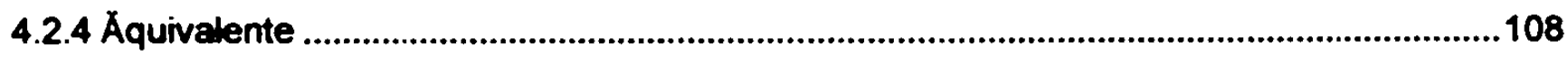

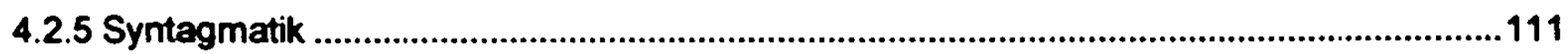

4.2.5.1 Syntagmatische Informationen bei den Substantiven ...........................................112

4.2.5.2 Syntagmatische Informationen bei den Adjektiven ................................................115

4.2.5.3 Syntagmatische Informationen bei den Verben.......................................................116

4.2.5.4 Syntagmatische Informationen bei den Prăpositionen ...........................................120

4.2.5.5 Syntagmatische Informationen durch Beispielsätze und Phraseologismen ..............121

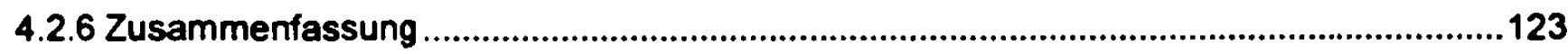

4.3 DIE MIKROSTRUKTUR DER ZWEITEN AUfLAGE DES RUSSISCH-DEUTSCHEN WORTERBUCHES........ 124

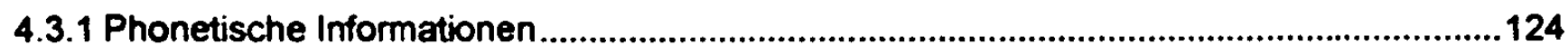

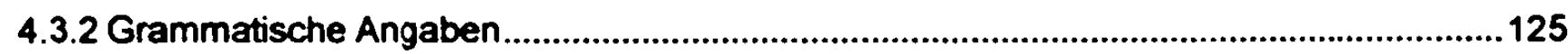

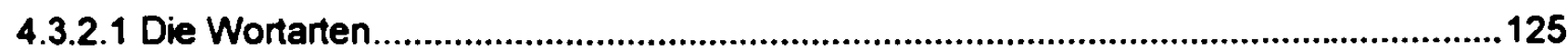

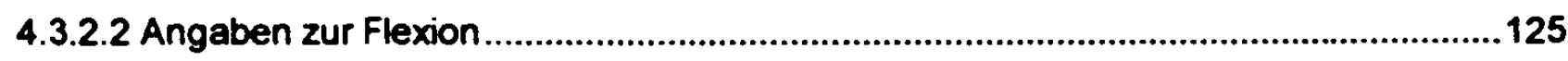

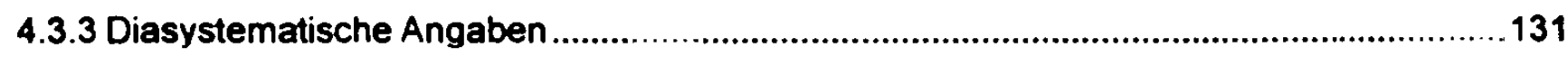

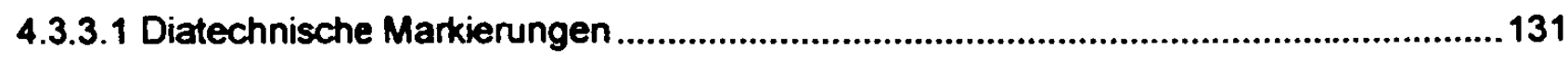

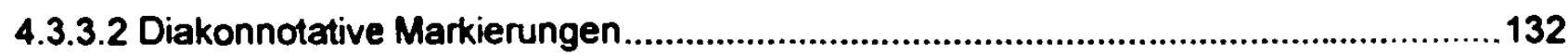


4.3.3.3 Diachronische Markierungen

4.3.3.4 Diastratische und diaintegrative Markierungen

4.3.3.5 Diatopische Markierungen

4.3.4 Äquivalente .135

4.3.5 Syntagmatik .138

4.3.5.1 Explizite Informationen zur Syntagmatik .138

4.3.5.2 Implizite Informationen zur Syntagmatik .138

4.3.6 Zusammenfassung .141

4.4 Die MiKROSTRUKTUR DER DRITTEN AUfLAGE DES RUSSISCH-DEUTSCHEN WORTERBUCHES VON PAWLOWSKY

4.4.1 Phonetische Angaben .141

4.4.2 Die grammatischen Angaben. 142

4.4.2.1 Wortarten 142

4.4.2.2 Flexion 143

4.4.3 Diasystematische Angaben 146

4.4.3.1 Diatechnische und diakonnotative Markierungen 146

4.4.3.2 Diachronische Markierungen 146

4.4.3.3 Diastratische Markierungen 148

4.4.3.4 Diaintegrative Markierungen 150

4.4.3.5 Diatopische Markierungen. .151

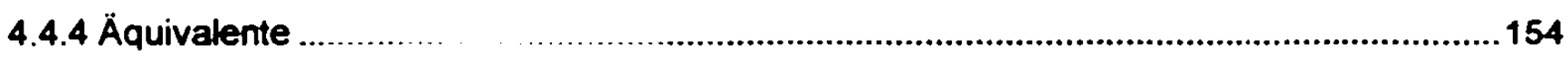

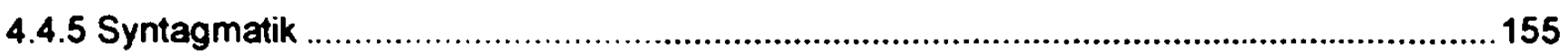

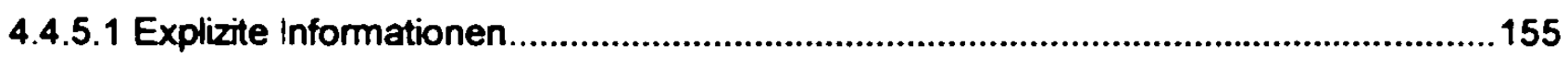

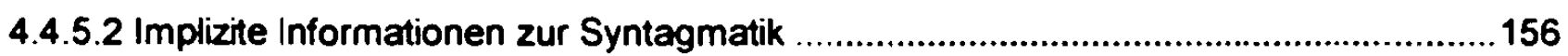

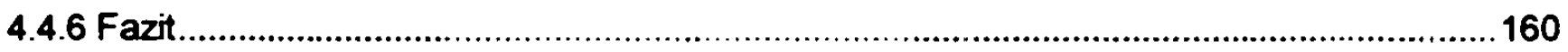

5 DIE QUELLEN DES WÖRTERBUCHES ....................................................................................161

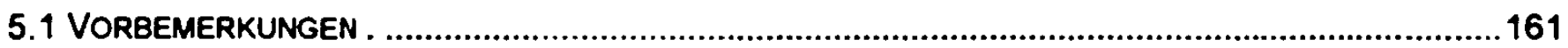

5.2 QUELLEN DER ERSTEN AUfLAGE DES RUSSISCH-DEUTSCHEN WORTERBUCHES.......................161

5.3 QUELLEN DER ZWEITEN AUfLAGE DES RUSSISCH-DEUTSCHEN WORTERBUCHES .......................169

5.4 QUELLEN DER DRITTEN AUfLAGE DES RUSSISCH-DEUTSCHEN WORTERBUCHES ..........................182

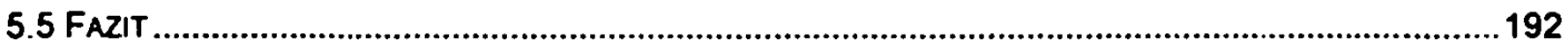




\section{Einleitung}

"Alle Menschen hatten die gleiche Sprache und gebrauchten die gleichen Worte. Als sie von Osten aufbrachen, fanden sie eine Ebene im Land Schinar und siedelten sich dort an. [...]. Dann sagten sie: Auf, bauen wir uns eine Stadt und einen Turm mit einer Spitze bis zum Himmel und machen wir uns damit einen Namen, dann werden wir uns nicht über die ganze Erde zerstreuen. Da stieg der Herr herab, um sich Stadt und Turm anzusenen, die die Menschenkinder bauten. Er sprach: Seht nur, ein Volk sind sie und eine Sprache haben sie alle. Und das ist erst der Anfang ihres Tuns. Jetzt wird ihnen nichts mehr unerreichbar sein, was sie sich auch vornehmen. Auf, steigen wir hinab und verwirren wir dort ihre Sprache, so daß keiner mehr die Sprache des anderen versteht. Der Herr zerstreute sie von dort aus über die ganze Erde und sie hörten auf, an der Stadt zu bauen. Darum nannte man die Stadt Babel, denn dort hat der Herr die Sprache aller Welt verwirt, und von dort aus hat er die Menschen über die ganze Erde zerstreut" (Genesis, 11, 1-9).

Dieser mehrere tausend Jahre atte Text macht deutlich, daß sich die Menschheit schon früh mit dem Phänomen der Sprachenvielfalt auseinandergesetzt hat und eine einleuchtende Erklärung dafür zu finden suchte. Obwohl fremde Sprachen „eine unerschöpfliche Quelle für höhnische Witze waren“ (Borst, 1963, 1976), galt doch fast überall „der Sprachenunkundige als bäurisch und beschränkt" (Borst, 1963, 1992). .Fremdsprachenkenntnis [...] war nicht nur Bestandteil der persönlichen Bildung, sondern ein Anfang zur Überwindung von Babel" (Borst, 1963, 1992). So veruundert es nicht, daß es schon sehr früh Be strebungen gab, die sprachlichen Hürden zwischen den Völkem zu überwinden und mit Hife von Wortlisten eine Verständigung zu ermöglichen.

Doch obwohl Wortlisten und ihre Nachfolger, die Wörterbücher, eine lange Tradition haben, entwickelte sich die wissenschaftliche Auseinandersetzung mit dem Phänomen Wörterbuch erst vergleichsweise spät. Wörterbücher wurden - auch in der Sprachwissenschaft - meist als bloße Hilfsmittel verkannt, was daran liegen mag, daß eine Beschäftigung mit ihnen auf den ersten Blick wenig attraktiv erscheint. Erst allmählich verändert sich die Einstellung gegenüber Wörterbüchem, ihren Verfassem und ihrer Bedeutung auch und gerade in der Sprachwissenschaft.

Das jahrhunderteatte Desinteresse an den Resultaten lexikographischer Arbeiten erklärt auch, daß das russisch-deutsche Wörterbuch von Iwan Pawlowsky, das der Gegenstand der vortiegenden Arbeit ist, bis zum jetzigen Zeitpunkt als terra incognita betrachtet werden muß. Ziel dieser Arbeit ist es, durch eine metalexikographische Einzelanalyse dieses Werkes einen Beitrag zur Geschichte der russisch-deutschen Lexikographie zu leisten. 
Im ersten Kapitel der Arbeit wird der Forschungsstand kurz skizziert. Zuerst müssen eine kurze Geschichte der russischen Lexikographie sowie ein Abriß der russisch-deutschen Lexikographie als Einführung in das Thema vorangestellt werden. Dabei stehen vor allem diejenigen lexikographischen Werke im Mittelpunkt des Interesses, die qualitativ Neuartiges in die Geschichte der Lexikographie eingebracht haben.

Dann wird die Entstehung der Metalexikographie nachgezeichnet werden, die zu verstehen ist als Beschäftigung mit dem Phänomen Wörterbuch, ohne die Herstellung von Wörterbüchern zum primären Ziel zu haben. Dabei werden auch die unterschiedlichen, zum Teil noch nicht voll entwickelten Forschungsrichtungen der Metalexikographie vorgestellt. In einem weiteren Unterpunkt soll die vorliegende Arbeit in das Spektrum der metalexikographischen Forschung eingeordnet und von den anderen Forschungsrichtungen abgegrenzt werden.

Nach dem eınfürenden Kapitel werden im zweiten Kapitel Leben und Werk derjenigen Personen beschrieben, die für die Erarbeitung des Wörterbuches verantwortlich waren. An erster Stelle wird dort natürtich der Namensgeber und Autor der ersten Auflage des Wörterbuches vorgestellt werden, im folgenden sollen aber auch seine Nachfolger Berücksichtigung finden, deren Arbeit bis heute im Schatten von Pawlowskys Wirken steht. Im Rahmen des zweiten Kapitels wird auch auf die Verleger des Pawlowskyschen Wörterbuches einzugehen sein, deren Bemühungen es zu verdanken ist, daß das Wörterbuch mehrfach wederaufgelegt wurde.

Mit dem dritten Kapitel beginnt dann die eigentliche metalexikographische Analyse des Wörterbuches. Schwerpunkt dieses Kapitels ist die genaue Untersuchung der Makrostruktur des russisch-deutschen Teils. In einem ersten Teil wird die bibliographische Geschichte des Wörterbuches entwirt werden, da nicht nur bei der Anzahl und dem Erscheinungsjahr der Abdrucke Unklarheit herrscht. Zentrale Aufgabe des zweiten Abschnittes wird es sein, die Makrostruktur, die den Inhalt und den Aufbau eines Wörterbuches umfaßt, in allen drei Auflagen zu untersuchen und die Veränderungen innerhalb der Makrostruktur in den unterschiedlichen Auflagen herauszuarbeiten. In einem ersten Schritt wird auf der Basis der Erkenntnisse über die Makrostruktur eine Systematik entwickelt werden, die eine ausfühniche metalexikographische Analyse ermöglicht. In einem weiteren Schritt erfolgt dann die kontrastive Analyse der Makrostruktur der drei Auflagen anhand einer Stichprobe, die sämtlichen Auflagen entnommen wurde. Ziel der Analyse ist es, Aussagen über den Aufbau des Wörterbuches und über Qualität und Umfang des Lemmabestandes zu treffen.

Das vierte Kapitel ist der Mikrostruktur des russisch-deutschen Wörterbuches von Pawlowsky gewidmet. In einem ersten Teil wird zunächst auf der Grundlage der konzeptionellen Werke ein Analyseinstrumentarium entwickelt. das eine genaue Untersuchung der 
Mikrostrukturen ermöglicht. In den weiteren Teilen wird - wiederum anhand der Stichprobe - die Entwicklung der Mikrostruktur der unterschiedlichen Auflagen des Wörterbuches nachgezeichnet. Im Mittelpunkt des Interesses steht die Frage nach dem Aufbau und der Qualität der einzelnen Wörterbuchartikel. Gestützt auf die Analyseergebnisse, wird abschließend für jede Auflage das jeweils zugrunde liegende mikrostrukturelle Aufbauschema angegeben.

Der Frage nach den Quellen, auf denen die unterschiedlichen Auflagen des untersuchten Wörterbuches basieren, ist das letzte Kapitel der Arbeit gewidmet. Besonders wichtig ist es, herauszufinden, welche Quellen Pawlowsky selbst bei der Erarbeitung der ersten Auflage herangezogen hat, denn darüber liegen bisher keinerlei Informationen vor. 


\section{Forschungsstand}

\subsection{Kurze Geschichte der russischen Lexikographie}

\subsubsection{Informationsgrundlage}

Vergleicht man die Qualität und die Quantität der Sekundärtiteratur zur Geschichte der russischen Lexikographie mit derjenigen anderer europäischen Sprachen, so ist festzustellen, daß es gerade über die Geschichte der russischen Lexikographie kaum Monographien gibt. Sämtliche neueren Arbeiten (vgl. Sorokoletov, 1998; Jachnow, 1990; Cejtlin. 1958) beziehen sich nahezu ausschließlich auf die Monographien von Bulič aus dem Jahr 1904 (vgl. Bulič, 1904) und von Jagič aus dem Jahr 1910 (vgl. Jagič, 1910). Aktuellere Informationen zum Thema müssen aus den wenigen Bibliographien (vgl. Stankiewicz, 1984; Aav, 1977; Lewanski. 1972; Vinogradov, 1954) gewonnen werden. Einzig die frühe Phase der russischen Lexikographie, die bis zum Beginn des 17. Jahrhunderts dauerte, kann aufgrund der Forschungen von Kovtun und der Bibliographie von Vomperskij als relativ gut erforscht getten (vgl. Kovtun, 1989; Vomperskij, 1986; Kovtun, 1975; Kovtun, 1963). Eine umfassende Geschichte der russischen und der sowjetischen Lexikographie, die dazu auch noch über die zweifellos sehr wichtige Akademielexikographie hinausginge, steht allerdings immer noch aus.

\subsubsection{Die Anfänge der russischen Wörterbuchschreibung}

Der Beginn der russischen Lexikographie ist geprägt durch die diglossische Sprachsituation in der Rus'. Die Frühphase der russischen Lexikographie, die vom 13. bis zum 17. Jahrhundert anzusiedeln ist, brachte deshalb vorrangig Ergebnisse hervor, die durch das Kirchenslavische als Objektsprache gekennzeichnet sind. Als Vorformen des Wörterbuches sind die kurzen Wortlisten zu verstehen, für die sich der Terminus Glossar durchgesetzt hat und in denen schwer verständliche nichtslavische und kirchenslavische Wörter erklärt wurden (vgl. Jachnow, 1990, S. 2310). Als ältestes bisher bekanntes Dokument gilt die der sogenannten Корихая книта beigefügte Wortliste aus dem Jahr 1282, in der insgesamt 174 Wörter erläutert werden. Neben biblischen Eigennamen wie Павел, Петр, Голтофа werden dort auch religiöse Termini wie подирь sowie schwere und unverständliche slavische Wörter wie z. B. КоB erklärt (vgl. Cejtlin, 1958, 6f). Die Glossare wurden im Laufe der Zeit abgeschrieben, erweitert und verändert und erfreuten sich im russischen Mittelalter einer langen Lebensdauer und einer relativ weiten Verbreitung. 
Zu einer qualitativen Veränderung kam es im 16. Jahrhundert in der frühen ostslavischen Lexikographie durch die Entstehung sogenannter Aз6yков- Hierbei handelt es sich um meist alphabetisch geordnete Wörtersammlungen, die im Unterschied zu den Glossarien nicht nur als Hilfsmittel für das kirchliche Schriftum dienten, sondern auch eine breitere Wissensvermittlung zum Ziel hatten, indem dort Erklärungen enzyklopädischen Charakters und der Unterhaltung dienende Passagen angeführt wurden (vgl. Jachnow, 1990, 2310). Die Азбуковнки effreuten sich in der Rus' großer Beliebtheit und trugen vermutlich nicht unerheblich dazu bei, daß die handschriftliche Wörterbuchschreibung abgelöst wurde durch die ersten gedruckten Wörterbücher. Für ausführlichere Informationen über die russischen Aз6уковки sei auf die Sekundärliteratur verwiesen (vgl. Kovtun, 1989; Kovtun, 1975, 206-258; Alekseev, 1968).

Das erste gedruckte Wörterbuch der ostslavischen Lexikographie ist das 1596 in Vilnius unter dem Titel Лексис сиречь речекия erschienene Wörterbuch von Lavrentij Zizanij (vgl. Jachnow, 1990, 2310). Das Wörterbuch enthält 1062 Einheiten, die hauptsächlich kirchenslavischen oder fremdsprachlichen Ursprungs sind (vgl. Cejtlin, 1958. 11) und mit vornehmlich ukrainischer und weißrussischer Metasprache erläutert werden (vgl. Jachnow, 1990, 2310). Das Wörterbuch von Zizanij steht in der Tradition der Азбуков-ки und wurde als Ergänzung zu den grammatischen Werken desselben Autors verfaßt.

Auch auf das 1627 in Kiev erschienene Wörterbuch Jeксикон славеноросский von Pamva Berynda (vgl. Zaunmüller, 1958, 333) hatte Zizanijs Arbeit großen Einfluß. Berynda hatte mehr als 30 Jahre an seinem Wörterbuch gearbeitet. Er benutzte sowohl geistliche Literatur als auch verschiedene andere Wörterbücher, deren Material er kritisch auswertete, als Quellengrundlage für seine Arbeit. Im Ergebnis besteht das Wörterbuch aus zwei Teilen, dessen erster kirchenslavische Ausdrücke umfaßt, die meist durch Erläuterungen in ukrainischer Sprache, aber auch in russischer, in weißrussischer und in polnischer Sprache erklärt werden. Im zweiten Teil des Wörterbuches werden nahezu ausschließlich Fremdwörter erklärt. Die große Bedeutung des Wörtertuches von Berynda und seine Verbreitung in der Bevölkerung spiegelt sich auch darin wider, daß bereits 1653 eine zweite Auflage erschien (vgl. Cejtlin, 1958, 12ff).

Durch die Arbeiten von Zizanij und Berynda ist der Grundstein für die Wörterbuchschreibung im eigentlichen philologischen Sinne gelegt und die Frühphase der ostslavischen Lexikographie abgeschlossen worden. Allerdings ist es wichtig, noch einmal explizit zu bekräftigen, daß der erklärende Teil der beiden Wörterbücher fast durchgängig genetisch ukrainisch ist. So hat Isačenko nicht unrecht, wenn er betont (vgl. Isacenko, 1980, 315-316), daß die ersten beiden gedruckten Wörterbücher des ostslavischen Raumes der 
Geschichte der ukrainischen Lexikographie zuzuordnen seien. Untermauert wird diese These durch die ausführliche Behandlung der Wörterbücher in Darstellungen der Geschichte der ukrainischen Lexikographie (vgl. Nimčuk, 1980, 69-89 und 100-197).

\subsubsection{Die russische Lexikographie im 18. Jahrhundert}

Zu Beginn des 18. Jahrhunderts lag der Schwerpunkt der Wörterbucharbeit auf den zwei- und den mehrsprachigen Wörterbüchern (vgl. Pkt. 1.2.3, 19-22), die wichtige Vorarbeiten für die einsprachig erklärende Lexikographie leisteten, da dort erstmals eine größere Anzahl genetisch russischer Lexeme fixiert wurde (vgl. Cejtlin, 1958, 17).

Im Zuge der technischen, wissenschaftlichen und politischen Weiterentwicklung, die sich auch in der Entwicklung einer Übersetzungsliteratur manifestiert, wuchs im Petrinischen Zeitalter der Bedarf an Fremdwortwörterbüchern und terminologischen Wörterbüchem. Bei den Übersetzungen wurde es Usus, im Anhang der übersetzten Monographien in Wortlisten eventuell schwer verständliche Lexeme zu erklären. Als Beispiel ist hier die Übersetzung von V. Suvorov Исти спия спо укрепленмя городов, изданын от

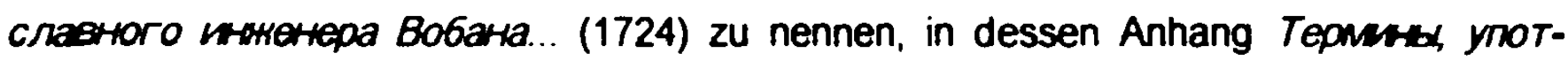
ребляемые в фортифккаими fast 130 Wörter erläutert werden (vgl. Sorokoletov, 1998. 72; Cejtlin, 1958, 19). Neben den Wortlisten im Anhang von Büchem finden sich auch in den Zeitschriften zahlreiche Fremdwortlisten (vgl. Cejtlin, 1958, 19).

Einen weiteren wichtigen Schritt in Richtung der einsprachig erklärenden Wörterbücher leisteten die zahlreichen etymologischen Arbeiten russischer Wissenschaftler. Die Begeisterung für etymologische Fragen spiegelt sich vor allem in den zahlreichen dieser Thematik gewidmeten Artikeln in unterschiedlichen Zeitschriften wider. So äußerten sich beispielsweise V. K. Tred'jakovskij, M. V. Lomonosov, A. P. Sumarokov, V. N. Tatiščev und viele andere Gelehrte zu etymologischen Fragestellungen in unterschiedlichen Publikationen (vgl. Cejtlin, 1958, 21ff).

Die einzige größere Wörterbucharbeit dieses Jahrhunderts war wiederum der kirchenslavischen Sprache gewidmet. In dem 1773 in Moskau erschienenen Lерковный словарь von P. A. Alekseev (vgl. Vomperskij, 1986, Nr. 84) werden über 20.000 Wörter aus biblischen Quellen erläutert (vgl. Sorokoletov, 1998, 74f; Cejtlin, 1958, 25f).

Die große Aufgabe, ein erklärendes Wörterbuch der russischen Sprache zu veröffentlichen, war damit allerdings noch immer nicht erfült; denn obwohl sich bereits seit 1735 im Umfeld der Petersburger Akademie immer wieder Gelehrte mit dieser Problematik auseinandersetzten, dauerte es nach der feierlichen Eröffnung der Russischen Akademie 1783. deren vorrangiges Ziel es war, ein Wörterbuch und eine Grammatik zu veröffentlichen, 
noch weitere sechs Jahre, bis der erste Band des ersten Akademiewörterbuches Croeapo Akanems Poccuixckoxi erschien, und noch einmal fünf Jahre, bis alle sechs Bände veröffentlicht waren ( $\mathrm{vgl}$. Vomperskij, 1986, Nr. 188). Von den 60 Mitgliedern der Akademie nahmen 47 direkten Anteil an der Wörterbucharbeit. Als Primärquellen wurden religiöse Schriften, altrussische Handschriften und aktuelle Werke von Schriftstellem und Gelehrten herangezogen, als Sekundärquellen dienten zahlreiche gedruckte und handschriftliche Wörterbücher (vgl. Cejtlin, 1958, 28f). Unmittelbare Vorlage für das erste Akademiewörterbuch war das Dictionnaire de l'Académie Francaise (vgl. Jachnow, 1990, 2311). Daß auch dieses Wörterbuch noch nicht ausreichend untersucht worden ist, zeigen die Ergebnisse von Keipert, der überzeugend belegt, daß das erste Akademiewörterbuch mit der Cellariustradition in Rußland eng verknüpft ist (vgl. Keipert, 1987, 314; Pkt. 1.2.3, 20). Das erste Akademiewörterbuch, das am Anfang einer langen Tradition steht und als erstes im sprachwissenschaftlichen Sinne geplantes und durchgeführtes Wörterbuch gelten kann. enthält ca. 43.000 Wörter, die nach dem Ableitungsprinzip angeordnet sind, was die Suche nach konkreten Wörtern sehr erschwert. Für detailliertere Informationen als die hier folgenden, zum Beispiel zum Wortbestand, zu den orthographischen Prinzipien sowie zu den grammatischen und semantischen Ertäuterungen im ersten Akademiewörterbuch sei auf die einschlägige Sekundärliteratur verwiesen (vgl. Sorokoletov, 1998, 98-126; Kutina, 1980, 70-88; Vinogradov, 1977a, 215-218; Bulič, 1904, 240-246).

Charakteristisch für das Korpus sind die Konzentration auf Lexeme gehobenen Stils sowie der fast vollständige Verzicht auf die Aufnahme von Fremdwörtern und von umgangssprachlicher Lexik (vgl. Cejtlin, 1958, 29f). Als Konsequenz daraus ergibt sich, daß das Korpus des Wörterbuches zum Zeitpunkt seines Erscheinens, vom usuellen Aspekt her betrachtet, schon nicht mehr der tatsächlichen Sprachsituation am Ende des 18. Jahrhunderts entsprach (vgl. Jachnow, 1990, 2311).

\subsubsection{Die russische Lexikographie im 19. Jahrhundert}

Ein Teil der eben erwähnten Mängel war auch den Autoren des Wörterbuches bewußt. denn nach Vollendung der ersten Auflage wurde entschieden, daß die Arbeit an einem neuen Akademiewörterbuch ( $=$ zweites Akademiewörterbuch) mit alphabetischer Ordnungsstruktur aufgenommen werden sollte (vgl. Cejtlin, 1958, 32). Der erste Band des nunmehr alphabetisch geordneten Wörterbuches erschien 1806, der sechste und letzte Band wurde 1822 veröffentlicht (vgl. Jachnow, 1990, 2311). Die Zahl der Einträge wurde zwar auf über 51.000 erhöht, aber weitere Verbesserungen wurden nicht vorgenommen, so daß auch dieses Wörterbuch den Wunsch nach einem Werk, das den aktuellen Sprachgebrauch reflektiert, nicht erfüllen konnte (vgl. Jachnow, 1990, 2311). Für eıne 
ausführliche Besprechung der zweiten Auflage sei auf das Standardwerk von Bulic verwiesen, der auf acht Seiten die Besonderheiten des Wörterbuches und die zeitgenössischen Reaktionen skizziert (vgl. Bulič, 1904, 948-956).

Die erste Hälfte des 19. Jahrhunderts war - bis auf das Erscheinen der zweiten Akademieausgabe - geprägt von einer Diskussion über grundsätzliche lexikographische Fragen (vgl. Cejtlin, 1958, 34), ohne daß qualitativ neuartige Wörterbücher veröffentlicht werden konnten. Eine wichtige Rolle spielte in diesem Zusammenhang das O6щес тво תo6nтелей российской словесности, das in seiner Zeitschrift Труды общества любителей россиихкаи словесности zwar zahlreiche theoretische Fragen erörterte, aber keine der sich selbst gestellten praktischen Aufgaben zu Ende bringen konnte (vgl. Bulič, 1904, 965977).

In gewisser Weise ein Novum stellt das 1847 erschienene neue viertändige Akademiewörterbuch (= drittes Akademiewörterbuch) (vgl. Slovar', 1847) dar, das unter dem Titel Cловары иерковжославаккаго и русскато языка von der Zweiten Abteilung für Literatur der Akademie der Wissenschaften veröffentlicht wurde. Der im Jahr 1841 als Nachfolgeorganisation der Akademie gegründeten Zweiten Abteilung war es gelungen, in nur sechs Jahren ein Wörterbuch zu erarbeiten, das sich von seinen Vorgängem insbesondere dadurch abhebt, daß sich seine Autoren dem Ziel verschrieben hatten, den gesamten russischen Wortschatz von den schriftsprachlichen Anfängen bis zur damaligen Gegenwart darzustellen (vgl. Sorokoletov, 1998, 8; Jachnow, 1990, 2311). Der Umfang des Wörterbulches verdoppelte sich durch die Hinzuziehung sämtlicher in Rußland bereits erschienener Wörterbücher sowie durch die Benutzung der umfangreichen Wortkartothek auf 114.749 Eintráge (vgl. Vinogradov, 1977a, 220). Die Erweiterung des Wortbestandes vollzog sich vor allem zugunsten von fremdsprachlichen Wörtern und zugunsten von Termini aus der zeitgenössischen russischen Sprache, zusätzlich wurden auch erstmals Wörter aus den Dialekten und der Umgangssprache aufgenommen (vgl. Sorokoletov, 1989, 181).

Dennoch manifestient sich der Wert des Wörterbuches nicht so sehr in der neuartigen Materialauswahl, sondem vielmehr in der "Art der explikativen, stilistischen und grammatischen Aufbereitung des Materials, die numehr eine gründliche sprachwissenschaftliche Reflexion erkennen läßt“ (Jachnow. 1990, 2312). Besonderen Anteil an dieser Entwicklung hatte der Sprachwissenschaftler A. Ch. Vostokov, auf dessen Grammatik die zahireichen grammatischen Markierungen beruhen (vgl. Cejtlin, 1958, 62). Aufgrund dieser Neuerungen ist der Словарь церковнославанскаго и русскаго языка als Beleg für die Weiterentwicklung der russischen Lexikographie zu werten. 
Das gleiche gilt auch für das zweite große Wörterbuch dieses Jahrhunderts, das bis heute von großem Wert für die Slavistik ist. Im folgenden wird der Toлковыи cлoвapb жнваго великорускаго языка von V. I. Dal', der in vier Bänden von 1863 bis 1866 herausgegeben wurde (vgl. Dal', 1863-1866), kurz charakterisiert werden. Die Einzigartigkeit dieses Wörterbuches zeigt sich unter anderem auch daran, daß der studierte Mediziner Dal' mehr als ein halbes Jahrhundert praktisch alleine an ihm gearbeitet hatte (vgl. Sorokoletov, 1998, 287)

Die Ziele, die er mit seinem Wörterbuch verfolgte, hatte Dal' bereits vor der Veröffentlichung in unterschiedlichen Vorträgen dargelegt, die dem eigentlichen Wörterverzeichnis vorangestellt wurden. Er verstand sich selbst nicht als „уитељ не наставнкв, не тоть, кто жаеть дыло лучие другихъ," sondem als „ученккъ, собиравиіи весь

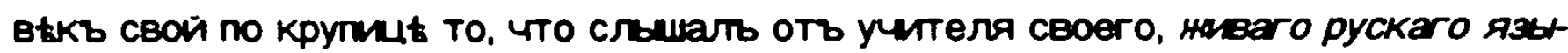
Ka゙ (Dal', 1863, XV). Der Autor erfaßte in seinem Wörterbuch erstmals in der Geschichte der russischen Lexikographie eine Fülle von Lexemen aus der mündlichen Kommunikationssphäre und aus den nichtschriftsprachlichen Varietäten der russischen Sprache, „HO He

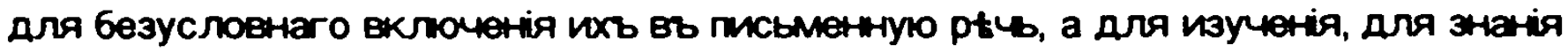
и о6сунденія ихъ, для изученія самаго духа языка и усвоенія его се6t, для выра6отки изь него постелен со своего, образованато языка" (Dal', 1863, XVIII).

Dal' nutzte neben einigen Wörterbüchern vor allem sein umfangreiches von ihm persönlich zusammengestelltes Material als Quelle (vgl. Sorokoletov, 1998, 289). Unterstützung effuhr er dabei von seinen Kollegen aus dem Pусское географинское общество und von den Mitgliedem des O6щество лиобителей русской словесности (vgl. Cejtlin, 1958, 76). Daß Dal' sein Wörterbuch als Gegenentwurf zu den Akademiewörterbüchem konzipierte (vgl. Jachnow, 1990, 2312; Vinogradov, 1977, 224), wird nicht nur durch seine Materialauswahl deutlich, sondern spiegelt sich auch in der Anordnung des Materials nach dem morphologischen Nestprinzip wider (vgl. Cejtlin, 1958, 84), ferner in den zum Teil quasienzyklopädischen Erklärungen (vgl. Cejtlin, 1958, 81) bei einzelnen Eintragungen, die das Werk unter anderem zu einer "своеобразная эниклопедия народной русской низни первой половиы XIX в." (Vinogradov, 1977a, 229) machten. Bereits kurz nach Erscheinen des Wörterbuches entwickette sich in Rezensionen eine kontroverse Debatte um das Werk Dal's (vgl. Sorokoletov, 1998, 293 u. 295; Kankava, 1958, 224-244). Daß das Wörterbuch eine Lücke in der russischen Wörterbuchlandschaft geschlossen und bis heute nicht an Aktualität vertoren hat, wird auch dadurch deutlich, daß von inm bislang sechs Auflagen erschienen sind, wobei vor allem die dritte, von Baudouin de Courtenay neu bearbeitete Auflage, die 1903 erschien, Erwähnung verdient, da Baudouin de Cour- 
tenay nicht nur das Korpus erweiterte, sondern auch Korrekturen am Nestprinzip und an den Explikationen vorgenommen hatte (vgl. Jachnow, 1990, 2312). Auch die Dal' gewidmete Monographie von Kankava (vgl. Kankava, 1958), die sich mit seiner Tätigkeit als Lexikograph auseinandersetzt, verweist auf die große Bedeutung Dal's in der russischen Lexikographie.

Bereits seit den 50er Jahren des 19. Jahrhunderts wurde über ein neues Wörterbuchkonzept diskutiert, das die Normen der lebendigen russischen Schriftsprache widerspiegeln sollte (vgl. Sorokoletov, 1998, 208). Doch erst unter der Leitung von Ja. K. Grot wurde im Jahr 1886 die Arbeit an einem solchen Wörterbuch aufgenommen (vgl. Sorokoletov, 1998, 210). Ziel der Arbeitsgruppe unter Grot war es, diejenige Lexik zu berücksichtigen, die seit dem Wirken Lomonosovs in Rußland gebräuchlich geworden war. Auf der Grundlage des Dal'schen Wörterbuches sowie des dritten Akademiewörterbuches von 1847 und zahlreicher literarischer Quellen (vgl. Sorokoletov. 1998, 217-220) wurde ein alphabetisch angeordnetes Wörterbuch geschaffen, das sich durch die Berücksichtigung der Enweiterung der semantischen Struktur der Lexeme, durch ausführliche grammatikalische Informationen sowie durch zahlreiche Belege aus der Belletristik auszeichnete. Als größter Unterschied zu den Vorgängem des Grotschen Wörterbuches ist aber die normative Intention des Autors zu nennen, dessen detaillierte stilistische Markierungen das Wörterbuch „zum ersten zeitadäquaten präskriptiven Wörterbuch des Russischen überhaupt“ (Jachnow, 1990, 2312) machten.

Da Grot im Jahr 1893, kurz nach der Veröffentlichung der ersten beiden Teilbände in den Jahren 1891 und 1892 verstarb, konnte seine Konzeption nur im ersten Band verwirklicht werden, der die Buchstaben A bis D umfaßt. Sein Nachfolger A. A. Šachmatov orientierte sich nicht mehr nur an der Literatursprache. sondern setzte sich zum Ziel, die gesamte russische Lexik ohne jede Einschränkung wiederzugeben (vgl. Pkt. 1.1.5, 10).

\subsubsection{Die russische Lexikographie im 20. Jahrhundert}

Die erste Wörterbucharbeit des neuen Jahrhunderts war die Fortführung des von Ja. K. Grot begonnenen Werkes durch A. A. Śachmatov. Dieser änderte die Konzeption des Wörterbuches so grundlegend, daß es sich eingebürgert hat, vom fünften Akademiewörterbuch zu sprechen, wenn die Rede von der Šachmatovschen Redaktion des Wörterbuches ist. Nicht mehr ein normatives Wörterbuch der modernen Schriftsprache - wie bei Grot - war das Ziel (vgl. Jachnow, 1990, 2313), sondern ein deskriptives Wörterbuch, das die gesamte russische Lexik berücksichtigen sollte (vgl. Sorokoletov, 1998, 251). Śachmatov arbeitete 12 Jahre lang an dem Wörterbuch, dessen einzeine Bände unter seiner Redaktion bis 1916 erschienen (vgl. Müller, 1999, 294). Unter der Redaktion von V. I. 
Čemyšev, L. V. Ščerba u.a. erschienen bis 1937 noch einzelne Bände zu unterschiedlichen Buchstaben, ehe die Arbeit im Jahr 1937 endgültig eingestellt wurde, da die sowjetischen Machthaber die Verwendung der alten Orthographie und die Ignorierung der neuesten Tendenzen in der russischen Schriftsprache als großes Manko ansahen (vgl. Jachnow, 1990, 2313).

Erst seit 1928 wurde in der Sowjetunion die Arbeit an einem neuen Wörterbuch ernsthaft gefördert. Das Ergebnis war das zwischen 1935 und 1940 in vier Bänden veröffentlichte Wörterbuch unter der Redaktion von D. N. Ušakov (vgl. Cejtlin, 1958, 111). Es ist streng normativ konzipiert, umfaßt die Literatursprache von Puškin bis Gor'kij und Material aus der gesellschaftlich-politischen Sprachsphäre. Deshalb gilt es als "das erste russische Wörterbuch sowjetischer Provenienz" (Jachnow, 1990, 2314). Für eine umfassende Charakterisierung des Wörterbuches sei auf einen Aufsatz in der Reihe Cospor pycская лексикография verwiesen (vgl. Zaiceva/Nazarova, 1966, 119-134).

Da mit Beginn der sowjetischen Lexikographie nicht nur die Zahl der veröffentlichten Wörterbücher sprunghaft anstieg (vgl. Vinogradov, 1966), sondern auch die Zahl der Veröffentlichungen über Wörtefoücher (vgl. z. B. Müller, 1999, 290-320; Günther, 1986, 1 8; Sorokoletov, 1978, 26-42; Vinogradov, 1977a, 206-242; Sorokoletov, 1974, 19-31; Babkin, 1965, 396-404; Senin, 1965, 150-153; Babkin, 1960, 3-14) und eine ausführliche Beschreibung der Geschichte der Lexikographie im 20. Jahrhundert für die vorliegende Arbeit von untergeordneter Bedeutung ist, soll im folgenden der bloße Hinweis auf weitere Literatur genügen. Ausführliche Informationen über das Wörterbuch von Ušakov enthalten die Monographien von Cejtlin (1958, 111-123) und von Sorokoletov (1998, 346-366).

Mit der Veröffentlichung des einbändigen erklärenden Wörterbuches von S. I. Ožegov im Jahr 1949, das auf dem vierbändigen von Ušakov basierte, wurde erstmals in der Geschichte der russischen Lexikographie ein Wörterbuch für die breite Masse der Bevölkerung konzipiert (vgl. Jachnow, 1990, 2314). Der Bedarf an einem solchen Wörterbuch manifestierte sich in den zahlreichen weiteren Auflagen, die das Wörterbuch im Lauf der Zeit erlebte (vgl. Müller, 1999, 294). Nach dem Tode Ožegovs im Jahr 1964 erschien 1972 die 9. Auflage des von inm begründeten Wörterbuches, die unter der Redaktion von N.Ju. Švedova vollständig überarbeitet wurde. Zwischen 1972 und 1991 erschienen weitere 14 Auflagen, wobei die jüngste überarbeitete Fassung aus dem Jahr 1989 stammt. Seit 1992 erscheint das Wörterbuch unter dem neuen Titel Толковым словарь русского языка. wobei nun auch die langjährige Herausgeberin N.Ju. Švedova als Mitautorin angeführt wird (vgl. Sorokoletov, 1998, 370-371). Daß das Wörterbuch auch heute noch als Standard- 
werk für den täglichen Gebrauch gilt (vgl. Benson, 1995, 431-435), zeigt sich auch darin, daß bereits 1993 und 1996 unveränderte Neuauflagen erschienen.

Als Fortschreibung des Wörterbuches von Usakov kann das zwischen 1957 und 1960 von der Akademie veröffentlichte vierbändige Wörterbuch Cловарь pycского языка gelten, das als "Kleines Akademiewörterbuch" bekannt ist (vgl. Sorokoletov, 1998, 421-437). Eine überarbeitete zweite Auflage des Wörterbuches wurde zwischen 1981 und 1984 veröffentlicht (vgl. Sorokoletov, 1998, 434; Müller, 1999, 295). Der neueste Stereotypabdruck des Wörterbuches stammt aus dem Jahr 1996 (vgl. Sorokoletov, 1998, Fußnote 327).

Als größte Leistung der russischen Lexikographie gilt das sog. Große Akademiewörterbuch Словары современного русского литературного языка, das zwischen 1948 und 1965 in 17 Bänden erschien (vgl. Sorokoletov, 1998, 378-421; Jachnow, 1990, 2314; Filin, 1982, 239-252; Vinogradov, 1966, 3-26). Derzeit entsteht eine zweite, überarbeitete Fassung des Wörterbuches, von der sechs der geplanten zwanzig Bände bereits veröffentlicht sind (vgl. Müller, 1999, 295).

Neben den drei eben genannten erklärenden Wörterbüchem, die sich großer Beliebtheit effreuen, entstanden im 20. Jahrhundert noch zahlreiche Spezialwörterbücher. Lediglich verwiesen sei hier auf den Sammelband unter der Redaktion von Babkin (1964), der sich mit den phraseologischen Wörterbüchem auseinandersetzt, und auf die Monographie zur Dialektlexikographie von Sorokoletov und Kuznecova (1987), da eine Charakterisierung der zahlreichen Spezıal- und Fachwörterbücher den Rahmen der Arbeit sprengen würde. $\mathrm{Zu}$ einem guten Übertlick über die weitere russische Wörterbuchlandschaft verhelfen die Aufsätze von Müller (1999, 300-313) und Jachnow (1990, 2315-2320), die außerdem auch über eine umfangreiche weiterführende Literaturliste verfügen.

\subsection{Kurze Geschichte der russisch-deutschen Lexikographie}

\subsubsection{Vorbemerkung}

Die am Beginn der russischen Lexikographie stehenden Wortlisten, wie zum Beispiel der Anhang zu der Кормиая книга (vgl. Pkt. 1.1.2, 4), markieren auch den Beginn der zweisprachigen Lexikographie, da sie zweisprachig-erklärend sind (vgl. Kovtun, 1963. 392). Obwohl die zweisprachige Lexikographie der einsprachigen zeitlich vorangeht und bei deren Entstehung eine wichtige Vorläuferrolle gespielt hat, hart die zweisprachige Lexikographie mit Russisch noch mehr als die einsprachig erklärende russische Lexikographie ihrer Erforschung. Dies betrifft auch die russisch-deutsche Lexikographie, deren Ergebnisse bis auf wenige Ausnahmen noch nicht untersucht worden sind. Als Konsequenz 
aus dieser Forschungssituation ergibt sich, daß auch eine Geschichte der russischdeutschen Lexikographie noch nicht geschrieben worden ist. Die Erforschung der zweisprachigen Lexikographie anderer Sprachpaare ist hier schon einen Schritt weiter. Verwiesen sei hier auf Arbeiten, die sich mit der Geschichte der spanisch-englischen (vgl. Steiner, 1970), der italienisch-englischen (vgl. O'Connor, 1990) sowie mit der italienischfranzösischen Lexikographie (vgl. Mormile, 1993) bzw. den zweisprachigen Wörterbüchern mit Italienisch (vgl. Marello, 1989) sowie den zweisprachigen Wörtertüchern mit Spanisch (vgl. Mühlschlegel, 2000, 61-99) und mit Portugiesisch (vgl. Mühlschlegel, 2000, 112-119) auseinandersetzen, und auf zahlreiche Arbeiten, die die Geschichte der zweisprachigen Wörterbücher mit Deutsch genauer untersuchen (vgl. Fraczek, 1999 über die deutschpolnische Lexikographie; Yüksekkaya, 1998 über die deutsch-türkische Lexikographie; Bergenholtz/Mogensen, 1995 zur Geschichte der Lexikographie mit Deutsch und Dänisch; Fejèr, 1995 zur Geschichte der Lexikographie mit Deutsch und Ungarisch: Virtanen, 1993 zur Geschichte der finnisch-deutschen Lexikographie; Meder, 1992 zum Stand der deutsch-(serbo)kroatischen Lexikographie; Papachristos, 1990 über die deutschneugriechische Lexikographie). Ziel dieses Abschnittes ist es deshalb, einen kurzen Überblick über die Geschichte der russisch-deutschen Lexikographie zu geben, um das im Mittelpunkt der Arbeit stehende Werk von Pawlowsky in diese einzuordnen und vor deren Hintergrund in den folgenden Kapiteln die Leistung Pawlowskys und seiner Nachfolger zu beurteilen.

Wenn im folgenden nun die Geschichte der russisch-deutschen Lexikographie kurz dargestellt werden soll, so geschieht dies emeut auf der Grundlage unterschiedlicher Bibliographien (vgl. Vomperskij, 1986; Stankiewicz, 1984; Aav, 1977; Lewanski, 1972; Zaunmüller, 1958; Vinogradov, 1954) und unter Hinzuziehung der wenigen vorhandenen Aufsätze über russisch-deutsche Wörterbücher. Als wichtiges Hilfsmittel haben sich außerdem Monographien erwiesen, die sich mit der Geschichte des Russischunterrichts und dessen Lehmaterialien auseinandersetzen (vgl. Basler, 1987; Baumann, 1977; Baumann, 1969). Weitere wichtige Informationen, insbesondere zur frühen Phase der russisch-deutschen Lexikographie, liefem die Einleitungen zu den verhältnismäßig zahlreichen Faksimileausgaben der handschriftlichen russisch-deutschen Gesprächsbücher (vgl. Pkt. 1.2.2, 14-18).

Nicht behandelt werden in diesem kurzen Überblick die zahlreichen handschriftlichen und gedruckten mehrsprachigen Glossare, in denen das Russische und das Deutsche enthalten sind (vgl. dazu Chajdarov, 1994, 21-30; Scholz/Freidhof/Kosta, 1982-1983, Bd. I-III; Berezina, 1980, 6-22), sowie die Gesprächsbücher, in denen die Ausgangssprache das Deutsche und die Zielsprache das Russische ist (vgl. Günther, 1999; Nikolaev/Troškina. 
1994, 129-147; Panzer, 1992. 189-200; Panzer, 1989 (vgl. hierzu die Kritik von Lunden, 1991, 297-298); Birkfellner, 1984; Johansen, 1955, 275-283).

\subsubsection{Der Beginn der russisch-deutschen Lexikographie: Gesprächsbücher}

In der ersten Phase der russisch-deutschen Lexikographie, die bis zum Ence des 17. Jahrhunderts dauerte, entstanden noch keine Werke, die mit dem Begriff Wörterbuch im heutigen Sinne bezeichnet werden könnten. Bei diesen ersten Dokumenten hanđelt es sich vielmehr um sogenannte Sprach- oder Gesprächsbücher, die meist von des Russischen mehr oder weniger mächtigen Deutschen verfaßt wurden und deren vorrangiges Ziel es war, den mit Rußland Handel treibenden deutschen Kaufleuten bei der Überwinjung ihrer Sprachprobleme behilfich zu sein. Bei der Entstehung dieser frühen Fremdsprachenlehrbücher für lebende Sprachen spietten die Lateinlehrbücher, die zumeist aus einem Grammatikteil, thematisch geordneten Vokalbellisten und einem Gesprächsteil bestarden, eine wichtige Vorbildrolle (vgl. Günther, 1999, 8).

Das älteste bisher bekannte Dokument, das der Geschichte der russisch-deutschen Lexikographie zugeordnet werden kann, ist ein russisch-hochdeutsches Gesprächsbuch aus dem Jahr 1546. Die Handschrift, die in der Berliner Staatsbibliothek aufbewahrt wurde, galt nach dem Zweiten Weltkrieg als verloren (vgl. Alekseev, 1974, 344; Günther, '964, 17). Da sie bis dahin nicht veröffentlicht worden war, mußte man sich bei der Charakterisierung des Werkes auf die Beschreibung anderer Philologen stützen, die die Handschrift vor 1945 untersuchten hatten. Genau dieser Aufgabe widmet sich Alekseev in seinem Autsatz Thomas Schrowe und das ${ }_{n}$ Russischbuch" von 1546 (vgl. Alekseev, 1974, 21-31 u. 344-348). Er kommt, nachdem er die vor dem Zweiten Weltkrieg von russischen Forschern rerfaßten Beschreibungen (vgl. Alekseev, 1974, 21-25) analysiert und verglichen hat, zu dem Schluß, daß es sich bei dem Gesprächsbuch um einen „für Ausländer bestimmten Leitfaden zum Studium der russischen Umgangssprache“ (Alekseev, 1974, 31) handele, dessen Original „Ende des 15. Jahrhunderts von einem Deutschen im Gebiet Novgorod oder aber mit Hilfe eines Russen aus Nordwestrußland zusammengestellt" worden sei (Alekseev, 1974, 31). Thomas Schrowe kommt nach der Untersuchung von Alekseev (vgl. Alekseev, 1974, 27-29), da er des Russischen nicht mächtig gewesen sei (vgl. Alekseev, 1974, 28), allenfalls als Kopist oder eher noch als Auftraggeber in Frage. Utheber der Handschrift war nach Alekseev vermutlich ein unbekannter deutscher Kaufmann, der die Vertreter des hansisch-russischen Handels unterstützen wollte (vgl. Alekseev, 1974, 29). Das Datum 1546 verweist demnach nicht auf das Entstehungsdatum des Russisch Buch, sondern .fixiert lediglich das Jahr, in dem die ehemals in der Bertiner Staatsbibliothek befindliche Kopie nach einer früheren Kopie angefertigt wurde" (Alekseev, 1974, 31). Inzwischen ist 
die Handschrift wieder aufgetaucht. Sie wird laut Panzer (vgl. Panzer, 1992, 189) mit einer Reihe von weiteren Manuskripten als Depot in der Biblioteka Jagiellońska in Krakau aufbewahrt

Die Arbeit von Alekseev veranlaßte den polnischen Slavisten Adam Fałowski, sich mit der ältesten erhaltenen russisch-deutschen Handschrift eingehender zu beschäftigen. Fałowskis Bemühungen ist es zu verdanken, daß 1992 der erste Band eines mehrbändigen Werkes erschienen ist, der neben einer Einführung auch eine Photokopie des Russisch Buch von Thomas Schrowe enthält (vgl. FalovskijNitkovskij, 1992). Im zweiten Band, der 1997 erschien, ist der Text des Gesprächsbuches erneut abgedruckt und mit linguistischen Kommentaren versehen (vgl. Falovskij/Nitkovskij, 1997). Die Richtigkeit von Alekseevs Ergebnissen wird von Fałowski, der diese in seiner Einleitung zusammenfaßt (vgl. Falovskij/Nitkovskij, 1992, 12-13), nicht angezweifelt. Allerdings kann der genaue Inhalt des in lateinischer Schrift verfaßten Gesprächsbuches, das im ersten Teil Gespräche über Handelsbeziehungen und im zweiten Teil eine thematisch geordnete russisch-deutsche Vokabelliste enthält, erst durch Fałowskis Arbeit wiedergegeben werden (vgl. FalovskijNitkovskij, 1992, 16-18).

Die wohl bekannteste, umfangreichste und inhaltlich vielfältigste Handschrift in der frühen Geschichte der russisch-deutschen Lexikographie ist das russisch-niederdeutsche Gesprächsbuch von Tönnies Fenne aus dem Jahr 1607, das in vier Bänden in Kopenhagen ediert und bearbeitet wurde (xgl. Hammerich/Jakobson, 1961, 1970, 1985 u. 1986). Dank dieser bereits vor dem Weltkileg angeregten Edition vertügen wir nicht nur über eine Faksimileausgabe der Handschrift (vgl. Hammerich/Jakobson, 1961), sondern auch über eine transliterierte gedruckte Fassung des russisch-niederdeutschen Gesprächsbuches mit englischen Übersetzungen (vgl. Hammerich/Jacobson, 1970), über ein alphabetisch geordnetes und mit Belegstellen versehenes russisch-niederdeutsches Glossar (vgl. Hammerich/Jacobson, 1985) und schließlich über ein mittelniederdeutsch-neuhochdeutsches Wörterbuch zum niederdeutschen Teil des Gesprächsbuches (vgl. Hammerich/Jacobson, 1986). Schreiben die Editoren noch Fenne die Autorenschaft zu (vgl. Hammerich/Jacobson, 1961, 5), obwohl auch sie bemerkt haben, daß die Handschrift nicht einheitlich sei (vgl. Hammerich/Jacobson, 1961, 10), so geht man inzwischen davon aus, daß das Werk wohl nicht von Fenne selbst verfaßt worden ist, sondern sich nur in dessen Besitz befand (vgl. Panzer, 1992, 190). Über die Person Fennes informiert der Aufsatz von Jeannin (1973, 50-53). Allerdings ist kritisch anzumerken, daß auch dieser Autor Fenne noch für den Urheber der Handschrift hält. 
Die Vermutung, daß die Handschrift nicht aus der Feder nur eines Autors stammt, wird durch eine Reihe von religiösen Texten ( $v g l$. Hammerich/Jacobson, 1961, 15), deren Handschrift und deren Sprachstil von den anderen Texten abweicht (vgl. Hammerich/Jacobson, 1970, X), und durch einige polnische Texte, die wohl zusätzlich angefügt wurden, gestützt (vgl. Hammerich/Jacobson, 1961, 15-16). Des weiteren besteht die Handschrift aus einem einleitenden Teil (vgl. Hammerich/Jacobson, 1961, 11), aus einem thematisch angelegten Wörterbuch der russischen Umgangssprache mit niederdeutschen Entsprechungen (vgl. Hammerich/Jacobson, 1961, 12-13), aber auch einem grammatischen Teil (vgl. Hammerich/Jacobson, 1961, 13-14), einem phraseologischen Teil (vgl. Hammerich/Jacobson, 1961, 14) und einem Teil, der den Sprichwörtern gewidmet ist (vgl. Hammerich/Jacobson, 1961, 15). Daß mit Hilfe des Gesprächsbuches eine Verbesserung der deutsch-russischen Handelsbeziehungen durch die Verringerung der sprachlichen und kulturellen Barrieren angestrebt wurde, beweisen nicht nur die Verhaltensregein für deutsche Kaufleute beim Handel in Rußland im einleitenden Teil (vgl. Hammerich/Jacobson, 1961, 11), sondem auch diejenigen Teile des Gesprächsbuches, die direkt dem russischdeutschen Handel gewidmet sind (vgl. Hammerich/Jacobson, 1961, 13-15).

Das Gesprächsbuch von Fenne umfaßt über viertausend Lemmata, deren größter Teil in ganzen Sätzen aufgenommen wurde (vgl. Hammerich/Jacobson, 1970, IX-X). In der Handschrift dominiert das Lateinische zur Wiedergabe der russischen Lemmata, einzelne Abschnitte erscheinen allerdings auch in kyrillischer Schrift (vgl. (Hammerich/Jacobson, 1961, 11, 14, 15). Eine relativ ausführliche Analyse des sprachlichen Materials findet sich im zweiten Band der Edition (vgl. Hammerich/Jacobson, 1970, XI-XXI). Ein von den Editoren vorgenommener Vergleich des Materials bei Fenne mit dem Inhalt des Gesprächsbuches von 1546 ergab, daß Ännlichkeiten in der Auswahl, in der Interpretation, in der Anordnung und in der Darstellung des lexikalischen Materials auf eine Verwandtschaft der beiden ältesten erhaltenen Dokumente hinweisen (vgl. Hammerich/Jacobson, 1961, 1922). Obwohl das Gesprächsbuch von Fenne durch die Edition einer breiteren Offentlichkeit zugänglich gemacht und die Arbeit mit der Faksimileausgabe durch die nachfolgenden Bände der Edition beträchtlich vereinfacht wurde, gilt auch dieses Werk als noch nicht genügend erforscht. Denn nicht nur die linguistischen Aspekte der beiden Sprachen im Gesprächsbuch, sondern auch die handels- und die kulturhistorische Dimension des Werkes warten noch auf eine Auswertung (vgl. Hammerich/Jacobson, 1986, l). Ein Anfang ist allerdings mit einem Sammelband der Akademie der Wissenschaften der DDR vollbracht worden, der sich den Einblicken widmet, die Fennes Werk in die Geschichte der deutschen Sprache bietet (vgl. Gernentz, 1988). 
Ein weiteres russisch-deutsches Gesprächsbuch aus dem 17. Jahrhundert mit dem Titel Ein Rusch Boeck, das einige Jahrzehnte lang für verschollen gehalten wurde (vgl. Fałowski, 1994, 6; Günther, 1964, 18), befindet sich ebenfalls in der Handschriftenabteilung der Jagiellonenbibliothek in Krakau. Fałowski, der sich mit diesem Gesprächsbuch schon in einem Aufsatz beschäftigt hatte (vgl. Falovskij, 1991/92, 211-217), veröffentlichte 1994 eine Faksimilefassung ( $v g l$. Fałowski, 1994). Der Verfasser des in lateinischer Schrift geschriebenen Gesprächsbuches ist ebenso wenig bekannt wie dessen Entstehungsort (vgl. Fałowski, 1994, 10). Aufgrund von orthographischen Eigenheiten bei der Aufzeichnung der russischen Lexeme und anderen Indizien (vgl. Fałowski, 1994, 11) ist allerdings davon auszugehen, daß es sich um einen deutschen Autor handelte. Auch über das genaue Entstehungsdatum des Opus können momentan noch keine Angaben gemacht werden. Falowski vermutet aufgrund des Wasserzeichens im Papier, daß es vor 1568 entstanden sein könnte (vgl. Falowski, 1994, 10). Inhaltlich zeichnet sich diese Handschrift durch eine Gliederung in drei Teile aus. Der erste Teil, der fünf Seiten umfaßt, enthält Verhaltensregein für deutsche Rußlandreisende in Versform, die vermutlich nicht vom Autor des Gesprächsbuches selbst verfaßt worden sind (vgl. Falowski, 1994, 12). Im zweiten Teil werden Gespräche verschiedensten Inhalts wiedergegeben. Neben den obligatorischen Handelsthemen werden auch die physischen und die psychischen Eigenschaften des Menschen, dessen Mahlzeiten und Kleidung sowie die Flora und die Fauna behandelt (vgl. Falowski, 1994, 12-14). Wie die bisher beschriebenen Handschriften, so enthält auch Ein Rusch Boeck neben den nach semantischen Prinzipien geordneten Vokabellisten einen Gesprächsteil, dessen Qualität allerdings, verglichen mit den Werken anderer Autoren dieser Zeit, überdurchschnittlich ist (vgl. Fałowski, 1994, 10).

Gegen Ende des 17. Jahrhunderts entstand ein weiteres russisch-deutsches Gesprächsbuch, das gegenwärtig in Trondheim aufbewahrt wird. Es liegt ebenfalls schon geraume Zeit in einer hervorragenden Faksimileausgabe vor (vgl. Lunden, 1972). Dieses Gesprächsbuch enthält neben den bereits bekannten thematisch geordneten russischdeutschen Vokabellisten ( $v g l$. Lunden, 1972, 4-7) alphabetische Schreibübungen in kyrillischer Schrift, die von Lunden in einem Aufsatz beschrieben (vgl. Lunden, 1963, 169-185) und deshalb nicht in die Faksimileausgabe aufgenommen wurden.

Wie Lunden überzeugend darstellt ( $v$ gl. Lunden, 1972, 18), handelt es sich bei der Trondheimer Handschrift um eine Abschrift eines möglicherweise 30 bis 40 Jahre älteren Originals, dessen sprachliche Merkmale und geographische Orientierung den russischen Nordwesten als Entstehungsort wahrscheinlich machen (vgl. Lunden, 1972, 33). Sowohl 
über den Autor des Originals als auch über die Autoren der Abschrift ist nichts bekannt. Da Lunden frappierende Ảhnlichkeiten in Aufbau und Gliederung der ältesten Sprachlehrbücher und Wörterbücher feststellt (vgl. Lunden, 1991, 297-298; Lunden, 1980, 91-93; Lunden, 1975, 47-60), vermutet sie einen gemeinsamen Ursprung dieser Werke (vgl. Lunden, 1972, 22). In einer Gegenüberstellung der Kapitelüberschriften der Trondheimer Handschrift mit denen der Janua Linguarum von J.A. Comenius zeigt sich eine verblüffende Übereinstimmung ( $\mathrm{vgl}$. Lunden, 1972, 23-25). Die wenigen Abweichungen führt Lunden überzeugend auf Abschreibefehler zurück (vgl. Lunden, 1972, 25). Des weiteren zeigt die Editorin auf, daß die Trondheimer Handschrift den Auftakt zu einer Comeniusrezeption bildet. der so wichtige Werke wie das Vocabularium in Ludolfs Grammatica Russica und der Nomenclator von Kopiewicz nachfolgen (vgl. Lunden, 1975, 47; Lunden, 1972, 26-33). Auch die Ausführungen von Baumann $(1969,35-37)$ bestätigen, daß die sprachpädagogischen Arbeiten von Comenius in Rußland bekannt waren. Aufgrund der engen Verwandtschaft zwischen den Janua und der Trondheimer Handschrift läßt sich die Veröffentlichung der Janua Linguarum im Jahr 1631 als terminus post quem für die Entstehung des Originals der Abschrift festlegen. So scheint für das Original eine Entstehungszeit in den 40er oder 50er Jahren des 17. Jahrhunderts wahrscheinlich. Die Trondheimer Abschrift entstand vermutlich, wie durch paläographische Daten deutlich wird, in den 80 er Jahren desselben Jahrhunderts (vgl. Lunden, 1972, 34).

Für die erste Phase der russisch-deutschen Lexikographie ist also zu konstatieren, daß die Gesprächsbücher, die noch nicht als Wörterbücher im heutigen Sinne bezeichnet werden können, zwar meist von Nichtrussen, wohl aber mit der Hilfe von russischen Muttersprachlern verfaßt wurden, mit dem Ziel, den mit Rußland Handel treibenden Kaufleuten bei der Überwindung der sprachlichen Barrieren behilflich zu sein. Diese ersten Gesprächsbücher, deren Autoren und deren Entstehungsort wohl oft im Umfeld der Hanse zu vermuten sind, zeichnen sich durch eine stark auf die Bedürnisse der Kaufleute zugeschnittene Lexik aus. Gemeinsam ist außerdem nahezu allen Gesprächsbüchem eine Zweiteilung in Gesprächsteil und thematisch geordneten Vokabelteil, wobei die inhaltlichen Übereinstimmungen auf eine enge Verwandtschaft der Werke untereinander deuten. Eine Vorbildfunktion der humanistischen Lateinlehrbücher, die allerdings meist auch noch einen grammatischen Teil enthielten, wie er in diesem Falle nur in Fennes Werk enthalten ist, ist nicht von der Hand zu weisen. Die Untersuchung dieser verwandtschaftlichen Bezüge der Gesprächsbücher untereinander und des Zusammenhanges mit den Lateinlehrbüchern ist eine weitere noch unzureichend gelöste Aufgabe der historischen Metalexikographie. Daß die Gesprächsbücher für die Kaufleute von enormer Bedeutung waren. wird durch die bisher gefundenen Handschriften deutlich, denn es handelt sich bei innen ausnahmslos um 
Kopien. Auf eine regelrechte Abschreibetradition deutet nicht nur die relativ große Zeitspanne zwischen vermuteter Entstehung der Originale und der der Kopien hin, sondern auch die hohe Qualität der Kopien, die auf professionelle Schreiber venweist. Obwohl das Interesse an den Handschriften in den letzten Jahren deutlich gestiegen ist, wie dies auch die Zahl der inzwischen vorliegenden Faksimileeditionen beweist, wird die Bedeutung der Gesprächsbücher für die Sprachgeschichte immer noch unterschätzt. So handelt es sich nach Meinung der angesehenen russischen Metalexikographin L. S. Kovtun bei innen nicht um .факт[Ы] русской лексикографи", sonderা um .факт[Ы] историм лексикографим родной страны создателя словаря" (Kovtun, 1963, 318). Diese Einstellung erstaunt besonders auch deshalb, weil die Gesprächsbücher wegen ihrer Nähe zur gesprochenen Sprache Zeugnis über die damalige Umgangssprache ablegen können, ist doch ein nicht geringer Teil der aus dieser Zeit bekannten Schriften aufgrund der diglossischen Sprachsituation im damaligen Rußland stark kirchenslavisch geprägt. Früh erkannte dies augenscheinlich nur Larin, der sich durch die Edition und spractwwissenschaftliche Auswertung früher Gesprächsbücher sehr verdient gemacht hat (vgl. Larin, 1959; Larin, 1948).

Es bleibt also festzuhalten, daß die Gesprächsbücher nicht nur den Beginn der russischdeutschen Lexikographie markieren, sondern daß sie aufgnund ihrer Orientierung an der gesprochenen Sprache auch eine wichtige sprachistorische Quelle darstellen. Aber auch inr kulturgeschichtlicher Wert ist durch die Orientierung an der Zielgruppe der Kaufleute nicht zu unterschätzen. Da nun zahlreiche Werke in Faksimileausgaben zur Verfügung stehen, bleibt zu hoffen, daß die einzelnen Disziplinen die Gesprächsbücher in nächster Zukunft für sich entdecken werden.

\subsubsection{Erster Aufschwung der russisch-deutschen Lexikographie im 18. Jahrhundert}

In der ersten Phase der Geschichte der zweisprachigen Lexikographie mit Russisch lag der Schwerpunkt noch eindeutig auf den zweisprachigen Wörterbüchern mit den klassischen Schulsprachen Griechisch und Latein, da in Rußland noch Übersetzungen aus dem Lateinischen ins Russische dominierten (vgl. Sorokoletov, 1998, 63). Im 18. Jahrhundert gewannen dann die modernen westlichen Sprachen, v. a. das Deutsche und das Französische, immer größeren Einfluß (vgl. Eismann, 1991, 3072). Dies ist durch eine enger werdende Bindung Rußlands zum westeuropäischen Ausland im Petrinischen Zeitalter zu erklären, die zu einem sprunghaften Anstieg der Übersetzungsliteratur führte und die Aufnahme moderner Fremdsprachen in den Unterrichtskanon nach sich zog (vgl. Cejtlin, 1958, 15). So entstanden in diesem Jahrhundert, in dem die zweisprachige Lexikographie die einsprachige zahlenmäßig überwog, 20 Wörterbücher mit Deutsch als Ziel- bzw. als Ausgangssprache (vgl. Biržakova, 1977, 96). 
Arffangs beherrschten noch Lehrbücher, Grammatiken und Gesprächsbücher das Feld. Erwähnt sei hier stellvertretend das Leidener russisch-deutsche Gesprächsbuch, das 1978 herausgegeben wurde (vgl. Klueting, 1978). Es muß allerdings darauf hingewiesen werden, daß der Herausgeber die offensichtliche Verwandtschaft zwischen dem Gesprächsbuch und dem Orbis Pictus von Comenius (vgl. Lunden, 1980, 91-93) nicht erkannt hat. Gegen Ende des Jahrhunderts erschienen dann erste selbständige Wörterbücher, die die Gesprächsbücher allmählich verdrängten.

Erwähnenswert ist in diesem Zusammenhang die Rezeption des von Christoph Cellarius entwickelten Konzepts zur Erlernung von Fremdsprachen, das auf einer "natürlichen Ordnung ${ }^{-}$der Wörter beruhte und in seinem Vocabularium latino-germanicum, 1688 - bekannt unter dem Kurztitel Liber memoralis - erstmals verwirklicht urde. Der Liber memoralis, der immer wieder an den verschiedensten Orten nachgedruckt wurde, war eines der am weitesten verbreiteten Lehrbücher im Deutschland des 18. Jahrhunderts (vgl. Keipert. 1987. 298), und er läßt sich nicht nur im Besitz russischer Gelehrter nachweisen, sondern wurde auch zu einem Standardwerk des Lateinunterrichts am Petersburger Akademiegymnasium (vgl. Keipert, 1987, 300). So ist es nicht erstaunlich, daß bereits 1746 bei der Petersburger Akademie eine russische Bearbeitung des Liber memoralis erschien, die den Titel Христофора Целлария латинкой лексикон с Россииским и Немеиким переводом аля употребления Санктпетербургской rимқазия trägt (vgl. Keipert. 1987. 301; Vomperskij. 1986, Nr. 42). Daß die Konzeption von Cellarius großen Einfluß auf die russische Lexikographie der damaligen Zeit hatte und höchstwahrscheinlich indirekt auch für die etymologische Anordnung des Wortmaterials im ersten Akademiewörterbuch ausschlaggebend gewesen ist, zeigen die Ausführungen von Keipert (1987, 302-304). Besonders verdient um die Cellariusrezeption machte sich der von 1763 bis 1779 als Lektor der deutschen Sprache an der Moskauer Universität tätige Franz Hölterhof. So veröffentlichte er in einem ersten Schritt 1765 einen Deutschen Cellarius (vgl. Keipert. 1987, 308; Vomperskij. 1986. Nr. 63), außerdem vier Jahre später eine russische Bearbeitung des französischen Cellanus (vgl. Keipert, 1987, 310; Stankiewicz, 1984, 131) und schließlich 1771 dann den Poccuícкой Lleллариyс (vgl. Keipert, 1987, 312; Vomperskij, 1986, Nr. 78), der den Autoren des ersten Akademiewörterbuches als Quellengrundlage diente (vgl. Sorokoletov, 1998, 67). Die von Hölterhof vorgelegten Wörterbücher genießen auch heute noch hohes Ansehen, nicht nur weil sie zu den ersten zählen, die sich des etymologischen Prinzips zur Anordnung des Wortmaterials bedienen (vgl. Cejtlin, 1958, 23), sondern auch wegen ihres Wertes als Belegquelle (vgl. Zolobov, 1994, 211-223; Keipert. 1987, 313). So gıbt beıspielweise die aus pädagogischen Gründen vorgenommene durchgehende Akzen- 
tuierung Auskunft über die Akzentverhältnisse im 18. Jahrhundert, informiert die gesonderte Darstellung der Fremowörter über die zur damaligen Zeit als entlehnt geltenden Wörter und belegt ein Teil der Eintragungen das Vorkommen der fraglichen Lexeme in der russischen Sprache zum ersten Mal.

Ein weiteres handschriftliches Wörterbuch stammt aus der Feder von Christoph Schmidt, genannt Phiseldek, der das Werk nach einem längeren Aufenthalt als Hauslehrer in Rußland in den Jahren 1774 bis 1779 schrieb. Das Wörterbuch, das sowohl einen russisch-deutschen als auch einen deutsch-russischen Teil enthält, blieb unvollendet und war wohl nur zum persönlichen Gebrauch des Autors bestimmt. Nach dem Zweiten Weltkrieg gelangte das Schmidtsche Wörterbuch in die Universitätsbibliothek in Halle, dessen Direktor das Werk 1978 als Faksimile edierte (vgl. Dietze, 1978). Prinzipiell strebte Schmidt wohl eine Anordnung der Lemmata nach dem Alphabet an, da er das Material aber des öfteren um neue Einträge und ganze Einschübe ergänzte, ist das alphabetische System an einigen Stellen durchbrochen ( $v g \mid$. Dietze, 1978, IX-X). In weiteren Anhängen beschäftigte sich Schmidt mit den in Rußland gebräuchlichen Abbreviaturen, mit der russischen Grammatik, wobei er sich in diesen Einschüben auf die russische Schulgrammatik von Jacob Rodde stützte, und mit den deutschen Entsprechungen der russischen Buchstaben. Diese Einschübe stützen neben der ungewöhnlichen Anordnung des Materials die Vermutung, daß sich Schmidt mit seinem Wörterbuch ein Hilfsmittel zur Lektüre russischer Texte geschaffen hat, das nicht zur Veröffentlichung bestimmt war (vgl. Dietze, 1978, XII). Daß das Werk Schmidts dennoch von einem gewissen Wert für die sprachwissensschaftliche Forschung ist, bekräftigt schon Dietze, wenn er sagt. daß das .Wörterbuch überraschende Einblicke in die Umgangssprache und zu einem gewissen Teil in den Dialekt bei teilweise phonetischer Schreibung" bietet, „aber auch die Semantik verschiedener Lexeme [...] erhelit, weil mit den deutschen Entsprechungen häufig alte, ursprüngliche oder heute abgestorbene Bedeutungen belegt werden" (Dietze, 1978, XII). Auch Eckert stellt in einem Aufsatz (vgl. Eckert, 1990, 805-810) fest, nachdem er die phraseologischen Eintragungen im Wörterbuch analysiert hat, daß es sich hierbei um „eine wertvolle Quelle für die Phraseologie der russischen Sprache des 18. Jh." handele (Eckert, 1990, 809). In einem weiteren Aufsatz (vgl. Flekenštejn, 1984, 914-920) untersucht Fleckenstein die semantische Gruppe der Berufsbezeichnungen im Schmidtschen Wörterbuch und kommt zu dem Schluß, daß der „словарь хорошо отражает становление современных названии лми по профессим, переход от опмсателыных обозначений $\mathrm{k}$ собствен но намменованиям и от двухкомпонентных к однокомпонентным названиям" (Flekenštejn, 1984, 919). 
Gegen Ende des Jahriunderts entstanden dann die ersten großen gedruckten russischdeutschen Wörterbücher, die bis heute das Interesse der Sprachwissenschaftler vornehmlich als Hilfsmittel, nicht aber als eigenständiges Forschungsobjekt gefunden haben. Will man nun ausführliche Informationen über diese Wörterbücher erhalten, so muß man, neben der Auswertung der zum Teil kommentierten Bibliographien, auf die Einleitungen der Wörterbücher zurückgreifen, da weder zusammenfassende Monographien, wie bei der einsprachigen russischen Lexikographie, noch ausführliche Einleitungen, wie in den Faksimileausgaben der Gesprächsbücher, zur Verfügung stehen.

Problematisch wird es aber schon bei dem 1784 in Riga bei Johann Friedrich Hartknoch herausgegebenen russisch-deutschen Wörterbuch von Jacob Rodde (vgl. Rodde, 1784a); denn nur das zeitgleich veröffentlichte deutsch-russische Pendant (vgl. Rodde, 1784) enthält ein Vorwort, das der Autor bereits im Jahr 1781 verfaßt hatte. Außerdem ist keiner der beiden Bände in den Bibliographien annotiert. Die nun folgenden Informationen wurden durch eine kurze Analyse des Wörterbuches gewonnen. Der Wortbestand, der auf 415 Seiten dargestellt wird, ist glattalphabetisch (vgl. 3.2.1, 62) angeordnet. Wenn mehrere Bedeutungen angegeben sind, werden diese durch Kommata voneinander getrennt. Da Rodde bei einigen Lemmata auch Kollokationen (vgl. 4.2.5. 111) anführt, hat er die zweite Variante innerhalb einer glattalphabetıschen Anordnung gewählt, die artikelalphabetisch genannt wird (vgl. 3.2.2.4. 71).

Bsp.: Иn y, ich gehe. Inf. итт'и, gehen; ид и съ м'иромr, gehe mit Frieden! Иа у предъ KtMrb, ich gehe vor jemanden; nд'y no koMr, ich gehe nach einem, folge einem; na y cъ Ktмr, ich gehe mit einem; un'y cnatb, ich gehe schlafen.

Durch dieses Beispiel wird außerdem deutlich, daß Rodde bei mehrsilbigen Wörtern (vgl. Pkt. 4.2.1, 90) durchgehend den Akzent angibt und daß er die Verben - wie in lateinischen Wörterbüchern - nach der 1. Person Singular lemmatisiert, ohne auf den Infinitv oder auf ein Konjugationsmodell zu verweisen. Die von Rodde benutzten Quellen müssen weitgehend im dunkeln bleiben, da, um sie nachzuweisen, eine ausführlichere Analyse als die im Rahmen dieser Arbeit mögliche nötig gewesen wäre. Allerdings verweist Baumann darauf (vgl. Baumann, 1969, 19), daß Rodde sich stark an dem deutsch-russischen Teil aus dem dreisprachigen deutsch-lateinisch-russischen Wörterbuch von Weißmann orientiert habe, wobei er allerdings zahlreiche Korrekturen an dem von inm als .sehr unvollkommen und mangelhaft" (Rodde, 1784, I) kritisierten Werk vorgenommen habe. Zusätzlich verweist Rodde in seiner Einleitung auf die Reisebeschreibungen von Pallas und die Arbeiten von Linné, die inm insbesondere bei der Beschreibung der Flora und der Fauna hilfreich gewesen seien, sowie auf die Werke von Lomonosov, aus denen zahlreıche Re- 
densarten stammten ( $\mathrm{vgl}$. Rodde, 1784, III). Für die Vermutung, daß Rodde die deutschen Muttersprachler als Zielgruppe beider Teile seines Wörterbuches betrachtete, spricht die Tatsache, daß nur der zuerst erschienene deutsch-russische Teil mit einem Vorwort, noch dazu nur in deutscher Sprache, versehen ist.

Roddes Werk enthält weder einen grammatischen Anhang, noch eine aus anderen Wörterbüchern bekannte Liste von Anthroponymen. Das Fehlen von grammatischen Angaben läßt sich dadurch plausibel machen, daß Rodde sich bereits als Verfasser eines Lehrbuches mit dem Titel Russische Sprachlehre (vgl. Berkov, 1958, 79), das erstmals 1773 erschienen war, einen Namen gemacht hatte, so daß ein grammatischer Teil in dem Wörterbuch nicht als nötig betrachtet wurde. Bestätigt wird diese Vermutung durch den Hinweis in der Einleitung des deutsch-russischen Wörterbuches, daß sich "in dem Russisch-Deutschen Wörterbuch [...] die mit 1. 2. 3. 4. bemerkten Deklinationen auf meine ausgegebene Grammatik" (Rodde, 1784, III) bezögen.

Unbedingt Erwähnung finden müssen hier auch die deutsch-russischen und die russisch-deutschen Wörterbücher des Johann Heym, die 1795 bzw. 1798 veröffentlicht wurden (vgl. Vomperskij, 1986, Nr. 254; Stankiewicz, 1984, 134) und die danach noch mehrere Auflagen (vgl. Baumann, 1977, 247) erlebten. Der folgenden kurzen Beschreibung liegt die 1800 erschienene zweite Auflage zugrunde (vgl. Heym, 1800). Heym, der zuerst als Privatlehrer und Lektor der deutschen Sprache, später dann als Professor an der Moskauer Universität tätig war (vgl. Baumann, 1977, 246), widmete sein russisch-deutsches Wörterbuch dem Fürsten F. N. Golicyn, der ihn auch in Zeiten der Krankheit immer unterstützt habe und so mitverantwortlich für die Fertigstellung des Wörterbuches gewesen sei (vgl. Heym, 1800, o. S.). Im Gegensatz zu Roddes Wörterbuch enthält Heyms Werk ein Vorwort, das, wie auch die Danksagung und die Widmung, sowohl in russischer wie auch in deutscher Sprache abgedruckt ist. Bei der Formulierung des Ziels seines Werkes, das "bequemer und vollständiger [...] als das Roddesche und Nordstätsche" (Heym, 1800, 0. S.) sein solle, nimmt Heym sogar direkt auf das Roddesche Wörterbuch Bezug.

Relativ einfach ist es in diesem Fall, die Frage nach den von Heym benutzten Quellen zu klären, findet man doch schon im Titel den Zusatz "nach dem grossen Wörterbuche der Russischen Akademie bearbeitet". Doch außerdem ist "auch keine andere, mir nur irgend bekannt gewesene Quelle, unbenutzt geblieben“ (Heym, 1800, o. S.), so daß Heyms vorrangiges Ziel, "besonders den russisch-deutschen Theil so vollständig als möglich zu machen" (Heym. 1800, o. S.), erreicht worden sein dürtte. Besonders verdient hat sich Heym um die Darstellung des fachsprachlichen Wortschatzes gemacht, ein Umstand, der sich auch in den von inm benutzten Quellen widerspiegelt. So hat er neben mehreren zeitgenössischen Naturgeschichten auch mineralogische, botanische und pharmazeutische 
Spezialliteratur zu Rate gezogen (vgl. Heym, 1800, o. S.). Das Ziel, ein qualitativ höherwertiges Hilfsmittel als das Roddesche Wörtertuch zu schaffen, hat Heym mit seinem 2307 Spalten umfassenden und in drei Teilstücke untergliederten Werk, das ca. 41.000 Wörter enthält (vgl. Stankiewicz, 1984, 135), gewiß erreicht. So gibt er bei den Substantiven generell neben dem Genus auch die Endung des Genitiv Singular an. Die Verben versieht er im Gegensatz zu Rodde mit Hinweisen auf die Konjugation, und außerdem bedient er sich bereits besonderer Markierungen als eines lexikographischen Hilfsmittels, wie zum Beispiel der Markierung Slav. für genetisch kirchenslavische Lexeme. Besonders ins Auge fallen die zum Teil quasiethnographischen Eintragungen, die dem deutschen Russischlernenden auch die russische Lebensweise näherbringen (vgl. Stankiewicz, 1984, 135).

Bsp.: u'bбикъ, a, m. Ein Kasten von hart gemachtem Leder, unter welchem Holz, das inwendig mit Bley ausgelegt ist, in welchem gewöhnlich der Thee aus China nach Russland gebracht wird und der meistentheils sechzig bis siebzig und fünf und siebzig Pfund enthält.

Doch die russisch-deutschen bzw. deutsch-russischen Wörterbücher waren nicht das einzige lexikographische Projekt Heyms, der sich durch seine russiscin-französischdeutschen Wörterbücher und Taschenwörterbücher (vgl. Stankiewicz, 1984, 135, 136) auch auf dem Gebiet der mehrsprachigen Lexikographie verdient gemacht hat (vgl. Baumann, 1969, 52f). Aber auch Heym teilt das hier schon mehrfach bedauerte Schicksal vieler bedeutender Lexikographen, denn auch seine Leistung hart bis zur heutigen Zeit ihrer wissenschaftlichen Entdeckung.

Abschließend bleibt festzuhalten, daß mit dem Erscheinen der ersten beiden großen gedruckten russisch-deutschen Wörterbücher von Rodde und Heym der Aufschwung der russisch-deutschen Lexikographie eingeleitet wurde, der sich, wie nun zu zeigen sein wird. im 19. Jahthundert fortsetzte.

\subsubsection{Die zweisprachige Lexikographie russisch-deutsch im 19. Jahrhundert}

Bedauerlich ist. daß auch für die großen zweisprachigen Wörterbücher des 19. Jahrhunderts gilt, daß sie noch weitgehend unerforscht, höchstens als Hilfsmittel benutzt, ihr Dasein fristen. Ein dringendes Desiderat der slavistischen Forschung ist neben einer zusammenfassenden Darstellung der zweisprachigen Lexikographie mit Russisch eine Reihe von Einzeluntersuchungen, die sich ähnlich wie die hier vorgelegte Analyse mit den Arbeiten der bedeutendsten Lexikographen in der Geschichte der russisch-deutschen Lexikographie auseinanderzusetzen hätte. Da die Wörterbuchproduktion gerade gegen Ende des 19. Jahrhunderts sprunghaft anstieg, werden hier nur die wichtigsten russisch-deutschen Wörterbücher vorgestellt. Als Kriterien für die Wichtigkeit eines Wörterbuches gelten die 
Konzeption des Wörterbuches, Art und Umfang des Lemmabestandes, aber auch die Popularität des Werkes bei seinen Benutzern.

Nicht in die Beschreibung mit einbezogen werden neben den mehrsprachigen Wörterbüchern, wie zum Beispiel den Parallelwörterbüchern von Carl Philipp Reiff, die zu den populärsten Wörterbüchern des 19. Jahrhunderts zählten (vgl. Jakimovič, 1985, 92), die zahlreichen russisch-deutschen und deutsch-russischen Taschenwörterbücher, obwohl sie aufgrund ihrer Funktion als Hilfsmittel zum täglichen Gebrauch sehr beliebt waren und häufig aufgelegt wurden. Aus diesem Grund beschränkten sich ihre Verfasser allerdings meist auf den gängigen Wortschatz und stützten sich dabei auf umfangreichere Werke inrer Vorgänger. Eine Ausnahme von dieser Regel stellt August Ol'dekops Russischdeutsches und deutsch-russisches Taschenwörterbuch dar, das in drei Bänden ca. 40.000 Wörter umfaßt (vgl. Stankiewicz, 1984, 137; Lewanski, 1972, 1492). Zum Vergleich sei hier nun der Lemmabestand des russisch-deutschen Taschenwörterbuches des in diesem Jahrhundert besonders produktiven Lexikographen Johann Adoff Erdmann Schmidt herangezogen, der als Lektor für die russische und die neugriechische Sprache an der Universität Leipzig arbeitete. Dessen Taschenwörterbuch, das erstmals im Jahr 1815 erschien (vgl. Baumann, 1969, 88) und nach einer Überarbeitung gegen Ende des Jahrhunderts bis weit in das 20. Jahrhundert hinein aufgelegt wurde (vgl. Baumann, 1977, 247, Fußnote 23), umfaßte nur 26.000 Einträge (vgl. Lewanski, 1972, 1507).

Aber J.A.E. Schmidt hat sich nicht durch sein Taschenwörterbuch die Anerkennung der Nachwelt verdient, sondern vor allem durch seine überaus produktive Tätigkeit bei der Vermittlung der russischen Sprache in Deutschland. Er veröffentlichte eine Grammatik und mehrere Sprach- und Lehrbücher sowie neben dem Taschenwörterbuch noch weitere Wörterbücher (vgl. Baumann, 1977, 247; Baumann, 1969, 88-89), die alle mehrfach in Leipzig aufgelegt wurden (vgl. Eismann, 11991, 3078). Daß sich Schmidt zum Teil an seinem Vorgänger Heym orientierte ( $\mathrm{vgl}$. Baumann, 1977, 247) und wie dieser auch an den Akademiewörterbüchern, wird schon dadurch deutlich, daß der Titel seines Py-10n croварь россииско-икий и немецко-россииский, dessen zweite Auflage 1839/40 erschien (vgl. Stankiewicz. 1984, 139), ähnlich wie bei Heym den Hinweis no croвapro Aкадеми Российской Санкт Петербургской [ ...] enthält (vgl. Stankiewicz, 1984, 139). Schmidt selbst berücksichtigte bei der Überarbeitung seiner Wörterbücher die neuesten Entwicklungen. Dies zeigt sich an der Überarbeitung seines Vollständigen RussischDeutschen und Deutsch-Russischen Wörterbuches zum Gebrauch beider Nationen, das er in der zweiten Auflage .mit mehreren Redensarten und Beispielen, da, wo es nöthig schien, versehen" (Schmidt, 1844, o.S.) hat. Besonders benutzerfreundlich ist der in diese 
Auflage neu aufgenommene Anhang, der neben einem geographischen Wörterbuch (vgl. Schmidt, 1844, 503-511) auch ein Verzeichnis von Männer- und Frauennamen und von geschichtlichen Namen (vgl. Schmidt, 1844, 511-517) enthält. Ebenfalls sehr hilfreich ist der grammatische Anhang, der „zugleich die Stelle einer kurzen Sprachlehre vertreten kann" (Schmidt, 1844, o.S.) und der dem Schüler - denn diese sind die erklärte Zielgruppe von Schmidts lexikographischem Werk - auf knapp 50 Seiten (vgl. Schmidt, 1844, 468515) die russische und die deutsche Deklination sowie die russische und die deutsche Konjugation vorstellt. Aber auch im Bereich des Wortschatzes orientiert sich Schmidt an den zeitgenössischen Bedürfnissen, was sich zum Beispiel durch eine höhere Zahl von fachsprachlichen Markierungen als bei seinen Vorgängern bemerkbar macht.

Bsp.: Изъяв ителыныи, anzeigend; (in der Sprachlehre) Изъяв ителыне наклон еніе, der Indikativ.

Интегр'arto, (mathem.) Integral, $n$. Integrale, f.

Прутн '9xъ, Strauchwerk, junges Holz, n.; (Botan.) Keuschbaum, m.

An den letzten beiden Beispielen ist deutlich zu erkennen, daß das Ziel von Schmidts Konzeption, beiden Nationen gleichermaßen dienlich zu sein, erreicht wurde; denn für den russischen Muttersprachler ist das Genus deutscher Substantive angegeben, wann immer es nötig ist.

An nächster Stelle sind nun die Wörterbücher von Iwan Pawlowsky zu nennen, dessen Vollständiges Deutsch-Russisches Wörterbuch (vgl. Pawlowsky, 1856) in zwei Bänden 1856 in Riga erschien. Das russisch-deutsche Pendant mit dem Titel Vollständiges Russisch-Deutsches Wörterbuch (vgl. Pawlowsky, 1859) erschien nur drei Jahre später ebenfalls in Riga. Ähnlich wie einige seiner jüngsten Vorgänger hat sich Pawlowsky nicht nur als Lexikograph einen Namen gemacht, sondern auch durch seine Russische Sprachlehre für Deutsche (vgl. Pawlowsky, 1838), die in mehreren Auflagen erschienen ist. Weitere Angaben über das Leben und das Werk Pawlowskys finden sich im zweiten Kapitel der vorliegenden Arbeit (vgl. 2.2, 45-47). Pawlowskys Wörterbuchkonzeption unterschied sich von der seiner Vorgänger dadurch, daß der Autor, wie noch zu zeigen sein wird, neben der Literatursprache auch die Umgangssprache (vgl. 3.2.2.2, 68) und, wie in Ansätzen auch schon Schmidt, die Terminologie unterschiedlichster Bereiche (vgl. 4.2.3.1, 104-105) berücksichtigte. Seiner Zeit voraus war Pawlowsky aber auch durch die systematische Anordnung des Lexembestandes, da die einzelnen Bedeutungen erstmals auch hierarchisch gegliedert wurden (vgl. Eismann, 1991, 3077).

Nach dem Tod Pawlowskys wurde sowohl der deutsch-russische als auch der russischdeutsche Teil des Wörterbuches mehrmals überarbeitet und neu aufgelegt (vgl. 3.1, 58- 
60). Noch heute wird vor allem die dritte Auflage des russisch-deutschen Wörterbuches benutzt, was die unveränderten Abdrucke des Zentralantiquariats der DDR aus dem 20. Jahrhundert beweisen (vgl. Pawlowsky, 1972; Pawlowsky, 1960; Pawlowsky, 1952). Trotz der unbestrittenen Anerkennung, die dieses Werk in den wenigen Nennungen durch die Sekundärtiteratur erfahren hat (vgl. Eismann, 1991, 3077; Basler, 1987, 59; Baumann. 1969, 126 u. 155; Mai, 1969, 112; Bielfeldt, 1956, 19), und ungeachtet seiner Verwendung bei unterschiedlichen linguistischen Untersuchungen als Belegquelle (vgl. Raecke, 1972, 6f), hat sich noch niemand eingehend mit inm beschäftigt. Diese Lücke soll mit dieser Arbeit geschlossen werden.

Wie groß die Unkenntnis über das Pawlowskysche Wörterbuch ist, zeigt auch die einzige Arbeit, die sich etwas ausfühnlicher mit inm auseinandersetzt. So nennt Jakimovic in dem Kapitel ihrer Monographie Деятелм русской культуры и словарнюе дело, das Pawlowsky gewidmet ist (vgl. Jakimovic, 1985, 93-131), nicht nur falsche Jahreszahlen für die einzelnen Auflagen des russisch-deutschen Teils (vgl. Jakimovič, 1985, 100), sondem sie zieht auch noch aus dem Wortbestand der zweiten Auflage, die nicht von Pawlowsky selbst überarbeitet murde, falsche Schlüsse über die politische Gesinnung Pawlowskys (vgl. Jakimovič, 1985, 112). Auf diese Fehler hat bereits Lehfeldt in seinem Aufsatz Zur Stellung des ${ }_{n}$ Russisch-Deutschen Wöterbuchs" von I.Ja. Pavlovskij in der nussischen Lexikographie des 19. Jahrhunderts hingewiesen (vgl. Lehfeldt, 1990, 276), in dem er den Wert des Wörterbuches für dialektologische Untersuchungen aufzeigt.

Da im Lauf der Arbeit ausführlich auf den Aufbau und den Inhalt des Wörterbuches sowie auf die Quellengrundlage eingegangen wird, mag diese kurze Darstellung im Rahmen des einführenden Kapitels genügen.

Das 1871 erstmals erschienene russisch-deutsche und deutsch-russische Wörterbuch von N. Lenstroem (vgl. Lewanski, 1972, Nr. 1468) hat das Ziel, „язиться достаточн

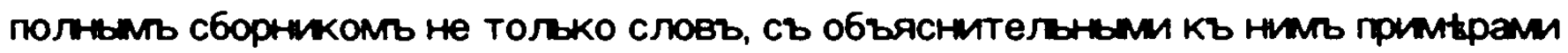
изъ образцовыхь писателей, или изъ обиходно-разговорной рћй, но и Тћхь образныхь выражеміи, которыя луше всего отражакть въ се6t особенности народнаго духа" (Lenstroem, 1891, о.S.). Der Autor ist den Anforderungen gerecht geworden, indem er Redewendungen und Kollokationen zur genaueren Beschreibung der Lemmata aufgenommen hat, deren Bedeutungen er, wann immer es vonnöten ist, hierarchisch gliedert. Des weiteren zeichnet sich das Lenstroemsche Wörterbuch durch ethnographische Eintragungen aus, die die nationalen Besonderheiten des russischen Volkes widerspiegeln. 
Bsp.: Буненін, gebackener Schweineschinken, in Essig gebratenes Schweinefleisch mit Zwiebeln oder Knoblauch zugerichtet.

Ebenfalls neu ist, daß Lenstroem das Wortmaterial nicht mehr nur glattalphabetisch anordnet, sondern daß er einige Lexeme, die der gleichen Wortfamilie angehören, unter einem einzigen Eintrag zusammenfaßt.

Bsp.: Aaмmp' аmb, Admiral, m.; -льскій, adj., Admirals-; адм. кор абль Admiralsschiff, $n$.; -лоство, Admiralswürde, f., -rang, m.; -льша, die Frau des Admirals; -лा'ейскій, adj., zur Admiralität gehörig. Admiralitäts-; -лт'ейство, Admiralität, f.; адмиparm 'eñctвb-cos't Trb Admiralitätsrath, $m$.

Auffällig ist außerdem, daß das Lenstroemsche Wörterbuch nicht nur das mittlerweile schon aus anderen Wörterbüchem bekannte Verzeichnis von Nomina propria nach dem Wörterverzeichnis enthält, sondern auch zwei Aufsätze, die dem Wörterverzeichnis vorangestelt sind. In dem ersten Aufsatz setzt sich Lenstroem selbst mit dem russischen Verbum und dessen Konjugation auseinander, wobei er unter Berücksichtigung der tatsächlich verwirklichten Konjugationsformen drei Gruppen von Verben unterscheidet (vgl. Lenstroem, 1891, 1). Neben den imperfektiven Verben, die bei inm die erste Gruppe bilden (vgl. Lenstroem, 1891, II-V), und den perfektiven Verben, die der zweiten Gruppe angehören (vgl. Lenstroem, 1891, V-VI), benennt er die iterativen Verben als dritte Gruppe ( $\mathrm{vgl.}$ Lenstroem, 1891, VI-VIII).

In einem zweiten Aufsatz analysiert der Bertiner Lehrer Wilhelm Kömer die russische Schrift, die Aussprache und die Orthographie. Dieser Aufsatz, der ebenfalls mit römischen Ziffern numeriert, aber auf grün eingefärbtem Papier gedruckt ist, enthält eine Schriftentabelle mit Ausspracheerläuterungen und Transkriptionsempfehlungen (vgl. Kömer, 1891, IIIV), an die sich "Bemerkungen über die Aussprache einzelner Buchstaben" (vgl. Körner, 1891, VI-XIV) und ein Kapitel über die .Betonung im Russischen“ (vgl. Körner, 1891, XIVXV) anschließen.

Unbedingt Erwähnung finden müssen hier noch zwei im 19. Jahrhundert äußerst produktive Autorengruppen, deren zahlreiche sprachpädagogischen Werke bis in das 20. Jahrhundert hinein aufgelegt wurden. Die erste Gruppe scharte sich um Friedrich Booch (später Booch-Árkóssy), der auch als Autor eines Lehrbuches und eines Sprachführers in Erscheinung getreten ist (vgl. Baumann, 1977, 249). Zusammen mit Frey und Messer veröffentlichte Booch 1871 ein Handworterbuch der russischen und der deutschen Sprache, das 1871 in Leipzig erschien und das schon 1907 in der 10. Auflage herausgegeben murde (vgl. Lewanski, 1972, Nr. 1452). Frey alleine publizierte außerdem ein deutschrussisches und nussisch-deutsches Taschenwörterbuch, das ebenfalls 10 Auflagen erlebte 
(vgl. Lewanski, 1972, Nr. 1460), sowie ein Schulwörterbuch der deutschen und der russischen Sprache, das mehrfach wiederaufgelegt wurde (vgl. Baumann, 1977, 249).

Ebenfalls durch Schulwörterbücher bekannt wurde der zweite Autorenkreis um N. P. Makarov, der nicht nur für die Herausgabe eines französisch-russischen bzw. russischfranzösischen Wörterbuches verantwortlich war, das 1870 erstmals erschien, sondern der auch ein vollständiges Wörterbuch dieses Sprachenpaares geschaffen hatte, das drei Jahre zuvor erschienen war (vgl. Eismann, 1991, 3077; Zaunmüller, 1958, 326). Zusammen mit V.V. Šeerer und A.N. Engel'gardt gab Makarov zusätzlich noch die entsprechenden deutsch-russischen und russisch-deutschen Wörtertücher heraus, die bis 1917 immer wieder neu aufgelegt wurden (vgl. Eismann, 1991, 3077; Lewanski, 1972, Nr. 1479).

Obwohl bei der Darstellung der Geschichte der russisch-deutschen Lexikographie des 19. Jahrhunderts der Schwerpunkt unserer Dartegungen auf den großen Wörterbüchern lag, konnte bereits eine stattliche Anzahl von Wörtertüchern beschrieben werden. Wenn man nun bedenkt, daß in dieser Zeitspanne zusätzlich eine große Zahl von mittleren und kleinen russisch-deutschen Wörterbüchem erschienen ist und gerade gegen Ende des Jahrhunderts zweisprachige Fachwörterbücher immer stärker auf den Markt drängten, so ist für das 19. Jahrhundert eine relativ hohe Wörterbuchproduktion in der Geschichte der russisch-deutschen Lexikographie zu konstatieren, die dem Vergleich mit anderen Sprachen und Deutsch durchaus standhält. So ist dem Zeitgenossen und berühmten Philologen Jagić zuzustimmen, der gegen Ende des Jahrhunderts feststellte, daß „in der slavischen Philologie in letzter Zeit die Aera der Lexikographie angebrochen ist" (Jagić, 1892, 616).

Besonders auffällig ist, daß sich im 19. Jahrhundert nicht nur auf der Ebene der Wörterbuchkonzeption ein Wandel vollzieht, sondem daß auch der Autorenkreis ein völlig neuer wurde. Waren die Autoren der Gesprächsbücher und der ersten Wörterbücher noch Autodidakten auf ihrem Gebiet, die mit ihren Wörterbüchern vor allem praktische Ziele verfolgten, so ist bereits im 18. Jahthundert bei den Wörterbüchern von Rodde und Heym zu erkennen, daß ihre Verfasser auch sprachpädagogische Ziele formulierten, wie zum Beispiel eine grammatikalisch korrekte Ausdrucksweise.

Dieser Trend setzt sich im 19. Jahrhundert endgültig durch, wie die Tätigkeitsfelder der hier vorgestellten Lexikographen beweisen, die meist auch als Autoren von Sprachlehren oder Grammatiken und als Lektoren gearbeitet haben.

Im 20. Jahrhundert wird nun, wie im weiteren zu zeigen sein wird, eine wertere Spezialisierung zu beobachten sein, die ihren Grund in der zunehmenden Arbeitsteiligkeit der Welt und der Tendenz vom Universalismus früherer Jahrhunderte hin zum Spezialismus der heutigen Zeit hat. 
1.2.5 Die zweisprachige Lexikographie Deutsch-Russisch im 20. Jahrhundert: Ein breites Spektrum

Abschließend soll nun auch noch ein kurzer Abriß über die Geschichte der russischdeutschen Lexikographie im 20. Jahrhundert gegeben werden. Allerdings muß dieser sehr knapp gehalten werden, da zum einen in dieser Zeit unzählige allgemeine Wörterbücher und zahlreiche Spezialwörterbücher erschienen sind, deren Geschichte eine eigenständige Darstellung gewidmet werden müßte, und zum anderen die in diesem Zeitraum erschienenen Wörterbücher für das Thema dieser Arbeit von untergeordnetem Interesse sind. Hier werden nur einige allgemeine zweisprachige Wörterbücher vorgestelt, die in der von Ožegov erarbeiteten Wörterbuchtypologie, nach der es neben einem kleinen einbändigen Wörterbuch auch ein mittleres und ein großes Wörterbuch für jede Sprache und jedes Sprachenpaar geben soll ( $v g l$. Ožegov, 1952, 85-104), als Vertreter des mittleren Typs gelten. Für nähere Informationen über die zweisprachigen Spezialwörterbücher muß - aus Platzgründen - auf die einschlägigen Bibliographien verwiesen werden (vgl. Birkenmayer/Mohl, 1990; Müller, 1965).

Nach dem Zweiten Weltkrieg stieg in der Sowjetunion die Wörterbuchproduktion um die Mitte des Jahrhunderts sprunghaft an, da die sprachliche Situation im Vielvölkerstaat aus gesellschafts- und wirtschaftspolitischen Gründen einen ungeheuren Bedarf an nationalsprachlich-russischen und russisch-nationalsprachlichen Wörterbüchern bewirkte. Daß die Lexikographen in jener Zeit vor allem quantitativ Überragendes leisteten, zeigt Vinogradovs umfangreiche Bibliographie der in der UdSSR veröffentlichten Wörterbücher (vgl. Vinogradov, 1966). E. S. Istrina kommt in ihrem Aufsatz Заметки по двуязыным словарям sogar zu dem wenig überzeugenden Schluß, dаß "в историм человечества еще не было случая, когда 6ы шла такая болышая, сосредоточая работа над двуязыми словарями [...]" (Istrina, 1944, 78). Zwar erschienen in dieser Zeit tatsächlich überdurchschnittlich viele zweisprachige Wörterbücher, doch muß bei Aussagen wie den eben zitierten die ideologisch bedingte Übertreibung immer mit berücksichtigt werden. AuBerdem sollte nicht unerwähnt bleiben, daß die nach 1917 veröffentlichten Wörterbücher mehr oder weniger stark durch ideologische Einflüsse geprägt waren (vgl. Keipert, 1992, 386).

Betrachtet man nun die russisch-deutsche Lexikographie im 20. Jahrhundert, so ist festzustellen, daß sie zu Anfang des Jahrhunderts noch von den zahlreichen zum Teil neu bearbeiteten Wörterbüchern dominiert wurde, die im vorangehenden Jahrhundert entstanden waren; denn die Neuerscheinungen blieben qualitativ hinter den älteren Wörterbüchern zurück (vgl. Baumann, 1969, 155). Als Ausnahme von dieser Regel gilt einzig das 1906 
erstmals bei Langenscheidt veröffentlichte Taschenwörterbuch der russischen und deutschen Sprache von K. Blattner (vgl. Blattner, 1906), der „bei jedem Worte sowohl Deklination und Konjugation wie auch Betonung nach bestem Wissen und Können“ (Blattner, 1906, VII), außerdem auch die Rektion der Verben und die Aussprache der russischen Lexeme angibt. Daß Blattners Wörterbuch, das sich vor allem um genaue grammatische Angaben bemühte, gut aufgenommen wurde, zeigt sich auch daran, daß von ihm ein Dutzend weitere Auflagen erscheinen konnte (vgl. Bielfeldt, 1956, 19).

Einen neuen Impuls erhielt die zweisprachige Lexikographie mit Russisch durch eine von Ščerba entwickelte Konzeption, die für jedes Sprachenpaar vier Wörterbücher forderte. Erstmals formuliert wurde diese Bedingung von Ščerba im Vorwort zu seinem 1936 erschienenen russisch-französischen Wörterbuch, in dem es heißt, "для каждой пары языков нунно два объяснителыных (толковых) иностранно-наиионалыных словаря - для русских с объяснениями на русском языке, а для иностранцев - на их соответствеш язхах" (\$̌čerba, 1974b, 307). Weiter schreibt er, daß "эти nepeводные русско-иностранные словари долнны быть переделаны совериенно заново С Ясно осознаной целыо дать возмонность русскому человеку делать правилыные переводы ето русских фраз" (Ščerba, 1974b, 308). Als erstes Beispiel für ein diesen Prämissen folgendes Wörterbuch gilt das von Ščerba selbst verfaßte Werk. Um eine weitere theoretische Abgrenzung seiner Konzeption bemühte sich Sčerba in seinem 1940 im Лексикографический сборик erstmals erschienenen Aufsatz Oпыт общей теорим лексикотрафия (vgl. Ščerba, 1974a, 265-304), in dem er noch einmal bekräftigt, daß man pro Sprachenpaar vier Wörterbücher benötige, nämlich jeweils zwei die Fremdsprache in der Muttersprache erklärende, die heute als passive Wörterbücher bezeichnet werden, und zwei von der Muttersprache in die Fremdsprache übersetzende, die sogenannten aktiven Wörterbücher (vgl. Ščerba, 1974a, 303). Diese Konzeption erzielte nicht nur in den sozialistischen Staaten große Resonanz, sie wurde auch von westlichen Sprachwissenschaftlem weiterentwickelt (vgl. z. B. Mikkelsen, 1992, 25-40; Mugdan, 1992. 17-24; Mugdan, 1992a, 25-48; Kromann/Riiber/Rosbach, 1984, 159-238) und diente zahlreichen Wörterbuchprojekten als theoretische Basis (vgl. Eismann, 1991, 3081).

Auch der 1941 erstmals unter der Redaktion von A. B. Lochovic erschienene PycckoHeneuкии Cловарь (vgl. Vinogradov, 1966, Nr. 2137) bediente sich bereits der von Ščerba neu entwickelten Konzeption, wandte sich aber vomehmlich an das russische Publikum (vgl. Lochovic, 1943, o. S.). Dies beweist nicht nur das nur in russischer Sprache geschriebene kurze Vorwort, sondern auch der grammatische Teil des Wörterbuches, der allein der deutschen Sprache gewidmet ist. Daß der Bedarf nach einem guten russisch- 
deutschen Wörterbuch vorhanden war, zeigen die zahlreichen Neu- und Stereotypauflagen dieses von Lochovic begründeten Wörterbuches. Denn bereits 1948 erschien unter der Redaktion von A. A. Leping die zweite Auflage, der nur acht Jahre später eine dritte Auflage folgte (vgl. Vinogradov, 1966, Nr. 2137). Ein wichtiges Anliegen war den Autoren bei der Überarbeitung des Wörterbuches, angemessen auf die Veränderungen in den beiden Sprachen zu reagieren und den Wortschatz im Hinblick auf die neuesten Entwicklungen zu korrigieren (vgl. Leping/Strachovaja, 1960, 0.S). Doch obwohl seit der siebten Auflage das Vorwort sowohl in russischer als auch in deutscher Sprache abgedruckt wurde (vgl. Leping/Strachovaja/Lejn/Ekkert, 1976, o.S.) und gerade in dieser Auflage mit K. Lejn und R. Eckert auch zwei deutsche Spezialisten an der Überarbeitung des Wörterbuches beteiligt waren, blieb der primäre Zweck des Wörterbuches erhalten, nämlich eine aktive Übersetzungshilfe für russische Muttersprachler zu sein.

Ebenfalls an den russischen Muttersprachler wendet sich das russisch-deutsche Wörterbuch von O. N. Nikonova, das 1952 erstmals veröffentlicht wurde und das bereits 1953 und 1955 in weiteren Stereotypauflagen erschien (vgl. Vinogradov, 1966, Nr. 2140), bevor dann 1963 eine überarbeitete Fassung auf den Markt kam (vgl. Nikonova, 1963), der weitere Stereotypauflagen folgten (vgl. Nikonova, 1973).

Auch das jüngste Werk der russisch-deutschen Lexikographie, das 2000 in der vierten Stereotypauflage erschienene, von $\mathbf{M}$. Ja. Zvilling erarbeitete russisch-deutsche Wörterbuch hält an der Konzeption von Ščerba fest und dient vor allem den Deutsch lernenden russischen Muttersprachlern (vgl. Cvilling, 2000, 5).

Bei der Rezeption des Ščerbaschen Ansatzes in der russisch-deutschen Lexikographie für deutsche Muttersprachler muß der Arbeitskreis um und mit $\mathbf{H}$. $\mathbf{H}$. Bielfeldt enwähnt werden, der sich nicht nur in einigen Aufsätzen mit dieser Konzeption auseinandersetzte (vgl. Bielfeldt, 1983, VII, Fußnote 2), sondern unter dessen Redaktion auch ein passives russisch-deutsches Wörterbuch (vgl. Bielfeldt, 1958) sowie ein aktives deutsch-russisches Wörterbuch herausgegeben wurden (vgl. Bielfeldt, 1983). Diese Wörterbücher, die sich ausschließlich an den Kreis der deutschsprachigen Benutzer richten, haben eine große Popularität erlangt, wie sich auch anhand der Auflagenzahlen verdeutlichen läßt. So erschien bereits 1961 eine zweite Auflage des passiven russisch-deutschen Wörterbuches, und bereits im Jahr 1982 wurde eine 14. Auflage herausgegeben (vgl. Eismann, 1991. 3081).

Nach diesem kurzen Überblick über die Geschichte der russischen und der russischdeutschen Lexikographie, der als Rahmen für die Einordnung des Werkes von Pawlowsky unertäßlich ist, soll nun im nächsten Unterpunkt die Entstehung der Metalexikographie nachgezeichnet werden. 


\subsection{Die Entstehung der Metalexikographie}

\subsubsection{Vorbemerkung}

Jahrhundertelang wurde unter dem Begriff der Lexikographie eine Tätigkeit verstanden, deren Ziel es war, Wörterbücher zu erstellen. Mit dieser praktischen Tätigkeit ging aber schon sehr früh auch eine Debatte über die theoretisch-methodischen Probleme der Lexikographie einher. Ihr Ziel war es, durch die Reflexion über die Tätigkeit des Wörterbuchschreibens die Endprodukte zu verbessern. Vor dem 20. Jahrhundert finden sich Spuren dieser Diskussion unter anderem in den Vorwörtern von Wörterbüchern, in Artikeln von Lexika, in Bibliographien und in den Rezensionen über Wörterbücher (vgl. Hausmann, 1989, 216-217; Hausmann, 1989a, 77-90).

Mitte des 20. Jahrhunderts erreichte die theoretische Debatte eine neue Qualität. Etwa zeitgleich begann in verschiedenen Ländem eine rege Auseinandersetzung mit den theoretischen Problemen der Lexikographie, die nicht mehr an die Produktion der Wörterbücher direkt gekoppelt war und deren vorrangiges Ziel demnach auch nicht mehr darin bestand, konkrete Wörterbuchprojekte weiterzuentwickeln, zu verbessem oder zu kritisieren. Für diese neue Richtung hat sich in jüngster Zeit der Begriff Metalexikographie etabliert (vgl. Wiegand, 1998, 72). Über die Debatte um den Begriff und das Verständnis von Lexikographie im Wandel der Zeit sei auf die zusammenfassende Darstellung bei Wiegand verwiesen (vgl. Wiegand, 1998, 15-29). Da diese neue Disziplin noch sehr jung ist, ist sie wie noch zu zeigen sein wird - in den verschiedenen Ländern mit den Namen einer jeweils geringen Zahl von Wissenschaftlern verknüpft, die sich um die Weiterentwicklung der Disziplin verdient gemacht haben.

Ziel dieses Abschnittes ist es deshalb, die Entwicklung dieser Diskussion in den verschiedenen Ländern kurz nachzuzeichnen, wobei keineswegs Anspruch auf systematische Vollständigkeit erhoben wird. Es wird vielmehr angestrebt, die initiierenden Arbeiten in den einzelnen Ländern kurz vorzustellen und dann auf die jüngsten Arbeiten zu verweisen, um anschließend die Metalexikographie in unterschiedliche Forschungsrichtungen einzuteilen und die vorliegende Arbeit in die Disziplin einzufügen. Wie bereits bei der Darstellung der Geschichte der zweisprachigen Lexikographie festgesteltt wurde, konzentrieren sich die Bemühungen der Wissenschaftler im Bereich der metalexikographischen Forschung vornehmlich auf die einsprachige Lexikographie. Erst ganz allmählich verschieben sich die Interessensschwerpunkte in Richtung der zweisprachigen Lexikographie, die im Zuge der zunehmenden Internationalisierung und der dadurch notwendig gewordenen internationalen Kommunikation, die nicht zuletzt durch die Qualität der vorhandenen zweisprachıgen 
Wörterbücher beeinflußt wird, eine ganz wesentliche Bedeutung hat. Deshalb sollen zuerst die Ergebnisse der Metalexikographie auf dem Gebiet der einsprachigen Lexikographie dargestellt werden, damit wir in einem zweiten Schritt die wichtigsten theoretischen Erkenntnisse über die zweisprachige Lexikographie darstellen können.

\subsubsection{Der Aufschwung der Metalexikographie um die Mitte des 20. Jahrhunderts}

\subsubsection{Vorläufer}

Schon vor dem großen Aufschwung der theoretischen Abhandlungen über die Lexikographie erschienen vereinzelt theoretische Schriften. Enwähnenswert ist in diesem Zusammenhang, da - rückblickend betrachtet - aus den hispanophonen Ländem kaum metalexikographische Literatur vorliegt (vgl. Morán, 1993, 93), die bereits 1950 erschienene Monographie des Spaniers Casares, dessen Werk durch die Arbeit an einem historischen Wörterbuch des Spanischen angeregt worden war.

Daß die Monographie von Casares schon 1958 in einer russischen Übersetzung vorlag (vgl. Kasares, 1958), die hier benutzt wurde, weist auf die Vorreiterrolle der sowjetischen Sprachwissenschaftler auf dem Gebiet der Metalexikographie hin. Diese Rolle ist auch damit zu erklären, daß im Vielvölkerreich Sowjetunion aus politischen, kulturellen und wirtschaftlichen Gründen innerhalb kürzester Zeit Wörterbücher geschaffen werden mußten, die das faktisch als lingua franca fungierende Russisch im ganzen Staat verbreiten helfen sollten. Als Pionier auf dem Gebiet der Metalexikographie muB L. V. Šcerba erwähnt werden, der seine lexikographischen Theorien zuerst noch - wie es ähnlich seit Jahrhunderten üblich gewesen war - während seiner Arbeit an einem russisch-französischen Wörterbuch formulierte, dann aber dazu überging, die Theorie ohne einen konkreten Praxisbezug weiterzuentwickeln. In seinem Aufsatz Onst o6uеn теорим nексикографим, der 1940 erstmals in der Zeitschrift der Akademie der Wissenschaften veröffentlicht wurde (vgl. Ščerba, 1974a, 265-304), entwarf Ščerba eine auf verschiedenen Unterscheidungsmerkmalen basierende Wörterbuchtypologie, die bis heute für die Forschung nicht an Wert verloren hat, wie beispielsweise die Aufnahme des Textes in einen Sammelband belegt, der (meta)lexikographische Beiträge sowjetischer Forscher dem deutschen Publikum vorstellen will (vgl. Wolski, 1982, 63-88). Im Hinblick auf die bilinguale Metalexikographie ist insbesondere die im Rahmen der binären Opposition zwischen roлковый crosaps und neposoaнысі словары erarbeitete Forderung nach vier Wörterbüchern pro Sprachenpaar von Bedeutung, die nach jeweils einem fremdsprachlich-muttersprachlichen Wörtertbuch für das Verstehen der Fremdsprachen und einem muttersprachlich-fremdsprachlichen für die Er- 
stellung von Texten in der Fremdsprache verlangt (vgl. Ščerba, 1974, 297-303; Pkt. 1.2.5, 31).

Ebenfalls von grundsätzlichem Wert sind die Arbeiten von V. V. Vinogradov, die den Problemen der Lexikographie gewidmet sind. An erster Stelle ist hier der Aufsatz $O$ HOKOторых вогросах теорим русской лексикографим zu nennen, der 1956 in den Borpocb языкознамия erschienen ist (vgl. Vinogradov, 1977b, 243-264). Dort setzt sich Vinogradov vor allem mit den Problemen der semantischen Bedeutungsdifferenzienung im allgemeinen einsprachigen Wörterbuch auseinander, die er anhand von Beispielen aus dem siebzehnbändigen Akademiewörterbuch formuliert (vgl. Vinogradov, 1977, 243-264).

\subsubsection{Die Entwicklung der Metalexikographie zu einer wissenschaftlichen Disziplin}

\subsection{Die angelsächsische Metalexikographie}

Eingeleitet wurde die neue Phase der Wörterbuchforschung in der westlichen Welt in den Vereinigten Staaten von Amerika mit einem zweitägigen Kongress in Bloomington im Jahr 1960, dessen Ergebnisse in einem 1962 publizierten Sammelband vorgestellt wurden (vgl. Householder/Saporta, 1962). Die unterschiedlichen Aufsätze gehören zu vier großen Schwerpunktthemen. Zum einen wurden theoretische und praktische Probleme bei der Erstellung von Wörterbüchem behandelt, zum anderen wurde der Zusammenhang zwischen der strukturellen Linguistik und der Wörterbuchproduktion untersucht, der gerade die amerikanische Metalexikographie noch viele Jahre lang beschäftigen sollte. Außerdem wurden auch spezielle Probleme der Lexikographie einzelner Sprachen diskutiert.

Zu dem ersten Schwerpunktthema erarbeitete Yakov Malkiel eine typologische Klassifikation von Wörterbüchern auf der Basis von distinktiven Merkmalen (vgl. Malkiel, 1962, 324). Uriel Weinreich setzte sich kritisch mit der bisherigen Methodik der lexikographischen Definition auseinander (vgl. Weinreich, 1962, 25-43), H. A. Gleason beschäftigte sich im Rahmen des dritten Schwerpunktes mit der Beziehung zwischen Wörterbuch und Grammatik (vgl. Gleason, 1962, 85-102), daneben wurden in allen Schwerpunkten unterschiedliche Probleme der zweisprachigen Lexikographie behandelt (vgl. lanucci, 1962, 201-216; Haas, 1962, 45-50). Schon bald nach der Veröffentlichung des Sammelbandes kamen weitere Arbeiten auf den Markt, die sich der Lexikographie von der theoretischen Seite näherten.

$\mathrm{Zu}$ nennen sind für den angelsächsischen Raum neben dem bereits besprochenen Sammelband die zahlreichen Arbeiten von Zgusta sowie die Sammelbände, die unter seiner Redaktion veröffentlicht wurden (vgl. Zgusta, 1992; Zgusta, 1985; Zgusta, 1980). In seiner ersten Monographie Manual of lexicography aus dem Jahr 1971 versuchte Zgusta, 
einen Leitfaden für die Produktion eines qualitativ hochwertigen Wörterbuches zu erarbeiten (vgl. Zgusta, 1971). Dabei widmete er sich in einem ersten Teil den einsprachigen Wörterbüchern, um darauf aufbauend in einem zweiten Teil die spezifischen Unterschiede und Gemeinsamkeiten bei der Herstellung eines zweisprachigen Wörterbuches zu analysieren (vgl. Zgusta, 1971, 295-344). Da dies eine der ersten metalexikographischen Arbeiten ist, erstaunt es nicht, daß sich Zgusta in seiner Darstellung noch eng an den einzelnen Arbeitsschritten bei der Herstellung eines Wörterbuches orientierte. Nachdem er zuerst unterschiedliche Typen von zweisprachigen Wörterbüchem beschrieben hatte, wobei er die bereits von Ščerba erarbeitete Differenzierung in aktive und passive Wörterbücher als .probably the most important dimension of the typology of the bilingual dictionaries" (Zgusta, 1971, 299) bezeichnete, skizzierte er die Aufgaben und Probleme des Lexikographen bei der Materialsammlung (vgl. Zgusta, 1971, 307f), bei der Lemmaauswahl (vgl. Zgusta, 1971, 309-312), bei der Wahl der Äquivalente (vgl. Zgusta, 1971, 312-325), bei den Markierungen, Glossen, Beispielen und grammatischen Angaben (vgl. Zgusta, 1971, 329-342). Zusătzlich zu den bisher vorgestellten Arbeiten erstellte Zgusta auch eine annotierte Bibliographie zur Theorie der Lexikographie (vgl. Zgusta, 1988).

Von der Seite des Praktikers näherte sich Landau den englischen Wörterbüchern in der Monographie Dictionaries, the Art and Craft of Lexicography (vgl. Landau, 1984). Nachdem er sich kurz unter anderem mit der von Malkiel entworfenen Wörterbuchtypologie und der Geschichte der englischen Lexikographie auseinandergesetzt hatte, konzentrierte sich Landau im sechsten Kapitel seiner Arbeit auf die Wörterbucherstellung und die drei Phasen Planung, Verfassen, Produktion, die dieser Prozess seiner Meinung nach durchlaufen muss (vgl. Landau, 1984, 227-271).

\subsection{Die franzósische Metalexikographie}

Auch die französische Wissenschaft trug in den siebziger Jahren des 20. Jahrhunderts entscheidend zur Weiterentwicklung der Metalexikographie bei. Dort ist die Fortentwicklung dieser Disziplin, wie in den anderen Ländern, eng mit den Namen einiger weniger Wissenschaftler verbunden. Zu nennen ist hier die initiierende Arbeit von Quemada ( $v g l$. Quemada, 1967), die sich mit der Geschichte der französischen Wörterbücher von 1539 bis 1863 auseinandersetzt, wobei der Autor sich nicht chronologisch, sondern systematisch dem Thema nähert, was der Arbeit nicht nur einen wörterbuchgeschichtlichen, sondern auch einen theoretischen Wert verleiht. In der Folgezeit machten die Autoren der großen Wörterbücher mit metalexikographischen Publikationen auf sich aufmerksam. So veröffentlichten Claude und Jean Dubois im Jahr 1971 eine Einführung in die französische Lexikographie (vgl. Dubois, 1971), in der sie Aufbau und Inhalt des Wörterbuches charakteri- 
sierten. Josette Rey-Debove publizierte im selben Jahr eine exzellente Studie über die französischen Gesprächswörterbücher (vgl. Rey-Debove, 1971). Für die französische Metalexikographie ist deshalb das Fazit zu ziehen, daß „im gewissen Sinne aus dem Nichts heraus eine metalexikographische Bibliothek" entstand, was .zu diesem Zeitpunkt absolut einmalig“ war und „in den anderen Ländern erst sehr viel später nach- und eingeholt werden" (Hausmann, 1989a, 98) konnte.

\subsection{Die deutsche Metalexikographie}

Den Auftakt der deutschen Metalexikographie markiert die Habilitationsschrift von $\mathbf{H}$. Henne. Ziel dieser Arbeit ist es, eine Theorie der lexikalischen Kodifikation zu entwerfen. Nach der Darlegung umfangreicher theoretischer Prämissen, die sich vor allem an den Erkenntnissen der strukturellen Semantik orientieren, erarbeitet Henne vor dem Hintergrund der Untersuchung der lexikalischen Kodifikationsprinzipien in drei Wörterbüchern aus dem deutschen Sprachraum aus den Jahren 1793-1813 Operationsmodelle zur semantischen Deskription (vgl. Henne, 1972). Fortgeführt und auch praktisch angewendet wurde diese Richtung in Deutschland vor allem von Gerhard Wahrig, der nicht nur als Autor zahlreicher Wörterbücher in Erscheinung getreten ist, sondern sich auch immer wieder in theoretischen Schriften äußerte (vgl. Wahrig, 1983).

Besonders verdient um die metalexikographische Forschung nicht nur in Deutschland hat sich Herbert Ernst Wiegand gemacht. Er veröffentlichte umfangreiche Aufsätze zu den unterschiedlichsten Problemen der Metalexikographie und fungierte als Herausgeber zahlreicher metalexikographischer Sammelbände und Reihen. Er war maßgeblich daran beteiligt, daß sich die Wörterbuchforschung zu einer selbständigen Disziplin entwickelte. Wer einen Überblick über die Entwicklung der Disziplin in Deutschland nach Henne erhalten will, sei hier auf die von Wiegand verfaßten Vorworte zu den Studien zur Neuhochdeutschen Lexikographie verwiesen, in denen er die aktuelle Situation der Metalexikographie nachzeichnet, wobei auch weiterführende Literaturhinweise nicht fehlen (vgl. Studien V.1. 1986, III-XVI; Studien V, 1984, III-IV; Studien IV, 1984, 3-7; Studien II, 1982, 3-5; Studien I, 1981, 3-5).

In seiner neuesten Monographie Wörterbuchforschung (vgl. Wiegand, 1998) versucht Wiegand eine allgemeine Theorie der Lexikographie zu erarbeiten, wobei sein Werk auch als Spiegel der bisherigen Wörterbuchforschung getten kann, da die maßgeblichen westeuropäischen Beiträge zum größten Teil in seine Arbeit mit eingeflossen sind.

\subsection{Die russische Metalexikographie}


Nachdem durch die Arbeiten von Ščerba und Vinogradov schon früh der Einstieg in die Metalexikographie gefunden worden war, konzentrierten sich die russischen Forscher aus praktischen Gründen vor allem auf das Gebiet der sog. yияная лексикография. Besonders verdient gemacht haben sich auf diesem Gebiet P. N. Denisov und V. V. Morkovkin, die nicht nur Monographien (vgl. Denisov, 1974) zu diesem Thema veröffentlicht haben, sondern auch als Herausgeber für die Veröffentlichung von zahlreichen Sammelbänden verantwortlich waren. So setzt sich beispielsweise ein 1969 erschienener Sanmelband (vgl. Denisov/Novikov, 1969) bereits mit dieser Thematik auseinander. In einem 1977 von den Herausgebern P. N. Denisov und V. V. Morkovkin veröffentlichten Sammeband werden sowohl allgemeine Probleme der yчебная лексикография als auch die besonderen Probleme bei zweisprachigen Lernwörterbüchern und Fachwörterbüchern für den Sprachschüler näher beleuchtet ( $v g l$. Denisov/ Morkovkin, 1977). In einem weiteren Sanmelband unter der Redaktion von Denisov und Morkovkin, der 1978 erschienen ist (vgl. Denisov/Morkovkin, 1978), wurden die Erkenntnisse verarbeitet, die die erste Konierenz zur yебкая лексикография im Jahr 1976 hervorgebracht hatte. Neben allgemeinen Fragen zur ушбная лексикография wurden dort auch Berichte über konkrete Wörterbuchprojekte veroffentlicht.

Eine eigenständige Sprachtheorie liegt den von Ju. D. Apresjan und dem sfäter nach Kanada emigrierten I. A. Mel'žuk erarbeiteten Wörterbüchern zugrunde. Grundlage der Theorie ist das sog. smysl-tekst-Modell (vgl. Mel'čuk, 1974), mit dessen Hilfe die Sprachbeherrschung (владение языком, vgl. Apresjan, 1995, 39) beschrieben werden soll. Dabei .handelt es sich um ein Stratifikationsmodell, in dem die linguistische Beschreibung auf verschiedenen, in bestimmter Abfolge einander zugeordneten Abstraktionsebenen erfolgt" (Hartenstein, 1981, 3). Wesentlicher Bestandteil des Modells ist ein spezielles Lexikon, das sog. erklärend-kombinatorische Wörterbuch, in dem „sämtliche Charakteristika zur Flexion, Wortbildung, Syntax, Semantik und Stilistik eines Stichwortes" (Hartenstein, 1981, 8) aufgeführt sind. Vor diesem theoretischen Hintergrund entstanden zahlreiche qualitativ hochwertige Wörterbücher (z. B. Apresjan u.a., 1997; Mel'zuk/Žolkovskij, 1984). Einen Überblick über die Theorie und ihre lexikographischen Ergebnisse, wie er im Rahmen dieser Arbeit aus Platzgründen nicht ausführlicher geliefert werden kann, bietet folgende Literatur: Weiss, 1999, 873-9C9; Hartenstein, 1999, 910-953; Apresjan, 1995; Mel'čuk, 1982; Hartenstein, 1981; Mel'cuk, 1974.

Zu einem Zentrum metalexikographischer Forschung hat sich in jüngster Zel die Universität in Charkov entwickelt. 1992 wurde dort eine Lexikographische Gesellschaft gegründet, deren Mitglieder, die aus unterschiedlichen Ländern und Städten stammen, nicht 
nur an zahlreichen Wörterbuchprojekten mitwirken, sondern es sich auch zur Aufgabe gemacht haben, die lexikographische Theorie und Methodologie weiterzuentwickeln. Als Boleg dafür kann die 1998 erschienene Monographie Теоретическая и практинеская лексикотраяия (vgl. Dubixinskij, 1998) dienen, die als gelungene Einführung in die (Meta)lexikographie zu bezeichnen ist. Im Anhang der Arbeit findet sich außerdem eine knappe Zusammenfassung der Aktivitäten und Pläne der Lexikographischen Gesellschaft (vgl. Dubičinskij, 1998, 151-152), die seit 1994 auch der Vereinigung EURALEX angehört (vgl. Dubicinskij, 1998, 152; Pkt. 1.3.2.2.6, 50)

\subsection{Die bilinguale Metalexikographie}

Wie bereits mehrfach festgestellt, hat die Erforschung der bilingualen Lexikographie .an unusually short history considering the long history of these socially important dictionaries" (Kromann/Riiber/Rosbach, 1991, 2715). Vergleicht man die Ergebnisse der metalexikographisch führenden Länder mit denjenigen aus der zweiten Reihe, ist auffällig, daß sich insbesondere Wissenschaftler kleinerer Länder um die Erforschung der zweisprachigen Wörterbücher verdient gemacht haben (vgl. Hausmann, 1988, 137). Zu nennen sind hier insbesondere die dänischen Spractwwissenschaftler Hans-Peder Kromann, Theis Riiber und Poul Rosbach, die bereits 1984 in den von H. E. Wiegand herausgegebenen Studien zur Neuhochdeutschen Lexikographie einen vielbeachteten Aufsatz zu den Grundfragen der zweisprachigen Lexikographie veröffentlicht haben (vgl. Kromann/Riiber/Rosbach, 1984, 159-238). Auch sie orientieren sich an den von Ščerba formulierten Forderungen nach Schaffung eines zweisprachigen Wörterbuches und wenden diese erstmals konsequent auf alle Bereiche eines Konzeptes für zweisprachige Wörterbücher an. Dadurch gelingt es ihnen, „eine wesentliche Grundlage einer spezifischen Theorie der zweisprachigen Lexikographie* (Wemer, 1990, 270) zu schaffen.

Ebenfalls Erwähnung finden muß in diesem kurzen Überblick die Arbeitsgruppe um den deutschen Sprachwissenschaftler W. Duda. In einer 1986 veröffentlichten Arbeit setzen sich die Autoren dieser Gruppe zum Ziel, durch die .Vorstellung und Diskussion der Projekte für ein neues russisch-deutsches Wörterbuch [...] keine abgeschlossene Theorie der zweisprachigen Lexikographie vor[zu]legen", aber doch .zumindest theoretische Diskussionen als Vorstufe der Schaffung einer Theorie der zweisprachigen Lexikographie" (Duda, 1986, 1-2) anzuregen. Dabei orientieren auch sie sich an dem bereits vielfach genannten Konzept von Ščerba.

Verdient gemacht um die Erforschung der zweisprachigen Lexikographie hat sich auch der russische Metalexikograph V. P. Berkov, der bereits 1973 eine erste Monographie mit dem Titel Вогросы двуязынкй лексикотрафим veröffentlichte, in der er sich mit denje- 
nigen theoretischen Fragen der Lexikographie auseinandersetzte, die entscheidend für die praktische Wörterbucharbeit sind (vgl. Berkov, 1973). 1977 folgte dann eine weitere Arbeit, die sich mit der Erstellung des Korpus für ein zweisprachiges Wörterbuch, mit der grammatischen und phonetischen Charakterisierung der Lemmata sowie mit der Äquivalenzproblematik beschäftigte (vgl. Berkov, 1977). Grundlage der eben vorgestellten Bücher war die 1971 abgeschlossene Dissertation von Berkov (vgl. Berkov, 1996, 3-4). In seinem neuesten Werk, das 1996 erschienen ist, gewährt Berkov einen Einblick in die Praxis der Herstellung von zweisprachigen Wörterbüchem mittleren und großen Umfangs. Dabei konzentriert er sich erneut auf das Korpus des Wörterbuches und auf den Aufbau und den Inhalt des Wörterbuchartikels (vgl. Berkov, 1996).

In Frankreich blieb die Erforschung der zweisprachigen Lexikographie deutlich hinter der der einsprachigen zurück. Erst 1996 erschien ein Sammelband von H. Béjoint und P. Thoiron (vgl. Béjoint/ Thoiron, 1996), der ausschließlich den zweisprachigen Wörterbüchem gewidmet ist, um dem Mißstand entgegenzuwirken, daß „en France, et dans les autres pays occidentaux, on a surtout écrit sur les dictionnaires monolingues généraux (Béjoint Thoiron, 1996, 5).

\subsection{Metalexikographische Gesellschaften und Zeitschriften}

Das stark angewachsene Interesse an den Problemen der Metalexikographie äußert sich auch in der Gründung von zahlreichen wissenschaftlichen Gesellschaften und in der Herausgabe einer Fülle von Zeitschriften, die sich speziell den Problemen der Metalexikographie widmen.

Eine .жаительню рољ в обсундени теоретиеских проблем словарного дела" (Sorokoletov, 1978, 38) spielte die seit 1957 veröffentlichte russische Reihe Лексикоrрафиеский с6орик, deren Herausgeber es sich zur Aufgabe gemacht hatten, die Fragen, die die praktische Lexikographie aufwirft, theoretisch zu erörtern. In den sechs bis zur Einstellung der Serie 1963 erschienenen Bänden wurden neben den theoretischen Fragen der Lexikographie auch die praktische Wörterbucharbeit und die Geschichte der Lexikographie bearbeitet, wobei Abhandlungen über die einsprachige Lexikographie des Russischen dominierten. Der Erörterung von aktuellen Problemen der russischen Lexikographie bot seit 1974 die Zeitschrift Coвpemer русккая лексикография Raum, in der ebenfalls Aufsätze über die einsprachige Lexikographie dominierten.

Den französischen Metalexikographen dient seit 1982 die Zeitschrift Lexique als Diskussionsforum. Schon seit 1959 wurden außerdem immer wieder metalexikographische Fragestellungen in der Reihe Cahiers de lexicologie erörtert. 
Bereits 1975 wurde in Amerika eine lexikographische Gesellschaft gegründet, die sich seit 1977 Dictionary Society of North America nennt. Sie veröffentlicht seit 1979 ein Jahrbuch unter dem Titel Dictionaries und zusätzlich dreimal im Jahr einen Newsletter ( $v g l$. Hausmann, 1989a, 100f).

Erst acht Jahre später, im Jahr 1983, wurde die European Association for Lexicography (EURALEX) gegründet, deren Intemational Joumal of Lexicography seit 1988 erscheint.

In Zusammenarbeit mit den eben genannten Vereinigungen erscheint seit 1985 das $\mathrm{Pe}-$ riodikum Lexicographica. Intemationales Jahrbuch für Lexikographie, das von A. Kučera, A. Rey, H. E. Wiegand und L. Zgusta herausgegeben wird. In jedem Band werden neben Aufsätzen zu jeweils einem Schwerpunktthema auch Rezensionen über lexikographische und metalexikographische Werke sowie Konferenzberichte, nicht themengebundene Aufsätze und bibliographische Berichte veröffentlicht. Seinem Selbstverständnis als internationales Jahrbuch, das als Forum für alle theoretischen und praktischen Probleme der Lexikographie dienen soll, wird das Periodikum nur bedingt gerecht, da es sich größtenteils auf die westeuropäische Forschung bezieht.

Ergänzend dazu erscheint seit 1984 eine Reihe unter dem Titel Lexicographica. Series maior, in deren Rahmen Monographien veröffentlicht werden, die sich mit lexikographischen und metalexikographischen Problemen beschäftigen, wobei auch hier kritisch anzumerken ist, daß nahezu ausschließlich Arbeiten von Germanisten, Romanisten und Anglisten veröffentlicht wurden. Ein zweiter Schwerpunkt der inzwischen gut 100 Monographien umfassenden Serie ist die Veröffentlichung von Sammelbänden, die Vorträge von unterschiedlichen Konferenzen enthalten (vgl. Wiegand, 2000; Wiegand, 1998a; Wiegand, 1996; Wiegand, 1989a; Bergenholtz/Mugdan, 1985; Hartmann, 1984; 1.3.2.2.6, 42-43).

Daneben existieren auch noch kürzere Serien, die im Rahmen der Zeitschrift Germanistische Linguistik unter der Redaktion von $\mathrm{H}$. E. Wiegand erschienen sind. Zu nennen sind hier zum einen die zwischen 1981 und 1988 veröffentlichten sieben Bände der Studien zur Neuhochdeutschen Lexikographie (vgl. Werner, 1990, 267-284), zum anderen die seit 1993 erschienenen Bände der Studien zur zweisprachigen Lexikographie mit Deutsch, deren siebter und letzter Band 2001 publiziert worden ist. Ziel der ersten Serie war es, „ein größeres Gemeinschaftswerk zu initiieren, dessen thematisches Zentrum die neuhochdeutsche Lexikographie bilden sollte" (Studien VI.2, 1988, 915). Die zweite Serie .will dazu beitragen, daß das wissenschaftliche und öffentliche Interesse an der zweisprachigen Lexikographie im allgemeinen und insbesondere an der mit Deutsch größer wird" (Wiegand, 1993, 6). Da diese Serie nach dem im folgenden vorgestellten Handbuch erschienen ist. 
konzentriert man sich vorrangig auf jene Themen, die dort gar nicht oder nicht umfassend genug behandelt worden waren.

Als Meilenstein in der Geschichte der europäischen Metalexikographie kann die Herausgabe des dreibändigen Werkes Wörterbücher in der Reihe der Handbücher der Sprach- und Kommunikationswissenschaften angesehen werden. Unter der Redaktion der bereits mehrfach genannten Metalexikographen F. J. Hausmann, O. Reichmann, H. E. Wiegand und L. Zgusta ist ein Standardwerk geschaffen worden, das nicht nur die Ergebnisse der bisherigen metalexikographischen Forschung zusammenfaßt, sondern in vielen Punkten über die bis dahin geleistete Arbeit hinausgeht. Der hochgesteckten Zielsetzung der Herausgeber des Handbuches, nämlich „die Lexikographie aller Sprachkreise der Erde zu registrieren [...], den Status und die Funktion von lexikographischen Nachschlagewerken [...] zu beschreiben, die Geschichte der Lexikographie an Beispielen größerer Kulturen zu entwerfen [...], Ausschnitte zu einer Algemeinen Theorie der Lexikographie zu liefern [...] und die Methodik der Lexikographie [...] darzustellen und weiterzuentwickeln“ (Wörterbücher, 1989, VIf), konnten die Autoren des Werkes tatsächlich gerecht werden. Kritisch angemerkt werden muß jedoch, daß auch dieses hervorragende Werk - insbesondere in seinen theoretischen Teilen - nicht frei ist von einer gewissen westlichen Einseitigkeit (vgl. Keipert, 1992, 380-381).

Als weiteres Indiz für die sprunghafte Entwicklung der Metalexikographie in den letzten drei Jahrzehnten können die zahlreichen Symposien dienen, die in verschiedenen Ländem mehr oder weniger regelmäßig durchgeführt werden. Beispielhaft ist hier das Internationale Symposium über Lexikographie der Universität Kopenhagen vorzustellen. Im Jahr 1976 versammelten sich erstmals Wissenschaftler aus Deutschland und Dänemark in Kopenhagen, um im Rahmen eines Kolloquiums über lexikographische Probleme zu diskutieren. Die Beiträge der Teilnehmer wurden 1977 in den Kopenhagener Beiträgen zur Germanistischen Linguistik (12, 1977) veröffentlicht. Sechs Jahre später versammelte man sich erneut in Kopenhagen, um im Rahmen eines Internationalen Symposiums über die aktuellen Probleme der Sprachlexikographie zu diskutieren (vgl. Hyldgaard-Jensen, 1983). Damit war der Grundstein gelegt für ein in Zweijahresabständen stattfindendes Symposium, zu dem sich Wissenschaftler aus unterschiedlichen Nationen in Kopenhagen versammeln, um über die neuesten Entwicklungen im Bereich der Lexikographie und der Metalexikographie zu diskutieren. Die Akten des Symposiums werden seit der Veranstaltung im Jahr 1984 in der Serie Lexicographica. Series maior präsentiert (vgl. Mogensen/Pedersen/Zettersten, 2000; Zettersten/Mogensen/Pedersen, 1999; Zettersten/Pedersen, 1996; HyldgaardJensen/Pedersen, 1994; Hyldgaard-Jensen/Zettersten, 1992; Hyldgaard- 
Jensen/Zettersten

1988a;

Hyldgaard-Jensen/Zettersten,

1988;

Hyldgaard-

Jensen/Zettersten, 1985).

\subsubsection{Zusammenfassung}

Die inzwischen recht zahlreichen metalexikographischen Arbeiten lassen sich vier groBen Forschungsgebieten zuordnen (vgl. Wiegand, 1998, 6ff). Dem Ziel, eine allgemeine Theorie der Sprachlexikographie zu erarbeiten, dienen all jene Arbeiten, die sich mit den Aufgaben auseinandersetzen, die während des Herstellungsprozesses eines Wörterbuches anfallen, aber auch jene, die sich mit einer Theorie der Wörterbuchform, das heißt vornehmlich mit der Mikro- und der Makrostruktur sowie mit einer Typologie der Wörterbücher beschäftigen. In diesem metalexikographischen Teilgebiet, das nach Wiegand als systematische Wörterbuchforschung bezeichnet wird (vgl. Wiegand, 1998, 7), sind bislang vor allem für die einsprachigen Wörterbücher, in Ansätzen aber auch für die zweisprachigen Wörterbücher die qualitativ und quantitativ größten Fortschritte erzielt worden, wie die bisherige Darstellung gezeigt hat.

Noch ganz am Anfang steht dagegen die Wörterbuchbenutzungsforschung als weitere Forschungsrichtung der Metalexikographie. $\mathrm{Zu}$ finden sind zu dieser Thematik erste empirische Untersuchungen, die sowohl die ein- als auch die zweisprachigen Wörterbücher behandeln (vgl. z. B. Krings, 1986; Wiegand, 1985, 20-98; Hartmann, 1983, 195-201; Ard, 1982, 1-22; Béjoint, 1981, 207-220), sowie Arbeiten, deren Autoren den Gegenstandsbereich darstellen und abgrenzen, ohne eigene Untersuchungen durchzuführen (vgl. Hartmann, 1987, 154-165; Ripfel/Wiegand, 1988, 491-520). Es bleibt zu hoffen, daß in Zukunft die von Wiegand entworfene Theorie der Wörterbuchbenutzung (vgl. Wiegand, 1998, 259ff) einen Anreiz bietet, empirische Untersuchungen zu unternehmen, die wichtige Erkenntnisse über das Benutzungsverhalten der Wörterbuchbenutzer liefern können.

Im Aurwind befindet sich gegenwärtig die historische Wörterbuchforschung, obwohl Hausmann im Geleitwort zu Papachristos' Arbeit noch konstatiert, daß "die Landkarten der historischen Wörterbuchforschung mit weißen Flecken übersät sind" (Papachristos, 1990, V). Aber gerade in den 90er Jahren des 20. Jahrhunderts hat diese Richtung sowohl auf dem Gebiet der einsprachigen als auch auf dem der zweisprachigen Lexikographie zahlreiche wichtige und qualitativ hochwertige Arbeiten hervorgebracht (vgl. Pkt. 1.2.1, 13).

Ebenfalls noch in den Kinderschuhen steckt die kritische Wörterbuchforschung, die zwar auch die jahrhundertealte Tradition der Wörterbuchrezensionen umfaßt, sich aber ebenso um die Entwicklung einer Theorie der Kritik bemühen soll. Ziel dieser Theorie muß sein, Standards zur Wörterbuchkritik zu entwickeln. Die erste Arbeit, die sich dieser Thematik ausführlich widmet, ist die 1989 veröffentlichte Dissertation von Martha Ripfel, in der sich 
die Autorin auf eine empirische Analyse unterschiedlicher Wörterbuchrezensionen über die großen einsprachigen Wörterbücher des Deutschen konzentriert (vgl. Ripfel, 1989).

\subsection{Einordnung der Arbeit in den Kontext der Metalexikographie}

Die vorliegende Arbeit ist dem Forschungsgebiet der historischen Metalexikographie zuzurechnen, das es sich zur Aufgabe gemacht hat, die Geschichte der Wörterbücher aufzuarbeiten. In diesem Sinne ist es ein übergeordnetes Ziel der Arbeit, durch eine Einzeluntersuchung einen Beitrag zur Darstellung der über 400jährigen Geschichte der russischdeutschen Lexikographie zu leisten. Im Mittelpunkt des Interesses steht, neben dem Aufbau und dem Inhalt des Wörterbuches, die Frage nach den von den unterschiedlichen Autoren benutzten Quellen.

Um dieses Ziel zu erreichen, sind allerdings auch die Ergebnisse der systematischen Wörterbuchforschung zu berücksichtigen. Dies gilt insbesondere für die Kapitel drei und vier, in deren Rahmen unter Auswertung der Erkenntnisse der systematischen Wörterbuchforschung die Mikro- und die Makrostruktur des Wörterbuches genauer untersucht werden sollen. Als theoretische Ausgangsbasis dienen dabei unter anderem die entsprechenden Aufsätze aus dem bereits vorgestellten Handbuch über die Wörterbücher (vgl. Wörterbücher, 1989-1991), die gegebenfalls um neuere Forschungen ergänzt werden. 


\section{Das Pawlowskysche Wörterbuch: Leben und Werk der Autoren und} der Verleger

\subsection{Vorbemerkung}

Dieses Kapitel ist den Biographien von Pawlowsky und dessen Nachfolgern gewidmet. Ziel des Abschnittes ist es, den in Vergessenheit geratenen Nachfolgern Pawlowskys, die für das Wörterbuch in der heute noch benutzten Form verantwortlich zeichneten, durch die Aufnahme in das Kapitel einen Teil der Anerkennung, die ihre Arbeit verdient, zukommen zu lassen. Relativ problemlos gestaltet sich diese Aufgabe für I. Nikolič und N. Asmuß (vgl. 2.3, 47-51), die für die zweite Auflage des Wörterbuches verantwortlich waren, weil die Sekundärliteratur recht ausführliche Informationen über deren Leben bereitstellt. Ebenfalls keine Schwierigkeiten bereiten Leben und Werk der Bearbeiter der dritten (vgl. 2.4.1, 5152) und der vierten Auflage (vgl. 2.5, 52-55) des deutsch-russischen Teils des Wörterbuches, da diese in den jeweiligen Vorwörtern benannt werden. Aufgrund der dürftigen Vorworte ungleich schwieriger zu beantworten ist die Frage nach den bisher noch unbekannten Bearbeitern der dritten Auflage des russisch-deutschen Teils (vgl. 2.4.2, 52).

Da es den Bemühungen der Verleger Nikolaj Georg Kymmel und Nikolaj Kymmel zu verdanken ist, daß das Wörterbuch in den überarbeiteten Fassungen erscheinen konnte, wird am Ende des Kapitels auch auf ihr Leben und Werk einzugehen sein (vgl. 2.6, 55-56).

Als besonders hilfreich bei der Beschreibung von Leben und Werk der oben genannten Personen hat sich das Baltische Biographische Archiv (1995) erwiesen, in dem Informationen aus über 200 biographischen Nachschlagewerken enthalten sind. Aus Gründen der Übersichtlichkeit und der Lesbarkeit wurde darauf verzichtet, diese häufig benutzte Quelle immer wieder anzugeben. Selbstverständlich angegeben werden diejenigen Quellen, die zusätzlich herangezogen wurden.

\subsection{Der Begründer des Wörterbuches: I. Ja. Pawlowsky}

Ivan Jakovlevič Pavlovskij' wurde am 23. September 1800 in Riga geboren. Seine schulische Ausbildung begann am dortigen Gymnasium, das er allerdings verließ, ohne den Kurs beendet zu haben, um am 20. September 1817 seinen Dienst als Postkanzleigehilfe beim Postkontor in Valka (Livland) anzutreten. Welche Gründe inn veranlaßten, die schulische Ausbildung abzubrechen, ist nicht bekannt. Am 4. Februar 1821 verließ Pawlowsky die Stelle in Valka, die offenbar nicht seinen Fähigkeiten und Neigungen entsprach, um nur

\footnotetext{
' Da sich in der deutschen Slavistik die Dudentranskription zur Wiedergabe des Namens des Autors durchgesetzt hat, wird dieser im folgenden - wie bisher auch - transkribiert angegeben
} 
13 Tage später in derselben Stadt eine Stelle als Lehrer am Kreisgymnasium anzunehmen. Dort unterrichtete er gut zehn Jahre lang die Fächer Russisch und Kalligraphie, ehe er am 16. September 1831 an die Kreisschule seiner Geburtsstadt Riga versetzt wurde.

In Riga wurden Pawlowskys pädagogische Fähigkeiten bei einer Überprüfung der Qualität des Russischunterrichts an den Rigaer Schulen von Prof. Rozberg (vgl. Pravdin, 1954, 142-146; Levickij, 1903, 355-357) erkannt, der ihn daraufhin im Jahr 1837 zum Dienst an der Universität in Dorpat einlud. Im August desselben Jahres wurde Pawtowsky zum Lektor der russischen Sprache und zum Übersetzer an der Kaiserlichen Universität Dorpat berufen. Daß diese Anstellung seinen persönlichen Anforderungen entsprach, zeigt sich schon daran, daß er die folgenden 20 Jahre an der Universität arbeitete. In seinen Kursen vermittelte Pawlowsky die Grammatik der russischen Sprache, wie die Kursbezeichnungen "Водопадъ, Дернавина, сь грамматинекими объясненіями", "Причудница, позма Дмитріева, сь грамматинескими упранненіями", "Рыбаки, Гныдима, сь грамматинескимь анализомъ" beweisen. Ein zweiter Schwerpunkt seiner Tätigkeit war die Leitung von Übersetzungskursen, in denen Übersetzungen sowohl aus dem Russischen in das Deutsche als auch aus dem Deutschen in das Russische angefertigt werden mußten.

Doch Pawlowsky begnügte sich nicht allein mit seiner Tätigkeit als Lektor. In den Jahren 1838 und 1839 arbeitete er zusätzlich noch als Russischlehrer am Gymnasium in Dorpat. Außerdem überprüfte er im Jahr 1846 im Auftrag des Kurators für das Schulwesen die Qualität des Russischunterrichts an den Schulen in Riga.

Besonders hervor tat Pawlowsky sich durch die Veröffentlichung zahlreicher Lehrbücher. Fast zu erwarten waren bei dem engagierten Pädagogen Werke, die zur Vermittelung der russischen Sprache beitragen sollten. So veröffentlichte er eine russische Sprachlehre für Deutsche, die mehrmals wieder aufgelegt wurde (vgl. Pawlowsky, 1838) und für die .seine Kaisertiche Majestät haben in Berücksichtigung der nützlichen Bedingungen des Titulärraths Pawlowsky ihm einen Brillantring allergnädigst zu verleihen geruht" (Ministerium, 1848. Nr. 2202). Außerdem publizierte er eine enweiterte Fassung seines Lehrbuches der russischen Sprache, das neben einem theoretischen Teil auch einen Übungsteil enthielt (vgl. Pawlowsky, 1838a). Die von Pawlowsky verfaßte Grammatik des modemen Kirchenslavischen für Deutsche wurde 1981 in den Skripten des Slavischen Seminars der Universität Tübingen im Neudruck vorgelegt (vgl. Pawlowsky, 1857/1981). Des weiteren begeisterte sich Pawlowsky für die Geographie Rußlands, was sich nicht nur in der Mitgliedschaft in dem Pyсcкоe reorpaфuкескоe oбщество zeigte, sondern sich auch in der Veröffentlichung zahlreicher Lehrbücher zu diesem Thema niederschlug (vgl. Pawlowsky, 1844; Pawlowsky, 1843; Pawlowsky, 1841). Es erstaunt nicht, daß auch diese 
Werke bereits zu Lebzeiten ihres Autors mehrfach wiederaufgelegt wurden. Für die hohe Qualität der Arbeiten spricht neben der eben genannten Tatsache auch, daß er für seine Werke eine Reihe von Preisen und Auszeichnungen erhielt.

Heute ist Pawlowsky allenfalls noch wegen seiner größten Leistung bekannt, die er als Verfasser eines deutsch-russischen und eines russisch-deutschen Wörterbuches vollbrachte. In der Einladung zur Subskription (vgl. Pawlowsky, 1849) für sein deutschrussisches Wörterbuch analysierte Pawlowsky Artikel aus den gebräuchlichsten Wörterbüchern der damaligen Zeit, um nachzuweisen, „daß sie nicht nur keinen wesentlichen Nutzen dem Lernenden bringen, sondern ihm sogar das gründliche Erlernen der russischen Sprache durch die nicht näher erklärten, oft auch nicht richtig gewählten oder ungebräuchlichen Ausdrücke erschweren" (Pawlowsky, 1849, 9). Ziel Pawlowskys war es, diesen Mißstand durch ein Werk zu beheben, das „zum gründlichen Erternen der russischen Sprache möglichst beitragen möchte" (Pawlowsky, 1849, 9). Daß der Bedarf nach einem solchen Wörterbuch vorhanden war, zeigte sich schon daran, daß nur sieben Jahre später die für die Veröffentlichung des Werkes nötige Anzahl von 800 bis 900 Subskribenten (vgl. Pawlowsky, 1849, 10) erreicht war, so daß das Vollstándige Deutsch-Russische Wörterbuch von I. Ja. Pawlowsky 1856 erscheinen konnte. Nach "elf Jahren des angestrengtesten Fleißes" (Pawlowsky, 1856, V) erfuhr der Autor nun die verdiente Anerkennung für sein Werk (vgl. Pawlowsky, 1859, III). Durch die wohlwollende Kritik ermutigt, veröffentlichte er bereits 1859 das nach demselben Konzept verfaßte Vollständige Russisch-Deutsche Wörterbuch. Dies ist um so bemerkenswerter, als ihn seine geschwächte Gesundheit dazu zwang, bereits am 3. September 1858 sein Gesuch um Verabschiedung aus dem Dienst der Universität einzureichen. Trotz seiner gesundheitlichen Probleme begann Pawlowsky mit der Überarbeitung des deutsch-russischen Teils des Wörterbuches, so daß im Jahr 1867 die zweite Auflage dieses Teils erscheinen konnte. Auch die überarbeitete Fassung wurde von der Kritik sehr positiv aufgenommen. Das Akademiemitglied Sreznevskij bezeichnete das Werk Pawlowskys in einer Rezension als ,единтвены словарь, къ которому монно обращаться съ увьренностьо, что наидешь нунное" (Izvlečenie, 1868, 195).

Der deutsch-russische Teil des Wörterbuches war die letzte Veröffentlichung Pawlowskys, der am 13. Juli 1869 im Alter von 69 Jahren in Riga verstarb.

\subsection{Die Nachfolger Pawlowskys: I. Nikolič und N. AsmuB}

Bereits 11 Jahre nach der Veröffentlichung des russisch-deutschen Teils des Wörterbuches erschien es dem Verlag unerläßlich, eine Überarbeitung zu veranlassen. In der Einleitung der zweiten Auflage des russisch-deutschen Teils verweist der Herausgeber darauf, 
daß die Gründe für die Überarbeitung nicht allein in den wenigen Fehlem und Ungenauigkeiten der ersten Auflage lägen, sondern insbesondere in der stetigen Weiterentwicklung der beiden Sprachen zu suchen seien (vgl. Pawlowsky, 1979, I). Als Bearbeiter der Neuauflage konnten Ivan Nikolič und Napoleon Asmuß gewonnen werden, deren Biographien im folgenden vorgestellt werden. Da der Löwenanteil der Arbeit von I. Nikolič geleistet wurde (vgl. Želtov, 1880, 121), werden dessen biographische Daten zuerst genannt.

\subsubsection{Leben und Werk von Ivan Nikolič}

Ivan Michajlovič Nikolič wurde am 4. Dezember 1820 in Riga geboren. Nach Abschluß des dortigen Gymnasiums begann er zunächst 1840 ein Medizinstudium an der Universităt zu Dorpat. Er wechselte dann jedoch rasch an das Pädagogische Institut in St. Petersburg. um sich dem Studium der historisch-philologischen Fächer zu widmen. Nach Beendigung des Lehrerseminars trat Nikolič als Oberiehrer für die russische Sprache und die Literatur in den Dienst des Dorpater Gymnasiums. Schon sechs Jahre später - im Jahr 1849 wechselte er seinen Arbeitsplatz und trat eine Stelle als Oberlehrer in Mitau an. Von dort wurde er im Jahr 1863 nach Kostroma berufen, um als Inspektor die Aufsicht über das Gouvernementgymnasium und das adelige Pensionat zu übernehmen.

Von nun an entwickelte sich Nikoličs Karriere schnell weiter. Zunächst übernahm er für das Jahr 1864 das Direktorat aller Volksschulen in den Gouvemements Vitebsk und Mogilev, ehe er noch im selben Jahr zum Vizekurator des Lehrbezirks Kazan' emannt wurde. Aufgrund seiner guten Arbeit wurde er nach vier Jahren Dienst auf die neugeschaffene Stelle eines Vizekurators des Dorpatschen Lehrbezirks berufen. Dieser Aufgabe widmete er sich bis zum Jahr 1873. Dann wechselte er wiederum nach Kazan' und arbeitete dort bis zu seinem frühen Tode 1879 in gleicher Funktion.

Anerkennung verdienen aber auch die zahlreichen wissenschaftlichen Arbeiten von $\mathrm{Ni}$ količ, in denen dieser sich der Erforschung der russischen Sprache widmete (vgl. Nikolič, 1843). Seine daraus gewonnenen Erkenntnisse verarbeitete er in den von inm verfaßten Lehrbüchern und in Chrestomathien der russischen Sprache. Darüber hinaus trat er als Autor von Festschriften für das Dorpater und das Mitauer Gymnasium an die Offentlichkeit. Besonders am Herzen lag inm die Verbesserung des Schulwesens in den Ostseeprovinzen, was sich in zahlreichen Aufsätzen zu diesem Thema widerspiegelt. Die umfangreichste und schwierigste Aufgabe, die Nikolič zu bewältigen hatte, begann im Jahr 1871. In diesem Jahr nämlich erteilte der Verleger Nikolaj Georg Kymmel inm und Napoleon Asmuß den Auftrag, das Pawlowskysche Wörterbuch zu überarbeiten. Ivan Nikolič war aus zwei Gründen für diese Aufgabe prädestiniert. Zum einen verfügte er natürlich über die unerläßliche Fachkenntnis, um diese Arbeit zu bewältigen, zum anderen fühlte er sich als Neffe 
des zwei Jahre zuvor verstorbenen Pawlowsky (vgl. Zeeltov, 1880, 122) persönlich verpflichtet, dessen Werk zu überarbeiten. Schon während seiner Tätigkeit in Dorpat, die ihn nicht sonderlich in Anspruch nahm, da der Lehrbezirk relativ klein war (vgl. Želtov, 1880. 122), begann Nikolič mit der Überarbeitung des russisch-deutschen Teils des Wörterbuches. Schwieriger gestaltete sich Nikoličs Arbeit, als er in den Lehrbezirk Kazan' übergewechselt war, da er nun nicht mehr soviel Zeit zur Verfügung hatte. Doch er widmete sich in jeder freien Minute seiner Aufgabe, und so gelang es inm beinahe, sein Lebenswerk zu vollenden.

Nikolič verstarb am 2. März 1879, nachdem die Überarbeitung des Wörterbuches bis auf die Korrektur von wenigen Seiten (vgl. Pawlowsky, 1879, III) abgeschlossen worden war. Anders als seinem Onkel war es ihm nicht vergönnt, sich über die positive Reaktion der Kritik auf das Wörterbuch zu freuen, das in einer zeitgenössischen Rezension als " $W M$ словаремь Пав ловскаго или же словаремь Нико лича" (Želtov, 1880, 122) bezeichnet wurde.

\subsubsection{Napoleon Asmuß}

Napoleon AsmuB wurde am 20. September 1805 in Lübeck geboren. Noch in jungen Jahren zog er mit seiner Mutter und seiner Schwester nach Dorpat. Nachdem er dort die Schule abgeschlossen hatte (vgl. Hollander, 1927, 185), schrieb er sich im Juli 1826 als Theologiestudent an der Universität zu Dorpat ein. Da er sein Studium zielstrebig und mit großem Fleiß absolvierte, erlangte er bereits drei Jahre später den Status eines Kandidaten der Theologie. Nun folgte Asmuß seinen pädagogischen Neigungen und trat eine Stelle als Lehrer und Erzieher bei dem Kaufmann Johann Heinrich Hollander an. Im Jahr 1833 gründete Asmuß eine eigene Erziehungsanstalt, die sich in den vielen Jahren ihres Bestehens zu einer Institution entwickelte solte und an der zahlreiche junge Männer aus Riga ihre Schulbildung erhielten.

Doch Asmuß' Engagement für die Stadt Riga beschränkte sich nicht allein auf die Erzjehung der Söhne der Stadt. Als Mitglied der Literärisch-practischen Bürgervertindung unterrichtete er nicht nur an der seit 1817 bestehenden Lutherschule für Handwerkslehrlinge, sondern setzte sich auch, wann immer es ihm die Zeit erlaubte, für die Belange der Verbindung ein, deren Ziel es war, .im Mittelstande und unter den niederen Volksklassen ohne Geräusch Nutzen zu stiften“ (Hollander, 1927, 30). Deshalb ist es auch nicht erstaunlich, daß Asmuß im Jahr 1852 mit der Redaktion der Rigaer Stadtblatter, des Organs der Verbindung, beauftragt wurde. In den folgenden 26 Jahren bis zu seinem Tode gelang es Asmuß, das Niveau des Blattes gleichbleibend hoch zu hatten. Neben Mitteilungen aus dem gemeinnützigen Leben der Stadt Riga wurden dort auch Informationen zur Geschichte und 
zur Statistik der Stadt veröffentlicht. Bemerkenswert ist außerdem, mit welcher Sachkenntnis Asmuß wirtschaftliche Fragen klärte. Diese Tatsache schlug sich später in seiner Emennung zum Dispacheur ${ }^{2}$ nieder.

Doch Asmuß war nicht nur Redakteur der Rigaer Stadtblătter, sondern er übernahm auch noch die Rolle des Historiographen der gemeinnützigen Literänisch-practischen Verbindung. In dieser Funktion erarbeitete er unter anderem einen Überblick über die $\mathrm{Ge}$ schichte der Verbindung während ihres 75jährigen Bestehens, der im Rahmen der Feier dieses Ereignisses im Jahr 1877 vorgestellt werden konnte. Es ist nur natürlich, daß Asmuß zahlreiche Auszeichnungen für sein Engagement erhielt. Beispielhaft ist hier seine Emennung zum Ehrenmitglied der Verbindung anläßlich seines 25jährigen Redakteursjubiläums genannt.

Auch dem Häckerschen Livländischen Kalender und dem Rigaschen Almanach stelte Asmuß sein umfangreiches lokalhistorisches Wissen zur Verfügung, denn in dem einen kommentierte er die Chronik Rigas, in dem anderen veröffentlichte er seine historischen Forschungen.

Ein neues Tätigkeitsfeld eröffnete sich Asmuß, als er am 6. Juni 1856 zum Dispacheur berufen wurde. Kurz nachdem er diese Stelle angetreten hatte, reiste er im Auftrag des Börsenkomitees in sein Geburtsland, um sich in Hamburg - der führenden Stadt im Dispachegeschäft - praktisch weiterzubilden. Daß er auch diese Herausforderung mit Bravour bewältigte, zeigt sich schon daran, daß er im Jahr 1864 bei einem intemationalen Kongreß zu Gast in York war, um seine Verbesserungsvorschläge hinsichtlich des Entwurts zur Regelung von Großhavarien vorzustellen.

Asmuß ist es ebenfalls zu verdanken, daß 1861 ein deutlich verbessertes Rigaer Adressbuch veröffentlicht werden konnte, als dessen Herausgeber er insgesamt dreimal fungierte. Mit seinem akribischen Fleiß und seiner Ausdauer sorgte er dafür, daß nun ein lange entbehrtes Hilfsmittel zur Verfügung stand, das zusätzlich noch einen topographischen, einen historischen und einen statistischen Anhang enthielt. Als Herausgeber des Rigaer Adressbuches, das im Verlag von Nikolaj Kymmel erschien, machte Asmuß bereits Bekanntschaft mit dem Verleger der Pawlowskyschen Wörterbücher.

Im Rahmen der vorliegenden Arbeit ist Asmuß als Bearbeiter der zweiten Auflage des russisch-deutschen Wörterbuches von Wichtigkeit. Für diese Aufgabe war er nicht nur durch sein umfangreiches Spezialwissen auf den unterschiedlichsten Gebieten geeignet, sondern insbesondere dadurch, daß Deutsch seine Muttersprache war. Während sich Ni-

\footnotetext{
2 Dispache: Berechnung der Schadensverteilung bei Verlusten im Seeverkehr (Havarie), erfolgt meist durch einen gerichtlich bestellten Sachverständigen (Dispacheur) (dtv-Lexikon, 1976, 130).
} 
količ der Konzeption und dem russischsprachigen Teil des Wörterbuches widmete, konzentrierte sich Asmuß vor allem auf die Korrektur der deutschen Entsprechungen (vgl. Želtov, $1880,121)$.

Auch Asmuß durfte das Erscheinen des Wörterbuches nicht mehr erleben, denn er verstarb nach einem erfülten und bis zum Tode arbeitsreichen Leben am 24. August 1878 in Riga.

\subsection{Die Bearbeiter der dritten Auflage}

2.4.1 Die Bearbeiter der dritten Auflage des deutsch-russischen Wörterbuches: Otto Stahl, Oskar Kühn und Th. Luther

Im Jahr 1875 beauftragte der Verleger Nikolaj Georg Kymmel Otto Stahl damit, die zweite Auflage des deutsch-russischen Wörterbuches zu überarbeiten, die bereits völlig vergriffen war.

Otto Stahl, der am 24. Dezember 1849 in Rjazan geboren worden war, besuchte das Gymnasium in Moskau, das er im Jahr 1869 mit dem Abitur abschloß. Anschließend schrieb er sich an der Universität für das Studium der Philologie und der Theologie ein. Nach Abschluß seines Studiums arbeitete Stahl als Hauslehrer auf der Glashütte Lisette in Livland. Dort wurde er vermutlich von Kymmel ,entdeckt" und mit der Überarbeitung des Wörterbuches betraut. Stahl überarbeitete in den folgenden Jahren die Einträge unter den Buchstaben A-K sowie diejenigen unter U und V (vgl. Pawlowsky, 1902, III). 1880 mußte er allerdings die Arbeit am Wörterbuch einstellen, da er aus beruflichen Gründen nach Moskau übersiedelte. Dort verbrachte er die letzten Jahre bis zu seinem Tode am 5 . November 1886.

Nachdem Otto Stahl die Arbeit an dem Wörterbuch eingestelt hatte, enwies es sich für Nikolaj Georg Kymmel als äußerst schwierig, einen adäquaten Ersatz für inn zu finden. Es waren zwar zahlreiche Leute bereit, sich dieser Arbeit zu widmen, doch die Größe der Aufgabe ließ die meisten von ihnen schon während der Vorarbeiten wieder zurückschrecken (vgl. Pawlowsky, 1902, III). Schließlich gelang es Kymmel, mit Oskar Kühn und Th. Luther Mitarbeiter zu finden, die die Herausgabe der dritten Auflage des deutsch-russischen Wörterbuches möglich machten.

Oskar Kühn wurde am 27. Juli 1835 in Riga als Sohn deutscher Einwanderer aus Sachsen-Weimar geboren. Er besuchte das dortige Gymnasium und widmete sich anschließend theologischen Studien. Nach Abschluß seines Studiums war er von 1865 bis 1873 als Lehrer in Nikolaev, Odessa und Kursk tätig. Von 1873 bis 1877 arbeitete Kühn als Inspektor der Kreisschule in Wolmar. Nach Beendigung dieser Tätigkeit kehrte er als wissenschaftii- 
cher Lehrer in seine Geburtsstadt Riga zurück und unterrichtete in den folgenden zwei Jahren am dortigen Stadtgymnasium. Zu dieser Zeit wurde er vermutlich von Kymmel dazu angeregt, die Arbeit am Wörterbuch zu übernehmen. 1881 beendete er seine Lehrtätigkeit, die inn zwischenzeitlich an das Pleskauer Gymnasium geführt hatte, und trat eine Stelle als Mitarbeiter beim Rigaer Tageblatt an.

Oskar Kühn war nach Pawlowsky der einzige, dem es vergönnt war, den Erfolg des überarbeiteten Wörterbuches mitzuerleben, denn er verstarb erst am 5. September 1904, nachdem bereits drei Abdrucke der dritten Auflage des deutsch-russischen Wörterbuches erschienen waren (vgl. 3.1.3. 59).

Über Th. Luther, den Mitarbeiter von Oskar Kühn, liegen nur diejenigen Informationen vor, die im Vorwort der dritten Auflage des deutsch-russischen Wörterbuches zu finden sind. Auch er war wie sein Kollege als Lehrer tätig und arbeitete nach Angaben des Verlegers in Orel (vgl. Pawlowsky, 1902, III). Die Suche nach weiteren Informationen über Leben und Werk von Th. Luther blieb ergebnislos. Weder im Baltischen noch im Russischen noch im Deutschen Biographischen Archiv ist ein Eintrag unter seinem Namen zu finden. Auch in der umfangreichen kommentierten Bibliographie von Kaufman (1955) ist kein Hinweis auf Luther enthalten.

\subsubsection{Die Bearbeiter der dritten Auflage des russisch-deutschen Wörterbuches}

Gar keine Informationen liegen über die Bearbeiter der dritten Auflage des russischdeutschen Teils des Wörterbuches vor, da dieser Teil weder ein Vorwort des Verlegers noch einleitende Bemerkungen enthält.

Diese Tatsache könnte dafür sprechen, daß einige Bearbeiter des deutsch-russischen Teils auch für den russisch-deutschen Teil verantwortlich waren. Da Otto Stahl bereits 20 Jahre vor Erscheinen dieses Teils die Arbeit am Wörterbuch aus beruflichen Gründen eingestellt hatte, kommt er als Bearbeiter wohl nicht in Betracht. In Frage kommt eher Oskar Kühn, der vier Jahre nach dem Erscheinen der dritten Auflage des russisch-deutschen Teils verstarb.

Abschließend klären läßt sich diese These aber nicht, da die intensive Suche nach näheren Informationen ohne Ergebnis geblieben ist. Weder Anfragen in Riga, in Moskau und in Leipzig, noch die Suche über das Börsenblatt des Deutschen Buchhandels brachten den gewünschten Erfolg.

\subsection{Die Bearbeiter der vierten Auflage}

Nachdem sich die von Kymmel beauftragten Fachleute fast ein Jahrzehnt lang der Überarbeitung des deutsch-russischen Teils des Pawlowskyschen Wörterbuches gewid- 
met hatten, konnte die vierte Auflage im Jahr 1911 erstmals erscheinen. Da zeitgleich ein zweiter Abdruck der dritten Auflage des russisch-deutschen Teils veröffentlicht wurde (vgl. 3.1.4, 60), ist zu vermuten, daß die Herausgabe einer vierten Auflage dieses Teils vom Verleger nicht geplant war. Da es das erklärte Ziel des Verlegers war, den fachsprachlichen Wortschatz bedeutend zu enweitern (vgl. Pawlowsky, 1911, III), ist es nicht verwunderlich, daß er neben dem Oberlehrer Kart Semberg, der die grundlegende Arbeit verrichtete, drei Spezialisten zur Mitarbeit am Wörterbuch verpflichtete.

\subsubsection{Karl Semberg}

Am wenigsten bekannt ist über den Mann, der die ,grundlegende Arbeit an dieser Auflage geleistet hat" und der ,seine ganze Lebenskraft angespannt [hat], um dieses Ziel zu erreichen" (Pawlowsky, 1911, III).

Geboren wurde Semberg am 5. September 1844 in Kurland. Über seine schulische Ausbildung liegen keine Informationen vor, gesichert ist nur, daß er von 1864 bis 1867 Medizin studierte. Ohne sein Studium abzuschließen, vertieß er die Universität, um eine Stelle als Hauslehrer anzutreten, die er bis 1872 innehatte. Im Jahr 1872 erhielt Semberg ein Stipendium, das es inm ermöglichte, slavische Sprachen an der Petersburger Universität zu studieren. Danach trat er eine Stelle als Lehrer am Gymnasium in Kaunas an, die er bis 1880 innehatte. Nachdem er im Jahr 1881 das russische Seminar in Leipzig besucht hatte, arbeitete er zunächst von 1882 bis 1887 am Gymnasium in Wilna und wechselte dann im Jahr 1888 als Inspektor an das Gymnasium in Odessa.

Es ist zu vermuten, daß Semberg nach 1888 an ein Gymnasium in Riga berufen wurde. wo er dann auch die Bekanntschaft mit dem Verleger der Pawlowskyschen Wörterbücher machen sollte. Darüber kann allerdings nur spekuliert werden, da sich dazu in der Sekundärliteratur keine Angaben finden lassen.

\subsubsection{Alexander von Schäfer}

Alexander von Schäfer wurde am 3. Juli 1855 in Lublin geboren. Nachdem er 1873 das dortige Gymnasium abgeschlossen hatte, legte er 1875 die Prüfungen für das Lehramt im Fach Russisch an Kreisschulen ab. Von 1876 bis 1882 war er als Lehrer an der Kreisschule in Wenden tätig. Nachdem er 1882 die Prüfungen als Russischlehrer für Gymnasien bestanden hatte, arbeitete er von 1882 bis 1892 am Gymnasium in Birkenruh. Seine Tätigkeit dort beendete er, um auch noch die Gymnasiallehrprüfung für das Fach Deutsch abzulegen. Von 1893 an war Schäfer dann als Lehrer beim Kadettencorps in Pleskau tätig.

Da Schäfer sowohl Deutsch-als auch Russischlehrer war und er aufgrund seiner Arbeit beim Kadettencorps über militärisches Spezialwissen verfügte, war er prädestiniert dafür, 
die Lücken zu füllen, die sich in der dritten Auflage des deutsch-russischen Wörterbuches auf dem Gebiet der Militär- und der Rechtswissenschaften bemerkbar gemacht hatten (vgl. Pawlowsky, 1911, III).

\subsubsection{Karl Heinrich Grevé}

Karl Grevé wurde am 28. Dezember 1854 in Moskau geboren. Seine erste schulische Ausbildung erhielt er an einer Privatschule in Riga. Nachdem er das Gymnasium in Riga abgeschlossen hatte, begann er 1875 ein Medizinstudium in Dorpat, wechselte aber noch im selben Jahr an die Universität Moskau. um sich dem Studium der Naturwissenschaften zu widmen. Von 1877 bis 1883 war Grevé als Hauslehrer in Livland. Polen und Moskau tätig. Im Anschluß daran widmete er sich wieder seinem Studium, das er in Greifswald und Leipzig fortsetzte.

In seiner wissenschaftlichen Arbeit beschäftigte sich Grevé mit geographischen und biologischen Themen. Besondere Kenntnisse erlangte er auf zoologischem Gebiet. Sein Fachwissen, das er 1890 bei einem Forschungsaufenthalt im Kaukasus und in Persien noch vertieft hatte, gab er als Lektor an der Imkerstation in Tula an den Nachwuchs weiter. Außerdem übernahm er Aufgaben in zahlreichen landwirtschaftlichen Gremien und Verbänden. Er war nicht nur Mitglied des Verwaltungsrates des Zoologischen Gartens in Moskau, sondern auch Korrespondent des Ministeriums für Landwirtschaft.

Dem Verleger des Pawlowskyschen Wörterbuches fiel Grevé vermutlich während seiner Lehrtätigkeit an der Töchterschule in Riga auf. Da Kymmel mit der vierten Auflage des Wörterbuches "manch fach wis sen schaftliches Lexikon ersetzen" (Pawlowsky. 1911, III) wollte, wollte er auf die Mitarbeit des versierten Zoologen und Landwirtschaftsexperten nicht verzichten.

\subsubsection{Woldemar von Rieder}

Mit dem am 9. Dezember 1853 im Gouvernement Novgorod geborenen Woldemar von Rieder gewann Kymmel einen Arzt für die Arbeit an dem Wörterbuch. Nachdem Rieder 1871 das Gymnasium in Dorpat abgeschlossen hatte, studierte er von 1872 bis 1878 an der dortigen Universität Medizin. In seiner Dissertation, die 1878 veröffentlicht wurde. setzte er sich mit embolischen Geschwulstmetastasen auseinander. Nach einer kurzen Tätigkeit als Assistent am Pathologischen Institut in Dorpat wechselte Rieder nach Petersburg. wo er erst als Assistent, später als Ordinator am Obuchov-Hospital arbeitete. 1882 ließ er sich als freipraktizierender Arzt in Werro nieder, wo er bereits vier Jahre später zum Stadtarzt berufen wurde. Von 1893 an hatte er die gleiche Stellung in Riga inne. Dort wurde er im Jahr 1899 zum Sanitätsarzt der Rigaer Stadtverwaltung emannt. 
Mit Hilfe der Fachkenntnis von Rieder sollten jene Lücken in der vierten Auflage des deutsch-russischen Wörterbuches geschlossen werden, die sich auf dem Gebiet der Medizin aufgetan hatten.

\subsection{Die Verleger des Wörterbuches: Nikolaj Georg Kymmel und Nikolaj Kymmel}

\subsubsection{Nikolaj Georg Kymmel}

Nikolaj Georg Kymmel wurde am 17. Juni 1816 in Riga geboren. Nach Beendigung der Schule trat er zunächst in die Fußstapfen seines Vaters, eines Brauereibesitzers, und begann eine kaufmännische Lehre bei W. B. Dickelmann in Riga. Nach dem plötzlichen Tod seines Chefs im Jahr 1832 entschloß er sich, als Lehrling in die Buchhandlung von Nikolaus Frantzen einzutreten (vgl. Pfau, 1890, 225). Seine Ausbildung genoß Kymmel damit in einer der ältesten Buchhandlungen Livlands, denn das Geschäft von $\mathbf{N}$. Frantzen war im Jahr 1762 von keinem geringeren als Johann Friedrich Hartknoch gegründet worden. Um sich ein Bild von der Bedeutung der verlegerischen Tätigkeit von Hartknoch zu machen, konsultiere man die weiterführende Literatur. Barenbaum, 1991, 61; Savel'eva, 1988, 5355; Zajceva, 1988, 42-44; Poelchau, 1918; Buchholtz, 1890, 211.

Nachdem Kymmel seine Ausbildung abgeschlossen hatte, blieb er, angestellt als Gehilfe, noch bis zum Jahr 1839 in der Frantzenschen Buchhandlung. Dann entschied er sich, nach Leipzig - der damals im Buchgewerbe führenden Stadt - zu gehen, um sich dort fortzubilden. Es gelang inm, eine Anstellung als Volontär bei dem damaligen Vorsitzenden des Vereins der Buchhändler, Friedrich Fleischer, zu erlangen. Dort vervollkommnete Kymmel in den Jahren 1840 und 1841 sein Wissen bei einer der wichtigsten und schillerndsten Persönlichkeiten der damaligen Buchhändlerszene (vgl. Lorck, 1883, 164-167). Es ist zu vermuten, daß die Zusammenarbeit von beiden Seiten als gelungen betrachtet wurde. denn der C. F. Fleischer-Vertag wurde nicht nur der Leipziger Komissionär für Kymmel, sondern die beiden Verlage veröffentlichten sogar die zweite Auflage und den erste ADdruck der dritten Auflage des russisch-deutschen Wörterbuches von Pawlowsky gemeinsam.

1842 kehrte Kymmel nach Riga zurück und machte sich durch den Kauf der Frantzenschen Buchhandlung selbständig. In seinem Verlagsgeschäft konzentrierte er sich auf die Herausgabe von Schul- und Unterrichtsbüchem sowie auf wissenschaftliche Werke. Neben regionalgeschichtlichen Werken (vgl. Buchholtz, 1899; Mettig, 1883) veröffentlichte Kymmel auch landwirtschaftliche (vgl. Pfuhl, 1895) und juristische Fachliteratur. Außerdem wurden in seinem Verlag etliche Periodika herausgegeben. So erschienen beispielsweise 
neben dem Rigaer Adressbuch auch die Mitteilungen aus dem Gebiete der Geschichte Livlands, Estlands und Kurlands bei Kymmel in Riga.

Kymmel nahm auch im Leben der Stadt Riga einen bedeutenden Platz ein. Er war Mitgründer der Riga-St.Petersburger Dampfschiffahrtsgesellschaft und der Baltischen Monatsschrift. Außerdem stand er von 1862 bis 1868 der Großen Gilde als Ältester vor (vgl. Lenz, 1970, 138). Auch er engagierte sich in der Literärisch-practischen Vereinigung, die inn 1902 zum Ehrenmitglied emannte (vgl. Hollander, 1927, 159 u. 228).

Da sein Sohn in seine Fußstapfen trat, beschränkte sich Kymmel, nachdem er bereits 1888 als Inhaber aus der Firma ausgeschieden war, bis 1894 auf die Leitung des Verlages.

Seinen Lebendsabend verbrachte Kymmel in Riga, wo er am 8. Juli 1905 fast 90jährig verstarb.

\subsubsection{Nikolaj Kymmel}

Nikolaj Kymmel wurde am 10. Juni 1845 als erster Sohn von Nikolaj Georg Kymmel in Riga geboren. Seine schulische Ausbildung erhielt er am Privatgymnasium von Napoleon Asmuß, was beweist, wie sehr sein Vater die Fähigkeiten von Asmuß geschätzt haben muß.

Im Jahr 1862 trat Nikolaj für die folgenden fünf Jahre als Lehrling in das Geschäft seines Vaters ein. Dann zog es auch inn ins Ausland, wo er seine handwerklichen Kenntnisse vervollkommnen wollte. In den folgenden zwei Jahren arbeitete er als Volontär in Berlin, Brüssel, Leipzig und Paris, um nach seiner Rückkehr im Jahr 1870 als Teilhaber in die vätertiche Firma einzusteigen, die er seit 1888 als alleiniger Inhaber führte.

Wie schon sein Vater, so engagierte sich auch der Sohn in den Vereinen und Verbänden der Stadt Riga. So war Nikolaj nicht nur seit 1885 Ältester der Großen Gilde, sondern engagierte sich auch in der Ortsgruppe Riga des Deutschen Vereins von Livland, deren Vizepräsident er zeitweilig war.

Von 1919 an lebte Kymmel, vermutlich aufgrund der politischen Veränderungen in seiner Geburtsstadt, in Garmisch-Partenkirchen. Seit 1922 firmierte er als Inhaber der abgeteilten Verlagsbuchhandlung N. Kymmel in Riga und Leipzig.

Über sein weiteres Schicksal und den Zeitpunkt seines Todes ist nichts bekannt, da seine Daten in die neueren biographischen Hilfsmittel (vgl. z. B. Anders, 1988) nicht aufgenommen wurden. Leider existiert im Gegensatz zu einem weiteren Rigaer Verlag ( vgl. Deubner, 1998) auch keine Verlagsgeschichte, die das Schicksal der Familie näher beleuchten könnte. 


\subsection{AbschlieBende Bemerkungen}

Es muß an dieser Stelle noch einmal deutlich gemacht werden, daß man von dem Pawlowsky etwa im gleichen Sinne wie von dem Duden zu sprechen hat. Denn in diesem Kapitel konnte gezeigt werden, daß sich eine ganze Reihe bekannter Männer in den Dienst des erstmals von Pawlowsky verfaßten Wörterbuches gestellt haben. Es ergibt sich die aus ähnlich gelagerten Fällen bekannte Situation, daß die heute gebräuchlichen Auflagen am engsten mit dem Namen Pawlowskys verbunden sind, obwohl das von diesem Autor gesammelte Material in jenen Auflagen, die ja mehrmals enweitert wurden, wohl den geringsten Teil ausmachen dürfte.

Trotz ihrer aufopferungsvollen und zum Teil langjährigen Hingabe an ihre Aufgabe sind die Nachfolger Pawlowskys heute nahezu alle in Vergessenheit geraten. Sinn dieses Kapitels war es deshalb auch, innen und ihrer Arbeit nach mehr als 100 Jahren ein Denkmal zu setzen, um ihnen die Anerkennung, die ihre Arbeit verdient, auf diese Weise zu bezeugen. 


\section{Die Makrostruktur des Wörterbuches}

Mit diesem Kapitel beginnt die metalexikographische Analyse des Wörterbuches von Pawlowsky. Im ersten Teil soll die Publikationsgeschichte der beiden Teile des Wörterbuches genau nachgezeichnet werden. Im Vordergrund steht im ersten Abschnitt die Klärung folgender Fragen: Wie viele Auflagen des Wörterbuches wurden veröffentlicht? Wann sind die Auflagen erschienen? Wie viele unveränderte Abdrucke der einzelnen Auflagen wurden publiziert?

Im zweiten Teil wird die Makrostruktur des russisch-deutschen Teils des Wörterbuches einer genauen Analyse unterzogen. In einem ersten Schritt müssen die theoretischen Voraussetzungen geklärt werden, damit dann im nächsten Schritt auf deren Grundlage die Untersuchung der Makrostruktur geschehen kann. Ziel dieses Abschnittes ist es, durch eine vergleichende Analyse der drei Auflagen des russisch-deutschen Teils die im Laufe der Jahre vorgenommenen Veränderungen in der Makrostruktur herauszuarbeiten.

\subsection{Die Publikationsgeschichte des Wörterbuches}

Zu Beginn sollen zunächst die bibliographischen Daten des Wörterbuches entwirt werden. Daß dies dringend erforderlich ist, beweisen die zum größten Teil ungenauen, zum Teil sogar falschen Angaben in den Bibliographien und in der Sekundärtiteratur. So verwechselt Bielfeldt beispielsweise das Erscheinungsdatum des deutsch-russischen Teils der ersten Auflage mit demjenigen des russisch-deutschen Teils (vgl. Bielfeldt. 1956, 19). Aav dagegen (1977) hat in seine Bibliographie zwar alle Auflagen des Pawlowskyschen Wörterbuches aufgenommen, allerdings beziehen sich seine Angaben nicht immer auf den ersten Abdruck der jeweiligen Auflage. Er nennt bei der dritten Auflage des deutschrussischen Teils nur den dritten Abdruck aus dem Jahr 1902, ohne dies zu kennzeichnen, nimmt dafür aber allein den 1911 erschienenen zweiten Abdruck der dritten Auflage des russisch-deutschen Teils als eigenständigen Eintrag in seine Bibliographie auf (vgl. Aav, 1977, 104-105).

\subsubsection{Die erste Auflage des Wörterbuches}

Das Vollständige Deutsch-Russische Wörterbuch von I. Ja. Pawlowsky erschien 1856 im Verlag von Nikolaj Georg Kymmel in Riga (vgl. Pawlowsky, 1856). Gedruckt wurde es bei I. F. Steffenhagen und Sohn in Mitau. Die Druckerei, die seit 1769 im Besitz der Familie Steffenhagen war, zählte zu den besten in Rußland (vgl. Barenaum, 1991, 78). Sie verfügte nicht nur über deutsche und russische, sondern auch über hebräische Schriftsätze (vgl. Namentliche Anzeige, 1809). Da der deutsch-russische Teil des Wörterbuches beim Ziel- 
publikum sehr gut ankam, wurde bereits drei Jahre später der russisch-deutsche Teil veröffentlicht (vgl. Pawlowsky, 1859). Auch dieser erschien im Verlag von Nikolaj Kymmel. Allerdings fehlt in diesem Band ein Hinweis auf die Steffenhagensche Druckerei.

\subsubsection{Die zweite Auflage des Wörterbuches}

Gut 10 Jahre nach dem Erscheinen des von Pawlowsky erarbeiteten deutsch- russischen Teils des Wörterbuches veröffentlichte der Verlag eine zweite, überarbeitete Auflage (vgl. Pawlowsky, 1867). Diese 1867 erschienene zweite Auflage des Wörterbuches war von Pawlowsky zwar wesentlich erweitert und verbessert worden, allerdings hatte der Autor seine Konzeption unverändert übernommen.

Nikoliz als Bearbeiter der zweiten Auflage des russisch-deutschen Teils (vgl. Pawlowsky, 1879) vermehrte nicht nur die Anzahl der Eintrăge um ein vielfaches, sondern verănderte auch die Konzeption des Wörterbuches. Der wesentlichste Unterschied gegenüber der ersten Auflage war die Abkehr von der rein alphabetischen Anordnungsweise zugunsten einer nach etymologischen Gesichtspunkten vorgenommenen Anordnung der Eintrăge, die mit einer enormen Platzerspamis einherging (vgl. 3.2.3.4, 78-80). Auch bei den Verlegern gab es eine Veränderung, denn die zweite Auflage des russisch-deutschen Wörterbuches erschien bei Kymmel, Riga und C. F. Fleischer, Leipzig (vgl. 2.6.1, 55).

Da von den ersten beiden Auflagen des Wörterbuches nur jeweils ein Abdruck erschienen ist, steht zu vermuten, daß sich Kymmel für die Überarbeitung des Wörterbuches entschied, nachdem die Auflagen vergriffen waren, um weiterhin ein Hilfsmittel anzubieten, das der Weiterentwicklung der beiden Sprachen gerecht werden sollte.

\subsubsection{Die dritte Auflage des Wörterbuches}

Wie bei den bisherigen Auflagen auch, so erschien zuerst die dritte Auflage des deutsch-russischen Teils (vgl. Pawlowsky, 1888). Im Jahr 1888 wurde die von Stahl, Kühn und Luther umgearbeitete und wesentlich vermehrte Auflage von dem Verleger Nikolaj Kymmel veröffentlicht. Die Nachfrage nach dem neu überarbeiteten Wörterbuch muß enorm gewesen sein, denn bereits 12 Jahre später wurde zeitgleich mit dem Erscheinen des 1. Abdrucks der dritten Auflage des russisch-deutschen Teils (vgl. Pawlowsky, 1900) ein zweiter Abdruck des deutsch-russischen Teils veröffentlicht (vgl. Pawlowsky, 1900a). Das im Jahr 1900 gedruckte Kontingent war ebenfalls schnell vergriffen, so daß nur zwei Jahre später der dritte Abdruck der dritten Auflage des deutsch-russischen Teils erfolgte (vgl. Pawlowsky, 1902).

Auch die dritte Auflage des russisch-deutschen Teils erlebte insgesamt drei Abdrucke. 11 Jahre nach der Veröffentlichung des ersten Abdrucks der dritten Auflage (vgl. 
Pawlowsky, 1900) erschien der zweite Abdruck des russisch-deutschen Teils (vgl. Pawlowsky, 1911). Der dritte Abdruck der dritten Auflage wurde im Jahr 1923 veröffentlicht (vgl. Pawlowsky, 1923).

\subsubsection{Die vierte Auflage des Wörterbuches}

Nur der deutsch-russische Teil des Wörterbuches erschien in einer vierten, völlig umgoarbeiteten Auflage, deren erster Abdruck (vgl. Pawlowsky, 1911a) zeitgleich mit dem zweiten Abdruck des russisch-deutschen Teils (vgl. Pawiowsky, 1911) im Jahr 1911 veröffentlich wurde. Auch die überarbeitete Fassung fand bei der Leserschaft eine positive Aufnahme, so daß bereits 1922, ein Jahr vor dem Erscheinen des dritten Abdrucks der dritten Auflage des russisch-deutschen Teils, der zweite Abdruck der vierten Auflage des deutschrussischen Teils erscheinen konnte (vgl. Pawlowsky, 1922).

\subsubsection{Die photomechanischen Nachdrucke durch das Zentralantiquariat in Leipzig}

Daß vor allem der russisch-deutsche Teil des Wörterbuches trotz seines Alters nicht an Wert für die Benutzer vertoren hat, zeigt sich daran, daß das Zentralantiquariat in Leipzig die dritte Auflage des russisch-deutschen Teils des Wörterbuches im 20. Jahrhundert mehrfach nachgedruckt hat.

Der erste unveränderte photomechanische Nachdruck der dritten Auflage des russischdeutschen Teils erschien bereits im Jahr 1952 beim Zentralantiquariat in Leipzig ( $v g$ l. Pawlowsky, 1952). Daß dieser Nachdruck in jener Zeit ein unentbehrliches Hilfsmittel beim Erlemen der russischen Sprache war, wird dadurch offensichtlich, daß bereits 8 Jahre später ein zweiter Nachdruck der Auflage erforderlich war (vgl. Pawlowsky, 1960). Doch auch dieser Nachdruck war nach einigen Jahren wieder vergriffen, so daß im Jahr 1972 der dritte und bislang letzte unveränderte, photomechanische Nachdruck des russischdeutschen Wörterbuches von Pawlowsky veröffentlicht wurde (vgl. Pawlowsky, 1972).

\subsection{Die Makrostrukur des russisch-deutschen Teils des Wörterbuches}

\subsubsection{Theoretische Grundlagen}

Der von Rey-Debove 1971 (21) in die Diskussion eingeführte Terminus "Makrostruktur" wird heute nicht mehr einheitlich verwendet. So versteht beispielsweise Wiegand unter der Makrostruktur lediglich eine .Ordnungsstruktur, deren Trägermenge eine (nichtleere, endliche) Menge von Leitelementträgern eines lexikographischen Nachschlagewerkes ist" (Wiegand, 1989, 372). In Anlehnung an Schaeder (vgl. 1987, 66), der den Begriff in einem weiteren Sinne definiert, werden in dieser Arbeit unter dem Begriff "Makrostruktur" der Inhalt und der Aufbau eines Wörterbuches verstanden. Bei einer Analyse der Makrostruktur 
müssen deshalb folgende Fragen geklärt werden: Gibt es neben dem Wörterverzeichnis im Wörterbuch weitere Teile? Wenn ja, um was für Teile handelt es sich? Was für Arten von lexikalischen Einheiten (qualitativer Aspekt) werden in welchem Umfang (quantitativer Aspekt) in das Wörterbuch aufgenommen? Nach welchem Prinzip werden die Lemmata im Wörterbuch angeordnet?

Um die Frage nach dem qualitativen Aspekt der Makrostruktur beantworten zu können, muß untersucht werden, welche Wortarten als Lemmata in ein Wörterbuch aufgenommen werden. Damit die wichtigsten Punkte bei der Frage nach der Lemmaqualität berücksichtigt werden, haben sich weniger theoretische Schriften zu diesem Thema (vgl. Swanson, 1962. 63-77), sondem vielmehr praktische Arbeitsinstruktionen als Hilfsmittel bewährt (vgl. Duda u. a., 1986, 47-53). Von besonderem Interesse wird sein, ob sich auf der qualitativen Ebene von Auflage zu Auflage ein Wandel vollzogen hat. Um diese Frage beantworten zu können, wurden jeweils die gleichen Teilabschnitte in den unterschiedlichen Auflagen untersucht.

Um den genauen Umfang eines Wörterbuches zu ermittein, gibt es außer dem sehr zeitintensiven und mühseligen Zählen der einzelnen Einheiten noch kein zuverlässiges Verfahren. Da aber von Hausmann $(1986,180)$ ein Verfahren entwickelt worden ist, mit dem der Umfang eines Wörterbuches zumindest annähernd genau ermittelt werden kann, wird auf das Zählen verzichtet. Nach der von Hausmann erarbeiteten Methode wird zunächst die Anzahl der Zeilen pro Spalte ermittelt. Danach wird die mittlere Anschlagszahl pro Spalte berechnet, wobei sowohl leere als auch gefülte Anschläge berücksichtigt werden. Im nächsten Schritt wird das Produkt aus Zeilenzahl, mittlerer Anschlagszahl und Anzahl der Spalten pro Seite gebildet. Multipliziert man dieses Ergebnis mit der Anzahl der Seiten des Wörterverzeichnisses, so erhält man den sog. theoretischen Werkinhalt (vgl. Hausmann, 1986, 180). Da diese theoretisch zur Verfügung stehende Spaltenfläche in den einzelnen Auflagen unterschiedlich intensiv ausgenutzt wird, muß das Ergebnis um einen geschätzten Ausnutzungsfaktor korrigiert werden, damit man den tatsächlichen geschätzten Werkinhalt erhält.

Es ist offensichtlich, daß dieses Verfahren Schwächen hat. Die erste Ungenauigkeit ergibt sich bereits bei der Ermittelung der mittleren Anschlagszahl, die allenfalls eine relative Größe darstellt. Ein weiteres Problem verbirgt sich hinter dem nur geschätzten und nicht etwa exakt berechneten Ausnutzungsfaktor. Da es die Methode aber mit relativ geringem Zeitaufwand ermöglicht, einen ungefăhren Eindruck vom quantitativen Umfang des jeweiligen Wörterbuches zu vermitteln, soll sie hier trotz ihrer Schwächen Anwendung finden.

Theoretische Grundlage für die Beantwortung der Frage nach den Anordnungskriterien der Lemmata im Wörterbuch ist die Klassifizierung von Wiegand (1989, 383-393). Wie- 
gand unterscheidet innerhalb der initialalphabetischen Ordnungsstruktur, die den meisten Wörterbüchern zugrundeliegt, zwei Arten von Makrostrukturen. Eine Makrostruktur heißt striktalphabetisch, „wenn alle Leitelementträger des Wörterbuches streng nach dem für dieses Wörterbuch festgelegten Zugriffsalphabet geordnet sind" (Wiegand, 1989, 383). Innerhalb der striktalphabetischen Makrostruktur muß man nun differenzieren zwischen den glattalphabetischen Makrostrukturen, bei denen jeder Textblock nur aus einem Lemma besteht, und den nischenalphabetischen Makrostrukturen, bei denen etymologisch zusammengehörige Lemmata - allerdings ohne die alphabetische Anordnung zu unterbrechen - in einem Textblock zusammengefaßt werden.

Wird bei der Zusammenfassung von Lemmata in einem Textblock die alphabetische Anordnungsstruktur wenigstens durch ein Sublemma unterbrochen, so liegt nunmehr die zweite Art von Makrostruktur vor, die von Wiegand als nestalphabetisch bezeichnet wird (vgl. Wiegand, 1989, 391).

Im folgenden soll untersucht werden, welche Art von Makrostruktur den unterschiedlichen Auflagen des russisch-deutschen Teils des Pawlowskyschen Wörterbuches zugrundeliegt.

\subsubsection{Die Makrostruktur der ersten Auflage des russisch-deutschen Wörterbuches}

\subsubsection{Der Aufbau des Wörterbuches}

Die 1859 in Riga erschienene erste Auflage des Vollständigen Russisch-Deutschen Wörterbuches von Iwan Pawtowsky wurde in zwei Teilbänden aufgelegt. Der erste Teilband enthält auf 376 Seiten das Wörterverzeichnis von A bis N. Der zweite Teilband umfaßt 470 Seiten. Im achtseitigen Vorspann des ersten Teilbandes befindet sich das von Pawlowsky verfaßte Vorwort (vgl. Pawlowsky, 1859, V-VI), in dem der Autor sich für die positiven Reaktionen auf den deutsch-russischen Teil des Wörterbuches bedankt und einige Hinweise zur Benutzung des Wörterbuches anführt.

Dem Vorwort folgt ein Abkürzungsverzeichnis, das 167 Eintragungen enthält (vgl. Pawlowsky, 1859, VII-VIII). Der größte Teil der Abkürzungen bezieht sich auf fachsprachliche Markierungen (vgl. 4.2.3.1, 104-105), die von „Accouch. bei den Geburtshelfern" über .Milit. im Militärwesen" bis zu "Zool. in der Zoologie" reichen. Außerdem finden sich dort Abkürzungen wie „augm. das Augmentativum”, „coll. das Collectivum”, „c. generis communis" und "inded. für indeclinabel", die den grammatischen Status der Lemmata näher charakterisieren (vgl. 4.2.2.1, 92-94). Der genaueren Beschreibung des regionalen bzw. sozialen Status eines Lemmas dienen die Abkürzungen .prov." für „provinziell“ ( $\mathrm{vgl}$. 4.2.3.5, 107) und .verächtl." für .verächtlich“ (vgl. 4.2.3.2. 105-106). 
Nach dem Abkürzungsverzeichnis findet sich ein nicht sehr umfangreiches Verzeichnis von Druckfehlern und Ergănzungen (vgl. Pawlowsky, 1859, VIII).

Die letzten vier Seiten des Vorspanns enthalten ein Verzeichnis der unregelmäßigen Verben des Deutschen (vgl. Pawlowsky, 1859, IX-XII). Bei den 211 aufgenommenen Verben werden neben dem Infinitiv die Präsensformen des Indikativs, die Imperfektformen des Indikativs und die des Konjunktivs sowie die Imperativform und das Partizip angeführt.

Der zweite Teilband enthält einen Nachspann, in dem auf sechs Seiten die gebräuchlichsten russischen Eigennamen und ihre deutschen Entsprechungen aufgeführt sind.

\subsubsection{Der qualitative Aspekt}

Um eine Aussage über die Qualität der aufgenommenen Lemmata treffen zu können, wurden 60 Seiten des insgesamt 846 Seiten umfassenden Wörterverzeichnisses ausgewertet. Im einzelnen handelt es sich hierbei um die acht Seiten umfassenden Eintragungen unter dem Buchstaben A, um die letzten zehn Seiten der Eintragungen des Buchstaben $\mathbf{B}$, um die ersten elf bzw. zehn Seiten unter den Buchstaben $M$ und $O$ sowie um 11 bzw. 10 Seiten unter den Buchstaben $\Pi$ und $C$. Insgesamt wurden 5.159 Lemmata berücksichtigt.

Mit Hilfe dieser Analyse soll zum einen aufgezeigt werden, welche Wortarten in welchem Umfang als Lemmata in das Wörterbuch aufgenommen wurden, zum anderen werden dadurch auch Besonderheiten der Lemmatisierung deutlich.

In den untersuchten Abschnitten bilden die Substantive mit 48,7\% die zahlenmäßig größte Klasse. Auffällig ist innerhalb dieser Gruppe die verhältnismäßig hohe Anzahl von substantivierten Verben. Auf deren Autnahme hätte Pawlowsky - wie er das bei den Adverbien getan hat (vgl. Pawlowsky, 1859, V) - verzichten können, da ihre Bedeutung durch die Aufnahme der entsprechenden Verben hinreichend deutlich gemacht worden ist.

Bsp.: Обвив аніе, s. n. das Umwinden, Umwickeln.

06 в ив а ть, о 6 в и ть, v. a. umwinden, umwickeln, umschlingen; [..].

Обвин еніе, s. n. die Beschuldigung. Anklage.

Обвин'ять, о 6 вин ить, v. a. beschuldigen, anklagen, Einen; [..].

О6вол акиваніе, s.n. das Beziehen, Ueberziehen.

О 6 вол акивать, о 6 вол'очь, v. a. beziehen, überziehen; [...].

Kritisch anzumerken ist außerdem, daß Pawlowsky jeweils nur die maskuline Form von substantivierten Adjektiven, die Personen bezeichnen, als Lemmata aufnimmt, obwohl er ansonsten bei Personenbezeichnungen auch die movierten Substantive als Lemmata ansetzt.

Bsp.: Бреж атый, aro (als Subst.) der Wächter. 
$M$ 'а л ой, aro (als Subst.) 1. der Diener, Bediente; 2. junger Mensch; [...].

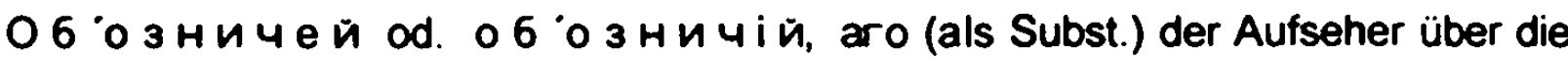
Fuhren, über einen Transport; der Wagenmeister.

По 6 ир чій, aro (als Subst. - sl.) der Zolleinnehmer.

Auffällig ist innerhalb dieser Klasse weiterhin, daß Pawlowsky zahlreiche Diminutive und in geringerer Zahl auch Augmentative als selbständige Lemmata berücksichtigt.

Bsp.: Aнекд о т ец ъ, тLа s. m. das Anekdötchen.

A 6 'у зище, s. m. augm. die große Arbuse.

G p юш ${ }^{\circ}$ '0, s. n. dim. kleiner Bauch.

Бутылища, s. f. augm. große Bouteille.

Малах айчик ъ, s. m. dim. kleine Pelzmütze mit Ohrklappen.

М ас т ер ищ е, s. m. augm. pop. ein großer Meister (in einer Sache).

$06 K^{\circ}$ о л о чек b, чka, s. m. dim. ein abgeschlagenes Stückchen.

06 op o 4k a, s. f. dim. schmaler (gefalteter) Besatz.

Als außerordentlich wichtig betrachtete Pawlowsky die Aufnahme von Lemmata aus unterschiedlichen Fachbereichen. Dies zeigt sich nicht nur an dem umfangreichen Abkürzungsverzeichnis (vgl. 3.2.2.1, 62-63), sondern es wird auch im Vorwort vom Verfasser betont: . [...] die gebräuchlichsten Ausdrücke aus dem Gebiet der Anatomie, der Botanik, der Jurisprudenz, der Medicin U. s. w. sind aufgenommen, [...]" (Pawlowsky, 1859, V).

Bsp. A 6 'ak a, s. f. (Archit.) die obere Säulenplatte.

A 6 p ик 'о с b, s. m. (Bot. armeniaca vulgaris) die Abrikose, Aprikose; der Aprikosenbaum.

Брюш ина, s. f. (Anat.) das Darm-, Bauchfell.

Б у у е ль, s. m. (Seew.) eiserner Reif, der Mastbaumring.

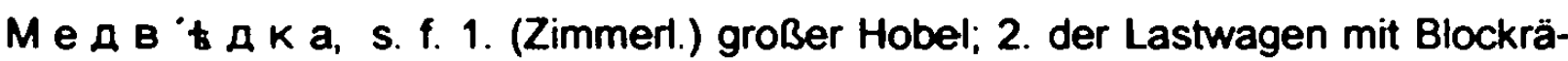
dem; 3. (Artill.) der Handprotzwagen; 4. (Bot. meum athamanticum) die Bärwurz, der Bärenfenchel; 5. (Zool.) s. Meдв ŁдоKъ.

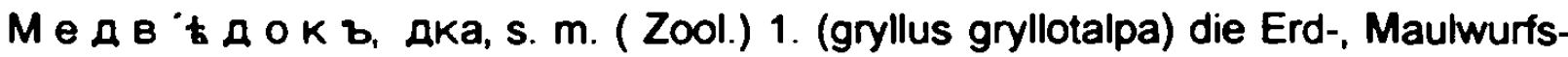
grille, Ackerwerre; 2. (mustalpinus) die Maulwurfsratte; 3. junger Biber (in Kamtschatka).

O 6 жиг 'альня, s. f. (Bergw.) die Röste, Röststätte.

С лё ток ъ, тка s. m. (Jäg.) junger Vogel, der noch nicht flügge ist; der Nestling. 
Mit $17,1 \%$ bilden die Adjektive die zweitgrößte Klasse innerhalb der untersuchten Abschnitte. Auffällig ist, daß Pawlowsky bei den endungsbetonten Adjektiven neben der Form mit -'on̆ auch immer die kirchenslavisch markierte Form mit -'bù angibt.

Bsp.: Б Б р щ е в 'о й, ('bй), 'ая, 'ое, adj. von Beten; [...].

Бр у с о в ой ('ьй), 'aя, 'oe, adj. vierkantig behauen; [...].

M а т е $p$ 'о й ('bu), 'ar, 'oe, adj. 1. außerordentlich groß, stark; [...]; 2. fest; [...].

M ах о в 'о й ('bй), 'aя, 'oe, adj. schwingend; [...].

Пл у т о вск'ой ("ï), 'ая, 'oe, adj. schelmisch; spitzbübisch; [...].

С к в о з н 'о й (' $\mathrm{\prime}$ ), 'ая, 'оe, adj. durch und durch gehend (von Rissen, Löchem); durchscheinend; durchsichtig; [...].

Ebenfalls nur mit der Markierung „adj." für Adjektive versehen sind die Kurzformen der Adjektive, die Pawlowsky als Lemmata aufgenommen hat.

Bsp.: 5 t лё хонекъ, Hoka, adjo, ganz weiß, schneeweiß.

Мал енекъ, Hoka, Ho, adj. etwas, ein wenig zu klein.

ח лох'OHek b, Hoka, Hoko, adj. ziemlich schlecht.

Ein Hinweis auf die Zielgnuppe, an die Pawlowsky bei seiner Arbeit gedacht hat, verbirgt sich hinter der Aufnahme von unregelmäßigen Komparativformen als selbständigen Lemmata. Hierdurch wird deutlich, daß sich Pawlowskys Wörterbuch an deutschsprachige Benutzer wendet, die nicht über die nötige Sprachkompetenz vertügen, um die dazugehörige Positivform zu bestimmen.

Bsp.: $\quad$ M е льч е, comp. feiner, kleiner; seichter, flacher.

M ен нш е, comp. weniger, kleiner, [...].

Пл о ше, comp. schlechter, schlimmer.

$\Pi л$ 'o щ e, comp. flacher.

Ck op ‘ e, comp. schneller, rascher, geschwinder, [...].

С л а щ е, comp. süßer, [...].

Die letzte große Gruppe in den untersuchten Abschnitten bilden mit 13,1\% Anteil die Verben. Eine Besonderheit dieser Gruppe ist, daß die aspektpaarigen Verben jeweils in einem Eintrag zusammengefaßt wurden (vgl. 3.2.2.4, 70-71). Großen Wert legte Pawlowsky auf die Aufnahme von präfigierten Verben. Dies zeigt sich daran, daß in den dafür in Frage kommenden ausgewerteten Abschnitten die Zahl der Verben diejenige der Adjektive übertrift.

Bsp.: О 6 в ар ив ат ь, о 6 в ар и ть, v. a. 1. abbrühen; [...]; 2. (Schuhm.) bepichen (den Faden, Draht); [...]. 
О 6 в ив ать, о в в ить, v. a. umwinden, umwickeln, umschlingen; [...].

06 воз ить, обвест' $и, v$. a. führen, fahren, um etwas, auf Umwegen.

О 6 д умывать, обд ум тьт, v. a. überdenken, -legen; bedenken.

ח $о 6$ ир $а$ т men, wegnehmen; [...].

П о 6 олт 'а ть, (voll.) 1. v. a. etwas, ein wenig umrühren (eine Flüssigkeit); 2. v. n. etwas plaudern, mit Jmd.

Под 6 алтывать, под 6 олтаты, $а$ с. a. einschlagen, einrühren (z. B. Mehl in eine Speise), hinzurühren, -mengen, -klopfen; [...].

Подвив ать, под в ить, v. a. aufrollen; aufwickeln (die Haare); [...].

Weitere im Wörterbuch repräsentierte Wortarten sind Adverben, Interjektionen, Konjunktionen, Präpositionen, Numeralia und Partikeln. Diese Aufzählung ist nach der abnehmenden Häufigkeit in den untersuchten Abschnitten geordnet. Da diese Klassen zahlenmäßig relativ gering vertreten sind, mag ein Beispiel pro Gruppe genügen.

Bsp.: 'A щ e, conj. (sl.) wenn; 'aue su wenn aber.

G b eine Partikel, die mit dem Präteritum des Indicativs den sogenannten Conjunctiv anderer Sprachen bezeichnet, z. В. зналь бы Я (od. 'еслм бы я знат), 4ro - würde ich wissen, wenn ich wüßte, wenn ich gewußt hätte, daß -; [...].

Б t $r$ л 0 , adv. 1. schnell, geläufig (z. B. lesen); 2. flüchtig, oberflächlich.

O, interj. o! ach!

О 6 ан а д е с я т b, num. ( sl.) zwölf.

חo, praep. auf, zu, bis, bis an, bis nach, bis über etc. [...].

Neben diesen, einzelnen Wortarten zuordenbaren Lemmata wurden durch die Analyse weitere Besonderheiten in der Makrostruktur des Wörterbuches aufgedeckt, die im folgenden beschrieben werden sollen. Sehr häufig greift Pawlowsky auf das Verweislemma als Hilfsmittel zurück, wobei alle Wortarten in dieser Eigenschaft angesetzt werden können. Einzig als Verweislemmata aufgenommen werden synonyme Formen bereits lemmatisierter Einheiten, nämlich perfektive Verbformen, aber auch orthographische und morphologische Varianten bereits berücksichtigter Lemmata.

Bsp.: Автократъ, s. Cамод ержецъ.

Акил ей, s. Акліей.

A p $x$ ив a, s. f. s Apхивb.

Бо с о й, s. Босон огіи; на 6 осу ногу auf bloßem Fuß. 
Булев 'ар в, s. Бульв'аръ.

Маж орный, s. дурныи.

О 6 ве з т и (voll.), s. unt. О6воз'ить.

О 6 в ор ов а т ь (voll.), s. unt. O6вор'овывать.

По6о 'я р ски, s. По6'арски.

Пов 'а А и ть, ся (voll.), s. unt. Пов'анызать.

Schon in seiner Einleitung betont Pawlowsky, daß es sein Ziel gewesen sei, „die üblichsten Russischen Sprüchwörter [...] und die besonderen Russischen Redensarten" (Pawlowsky, 1859, VI) in sein Wörterbuch aufzunehmen. Daß inm dies in der Tat gelungen ist, zeigen folgende Beispiele.

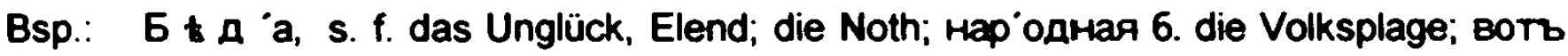

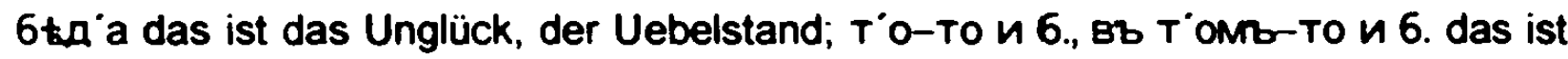

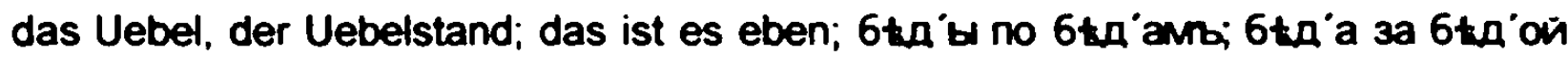
Unglück über Unglück; 6Łд'а да и т'олько ein wahres Unglück, Uebel; 'это ещё He 6. das ist noch kein Unglück; das hat noch nichts zu sagen; что за 6.? was hat es zu sagen? was denn? 6. Te6 $t$, ecrm - wehe Dir, wenn -; non'actb въ 6ta'y in's Unglück, in die Enge gerathen; случ'илось на 6tда, что - zum Unglück traf es sich, daß -; далёко лм до 6 бд'ы wie leicht kann nicht ein Unglück geschehen,

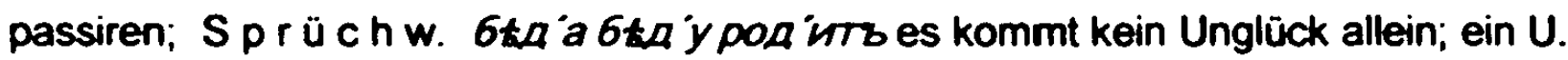

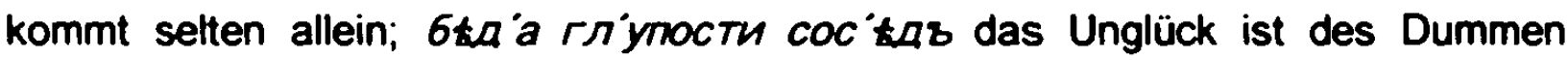
Nachbar, Bb 6ta't Богъ недалёкъ wenn die Noth am größten ist, ist Gott am

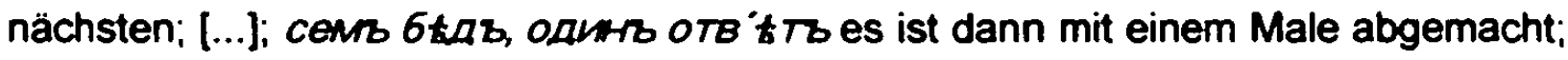
es geht alles auf eine Rechnung; es mag nun gehen wie es wolle; pop. es ist ein Auswisch.

В о л к в, s. m. (Zool. canis lupus) der Wolf; морск' oñ B. (anarrchias lupus) der

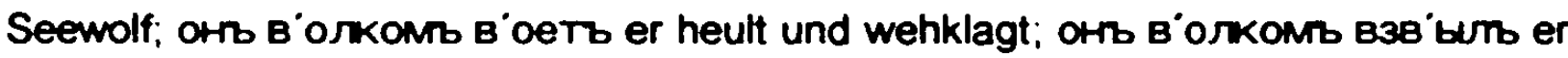
fing laut zu heulen an; вct er'o зн аютъ, какъ c'tparo в'олка (Sprüchw.) er ist bekannt, wie ein bunter Hund; чтобъ те6'я в олки съ' $љ л$ (Sprüchw.) daß dich der Tausend! hol' dich der Kuckuck! чтобъ в'олки 6' ыли с'ыты и 'овиы ц' тлы (Sprüchw.) so daß Niemand zu Schaden komme; so daß Jeder zufrieden gestellt werde; so daß die Kirche immer mitten im Dorfe bleibe; Sprüchw. Cb волк'amn

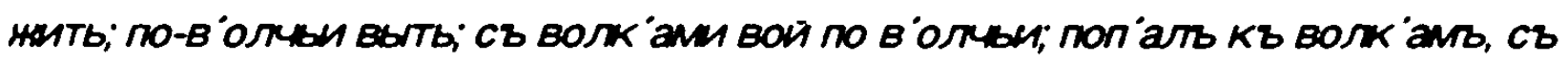

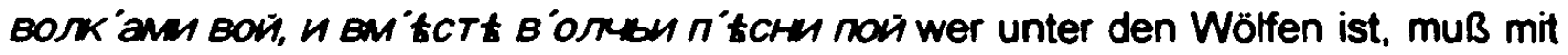


den Wölfen heulen; ск'олько в олка ни корм'и, а онв всё въ льсь глая итъ;

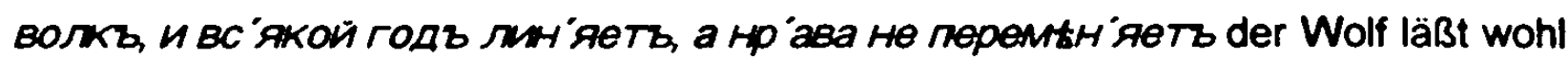
seine Haare, aber nicht seine Nicken (Mucken); der Wolf ändert wohl das Haar, sonst bleibt er, wie er war; в'олка $60^{\circ}$ яться, въ $\Omega$ tссь не ход ить wer Honig haben will, muß den Stachel der Bienen nicht scheuen; [...].

Als weitere Besonderheit, die nicht direkt mit einer Wortart verbunden ist, muß hier die Lemmatisienung von Lexik aus der Umgangssprache und den Dialekten genannt werden. Außerdem war es Pawlowsky wichtig, genetisch kirchenslavische Lexeme als Lemmata in sein Wörterbuch aufzunehmen.

Bsp.: AH b, conj. pop. aber.

A p 6 'a, s. f. (in Astrachan u. Krimm) der zweiräderige Wagen.

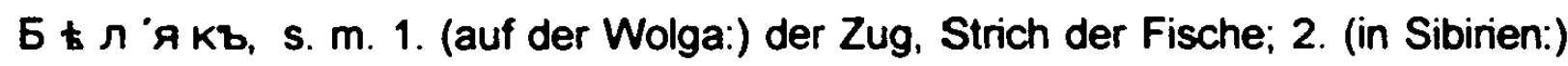
außerordentliche Abgabe an Pelzwerk; [...].

M akc a, s. f. prov. die Fischleber.

Ман ис та, s. f. (bei den Fischem auf der Wolga:) die Kinnlade vom Stör oder von der Beluga.

По 6 ' жник в, s.m. (bei den Kamtschadalen:) ein langer Riemen am Schlitten befestigt, der anstatt der Deichsel beim Fahren mit Hunden dient.

CK o p o M b, s. f. pop. 1. die an Festtagen verbotene Speise; 2. unzüchtige Reden.

Алк'аніе, s. n. (sl.) yer'o, die Gier, heißes Verlangen nach etwas.

M е двеный, ая, ое (sl.) honigsüß.

О 6 онп о лъ, adj. (sl.) jenseits.

Повинов ати, повин уути, v. а. (sl.) zum Gehorsam bringen.

Сл аный, ая, oe, adj. (sl.) salzig; [...].

Die Aufnahme von Kulturwörtern, die dem deutschen Benutzer fremd sein mußten, kann als weiteres Indiz dafür gedeutet werden, daß sich Pawlowsky bei der Auswahl der Lemmata an dem deutschen Muttersprachler orientierte.

Bsp.: Арт е ль, s. f. die Artel, Gesellschaft (von Arbeitern, Handwerkern, niedern Militärs etc., die zusammen leben und einen gemeinschaftlichen Tisch führen).

Б у жен иц а, s. f. gebackener Schweineschinken, mit Zwiebel od. Knoblauch zugerichtet. 
По 6 л ю дный, ая, ое adj. was unter eine Schüssel gelegt wird; [...]; n-ыя n' tсым (bei gemeinen Russen:) Lieder, die zwischen Weihnachten und dem Feste der heiligen drei Könige in Gesellschaften junger Mädchen gesungen werden.

Сл'авильщикъ, s. m. (Einer, der zur Weihnachtszeit in den Häusern geistliche Lieder zu Ehren der Geburt Christi absingt:) der Weihnachtssänger; (etwa wie bei den Katholiken:) der Currendaner, Lauf-, Straßensänger.

Zum Schluß muß noch die Frage geklärt werden, wie Pawlowsky homographe Wortformen behandelt. In den untersuchten Abschnitten kommen nur homographe Verbformen vor, die doppelt lemmatisiert und mit römischen Ziffern gekennzeichnet werden.

Bsp.: I. О в в а ливать, обв а л и ть, v. a. 1. umwerfen, umstoßen; 2. bewerfen, etwas (mit Erde, Steinen); [...].

II. О6в аливать, о6вал'я ть, v. a. einrollen (den Teig in Mehl); [...].

I. П о в а жи в а т b, v. a. dann und wann herumführen, Einen (z. B. an der Hand).

II. Пов а а ив а т

III. Пов аживать, пов адить, v. a. gewöhnen, angewöhnen; [...].

\subsubsection{Der quantitative Aspekt}

Ziel dieses Abschnittes ist es, auf der Grundlage des von Hausmann entwickelten Verfahrens den Umfang des Inhalts der ersten Auflage des russisch-deutschen Wörterbuches von Pawlowsky zu schätzen (vgl. 3.2.1, 61). Da diese Schätzung allein noch nichts über die Anzahl der lemmatisierten Einheiten aussagt. wird, um diesen Punkt zu klären, auf die Sekundärliteratur zurückgegriffen.

Um einen Wert für die mittlere Anschlagszahl pro Spalte zu erhalten, wurden in einem ersten Schritt jeweils die zehn ersten und die zehn letzten Zeilen auf fünf Seiten ausgezählt. In einem zweiten Schritt wurden die Zeilen pro Spalte auf den eben genannten Seiten ermittelt. Die mittlere Anschlagszahl pro Zeile liegt der Zählung zufolge bei 53 Anschlägen. Das heißt, daß bei 74 Zeilen pro Spalte ein geschätzter Spalteninhalt von 3.922 Anschlägen angenommen werden kann. Da jede Seite jeweils zwei Spalten enthält, ergibt sich ein geschätzter Seiteninhalt von 7.844 Anschlägen. Bei einem Wörterverzeichnis, das sich auf 846 Seiten erstreckt, bedeutet dies einen theoretischen Werkinhalt von 6.636 .024 Anschlägen. Als Ausnutzungsfaktor wird hier 0,6 angesetzt, da durch den gespertten Druck der Lemmata und durch die glattalphabetische Alphabetisierung (vgl. 3.2.2.4. 70) relativ viel Raum ungenutzt bleibt. Der relativ geringe Ausnutzungsfaktor von 0,6 wird auch 
dadurch gerechtfertigt, daß zwei der ausgezählten Spalten nur 73 anstelle der ansonsten 74 Zeilen enthalten.

Bereinigt man nun den theoretischen Werkinhalt um den Ausnutzungsfaktor, so erhält man den geschätzten tatsächlichen Werkinhalt des Wörterbuches, der in diesem Fall bei 3.981.614 Anschlägen liegt.

Diese Zahl sagt zwar nichts über die Anzahl der Lemmata im betreffenden Wörterbuch aus, aber es ist nun möglich, den Werkinhalt der ersten Auflage mit demjenigen der zweiten und der dritten Auflage zu vergleichen.

Um eine Aussage über die Anzahl der Lemmata treffen zu können, muß auf die Sekundärliteratur zurückgegriffen werden. In der Bibliographie von Vinogradov $(1954,102)$ finden sich unterschiedliche Angaben zum Lemmaumfang der ersten Auflage des russischdeutschen Wörterbuches. Unter der Ziffer 381 werden fast 60.000 Lemmata veranschlagt, unter der Ziffer 382 dagegen nur knapp 38.000! Berücksichtigt man nun, daß auf den 60 Seiten, die in der Stichprobe ausgewertet wurden, 5.159 Lemmata gezählt wurden, so ergibt sich daraus eine hochgerechnete Lemmazahl von 72.756 Einheiten.

Als Konsequenz daraus ergibt sich, daß die zweite Zahl von Vinogradov als zu niedrig ausgeschlossen werden kann. Auf der Grundlage der ersten bei Vinogradov angegebenen Zahl von ca. 60.000 Lemmata und der hochgerechneten Zahl von ca. 73.000 scheint es realistisch, von einem Umfang von 60.000 bis 70.000 Lemmata in der ersten Auflage des russisch-deutschen Wörterbuches auszugehen.

\subsubsection{Das Anordnungsprinzip}

In der ersten Auflage des russisch-deutschen Wörterbuches liegt prinzipiell eine glattalphabetische Anordnung vor, was bedeutet, daß ein Textblock zumeist aus einem Lemma besteht, das typographisch durch Sperrung und durch Einzug nach rechts hervorgehoben wird.

Bsp:: О 6 м'аниивость, s. f. die Täuschung.

О 6 м анчивый, ая, oe, adj. trügerisch, täuschend, illusorisch; $[\ldots]$.

О 6 м анщикъ, s. m. der Betrüger.

О 6 м анщица, s. f. die Betrügerin.

Dieses Anordnungsprinzip wird allerdings in unterschiedlichen Fällen durchbrochen. Mit didaktıschen Gründen läßt sich erklären, daß die aspektpaarigen Verben jeweils unter dem imperfektiven Verb zusammengefaßt werden, denn ihre Trennung ist nicht sinnvoll. Selbstverständlich hat Pawlowsky nicht darauf verzichtet, falls dies nötig war, an den vom Alphabetisierungsprinzip vorgeschriebenen Stellen die jeweils andere Verbform als Verweislemma aufzunehmen. 
Bsp.: О

O $6 \mathrm{M}^{\circ}$ о ч в с я (voll.), s. unt. O6mor'atbcя.

С лег 'a т b, с ле ч b, v. $n$. bettlägerig sein; krank befallen.

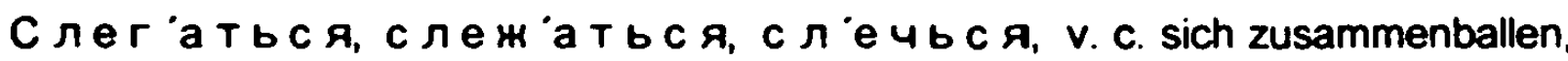
unbrauchbar werden, durch langes Liegen (wie z. B. das Mehl); sich vertiegen.

С ле чь, ся (voll.), s. unt. Cлer'atb, ся.

Ebenfalls jeweils in einem Eintrag zusammengefaßt werden orthographische, morphologische und akzentologische Varianten eines Lemmas. Da die glattalphabetische Anordnung mit dem in einem Wörterbuch nur begrenzt zur Verfügung stehenden Raum verschwenderisch umgeht, spart Pawlowsky durch diese Lemmatisierungsmethode ein wenig Platz ein. Allerdings gilt dies nur dann, wenn die Variante der gleichen Wortart angehört und ihre Aufnahme nicht mit der alphabetischen Reihenfolge kollidiert. Ist dies der Fall, so greift Pawlowsky auf das Hilfsmittel des Verweises zurück.

Bsp.: Авд о т ка, ав д о т в schnepfe.

Aнгелом удренный, - у удрый, ая, ое, adj. (sl.) mit Engetweisheit begabt.

Бр атовщина, 6 рат овщина, s. f. pop. 1. die Collecte; 2. die Brüderschaft.

$5^{\prime}$ у д т 0, 6 ' у д т о 6 d, conj. als ob, als wenn.

малов одіе, малов одье, s. п. малов одность, s. f. der Wassermangel.

Mан 'a, M'a

Da bei einer glattalphabetischen Anordnung der Lemmata zwischen einer artikelalphabetischen und einer itemalphabetischen Anordnung gewähtt werden kann (vgl. Hausmann, 1991, 2748), muß an dieser Stelle eine weitere Differenzierung vorgenommen werden. Wird für jede Einheit ein selbständiger Eintrag angesetzt, so spricht man von einer itemalphabetischen Anordnung. Dieses Prinzip liegt vor allem Fachwörterbüchern zugrunde. Enthält ein Wörterbuchartikel zusätzlich noch Mehr-Wort-Einheiten, sog. infralemmatische Adressen (vgl. Hausmann, 1991, 2731), so spricht man von einer artikelalphabetischen Anordnung. Pawlowsky folgt letzterem Prinzip, da er neben phraseologischen Einheiten auch Kollokationen und Wortverbindungen als infralemmatische Adressen aufnimmt.

Bsp.: Бе з вим Янный, ая, ое adj. ungenannt, namenlos; 6-oe rucbмio der anonyme Brief; 6-ая нед ' , Goldfinger; [...]. 
В о з лаг'ать, воз лож 'ить, v. а. что на ког'0-либо auferiegen, auftragen. Einem etwas; übertragen (ein Amt); в. на ког' о-либо поруч 'енie Einem einen Auftrag ertheilen, etwas auftragen; Einen mit etwas beauftragen; B. p'yky на се6 9 Hand an sich legen; в. Btн ецъ на глав'y die Krone aufsetzen; в. над ежду (od.

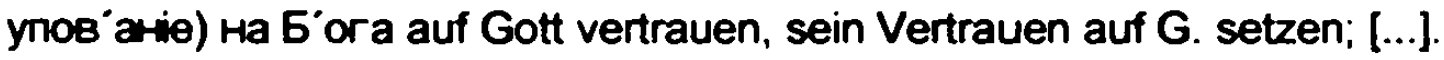

M o p e, s. n. das Meer, die See; Kacn ickoe M. die kaspische See; Балт "iйckoe M. das baltische Meer; die Ostsee; Чëpнoe M. das sctwarze Meer, отKр brtoe M. die offene See; M'ope $6 t_{n z}$ Unglück über Unglück; $3^{\circ}$ a mope (pop.) in's Ausland; in's fremde Land; no' tхать н'а море кyn'atbcя zum Seebad reisen; (Sprüchw.) y

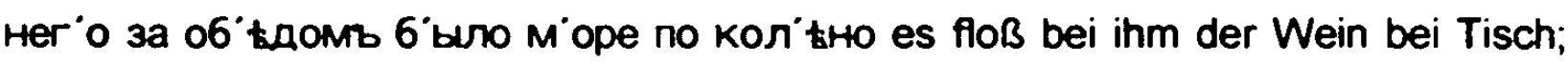
no'samy и м'ope no кол'tнto der Betrunkene kennt keine Gefahr; cha'tть у м оря и ждать пог'оды auf eine günstige Gelegenheit warten.

Allerdings verfährt Pawtowsky in diesem Punkt nicht einheitlich, denn einige Mehr-WortEinheiten werden als selbständige Lemmata aufgenommen.

Bsp.: Александр ійская 6 ум ат a das Regal-, Royalpapier.

Александр ійскій куст в (Bot. cassia senna) der Sennesblätterstrauch, Sennesbaum.

Маці альныя в оды eisenhaltige Quellen, Brunnen.

Скотопригоннний дорв der Viehhof, -markt.

\subsubsection{Die Makrostruktur der zweiten Auflage des russisch-deutschen Wörterbuches}

\subsubsection{Der Aufbau des Wörterbuches}

Die zweite Auflage des russisch-deutschen Wörterbuches von Pawlowsky erschien im Jahr 1879. Der bereits aus der ersten Auflage bekannte Titel I. Pawlowsky's RussischDeutsches Wörterbuch wurde mit dem Zusatz 2. Auflage, vollständig umgearbeitet und wesentlich vermehrt von I. Nikolitsch und $N$. Asmuß versehen. Erschienen ist diese Auflage in einem Band in Riga und Leipzig bei $N$. Kymmel und C. F. Fleischer. Sie umfaßt XII+1340 Seiten, was ungefähr einer Verdoppelung der Seitenzahl im Vergleich mit der ersten Auflage entspricht. Im Vorspann des Wörterbuches folgen dem sowohl in russischer als auch in deutscher Sprache abgedruckten Vorwort (vgl. Pawlowsky, 1879, III-IV) ebenfalls in beiden Sprachen verfaßte allgemeine Bemerkungen (vgl. Pawlowsky, 1879, V), die Hinweise zur Benutzung des Wörterbuches liefern. Im Anschluß daran werden die von Nikolič benutzten Abkürzungen erläutert, die sich auf den grammatischen Status der Lemmata sowie auf deren Markiertheit beziehen (vgl. Pawlowsky, 1879, V). Eine eigene Rubrik ist 
den Abkürzungen für die unterschiedlichen Fachbereiche gewidmet; sie umfaßt 161 Eintragungen (vgl. Pawlowsky, 1879, V).

Neben dem Verzeichnis der unregelmäßigen Verben des Deutschen (vgl. Pawlowsky, 1879, VIII-XII), das bereits in der ersten Auflage des Wörterbuches enthalten ist, hat Nikolič zusätzlich noch ein Schema aufgenommen, das bei der Konjugation der russischen Verben behilflich sein soll (vgl. Pawlowsky, 1879, VII). In dem ersten Teil des "Paradigma[s] für die Conjugation der russischen Zeitwörter" (Pawlowsky, 1879, VII) wird die regelmäßige Formenbildung derjenigen Verben erläutert, die den fünf produktiven Verbalklassen zuzurechnen sind. Abweichend von der heute üblichen Einteilung (vgl. Mulisch, 1993, 103), faßt Nikolič die Verben mit Infinitivstämmen auf -at', -jat' bzw. et' allerdings nicht als zwei, sondern nur als eine Klasse auf. Zusätzlich zu diesen allgemeinen Konjugationsregeln findet sich daran anschließend eine 31 Verben umfassende Konjugationstabelle der unregelmäBigen Verben.

Auf den in der ersten Auflage enthattenen Nachspann mit den gebräuchlichsten russischen Eigennamen hat Nikolič verzichtet, da er dessen Inhalt in das laufende Wörterverzeichnis eingegliedert hat.

\subsubsection{Der qualitative Aspekt}

Da es ein Ziel dieses Kapitels ist, eine Aussage über die Unterschiede in der Makrostruktur zwischen den unterschiedlichen Auflagen zu treffen, wurden in der zweiten Auflage die gleichen Abschnitte wie in der ersten Auflage ausgewertet. Es handelt sich hierbei um sämtliche Eintragungen unter dem Buchstaben $A$, die 14 Seiten umfassen. Des weiteren wurden 17 Seiten der Eintragungen unter den Buchstaben $\bar{B}$ und $\Pi$ analysiert. Außerdem wurden 20 bzw. 21 Seiten unter den Buchstaben $M$ und $O$ betrachtet sowie abschließend 15 Seiten der Eintragungen unter C. Insgesamt wurden 11.015 Lemmata auf 104 Seiten des 1340 Seiten starken Wörterverzeichnisses ausgewertet.

Vergleicht man die Anzahl der einzelnen Wortarten auf der quantitativen Ebene, so sind zwischen den einzelnen Auflagen nur kleine Unterschiede festzustellen. Auch in der zweiten Auflage bilden die Substantive mit 50,14\% innerhalb der ausgewerteten Seiten die zahlenmäßig stärkste Gruppe. Mit 18\% Anteil an der Menge der insgesamt ausgewerteten Lemmata sind die Verben die zweitstärkste Gruppe innerhalb der zweiten Auflage. gefolgt von den Adjektiven, die in der ersten Auflage noch die zweite Position eingenommen haben. Anteilsmäßig nahezu unverändert bleiben Adverben, Konjunktionen, Präpositionen, Numeralia und Partikeln. Im Gegensatz zur Analyse der Abschnitte der ersten Auflage wird im folgenden darauf verzichtet, für jede Wortart Beispiele anzuführen. Kommentiert und mit 
Beispielen versehen werden natürlich alle Veränderungen, die der Arbeit Nikoličs zu verdanken sind.

Geht man über die rein quantitative Ebene hinaus, so ist zu konstatieren, daß Nikolič auf der qualitativen Ebene interessante Neuerungen eingeführt hat. So hat er nicht nur die bei Pawlowsky in den Nachspann ausgegliederten Personennamen jeweils an entsprechender Stelle lemmatisiert, sondern auch Toponymika und ihre Ableitungen sowie Namen berühmter Personen neu in das Wörterbuch aufgenommen.

Bsp.: Aдpu arbs s. m. Adrian, Hadrian; Honoro Adrianopel.

A'ctpaxarb s. f. Astrachan; HeLı s.m. der Astrachaner, tha s. f. die A-in; HCKin adj. astrachanisch; [...].

Бріоселецъ, лын s. m. der Brüsseler, -ланақа s.f. die Brüsselerin; -ль s. m. Brüssel.

Б' „лая rop'a der Montblanc.

М'икель-Аінджело s. m. ind. Michel-Angelo.

Скандин авецъ, вua s. m. der Scandinavier; вiя s. f. Scandinavien; die Scandinavierin; -вскій adj. scandinavisch.

Dem Prinzip Pawlowskys, ein Wörterbuch zu schaffen, das möglichst vollständig sein und auch bei zahlreichen fachsprachlichen Begriffen als Hilfsmittel dienen können soll, ist Nikolič bei der Überarbeitung des Werkes seines Onkels getreulich gefolgt. Als Konsequenz aus dieser Haltung hat Nikolič die Zahl der aus den unterschiedlichen Fachbereichen stammenden Lemmata noch einmal deutlich erhöht. Neu in das Abkürzungsverzeichnis aufgenommen hat er mit "Theat." und "Versl." diejenigen Abkürzungen, die bereits von Pawlowsky verwendet wurden, aber nicht in dessen Abkürzungsverzeichnis auftauchen. Außerdem trug er mit ganz neu berücksichtigten Abkürzungen wie „Bchschm." und .Dampfm." der technischen und wissenschaftlichen Weiterentwicklung Rechnung. Da Nikolič insbesondere die Zahl der Fachtermini aus dem Bereich der Schiff- und Seefahrt eventuell eine Reaktion auf die kritische Rezension im Morskoj Sbomik (vgl. Slovar', 1859, o. S.) - und der Botanik überproportional erhöht hat, werden einige von ihnen im folgenden als Beispiele angeführt.

Bsp. A'6Hя s. f. (Schifff.) das Spill, die Winde.

Брекв'атеръ s. m. (Schifff.) der Wellenbrecher, Hafendamm.

Мант 'ылы. л'я s. m. (Seew.) der Hänger, Schenkel; -т’arm pl. s. m. (Seew.) die Wanttaue, Wanttaljen. 
Плот'икъ, K’a s. m. (Bot. Linaria vulgaris) das Leinkraut, der Frauen-, Marienflachs, das Löwenmaul.

Cкорода, -д 'urka s. f. 1. prov. die Egge; 2. (Bot. Allium paniculatum) der Lauch; (A. schoenoprasum) Fleisch-, Johannis-. Schnittlauch; [...].

Da sich die Zahl der Verben nur quantitativ erhöht hat, ohne daß auf der qualitativen Ebene Veränderungen vorgenommen worden sind, werden hier keine weiteren Beispiele angeführt. Dies gilt ebenso für Adverten, Interjektionen, Präpositionen, Numeralia und Partikeln. Nur eingeschränkt trifft diese Aussage auch auf die Adjektive zu, bei denen Nikolič aus Platzgründen auf die Angabe der femininen und der neutralen Form verzichtet hat.

Deutlich reduziert hat Nikolič im Vergleich mit der ersten Auflage die Zahl der Verweislemmata. Dadurch erhöht er die Benutzerfreundlichkeit erheblich, da das Nachschlagen unter mehreren Stichwörtern in den meisten Fällen entfällt. Wie schon in der ersten Aufiage, so erhalten insbesondere synonyme Formen bereits lemmatisierter Einheiten und orthographische oder morphologische Varianten jeweils den Status von Verweislemmata. Eine neue Gruppe von Verweislemmata bilden unregelmäßig konjugierte und deklinierte Wortformen, die darauf hinweisen, daß auch in der zweiten Auflage die Zielgruppe des Wörterbuches deutsche Muttersprachler sind.

Bsp.: Броатья plur. zu 6ратъ.

O6вис 'ать v. n. [...]; -вись praet. von 06в иснуть; [...].

חraw'y praes. von rugc'atb.

Cклио io fut. von склев atb.

Dem Prinzip, umgangssprachliche und dialektale Lexeme, genetische Kirchenslavismen und Phraseologismen in das Wörterbuch aufzunehmen, ist Nikolič treu geblieben, der auch auf diesen Gebieten die Zahl der Einträge wesentlich erhöht hat. Beispielhaft angeführt wird hier die Gruppe von neu berücksichtigten Lemmata, die die im Volk üblichen Tagesbezeichnungen benennt.

Bsp:: Asa otbn-mari intoвkn die Himbeem-Awdotja, pop. Name des 4. August; a-bnnrou иxи die (Schnee) plättende Awdotja, pop. Name des 1. März; [...].

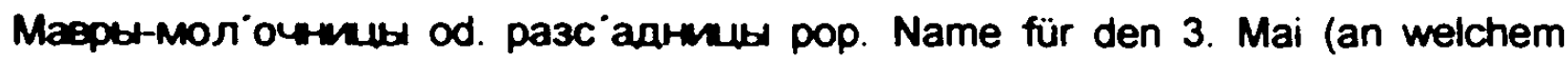
Tage die jungen Kohlpflanzen in die Beete verpflanzt werden und die Bauer [n. sic, C. B.] zum ersten Mal Milchgries essen).

Auch die Zahl der Kulturwörter, die in einem zweisprachigen Wörterbuch von enormer Bedeutung sind, da sie dem fremdsprachigen Benutzer normalerweise nicht geläufig sein können, wurde in der zweiten Auflage deutlich erhöht. Dies deutet ein weiteres Mal darauf 
hin, daß auch die überarbeitete Fassung sich vorrangig an deutschsprachige Benutzer wendet.

Bsp.: Apxиrinro s. m. das Wunderkraut, eine fabelhafte Pflanze, die, in der Johannisnacht gepflückt, verschiedene Krankheiten heilen soll.

Брод ильиинъ s. m. (in Kamtschatka Einer, der den Weg für die Zobelfänger bahnt) der Pfadfinder; (im innem Rußland Einer, der die Heuschläge nach seinem Augenma $B$ in gleiche Parzellen theit).

Mewnn'apse s. n. die Zeit zwischen dem Schluß der Saatzeit und dem Beginn der Heuernte (vom 15. Mai bis zum 15. Juni, wo die Bauern gewöhnlich weniger beschäftigt sind und Dünger auf die Brachfelder zu führen pflegen), die Zeit des Düngens; der Mist-, Brachmonat; [...].

Eine weitere von Nikolič eingeführte Neuerung betrifft die Buchstaben des russischen Alphabets, die als eigenständige Lemmata in die zweite Auflage des russisch-deutschen Wörterbuches aufgenommen wurden.

Bsp.: $M, M$ dreizehnter Buchstabe des russischen Alphabets, dem deutschen $m$ gleich.

0,0 , fünfzehnter Buchstabe des russischen Alphabets, in der gewöhnlichen Sprache dem deutschen o gleich, dialectisch aber mehr in den A-laut übergehend.[...].

Ebenfalls selbständigen Lemmastatus gewährt Nikolič einigen wortbildenden Morphemen, wobei neben deren Bedeutung auch die Verwendung erläutert wird.

Bsp.: 0, 06-, 06ъ-, (in Zusammensetzungen) entspricht im Deutschen 1. der untrennba-

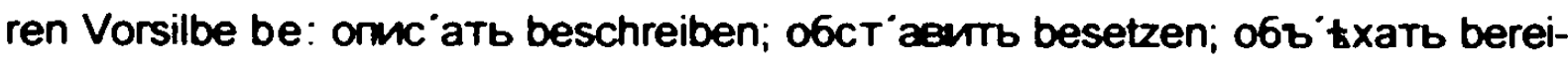
sen; 2. den Präpositionen u m, ü b e r, a n: окружить umkreisen; окр'асить anstreichen.

Пo (in Zusammensetzungen:) 1. mit Zeitwörtern bezeichnet a. eine vorübergehende oder nur kurze Zeit dauernde Handlung: под умать ein wenig nachgedacht haben; norул' ять eine Weile spazieren gegangen sein; $b$. eine Wiederholung der Handlung (in Verbindung mit Iterativformen auf ввать): погл ядывать hin und her sehen; c. eine Vollendung der Handlung (am häufigsten): nостр' оить aufgebaut haben; 2. mit Comparativen in der prädikativen Form entspricht no dem Deutschen „etwas" vor den Comparativen; no robu'te etwas geschickter; no yM- te etwas klüger. NB. Alle mit no verbundenen Zeitwörter, welche in Folgendem nicht aufgenommen sein sollten, sind als Ausdrucksformen einer vollendeten Handlung der ihnen entsprechenden einfachen, $d$. $h$. ohne Präposition no vorkommenden Zeitwörter anzusehen. 
Mit der Aufnahme dieser Morpheme war Nikolic seiner Zeit weit voraus, empfehlen doch theoretische Arbeiten über die Lexikographie ( $\mathrm{vgl}$. Kromann/Riiber/Rosbach, 1984, 219221: Bergenholtz/Mugdan, 1982, 31-32) erst seit kürzester Zeit die Lemmatisierung derartiger Wortbildungsmorpheme. Ihre Aufnahme und Erklärung macht genau dann die Lemmatisierung der unzähligen Ableitungen überflüssig, wenn die Verwendung für die anvisierte Zielgruppe - was in diesem Fall der deutsche Muttersprachler ist - transparent wird.

Durch die eben angeführten Beispiele konnte deutlich gemacht werden, daß sich Nikolič bei der Überarbeitung des Wörterbuches nicht nur darauf beschränkt hat, die Anzahl der Lemmata zu erhöhen, sondern daß er auch bemüht war, auf der qualitativen Ebene Verbesserungen vorzunehmen, um den Wert des Wörterbuches für den Nutzer zu steigern.

\subsubsection{Der quantitative Aspekt}

Um die erforderlichen Daten zur Schätzung des Wörterbuchinhaltes nach Hausmann zu erhalten, wurden - wie schon in der ersten Auflage - fünf Seiten ausgewertet. In der zweiten Auflage besteht eine Spalte aus jeweils 74 Zeilen. Da jede Seite jeweils zwei Spalten enthält und jede Zeile einer Spalte aus durchschnittlich 53 Anschlägen besteht, ergibt sich für die zweite Auflage ein geschätzter Seiteninhalt von 7.844 Anschlägen. Multipliziert man diese Zahl nun mit der Seitenzahl von 1340 Seiten, so erhält man den theoretischen Werkinhalt der zweiten Auflage des russisch-deutschen Wörterbuches von Pawlowsky, der 10.510.960 Anschläge beträgt.

Da Nikolič durch das neue Anordnungsprinzip (vgl. 3.2.3.4, 78-80) den zur Verfügung stehenden Raum weit effektiver als sein Vorgänger nutzt, wird der geschätzte Ausnutzungsfaktor mit 0.8 deutlich höher als in der ersten Auflage bewertet. Korrigiert man nun den theoretischen Werkinhalt um eben jenen Faktor, so ergibt sich ein geschätzter tatsächlicher Werkinhalt von 8.408.768 Anschlägen. Dies entspricht ungefähr einer Verdoppelung des Werkinhaltes gegenüber der ersten Auflage (vgl. 3.2.2.3. 70).

Angaben zu der Lemmazahl der zweiten Auflage finden sich nur bei Wolny $(1954,37)$, der nach seiner Zählung von ca. 145.000 Lemmata ausgeht. Die aus den ausgewerteten Seiten ermittelte Lemmazahl bestätigt diese Angabe: Die 104 Seiten umfassende Stichprobe aus der zweiten Auflage enthält insgesamt 11.015 Lemmata. Dies entspricht einer durchschnittlichen Lemmazahl von 106 Einheiten pro Seite. Rechnet man dies nun auf die Gesamtseitenzaht um, so ergibt sich eine geschätzte Gesamtlemmazahl von ungefähr 140.000 Lemmata! Dadurch wird deutlich, daß Nikoliž nicht nur die Seitenzahl, sondern auch den Werkinhalt sowie den gesamten Lemmabestand verdoppelt hat. 


\subsubsection{Das Anordnungsprinzip}

Auf den ersten Blick ins Auge fällt die Veränderung, die Nikoliž in bezug auf das Anordnungsprinzip vorgenommen hat. Die Anordnung der „einzelnen Artikel nicht mehr rein alphabetisch, sondern nach ihrer etymologischen Zusammengehörigkeit" (Pawlowsky, 1879, IV). bedeutete eine Abkehr von dem glattalphabetischen Anordnungsprinzip der ersten Auflage. Dadurch, daß .jede besondere Wortfamilie von ihrer Wurzel bis zur weitesten Ableitung unter einer Rubrik vereinigt ist" (Pawlowsky, 1879, IM), nutzt Nikolič den begrenzt zur Verfügung stehenden Raum des Wörterbuches weitaus effizienter als sein Vorgänger. Hervorgehoben werden die Lemmata nun nicht mehr durch Sperrung, sondern durch Fettdruck, wie aus den Beispielen ersichtlich wird.

Bsp.: O6M arß s. m. 1. der Betrug, die Betrügerei; [...]; 2. die Täuschung, das Blendwerk, die Illusion; [...]; +ka s. f. (Miner.) die Blende; [...]; + adj. trügerisch; täuschend; [...]; -нивость s. f. die Täuschung; +нивый adj. trügerisch, täuschend, illusorisch; [...]; +nuks s. m. der Betrüger, twunla s. f. die Betrügerin; -ншикескій, -ншиий, ья, ье adj. einem Betrüger eigen; нываніе s. n. das Betrügen; -нывать v. a. betrügen, anführen, hintergehen, täuschen; -нваться v. $r$. sich täuschen; sich irren.

Da laut Vorwort (vgl. Pawlowsky, 1879, IV) das Anordnungsprinzip des Dal'schen Wörterbuches als Muster für die Überarbeitung der Makrostruktur der ersten Auflage des Pawlowskyschen Wörterbuches übernommen worden ist, wäre nun eine nestaipabetische Makrostruktur zu erwarten. Daß aber gerade nicht "jede besondere Wortfamilie von ihrer Wurzel bis zu ihrer weitesten Ableitung unter einer Rubrik vereinigt" (Pawlowsky, 1879, IV) wurde, beweisen besonders eindrucksvoll die Eintragungen zum Wurzelmorphem вод-, die hier aus diesem Grund angeführt werden, obwohl sie nicht in den ausgewerteten Teilen zu finden sind.

Bsp.: Bon'a s. f. das Wasser; [...].

Bодоा60'язнъ s. f. (Med. Hydrophobia) die Wasserscheu; -в онда s. f. (sl.) die

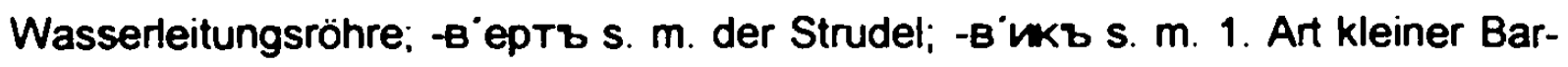
ken; 2. großer Schlitten, der Fischerschlitten (in welchem die Netze zum Fischplatze gebracht werden, wie z. B. auf dem Peipussee); -Buna s. f. ein besonderes Boot zu demselben Zwecke; -вмtст илмие s. n. s. водоёмъ.

Водов одъ [...].

Wäre die Dal'sche Anordnungsmethode ohne Modifikation übernommen worden, so hätten die tatsächlich als Vollemmata aufgenommenen Stichwörter водоводъ. водовозъ, 
водоворотъ, водовошикъ, водогонъ, вододействіе, водоемъ еtс. (vgl. Pawlowsky, 1879, 93f) den Status von Sublemmata erhalten müssen, da sie einer Wortfamilie angehören. Konsequent umgesetzt ist dies in Dal's Wörterbuch, in dem die eben genannten Lexeme als Sublemmata im Artikel вoдa angefühnt werden (vgl. Dal', 1863, 192ff). Im Dal'schen Wörterbuch kommt es durch diese Form der Textverdichtung zu einer nestalphabetischen Makrostruktur, da die alphabetische Struktur an einigen Stellen unterbrochen wird. So findet man dort im Gegensatz zum Pawlowskyschen Wörterbuch водоводъ, водовозь, водовороть еtс. vот водвитать, водвсрить еtс. (vgl. Dal', 1863, 192-194).

Für die überarbeitete Fassung des Pawlowskyschen Wörterbuches ist zu konstatieren, daß zusätzlich zu der alphabetischen Komponente als Richtlinie für die Anordnung der Lemmata von Nikolix der etymologische Gesichtspunkt mitherangezogen wurde. Das bedeutet, daß etymologisch zusammengehörige Lemmata genau dann in einem Textblock angeführt werden, wenn dies ohne Unterbrechung der alphabetischen Anordnungsstruktur möglich ist. Da dies die Kriterien für eine nischenalphabetische Makrostruktur sind, wurde von Nikolič der Wechsel von der glattalphabetischen zu der nischenalphabetischen Makrostruktur vollzogen. Eine weitere, aus Gründen der Übersichtlichkeit bedeutsame Größe ist der Umfang der Nischen. Überschreitet eine Nische einen gewissen Umfang, so legt Nikolič weitere Nischen an, obwohl dies gemäß den Regeln für eine nischenalphabetische Anordnung des Lemmabestandes nicht nötig wäre.

Gegen die durch das Alphabet vorgegebene Gliederung wird nur dann verstoßen, wenn ein Lemma als letzten Buchstaben die Grapheme $\mathbf{b}$ oder $b$ aufweist.

Bsp.: A6'optb s. m. der Abort, die Fehl-, Frühgeburt; -т'nвHth adj. abortiv, Leibesfrucht abtreibend.

Бор истость s. f. die Faltigkeit; -стьй adj. (von 6ор b) faltig, faltenreich; 2. (von 6opъ) mit Fichtenwald bewachsen, bestanden; fichtenbewachsen, fichtenbestanden; Fichten-.

Daß dieser Umstand aber dennoch nicht dazu veranlassen kann, von einer nestalphabetischen Anordnungsstruktur zu sprechen, beweist die erste der allgemeinen Eintragungen: „da die Buchstaben $\mathrm{b}$ und $\mathrm{b}$ im Russischen selbst lautlos sind und im Algemeinen nur zur Bezeichnung der harten oder weichen Aussprache des auslautenden Consonanten dienen, so ist bei Zusammenfassung der zu einem gemeinschaftlichen Grundwort gehörenden Wortformen für die alphabetische Aufeinanderfolge nur der dem $b$ oder b vorhergehende Consonant maßgebend gewesen" (Pawlowsky, 1879, V).

Obgleich das Dal'sche Wörterbuch als Muster für die Überarbeitung des Pawlowskyschen Wörterbuches gedient hat (vgl. 5.3, 170-180), bleibt festzuhalten, daß es sich in 
beiden Werken um zwei unterschiedliche Makrostrukturen handelt. Während in Dal's Wörterbuch die Etymologie die maßgebliche Größe ist, die zu nestalphabetischer Makrostruktur führt, bleibt in Pawlowskys Wörterbuch das Alphabet die entscheidende Komponente, so daß hier eine nischenalphabetische Makrostruktur vorliegt.

\subsubsection{Die Makrostruktur der dritten Auflage des russisch-deutschen Wörterbuches}

\subsubsection{Der Aufbau des Wörterbuches}

Der erste Abdruck der dritten, vollständig neu bearbeiteten, berichtigten und vermehrten Auflage des russisch-deutschen Wörterbuches von Pawlowsky erschien 1900 im Verlag von Nikolaj Kymmel in Riga. Der Umfang des Wörterverzeichnisses war im Vergleich mit der zweiten Auflage von den Autoren um ungefähr ein Drittel auf 1774 Seiten erhöht worden. Beibehalten wurde der schon aus den vorangehenden Auflagen bekannte Vorspann, der in diesem Fall auf XI Seiten neben den äußerst knappen allgemeinen Bemerkungen (vgl. Pawlowsky, 1923, III) und den Abkürzungserklärungen (vgl. Pawlowsky, 1923, III-V) auch ein Verzeichnis der starken und der unregelmäßigen Verben des Deutschen enthält (vgl. Pawlowsky, 1923, VII-XI).

Vergleicht man den Vorspann der zweiten Auflage mit demjenigen der dritten Auflage, so ist zu konstatieren, daß man bei der Überarbeitung sowohl auf das Vorwort als auch auf die Konjugationsparadigmen der russischen Verben verzichtet hat. Ersteres hat zur Folge, daß weder über die Gründe, die zur Überarbeitung des Wörterbuches den Anlaß gegeben haben, noch über die Autoren, die sich dieser Aufgabe gestelt haben, eine Aussage getroffen werden kann (vgl. 2.4.2, 52). Die zweite Weglassung bleibt ohne Folgen, da die Autoren die Angaben zur Konjugation in das Wörterverzeichnis integriert haben (vgl. 4.4.2.2, 144-145).

\subsubsection{Der qualitative Aspekt}

Die bereits aus den vorangehenden Kapiteln bekannte Stichprobe wurde auch der dritten Auflage entnommen und einer eingehenden Analyse unterzogen, um die Veränderungen zu belegen, die auf die Autoren der dritten Auflage zurückgehen. Ausgewertet wurden die 24 Seiten des Wörterverzeichnisses, die auf den Buchstaben A entfallen. Zusätzlich wurden jeweils gut 20 Seiten der Eintragungen unter den Buchstaben $5, M, O, \Pi$ und $S$ ausgewertet. Die untersuchte Stichprobe ist mit insgesamt 127 Seiten mehr als doppelt so umfangreich wie die Stichprobe aus der ersten Auflage (vgl. 3.2.2.2, 63). Insgesamt wurden in dieser Auflage 13.647 Lemmata untersucht. 
Ziel dieses Abschnittes ist es wieder einmal, die Unterschiede in der Makrostruktur im Vergleich mit der vorangehenden Auflage herauszuarbeiten und durch Beispiele zu belegen. Unverändert bleibt in der dritten Auflage die Rangfolge der Wortarten auf der quantirativen Ebene. Stärkste Gruppe sind auch hier mit 44.98\% die Substantive, gefolgt von den Verben mit $17.98 \%$ und den Adjektiven mit 17.64\%. Die letzte große Gruppe mit 16.99\% Anteil an den ausgewerteten Lemmata bilden die Verweislemmata. Anteilsmäßig nahezu unverändert bleibt auch in dieser Auflage die Zahl der Adverben, Konjunktionen. Präpositionen, Numeralia und Partikeln. Da diese Zahlen bereits deuttich machen, daß die Verbesserungen nicht auf einzelne Wortarten zurückzuführen sind, wird im Folgenden - wie schon bei der Untersuchung der zweiten Auflage - darauf verzichtet, Beispiele zu allen Wortarten aufzunehmen, um genügend Raum für solche Beispiele zu haben, die die Veränderungen belegen.

Die qualitativen Veränderungen, die von den Autoren der dritten Auflage eingeführt wurden, sind weniger einschneidend als jene von Nikolic. Die dritte Auflage zeichnet sich, wie schon die vorangehenden Auflagen, dadurch aus, daß die Bearbeiter bestrebt waren, den russischen Wortschatz unterschiedlicher Dimensionen abzubilden. Dies zeigt sich unter anderem daran, daß die Zahl der fachsprachlich markierten Lemmata unverändert hoch ist. Die Autoren der dritten Auflage haben neue fachsprachliche Markierungen in das Abkürzungsverzeichnis aufgenommen und auf einige der von Pawlowsky und Nikolič eingeführten Abkürzungen verzichtet. Insgesamt enthält das Abkürzungsverzeichnis der dritten Auflage des russisch-deutschen Wörterbuches mit 167 fachsprachlichen Markierungen (vgl. Pawlowsky, 1923, III-V) sieben mehr als dasjenige der zweiten Aufiage. Bei der Überarbeitung der fachsprachlich markierten Lexik orientierten sich die Autoren an den neuesten Entwicklungen in der Wissenschaft, wie Markierungen wie „Aeron." für Aeronautik belegen.

Im Vergleich mit der zweiten Auflage ist festzustellen, daß die Autoren die Zahl der lemmatisierten Dialektlexeme um ein Vielfaches gesteigert haben. Zum einen geschah dies durch eine detailliertere Markierung derjenigen Lemmata (vgl. 4.4.3.5, 151-153), die bereits von den Vorgängern aufgenommen worden waren, zum anderen aber auch durch Neuaufnahme zahlreicher Dialektlexeme. Bei den ersten beiden Beispielen handelt es sich um Lemmata, die - bis auf die diatopische Markierung - in der zweiten und der dritten Auflage identisch sind, bei den weiteren Beispielen handelt es sich um neu in die dritte Auflage aufgenommene Lemmata bzw. um neu aufgenommene Äquivalente.

Bsp.: Ariapı s. m. (Ostsib.) ein von Feldern umgebenes Wäldchen, die Waldinsel.

Ma'ethoctb s. f. (WestrußI.) das Land-, Rittergut.

M'awa s. f. (SüdrußI. ) mit Ochsen bespannter Wagen. 
O6ледев онить v. а. 1. (OstrußI.) niedermachen, zu Boden strecken; 2. (Moskau) übers Ohr hauen, übertölpeln, -listen; 3. (prov.) blamieren, beschämen, in Schmach bringen.

Mor'ofHrb s. m. [...]; 8. (Wolga) günstiger Wind; 9. (prov.) das Holzfloß; 10. (OstrußI.) ein Komplex von beiläufig 250 Angelhaken für den Fischfang im Winter (unter dem Eise); [...].

CKово|lpoд¡a s. f. [...]; 5. (Jaroslaw) die Wölbung des russ. Ofens; 6. (Archang.) die flache Klippe; [...].

Ebenfalls neu aufgenommen wurden von den Autoren der dritten Auflage des russischdeutschen Wörterbuches von Pawlowsky zahlreiche Entlehnungen aus westeuropäischen Sprachen, wobei oft auf die Gebersprache hingewiesen wird (vgl. 4.4.3.4, 150-151). Doch auch dieser wichtige Umstand ist von der Forschung bisher unentdeckt und daher ungenutzt geblieben.

Bsp.: Aвст ерія s. f. (ital. osteria, veralt.) ein Gasthaus od. eine Art Club, wie sie Peter der Große gründete, um die Russen mit dem europäischen Leben bekannt zu machen.

Epa s. n. indecl. (franz. bras) der Armleuchter, Wandleuchter.

Брет'ель s. f. (franz. bretelle, echt russisch noдт ' senträger, die Achselbänder.

Die Gruppe der Personennamen und der Namen berühmter Persönlichkeiten wurde von den Autoren der dritten Auflage um die Gestalten der griechischen Mythologie erweitert. Dies kann als Indiz dafür gedeutet werden, daß eventuell Speziallexika als Quellen herangezogen wurden (vgl. 5.4, 184).

Bsp.: 'Aвrï̌ n. pr. m. (gr. Mythl.) Augias, König von Elis.

Aлt|k ей n. pr. m. Alkäos (gr. Mythl.): 1. Sohn des Perseus und der Andromeda; 2.

Sohn des Herakles; 3. Dichter auf Lesbos u. andere weniger bemerkenswerthe Personen; [...].

Meлbnom ema n. pr. f. Melpomene (Muse).

Doch bei der Überarbeitung des Wörterbuches wurden nicht nur zahlreiche Lemmata neu aufgenommen, sondern es wurde auch auf einen Teil der von Pawlowsky und Nikolic lemmatisierten Einheiten verzichtet. So wurden einige, aber bei weitem nicht alle der bereits in den vorangehenden Auflagen als veraltet gekennzeichneten Lemmata nicht in die dritte Auflage des Wörterbuches übernommen (vgl. 4.4.3.2, 146-148). Des weiteren entschieden sich die Autoren der dritten Auflage gegen die Übernahme eines Teils der als fachsprachlich markierten Lemmata. 


\subsubsection{Der quantitative Aspekt}

Um eine Schätzung des Wörterbuchinhalts nach Hausmann vomehmen zu können, wurden die entsprechenden Werte auf fünf Seiten ausgezählt. Die ausgezählten Seiten enthalten pro Spalte jeweils 72 Zeilen, die mittlere Anschlagszahl pro Zeile beträgt 53 Anschläge. Durch Multiplikation dieser beiden Werte erhält man nun den geschätzten Spalteninhalt, der in diesem Fall bei 3.816 Anschlägen liegt. Da jede Seite zwei Spalten enthält, ergibt sich ein geschätzter Seiteninhalt von 7.632 Anschlägen. Bei einem Wörterverzeichnis von 1774 Seiten bedeutet dies einen geschätzten theoretischen Werkinhalt von 13.539.168 Anschlägen. Der Ausnutzungsfaktor wird mit 0.9 sehr hoch angesetzt, da durch die konsequenter als in der zweiten Auflage umgesetzte nischenalphabetische Lemmatisierung und durch die Einrückung der Nischeneingangslemmata nach rechts noch weniger Raum ungenutzt bleibt. Nachdem der geschätzte theoretische Werkinhalt nun durch den Ausnutzungsfaktor korrigiert worden ist, erhält man einen tatsächlichen geschätzten Werkinhalt von 12.185.251 Anschlägen.

Der Vergleich mit den vorangehenden Auflagen ergibt, daß der geschätzte Inhalt der dritten Auflage denjenigen der ersten Auflage (vgl. 3.2.2.3. 70) um das Dreifache übertrifft.

Leider stehen in der Sekundärliteratur wiederum nur die von Wolny $(1954,37)$ ermittetten Angaben zur Lemmazahl der dritten Auflage zur Verfügung, so daß erneut eine Schătzung der lemmatisierten Einheiten auf der Grundlage der Stichprobe vorgenommen wurde, um die Zahl von Wolny zu überprüfen. Da die 127 Seiten, die insgesamt ausgewertet wurden, 13.647 Lemmata enthalten, ist von einer durchschnittlichen Lemmazahl von 107 Einheiten pro Seite auszugehen. Multipliziert man diese Größe mit der Gesamtseitenzahl von 1774 Seiten, so ergibt sich daraus eine geschätzte Lemmazahl von knapp 190.000 Lemmata. Wolny, der umfangreichere Zählungen vorgenommen hat, gibt den Wortbestand der dritten Auflage mit ca. 180.000 Wörtern an. Da es sich bei den hier ermittelten Zahlen nur um grobe Schätzungen handelt - denn für ein differenzierteres Bild wäre es unabdingbar gewesen, eine größere Stichprobe als Grundlage zu wählen -, ist anzunehmen, daß die hier ermittelte Zahl nach unten korrigiert werden müßte. Doch auch wenn die errechnete Zahl als obere Grenze angesehen wird, so bleibt sie doch beeindruckend, bedenkt man, welche Lemmazahlen heutige zweisprachige Wörterbücher enthalten.

\subsubsection{Das Anordnungsprinzip}

Das von Nikoliž eingeführte nischenalphabetische Anordnungsprinzip wurde von den Autoren der dritten Auflage prinzipiell beibehalten. Allerdings entspricht die Gruppierung der Lemmata nicht immer derjenigen der zweiten Auflage. So steltten die Autoren der drit- 
ten Auflage zum Teil größere Nischen (vgl. 3.2.3.4, 79) zusammen, doch auch sie orientierten sich dabei primär an dem Alphabet und erst sekundär an der Etymologie als RichtgröBen, so daß auch bei der dritten Auflage nicht von nestalphabetischer Makrostruktur gesprochen werden kann. Beispielhaft werden nun zwei Abschnitte aus den unterschiedlichen Auflagen gegenübergestellt, um diese Aussage zu belegen.

Bsp.: СКв' өpHa s. f. (sl.) 1. die Unreinigkeit, Unsauberkeit; [...]; 2. der Schmutz, der Unflat, das Ekelhafte, die Garstigkeit; 3. die Unzucht, Sittenverderbnis; Haseuъ, aua s. m. abscheulicher, garstiger Mensch; -H'aвnua, -нaвka s. f. abscheuliches, garstiges Frauenzimmer, haskn adj. (st.) unrein, befleckt; H'ene s. n. die Verunreinigung, Befleckung; ніитель s. m. der Verunreiniger; ніить v. a. verunreinigen, beflecken, besudeln; fig. beschimpfen, entehren; +нится v. r. sich verunreinigen, sich beflecken; thula s. f. (sl.) liedertiches, garstiges Frauenzimmer, to adv. häßlich, garstig.

Сквернод 'tйll s. m. liederticher, ausschweifender Mensch; -ство s. n. die Liederlichkeit. Ausschweifung; -ствовать v. n. liederlich sein; ausschweifen; -hua s. f. (sl.) liederliches Frauenzimmer.

\section{Сквернотри6 'ытиество s. Скверностянанан.}

Сквернослі овъ, -вецъ, вuа s. m. Einer, der unzüchtige Reden führt; der Zotenreißer, das Schandmaul; -вить v. n. unzüchtige Reden führen; gemeine, unzüchtige Schimpfworte gebrauchen; Zoten reißen, ein Schandmaul haben; te s. n. unzüchtige Reden pl.; das Zotenreißen; -вka s. f. Eine, die unzüchtige Reden führt; die Zotenreißerin; unzüchtig, zotig.

СКв' ерность s. f. die Garstigkeit, Unfläterei.

Скверностянан s. n. sündhafte, unredliche Weise der Bereicherung.

СКв ернынй adj. häßlich; garstig; -H'Łть v. n. häßlich, garstig werden.

CKB epl|Ha s. f. der Makel, die Unreinigkeit, -sauberkeit, der Schmutz, der Unrath, -flat, das Ekelhafte, die Garstigkeit; die Unzucht, Sittenverderbnis.

Сквер|н- авецъ, виа s. m. abscheulicher, garstiger, elender Mensch; H'авиа, -навка s. f. abscheuliches, garstiges, elendes Frauenzimmer, -навыи adj. (sl.) unrein, befleckt; Hetie s. $n$. die Verunreinigung, Befleckung, Entehrung; нитель s. m., Нителыниа s. f. der Verunreiniger, die V-in; ніить v. a. verunreinigen, beflecken, -sudeln; fig. beschimpfen, entehren; Hiиться v. r. sich verunreinigen, sich beflecken; -Huцa s. f. liederliches, garstiges Frauenzimmer; -Ho adv. häßlich, garstig; нод'tй s. m. liederlicher, ausschweifender Mensch; нод tйka s. f. liederli- 
ches Frauenzimmer; +40д' tйсто s. n. die Liederlichkeit, Ausschweifung; Hoд tйстовать (-вуо) v. n. liederlich sein, ausschweifen; Hod trua s. c. liederticher, ausschweifender Mensch; -носліовъ, носл овецъ, вua der unzüchtige Reden fühnt, Zotenreißer, das Schandmaul; +осл oentb (fut. -Bno - enus - влать, -Bb -BsTe) v. n. unzüchtige Reden führen, gemeine, unzüchtige Schimpfworte gebrauchen, Zoten reißen, ein Schandmaul haben; Hocriosie s. n. unzüchtige Reden, das Zotenreißen; Hocrioßka s. f. die unzüchtige Reden führt, die Zotenreißerin; +осл оешй adj. unzüchtig, zotig; +مость s. f. die Abscheulichkeit, Garstigkeit, Unfläterei, Niederträchtigkeit; Hостаж amie s. n. sündhafte, unredliche Weise der Bereicherung; +ü adj. häßlich, garstig; + t'Tb v. n. häßlich, garstig werden.

Aus diesen Beispielen geht sehr deutlich hervor, daß die etymologische Komponente bei der Anordnung der Lemmata nicht von entscheidender Bedeutung ist. Die Autoren der dritten Auflage haben zwar einige etymologisch zusammengehörende Lexeme, die von Nikolič nicht in einem Eintrag abgehandelt wurden, nun zusammengefaßt, aber auch sie orientieren sich nicht ausschließlich an diesem Kriterium, wie das Beispiel zeigt.

Die Beispiele verdeutlichen außerdem, daß die Bearbeiter der dritten Auflage sich dafür entschieden haben, die Nischeneingangslemmata durch Fettdruck und Einzug nach rechts hervorzuheben. Diese Maßnahme führt mit der Verwendung von größeren Nischen zu einer noch effektiveren Ausnutzung des begrenzt zur Verfügung stehenden Raumes im Wörterbuch.

\subsubsection{Fazit}

Vergleicht man die Makrostruktur der unterschiedlichen Auflagen, so ist festzustellen, daß die einschneidendsten Veränderungen von Nikolič vorgenommen wurden. Denn dieser führte nicht nur das nischenalphabetische Anordnungsprinzip neu ein, sondern nutzte den unter anderem dadurch neu zur Verfügung stehenden Raum auch zu einer Verdoppelung des Lemmabestandes. Es erstaunt deshalb nicht, daß die zeitgenössische Kritik das Wörterbuch als "илм словаремь П а в $л$ о в с $k$ a $r$ o или же словаремь Николича" (Želtov, 1880, 122) bezeichnet hat - eine These, die durch die Analyseergebnisse bestätigt wird.

Relativ gering ist hingegen der Unterschied der Makrostruktur in der zweiten und der dritten Auflage. Die Autoren der dritten Auflage haben das von Nikolič gewählte Anordnungsprinzip ohne große Veränderungen beibehalten. Sie erhöhten den Lemmabestand im Vergleich mit der zweiten Auflage um ca. ein Drittel. Dabei beschränkten sie sich aber nicht 


\section{Die Mikrostruktur des Wörterbuches}

\subsection{Theoretische Grundlagen}

Bevor die eigentliche Untersuchung der Mikrostruktur begonnen werden kann, muß in einem ersten Schritt der theoretische Rahmen abgesteckt werden, der für die Analyse der Mikrostruktur des russisch-deutschen Wörterbuches von Pawlowsky gelten soll.

Der Begriff Mikrostruktur wurde zusammen mit dem Begriff Makrostruktur von ReyDebove (1971) in die Metalexikographie eingeführt. Zwar wird auch er heute nicht mehr einheitlich venwendet, doch sind die Unterschiede in den Definitionen nicht so gravierend wie bei der Makrostruktur. Unter dem Begriff Mikrostruktur werden in dieser Arbeit im Einklang mit den einschlägigen theoretischen Werken all jene Informationen zusammengefaßt, die in einem Wörterbuch nach dem Lemma angeordnet sind (vgl. Rey-Debove, 1971, 21; Hausmann, 1977, 4). Wichtigster Bestandteil der Mikrostruktur eines zweisprachigen Wörterbuches sind die zielsprachlichen Übersetzungsäquivalente (vgl. Hausmann, 1977, 6; Werner, 1991, 2796). Durch die Analyse der Mikrostruktur des Pawlowskyschen Wörterbuches sollen folgende Fragen beantwortet werden: Welche Informationen werden zur Phonetik und zur Grammatik der ausgangssprachlichen Lemmata gegeben? Welche diasystematischen Markierungen werden vorgenommen? Wie sind die zielsprachlichen Äquivalenzangaben angeordnet? Enthält die Mikrostruktur syntagmatische und/oder paradigmatische Informationen?

Grundlage der Analyse bilden die Stichproben aus den drei Auflagen, die bereits zur Beschreibung der Makrostruktur ausgewertet wurden. Ziel dieses Kapitels ist es, herauszuarbeiten, was für eine Mikrostruktur den Wörterbuchartikeln in den einzelnen Auflagen zugrundeliegt und welche Veränderungen die Autoren der unterschiedlichen Auflagen vorgenommen haben.

Zur Beantwortung des ersten Fragenkomplexes ist es nicht nötig, im voraus theoretische Grundlagen vorzustellen. Es gilt zu klären, ob und in welcher Form die Autoren des Wörterbuches Betonungs- und Ausspracheangaben zur Verfügung stellen und inwieweit grammatische Angaben angeführt werden. Ausführlich haben sich Henning Bergenholtz und Joachim Mugdan mit dem Problem der Grammatik im Wörterbuch beschäftigt. Die Untersuchung der grammatischen Angaben im Pawlowskyschen Wörterbuch basiert auf ihren Erkenntnissen, die im Rahmen einer Aufsatzserie in den Studien zur Neuhochdeutschen Lexikographie veröffentlicht worden sind (vgl. Bergenholtz, 1984a, 19-72; Mugdan. 1983, 179-237; Bergenholtz/Mugdan, 1982, 17-36). Durch die Analyse soll unter anderem herausgearbeitet werden, ob und auf welche Weise die Lemmata mit Wortartangaben ver- 
sehen werden, was für kategoriale Hinweise bei der Charakterisierung der verbalen Lemmata auftreten und inwieweit Deklinations- und Konjugationsangaben angeführt werden.

Da der Wortschatz natürlicher Sprachen nicht homogen ist, sind in Wörterbüchern Markierungen unerläßlich, die den neutralen Wortschatz von dem nicht neutral benutzten abgrenzen. Mit Markierungsproblemen haben sich die Metalexikographen schon sehr früh und relativ ausführlich auseinandergesetzt (vgl. Hausmann, 1989b, 652-53). Die Analyse der diasystematischen Markierungen im Pawlowskyschen Wörterbuch orientiert sich an den entsprechenden Aufsätzen im Handbuch Worterbücher und an Hausmann (1977, 112143), der insgesamt acht unterschiedliche Markierungstypen unterscheidet: Diachronische Markierungen kennzeichnen das Alter der Lemmata, wobei in den meisten Wörterbüchem sowohl alte als auch neue Wörter markiert werden. Kritisch anzumerken ist, daß auf die Markierung neuer Wörter verzichtet werden kann, da diese spezifische Qualität, sofem keine „Eintagsfliegen” lemmatisiert wurden, schnell vertoren geht (vgl. Schmidt, 1989, 660). Ist ein Lemma nur in einem räumlich begrenzten Raum gültig, so wird das durch diatopische Markierungen gekennzeichnet. Je nach der Größe des Raumes, für den das entsprechende Lemma gilt, können nach Niebaum $(1989,662)$ vier Ebenen von geographischen Varianten unterschieden werden, auf die gegebenenfalls an entsprechender Stelle eingegangen wird. Aus anderen Sprachen entlehnte Lemmata sollten mit diaintegrativen Markierungen versehen werden. Besonders wichtig in einem zweisprachigen Wörterbuch sind die diastratischen Markierungen, die den Wortschatz in unterschiedliche Stilebenen einteilen. Unter den diakonnotativen Markierungen werden diejenigen Markienungen zusammengefaßt, die auf den konnotativen Aspekt eines bestimmten Lemmas hinweisen, wobei ein enger Zusammenhang zwischen diastratischen und diakonnotativen Markierungen besteht. Um den Fachwortschatz in einem Wörterbuch von dem neutral gebrauchten Wortschatz abzugrenzen, wurden schon recht früh diatechnische Markierungen in die Lexikographie eingeführt. Mit Hilfe der diafrequenten Markierungen werden Lemmata, die selten gebraucht werden, von den häufig benutzten abgegrenzt. Dianormative Markierungen verweisen auf den grammatikalisch korrekten bzw. den falschen Gebrauch der ausgezeichneten Lemmata, wobei sie insbesondere in präskriptiven Wörterbüchem eine bedeutende Rolle spielen.

In dem Unterpunkt, der den Markierungen gewidmet ist, soll untersucht werden, welche Arten von diasystematischen Markierungen in bestimmtem Umfang in den einzelnen Auflagen des russisch-deutschen Wörterbuches von Pawlowsky vorkommen.

Um die Frage zu klären, wie die zielsprachlichen Äquivalente im Pawlowskyschen Wörterbuch angeordnet sind, müssen erst einmal einige theoretische Erkenntnisse vorausgeschickt werden. Da es nur wenige ausgangssprachliche Lemmata gibt, die mit genau ei- 
nem zielsprachlichen Äquivalent deckungsgleich sind, müssen verschiedene Arten von Aquivalenz unterschieden werden. Entsprechen die denotativen und die konnotativen Elemente eines Äquivalents genau denen des ausgangssprachlichen Lemmas, so spricht man von Volläquivalenz. Wenn aber eine Deckung nur teilweise besteht, so spricht man von partieller Äquivalenz. Existiert für ein ausgangssprachliches Lemma kein zielsprachliches Element und wird die Bedeutung durch eine zielsprachliche Umschreibung verdeutlicht, so liegt Nulläquivalenz vor (vgl. Baunebjerg Hansen, 1990, 12-15). Allerdings werden diese Termini in den unterschiedlichen Arbeiten nicht einheitlich gebraucht. So sprechen Kroman, Riiber und Rosbach (1984, 188-192) nicht von Nulläquivalenz, sondern von Äquivalenzsurrogaten. Hausmann $(1977,55)$ unterscheidet bei der partiellen Åquivalenz die Divergenz, bei der einem ausgangssprachlichen Lemma mehrere Äquivalente entsprechen, von der Konvergenz, wo das Verhältnis umgekehrt ist. Als theoretische Grundlage für diese Analyse dient die zuerst vorgesteltte Dreiteilung in Volläquivalenz, Teiläquivalenz und Nulläquivalenz. Durch die Untersuchung gilt es zu klären, mit welchen bedeutungsdifferenzierenden Mitteln die unterschiedlichen Äquivalenzarten von den einzelnen Autoren unterschieden werden und ob es bei den überarbeiteten Fassungen zu Veränderungen in diesem Bereich gekommen ist.

Außerdem können bei der Wiedergabe von zielsprachlichen Äquivalenten zumindest in der Theorie verschiedene Anordnungsprinzipien unterschieden werden (vgl. Hausmann, 1977, 41-43). Werden die Bedeutungen nach ihrer zeitlichen Entstehung angeordnet, so spricht man von einer historischen Anordnung. Sind die einzelnen Bedeutungsangaben dagegen aus einer Grundbedeutung heraus entwickelt worden, so liegt eine logische Anordnung vor. Bei einer frequenzorientierten Anordnung werden die einzelnen Bedeutungen nach Häufigkeit angeordnet, und bei einer distributionellen Anordnung erfolgt die Gliederung nicht nach dem semantischen Gehalt der Bedeutungen, sondern nach deren grammatischem Status. Von Werner (1982, 150-156) wurden die Anordnungskriterien auf sieben enweitert, wobei dieser Autor gleichzeitig feststellt, daß ,der Lexikograph prinzipiell gezwungen [ist], mehrere Kriterien miteinander zu kombinieren* (Werner, 1982, 156). Für die vorliegende Arbeit stellt sich die Frage, ob in der Mikrostruktur des Pawlowskyschen Wörterbuches eines oder mehrere der eben genannten Prinzipien Anwendung gefunden haben.

Die Kenntnis allein der Bedeutung einiger zielsprachlicher Wörter genügt einem Wörterbuchnutzer meist nicht zum Verständnis der Fremdsprache. Von entscheidender Bedeutung sind in diesem Zusammenhang die syntagmatischen Vorschriften einer Sprache. Um Sätze in einer Fremdsprache verstehen oder gar selbst erzeugen zu können, benötigt man beispielsweise Informationen über die Rektion eines Verbums, eines Adjektives oder einer 
Präposition oder aber Informationen über sog. Kollokationen, d. h. über syntaktischsemantisch verträgliche Lexemverbindungen einer Sprache. Ziel des Kapitel zur Syntagmatik des untersuchten Wörterbuches ist es, herauszufinden, ob solche Informationen von dem Wörterbuch geliefert werden. Theoretische Grundlage für diesen Teil der Untersuchung ist der letzte Aufsatz der Serie von Bergenholtz und Mugdan, der der Syntax im Wörterbuch gewidmet ist (vgl. Bergenholtz, 1984, 1-46).

Als weiteres Hilfsmittel bei der Analyse der Mikrostruktur in den drei Auflagen des russisch-deutschen Wörterbuches von Pawlowsky haben sich neben den bisher angeführten theoretischen Arbeiten metalexikographische Untersuchungen erwiesen, die unter andorem auch die Mikrostruktur verschiedener zweisprachiger Wörterbücher durchleuchtet haben (vgl. Fraczek, 1999; Yüksekkaya, 1998; Fejér, 1995; Papachristos, 1990).

\subsection{Die Mikrostruktur der ersten Auflage}

\subsubsection{Phonetische Angaben}

Untersucht man die Stichprobe aus der ersten Auflage des russisch-deutschen Wörterbuches auf phonetische Informationen, so ist festzustellen, daß im Wörterbuch zwar keine Ausspracheangaben enthatten sind, aber doch grundsätzlich zumindest bei den zwei- und den mehrsilbigen Lemmata sowie bei Mehrworteinheiten die Akzentstelle angegeben wird. Die betonten Vokale der Lemmata sowie die betonten Vokale von Mehmworteinheiten sind mit einem Akut versehen, der den Akzent in der fraglichen Wortform wiedergibt.

Bsp.: 6 р а т скій, aя, ce adj. brüderlich; 6p-aя no6 oss die Bruderliebe.

M 'a т о чны й, aя, oe, adj. (Anat.) zur Gebärmutter gehörig; M. pyк’aвъ, M-oe влаr'anme die Mutter-, Gebärmutterscheide; M-oe oтв epctie der Muttermund; M-ble приті aаки hysterische Zufälle; [...].

Wenn in den noch folgenden Beispielen bei zwei- und mehrsilbigen Lemmata keine Akzentuierung angegeben ıst, so spiegelt dies die tatsächlichen Verhältnisse im Wörterbuch wider. Da diese Fälle aber sehr selten sind, werden sie als Flüchtigkeitsfehler betrachtet und als solche nicht weiter beachtet.

Ein Problem ist allerdings der Verzicht auf die Akzentangabe bei einsilbigen Wortformen, was noch nicht einmal die moderne russische Lexikographie als solches erkannt hat. Denn ohne Akzentangabe wird der Unterschied verwischt zwischen solchen Wortformen, die normalerweise nicht akzentuiert sind - при, на, за, подъ usw. -, und denen, die den Akzent tragen: ст'олb, дंomb, nлiyrb usw.

Da der russische Akzent beweglich ist, wäre für ein zweisprachiges Wörterbuch wünschenswert, daß der Benutzer auch Informationen zum Akzentparadigma der einzelnen 
Lemmata erhält. Dies ist allerdings im vorliegenden Wörterbuch nicht der Fall. Einzig bei den Substantiven mit flüchtigem Vokal in den obliquen Kasus wird der Akzentwechsel angegeben.

Bsp:: Бр о дец в, ди'a, s. m. das Zugnetz.

Cke 6 'ok b, 6k'a, s. m. das Schab-, Kratzeisen.

Bei den Verben und den Adjektiven muß sich der Benutzer mit der Akzentangabe bei der kanonischen Form zufriedengeben, was insbesondere den deutschen Muttersprachler vor große Sctwierigkeiten stellt.

Abschließend ist zu konstatieren, daß die phonetischen Angaben des Wörterbuches nicht den Ansprüchen des deutschen Muttersprachlers genügen, da in der Regel nur über den Akzent der kanonischen Form informiert wird. Außerdem ist zu bemängeln, daß die erste Auflage auch im Vorwort den Benutzer nicht über die Akzentverhältnisse des Russischen informiert, so daß für Informationen über die korrekte Betonung einer bestimmten Wortform zusätzliche Hilfsmittel herangezogen werden müssen. Dies liegt aber auch darin begründet, daß die Akzentologie zu jener Zeit noch nicht soweit entwickelt war.

\subsubsection{Grammatische Angaben}

Die Untersuchung der grammatischen Angaben in der ersten Auflage des russischdeutschen Wörterbuches gliedert sich in zwei Abschnitte. Der erste Teil der Untersuchung ist den Wortarten gewidmet. Hier wird untersucht, ob das Wörterbuch Verweise auf Wortarten enthält und wie viele Wortarten unterschieden werden. Außerdem wird von Interesse sein, ob Pawlowsky das von inm benutzte Wortartsystem weiter in Subklassen aufspaltet.

Im zweiten Teil der Analyse stehen die Angaben zur Flexion im Mittelpunkt des Interesses. Dabei geht es um die Fragen, ob überhaupt Angaben zur Flexion der einzeinen Wortarten zur Verfügung gestellt werden und ob unregelmäßigen Formen ein selbständiger Lemmastatus gewährt wird.

\subsubsection{Die Wortarten}

Der Lexikograph hat laut Bergenholtz (1984a, 21) verschiedene Möglichkeiten, Wortarten in einem Wörterbuch zu kennzeichnen, sofern er diese überhaupt angibt. Pawtowsky hat sich dafür entschieden, wann immer dies möglich ist, die aufgenommenen Einheiten mit einem Kürzel zu versehen, das auf die Wortart hinweist. Einzig die als selbständige Lemmata aufgenommenen Mehr-Wort-Einheiten erhalten aus naheliegenden Gründen (vgl. Bergenholtz, 1984a, 28) nie einen Verweis auf die Wortart.

Bsp.: A лександр ійская 6 ум аг a das Regal-, Royalpapier.

Бур ачниковыя раст енія die boretschartigen Pflanzen. 
Медовок'аменная кислот'a, die Honigsteinsäure.

Nur teitweise mit einem Hinweis auf die Wortart oder eine dazugehörige Subkategorie vesehen sind die zahlreichen Verweislemmata. Explizit darauf hingewiesen wird immer dann, wenn die Wortart oder die Subkategorie des Verweislemmas abweicht von denjenigen des Lexems, auf das verwiesen wird. In allen anderen Fällen liegt nur eine implizite Markierung vor, da der Benutzer Informationen zur Wortart bei dem Lemma erhält, auf das verwiesen wurde. Die Enäuterung der in den folgenden Beispielen auftauchenden Abkürzungen erfolgt im Laufe des Unterpunktes.

Bsp.: Ай в a, s.f. s. Kentъ (Bot.).

Бр е з $r^{\circ}$ a, s. c. s. Брезг'унъ, Брезг'уння.

Mазн у ть, v. a. (einm.), s. unt. Mазать.

O 6 M ор о з и т b (voll.), s. unt. O6мор'онмвать.

Пов 'ы тіе, s. n. (veralt.), s. Пов втокъ.

Скалоз у у ить, v. n. S. ск'алить (з'у6ы)

Mit Ausnahme der beiden eben geschilderten Fälle erhalten alle anderen Lemmata einen Verweis auf die jeweilige Wortart. Allerdings bringt diese Kennzeichnung dem Benutzer keinen Vorteil, da der überwiegende Teil der betreffenden Kürzel weder im Abkürzungsverzeichnis aufgeschlüsselt ist. noch in einer vorangestellten Kurzgrammatik erläutert wird. Es wird im folgenden also auch von Bedeutung sein, die von Pawlowsky verwandten Kürzel zur Bezeichnung der Wortarten zu entschlüsseln und mit Beispielen zu belegen.

Am Anfang der Analyse der Wortarten im untersuchten Wörterbuch stehen mit den Substantiven, den Adjektiven, den Partizipien, den Verben, den Numeralen und den Pronomina die flektierbaren Einheiten der russischen Sprache.

Zumeist direkt hinter den als Lemmata aufgenommenen Substantiven folgt die Abkürzung "s.", die das Wort als Substantiv charakterisiert. Auf das .s." folgt in einem Großteil der Fälle die Genusangabe. Da die Genusmarkierung nur bei sehr wenigen und leicht einzuordnenden Substantiven fehlt, wird deren Fehlen als Flüchtigkeitsfehler angesehen. Bei den Genera unterscheidet Pawlowsky die bekannten drei Genera, die durch die Abkürzungen .m." für maskulinum, „f." für femininum und „n." für neutrum repräsentiert werden. Mit der Abkürzung "s. c." versehen, wobei "c." laut Abkürzungsverzeichnis für generis communis steht, sind all jene Substantive, die sowohl männliche als auch weibliche Personen bezeichnen können.

Bsp.: $\quad$ м и л а ш к a, s. c. ein lieber, netter Mensch; netter Junge; nettes Mädchen; nettes Kind. 
милліон ерка, s. f. die Millionärin.

милліон ер в, s. m. der Millionär.

C K p ' $r$ a, s. c. der Geizhals, Knauser, Knicker, Filz; geiziges Frauenzimmer, die Knickerin.

CK'y $\boldsymbol{\prime}$ Ka, s. f. der Aufkauf.

Сливн Якъ, s. m. 1. der Pflaumengarten; 2. der Pflaumenwein.

С ловап ишко, s. n. (verächtl.) schlechtes Wörterbuch.

Mit dem Zusatz .pl.“, der für pluralis steht, werden all jene Substantive markiert, deren Lemmaform im Plural steht. Pawtowsky hat allerdings nicht nur die im Plural lemmatisierten Substantive, die über einen Singular verfügen, mit einer Genusangabe versehen, sondem auch die Pluralia tantum, die in den Grammatiken, die nach der Orthographiereform von 1918 entstanden sind. üblicherweise ohne bestimmtes Genus angeführt werden (vgl. Zaliznjak, 1967, 75).

Bsp.: С л а с ти, ей, s. f. pl. die SüBigkeiten; eingemachte Früchte; das Naschwerk.

С $л$ 'ас т ь, s. f. die Süßigkeit; s. auch Сл'асти.

С л и в ии, вокъ, s. f. pl. 1. die Sahne, der Rahm, Milchrahm, der Schmant; 2. aus verschiedenen Gefäßen zusammengegossene Nachbleibsel.

Ausschlaggebend für die Zuordnung der jeweiligen Pluralia tantum zu einem der drei Genera waren für Pawlowsky morphologische Kriterien (vgl. Corbett, 1991, 175), denn die Genusbezeichnung verweist auf das jeweils relevante Deklinationsparadigma. Pawlowsky kennzeichnet demnach bei den Pluralia tantum nicht das Genus im herkömmlichen Sinne. sondem das morphologische Genus, wie Zaliznjak diese Kategorie später bezeichnet hat (vgl. Zaliznjak, 1967, 147). Dies zeigen folgende Beispiele, die nicht aus der Stichprobe stammen.

Bsp.: 6 p 'юки, OBb, pl. m. die Schiffertosen.

B о ро т $a$, в о р о т a, b, pl. n. 1. das Thor, die Pforte; kлюub отъ вор' отъ, Kл. Kъ вороотамъ der Pfortenschlüssel; 2. der Durchgang, das Fahmasser (zwischen Klippen od. Sandbänken); 3. (Bergw.) der Meiler, Kohlenhaufen.

Д р о в 'a, s. n. pl. das Brennholz.

н онницы, s. f. pl. die Schere.

С 'ани, еи, s. f. pl. der Schlitten; вза'а, кат' aнье въ сан яхъ die Schlittenfahrt; съд'я на с'аньяхъ (veralt.) am Rande des Grabes stehend; am Schlusse des Le-

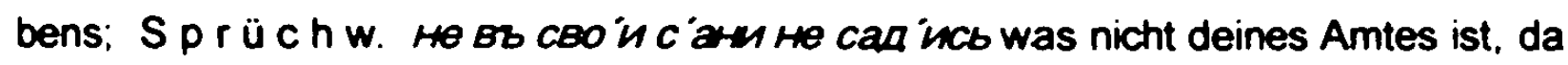
lasse deinen Vorwitz. 
4 a c 'b, 'osb, s. m. pl. 1. die Uhr, kapm'amble 4 . die Taschenuhr, cTtrwible 4 die Wanduhr, 6oes ble 4. die Schlaguhr; 4. cs penet vujeto die Repetiruhr; 2. die Zeit, wo ein Soldat zur Wache steht; сто'ять на час'axb zur Wache stehen, Schildwache st.; 3. der Gottesdienst in gewissen Stunden des Tages (außer der Früh-, Mittags- und Abendmesse), wobei Psalmen, Kirchenlieder und andere Gebete abgelesen werden; $L^{\circ}$ apcкie $4 а \mathbf{c}^{\circ} \mathbf{b}$ der Gottesdienst zwischen der Früh- und Mittagsmesse (am Tage vor Weihnachten und der heiligen drei Könige, auch am Charfreitage).

Mit der im Abkürzungsverzeichnis angegebenen Markierung "coll." unterscheidet Pawlowsky die Kollektiva von den übrigen Substantiven. Diese Differenzierung entspricht einer Subklassifizienung innerhalb der Wortart Substantiv (vgl. Bergenholtz, 1984a, 53).

Bsp.: Б p a т і я, s. f. coll. (sl.) die Brüderschaft (in Klöstern); н йlaя 6p. die Bettelmönche.

Бp y c b e, s. n. coll. die Brussen; vierkantig behauene Balken.

С кор вё, s. n. coll. (veralt.) unbearbeitete, rohe Felle.

Eine weitere Subklassifizierung nimmt Pawlowsky vor, indem er die Diminutiva und die Augmentativa mit einer entsprechenden Markierung versieht. Auch diese beiden Abkürzungen schlüsselt er in seinem Abkürzungsverzeichnis auf.

Bsp.: Ap 6 y з е $и$ b, зиа, [s. m., C. B.] dim. die kleine Arbuse.

А р 6 'у зи е е, s. m. augm. die große Arbuse.

A p 6 ' y 3 b, s. m. (Bot. cucurbita citrallus) die Arbuse, Wassermelone.

Бут 'ылища, s. f. augm. große Bouteille.

Бу т 'ылка, s. f. die Bouteille, Flasche.

Бу т 'ылочка, s. f. dim. das Fläschchen.

Keine Schwierigkeiten ergeben sich bei den Adjektiven, die durchgehend mit der Abkürzung „adj." als solche charakterisiert werden.

Bsp. Алфав ит ный, ая, ое, adj. alphabetisch.

Бугр истый, ая, ое, adj. hügelig.

маслен истый, ая, ое, adj. ölicht.

О 6 ж орливый, ая, ое, adj. gefräßig.

Als Subkategorisierung der Adjektive kann die Auszeichnung vereinzelter Lemmata mit den Abkürzungen „comp." für Komparativ und „supert." für Superlativ aufgefaßt werden. Zu betonen ist hier jedoch, daß nur einzelne unregelmäßige Komparativ- und Superlativformen selbständigen Lemmastatus erhalten haben. 
3sp.: Мал Ћ йшій, ая, $е$, supert. der, die, das kleinste, geringste; [...].

$M$ 'е л ь ч $\theta$, comp. feiner, kleiner, seichter, flacher.

M e н bu e, comp. weniger; kleiner; [...].

П л о ш е, comp. schlechter, schlimmer.

П л о $щ$ e, comp. flacher.

Bevor nun die Verben in den Mittelpunkt des Interesses rücken, werden die Partizipien behandelt, die als Subklasse der Verben interpretiert werden können. In der der Untersuchung zugrundeliegenden Stichprobe sind vier als solche gekennzeichnete Partizipien lemmatisiert. Nur mit der Abkürzung .partc.", die für Partizip steht, gekennzeichnet ist das einzige Partizip Präsens Aktiv der Stichprobe. Alle anderen Partizipien sind zusätzlich mit der Abkürzung .p." versehen. Da es sich in allen drei Fällen um Partizipien des Präteritum Passivs handelt, könnte dieses .p." sowohl für Präteritum oder für Passiv oder für beides stehen. Da die Abkürzung .p." auch bei der Klassifizierung der Verben Anwendung findet (vgl. 4.2.2.1, 95), wobei inr dort zweifelsfrei die Bedeutung Passiv zugeordnet werden kann, steht nunmehr fest, daß durch „p." das Passiv bezeichnet wird.

Bsp.: О О винённый, ая, фе, partc. p. beschuldigt; (als Subst.) der, die Beschuldigte; der, die Angeklagte; der Inculpat, die Inculpatin.

О 6 леч енный, ая, $е$, partc. p. 80 что bekleidet, angethan, mit -; [...].

Пов є ренный, ая, ое, partc. p. 1. verglichen; 2 . anvertraut; [...].

С к ор 6 я щ ій, ая, еe, partc. betrübt, bekümmert; leidtragend; [...].

Schwierigkeiten bereitet die von Pawlowsky vorgenommene Kategorisierung der Verben, da sie in dieser form in der russisch-deutschen Lexikographie heute nicht mehr üblich ist. Alle Verben werden durch das Kürzel „v." als solche gekennzeichnet. Darüber hinaus teilt Pawlowsky die Verben in sechs Klassen ein, die durch folgende Abkürzungen repräsentiert werden: .v. a., v. c., v. impers., v. n., v. p., v. r." Relativ einfach zu erklären ist die Abkürzung .v. p.", die für Verba passiva steht. Sie bezieht sich auf die grammatische Kategorie des Genus verbi und steht nach denjenigen Verben, die nur passivisch gebraucht werden.

Bsp.: Бр ак о в а т $b$, v. a. braken, ausschießen, ausmerzen, ausscheiden (das Untaugliche); -cя, v. p. gebrakt werden.

Бри т b, v. a. barbieren, rasiren; [...]; - - $9,[\ldots] ;$ v. p. rasirt werden.

м a з а т b, м а зн у т b, v. a. bestreichen (mit Theer, z. B. das Dach); schmieren (die Räder); einreiben (mit Salbe, mit Oel); [...];-cя, [...]; v. p. bestrichen werden, geschmiert w. 


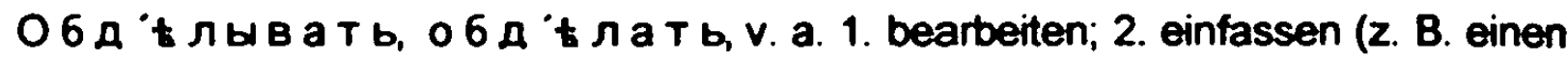
Edelstein); -ся v. p. bearbeitet werden, eingefaßt w.

Ebenfalls problemlos zu entschlüsseln sind die Abkürzungen .v. c." und .v. r.", die für Verbum commune und Verbum reflexivum stehen, da sie aus der heutigen Grammatikschreibung bekannt sind. Mit Verba communia wird die kleine Gruppe der Verben bezeichnet, die nur in der reflexiven Form auftreten können (vgl. Grammatika, 1960, 32 und 424). Die zweite Gruppe bilden diejenigen Verben, die durch Anfügung des Postfixes -ca von transitiven Verben gebildet werden können und dann reflexiv gebraucht werden (vgl. Grammatika, 1960, 412-423).

Bsp.: А т л а с и т b, v. a. gleich dem Atlaß machen; -cя, v. r. glatt, blank wie Atlaß werden.

Б о 'я Т ь С я, v. с. чer'o-ת 160 fürchten, etwas; sich fürchten, vor etwas; bange sein; $[\ldots]$.

Бри т b, v. a. barbieren, rasiren; [...]; -cя v. r. sich rasiren; [...].

M 'а з а т b, м а зн у у $\mathbf{b}, v$. a. bestreichen (mit Theer, $z$. B. das Dach); schmieren (die Räder); einreiben (mit Salbe, mit Oel); [...];-cя, v. r. sich einreiben (mit Salbe. Oel); [...].

Mер 'е щи тьс я, v. c. flimmem (vor den Augen); [...].

О 6 е знадёживать, о 6 е знадёнить, v. a. Kor'o Einem die Hoffnung nehmen, Einen der $H$. berauben, auf etwas; -cя, v. r. die $H$. vertieren; v. p. der Hoffnung beraubt werden.

O 6 M or 'а т b с 9, 06 M 'о 4 b С 9, v. c. genesen; sich wieder erholen.

Auch die Klasse der unpersönlichen Verben, die von Pawlowsky mit der Abkürzung „V. impers." versehen wurde, bereitet keine Schwierigkeiten, da sie in der Grammatikographie heute noch üblich ist.

Bsp.: Бр е зжи т с я, v. impers. dämmem (am Morgen), anfangen zu tagen; [...].

О 6 д а в а тb, о 6 д 'а т b. v. a. 1. begießen, übergießen (z. B. mit Wasser); [...]. 2. v. impers. обдаёть $x^{\prime}$ олодомъ es überläuft mich eine Kälte; es wird mir ganz kalt; при в'ыходы изъ к'омнаты 'обдало мен'я х олодомъ beim Heraustreten aus dem Zimmer schlug mir Kälte entgegen; [...].

О 6 м ё тыв а т b, о 6 ме т'а т b, v. a. 1. bewerfen (die Wände mit Kalk); 2. benähen (die Knopflöcher); 3. um etwas herumwerfen; [...]; 4. v. impers. y Her'o обмет' ало лмцё, $r^{\circ}$ убы sein Gesicht ist ausgeschlagen, seine Lippen sind a.; [...]. 
Problematischer ist die Klärung der Abkürzungen „v. a." und .v. n.", die in dieser Form in der heutigen Grammatikographie keine Anwendung mehr finden. Eine umfangreiche Analyse der mit diesen Abkürzungen versehenen Verben ergab, daß derart das Verhältnis zwischen Verb und Objekt bezeichnet wird. Transitive Verben, die ein direktes Objekt regieren, werden von Pawlowsky als Verba activa bezeichnet, intransitive Verben als Verba neutra. Zurückzugehen scheint diese Klassifizierung auf Johann Christoph Adelung, der nicht nur in seinen Grammatiken zwischen Verba activa und Verba neutra unterscheidet. sondern auch in seinem grammatisch-kritischen Wörterbuch der Hochdeutschen Mundart Verben auf diese Weise markiert (vgl. Henne, 1970, IX). In die russische Grammatikographie übemommen wurde die Klassifizienung vermuttich von $\mathbf{A}$. $\mathrm{CH}$. Vostokov, auf dessen Grammatik die Markierungen im 1847 erschienenen Akademiewörterbuch beruhen (vgl. 1.1.4, 8; 5.2, 162). Daß diese Klassifizierung auch in der neveren Grammatikographie benutzt wurde, beweist die 1941 erschienene russische Sprachlehre von Bahder. Dort bezeichnet .die Tatform (Aktiv) [...] eine auf eine andere Person oder einen anderen Gegenstand bezügliche Handlung, [die] eine Satzergänzung ohne Verhältniswort im Wenfall bei sich haben kann" (Bahder, 1941, 69).

Bsp.: Алчничать, v. n. yer'o gierig sein, trachten, nach etwas; heftig begehren, etwas.

м и л о в а т b, v. a. kor’o 1. gnädig sein, Einem; 2. Nachsicht haben, mit Jmd.; [...].

О 6 и т $а$ T $b, v$. n. wohnen (in einem Orte), bewohnen (einen Ort).

O $6 K$ у усыватb, O6K у с $a$ T $b, v$. a. benagen.

06 лет 'a тb, о6 лет 'т b. 1. v. n. a, um etwas herumfliegen; $b$, herabfallen (von Blättern); c, im Fliegen einem zuvorkommen; 2. v. a. durchfliegen (eine Gegend); $[\ldots]$

П о 6 о л т 'a т b, (voll.) 1. v. a. etwas, ein wenig umrühren (eine Flüssigkeit); 2. v. n. etwas plaudern, mit Jmd.

С к о м л є т и, v. n. (sl.) bewegen, rühren (die Zunge); не ск. языком⿰ прот'หвъ Kor'0-תм60 den Mund nicht aufthun gegen Jmd.; nicht mucken, nicht mucksen.

Auch bei den Verben benutzt Pawlowsky zwei Subklassifizierungen zur näheren Beschreibung. Zum einen werden einige der im perfektiven Aspekt lemmatisierten Verben mit "voll." für .vollendeter Aspekt" gekennzeichnet, zum anderen werden diejenigen Verben, die die semelfaktive Aktionsart (vgl. Mulisch, 1993, 180) ausdrücken, mit der Abkürzung .einm." für einmalig markiert. 
Bsp.: О овин 'ить, ся (voll.), s. unt. Обеин'ять, ся.

О 6 е р н у т ь, ся (voll. einm.), s. unt. Обёртьвать.

Cкр ипнуть, v. n. (einm.) knarren.

C k ' у ш a T b. v. a. (voll.) aufessen, verzehren.

Сл изнуть, v. a. (voll. einm.) 1. s. unt. Слinзвать; 2. fig. envischen; heimlich zu sich stecken; stehlen.

Zu kritisieren ist allerdings, daß Pawlowsky bei weitem nicht alle Verben, die hätten markiert werden müssen, tatsächlich markiert hat. Deshalb ist diese Subklassifizienung für den Benutzer von geringem Nutzen, zumal sie, wie die Kategorisierung selbst, weder in der Einleitung erläutert wurde, noch für den Benutzer erschließbar ist, weil die Abkürzungen nicht durchgehend bei den entsprechenden Lemmata angesetzt wurden.

Keine Schwierigkeiten gibt es bei der Wortart der Numeralia, die durch die Abkürzung "num." markiert wird. In der Stichprobe finden sich nur unter dem Buchstaben $O$ zwei Beispiele, die als Beleg für die Kategorie genügen sollen.

Bsp.: '0 6a, $06^{\circ} \circ n \times b, m$. u. n. 06 t, $06^{\circ}$ t $n \times$ b, f. num. beide.

О 6 ан ‘а д е с я т b, num. (sl.) zwölf.

Weil in der Stichprobe keine Pronomina enthalten sind, wurden einige Pronomina im Wörterbuch nachgeschlagen, um die Frage zu klären, auf welche Weise Pawlowsky diese markiert. Sämtliche Pronomina sind mit der Abkürzung „pron." als solche gekennzeichnet worden. Auffällig ist, daß Pawlowsky innerhalb der Gruppe der Pronomina keine semantisch funktional begründete Differenzienung vorgenommen hat und daß er auf direkte Deklinationshinweise -bis auf eine Ausnahme - verzichtet hat.

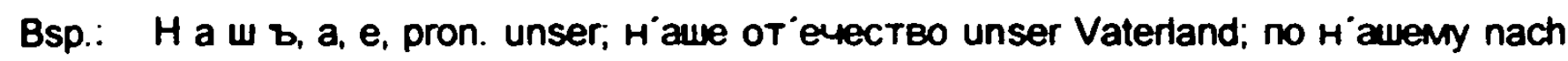
unserer Art; so wie wir es thun; 'это не nо н' ашему es ist nicht unser Einem gleich;

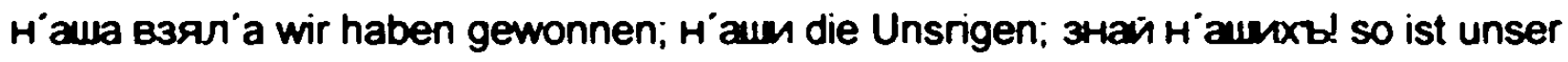
Einer! hüte dich vor uns.

H e K T o, pron. Jemand.

C e $6^{\circ}$ A, pron. sich.

4 е й, Чă, ube, pron. wessen? wem gehörig?

Э

Я, Gen. мен 'я, pron. ich.

Sieht man einmal von der Einteilung an sich ab, die insbesondere bei den unflektierbaren Wortarten Probleme bereitet (vgl. Bergenholtz, 1984a, 31), so ist die Markierung dieser Wortarten weniger problematisch als die der flektierbaren, weil bei innen keine Subklassen 
vorliegen. Da die Gruppe der unflektierbaren Lemmata in der Stichprobe relativ gering ist, beschränken wir uns im folgenden darauf, die einzelnen Wortarten vorzustellen, wobei die Einteilung als gegeben betrachtet und nicht weiter hinterfragt wird. Es wäre allerdings eine interessante Aufgabe, die Kategorisierung Pawlowskys genauer zu untersuchen, da nichtflektierbare Wörter und Pronomina „zusammen nur etwa $0,1 \%$ aller Wörter im Lexikon, aber etwa 50\% aller Wörter im Text ausmachen" (Bergenholtz, 1984a, 31).

Weil die Adverben im Russischen durch feste morphologische Regeln von den Adjektiven abgeleitet werden und ihre Bedeutung meist mit derjenigen der Adjektive identisch ist, hat sich Pawlowsky dafür entschieden, nur diejenigen Adverben gesondert aufzunehmen. „die man auch anders, als die entsprechenden Adjective übersetzt" (Pawlowsky, 1859, V)). Die lemmatisierten Adverben werden durchgehend mit der Abkürzung „adv." versehen.

Bsp.: Бо сик' о $\mathrm{z}$, adv. barfuß; mit błoßen Füßen.

Ма л еньк о, адв. еин щениг; етщас.

П о в и д им о м у, адв. сuхемнар; шие ес сuхемнт; дем Aнсuхенне наих.

Daß sich Pawlowsky keineswegs immer an die von inm aufgestellte Regel hält, zeigen folgende Beispiele.

Bsp.: CKв ер рн O, adv. häßlich, garstig.

Скв ер ный, ая, ое, адй хяымих; гарсти.

С л а 6 о, адв. сцхнацх, нмихт старк; гелмнде; (вон Саитен, Стрикен) rmext stramm, $n$. straff, schlaff.

С л а 6 ый, ая, ое адй. сихнацх, нмихт старк; (вон Пфропфен:) нмихт фест, лос; (вон Саитен, Стрикен) ницхт страфф; сцхлафф.

Aufgrund ihres zahlenmäßig geringen Gewichts in der untersuchten Stichprobe werden Konjunktionen. Intejjektionen und Partikeln gemeinsam behandelt. Mit der Abkürzung .conj.", die für Konjunktion steht, werden all jene lemmatisierten Einheiten versehen, die zur Wortart der Konjunktionen zählen. Interjektionen werden mit der Abkürzung "interj." markiert. Der einzigen Partikel in der Stichprobe hat Pawlowsky keine Abkürzung zugeteilt.

Bsp.: A, 1. conj. und, aber; [...]; 2. interj. a! ach! ei! ha! [...].

6 ' y д e, conj. wenn, wofern, falls.

6 y $\times$ b, interj. plump! plumps! [...].

Б $\mathbf{b}$ eine Partikel, die mit dem Präteritum des Indicativs den sogenannten Conjunctiv anderer Sprachen bezeichnet, z. В. зналь бы я (od. 'еслм бы я знать), 
4To - würde ich wissen, wenn ich wüßte, wenn ich gewußt hätte, daß-; хороw'o 6'buno 6ы, 'если 6ы - es wäre gut, wenn -.

0 , interj. o! ach!

С $л$ о в н о, conj. eben (gerade) so, wie; [...].

Abschließend wird nun noch die kleine Gruppe der Prăpositionen vorgestellt, die im Wörterbuch mit der Abkürzung .praep." versehen worden ist.

Bsp.: $\quad$ 'е в д у у, praep. zwischen, unter, [...].

O (060, 06ъ), praep. von, an, um, über [...].

П o, praep. auf, zu, bis, bis an, bis nach, bis über [...].

C к в $о$ з b, praep. durch.

Da Pawtowsky aus unerklärlichen Gründen auf die Erläuterung zahlreicher Abkürzungen verzichtet hat, werden nun am Ende des Unterpunktes zu den Wortarten der Übersichtlichkeit halber noch einmal alle in diesem Zusammenhang verwendeten Abkürzungen in alphabetischer Reihenfolge in einer Tabelle aufgeschlüsselt.

\begin{tabular}{|c|c|}
\hline \multicolumn{2}{|c|}{ Abkürzungsverzeichnis } \\
\hline a. & activum \\
\hline adj. & Adjektiv \\
\hline adv. & Advert \\
\hline augm. & Augmentativum \\
\hline c. & commune \\
\hline coll. & Kollektivum \\
\hline comp. & Komparativ \\
\hline conj. & Konjunktion \\
\hline dim. & Diminutivum \\
\hline einm. & einmalig \\
\hline$f$. & Femininum \\
\hline impers. & unpersönlich \\
\hline interi. & Interjektion \\
\hline $\mathrm{m}$ & Maskulinum \\
\hline$n$. & Neutrum \\
\hline num. & Numerale \\
\hline p. & passivum \\
\hline part. & Partikel \\
\hline partc. & Partizip \\
\hline pl. & Plural \\
\hline praep. & Präposition \\
\hline pron. & Pronomen \\
\hline$r$. & Reflexivum \\
\hline s. & Substantiv \\
\hline supert. & Superlativ \\
\hline v. & Vert \\
\hline voll. & vollendeter Aspekt \\
\hline
\end{tabular}


Abb. 1: Wortarten und ihre Subkategorien in der ersten Auflage des russisch-deutschen Wörterbuches von Pawlowsky

\subsubsection{Angaben zur Flexion}

Fast gänzlich allein gelassen wird der Benutzer des russisch-deutschen Wörterbuches von Pawlowsky, wenn er mit Hilfe des Wörterbuches Fragen nach der Flexion der ausgangssprachlichen Lemmata beantworten will, denn die flektierbaren Lemmata werden prinzipiell nicht mit Hinweisen auf ihre Flexion versehen. Dies bedeutet, daß das Wörterbuch weder in einem Grammatikteil im Vorwort noch direkt bei den Lemmata Himweise auf die regelmäßige Flexion von Substantiven, Verben und Adjektiven enthält. Allerdings stellt es, wenngleich nur in begrenztem Maße, Informationen zu einigen unregelmäßigen Flexionsmustern vor, die im Folgenden beschrieben werden.

Verhältnismäßig zahlreich sind die Verweise auf Unregelmäßigkeiten bei der Substantivflexion. Keine feste Regel scheint es bei den im Plural lemmatisierten Substantiven zu geben, von denen ein Teil mit, der andere aber ohne Genitivform aufgenommen uurde.

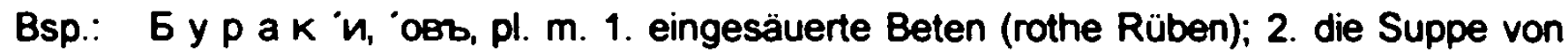
rothen Rüben; die Betensuppe.

М а р к и 3 औ, s. m. pl. die Marquisen, Fenstervorhänge, der Fensterschirm, Sonnenschirm über den Fenstern.

06 и в к и, вокъ, s. f. pl. das beim Reinigen des Fischrogens nachgebliebene Fett und die Sehnen (woraus man Thran bereitet).

По д в з д 'о хи, s. m. pl. (Anat.) die Weichen, Seitenweichen, Dünnung.

Ск л а д ни, ей, s. m. pl. zwei oder mehrere Brettchen mit Heiligenbildern, zum Zusammenschlagen eingerichtet.

Bei denjenigen Substantiven, bei denen ein Vokal in den obliquen Kasus .flüchtig" ist, wird die Genitivform grundsätzlich direkt nach dem Lemma angegeben.

Bsp.: Бр 'е д ен $b$, дня, s. m. das Zugnetz.

M e c т b, Gnt. мcta, s. m. (sl.) der Traubensaft.

O 6 л о м о Kъ, MKa, s. m. ein abgebrochenes Stück; [...].

Пов ар ёнок в, Hка, s. m. der Kochjunge.

СКл'а д ень, дня, S. m. das Halsband, die Halsschnur (aus Edelsteinen).

Ebenfalls immer mit der Genitivangabe lemmatisiert sind die substantivierten Adjektive, die als selbständige Lemmata aufgenommen wurden.

Bsp.: Бреж 'а тый, aro (als Subst.), der Wächter.

M а л о й, аго (als Subst.) 1. der Diener, Bediente; 2. junger Mensch; [...]. 
О 6 о зничей оd. о $6^{\circ}$ о зничій, ато (als Subst.) der Aufseher über die

Fuhren, über einen Transport; der Wagenmeister.

По 6 и р ч ій, aro (als Subst.-sl.) der Zolleinnehmer.

С ле с 'ар ная, ой (als Subst.) die Schlosserwerkstatt.

Die Genitivform wird auch angegeben bei Substantiven, die in den deklinierten Formen eine Stammenweiterung autweisen.

Bsp.: $\quad$ р р е $м$ я,

M а т b, epn, s. f. die Mutter; [...].

Bei einer kleinen Gruppe von Substantiven wird auf unregelmäßige Pluralformen hingewiesen. Wenn Pawlowsky auf eine Stammveränderung im Plural verweist, so tut er dies stets direkt nach dem Hinweis auf die Wortart. Ob dies für das ganze Wörterbuch gilt, ist allerdings fraglich, da in der Stichprobe nur im Abschnitt des Buchstabens 5 Beispiele für diese Art von Angabe gefunden werden konnten.

Bsp.: $\quad$ Б p a т b, s. m. (pl. 6p aтbя, beвb) 1. der Bruder, [...].

6 р е в н 'o, s. n. (pl. 6рёвна, 6рёвенъ) der Balken (rohe).

Б р у с ъ, s. m. (pl. 6p усья, ьевъ) 1. der Brussen; vierkantig behauener Balken; [...].

5 о я рин ъ, s. m. (pl. 60'яра u. $60^{\circ}$ яpe, ъ) der Bojar, Große, Vomehme.

Ist ein Substantiv undeklinierbar, so gibt Pawlowsky dies durch die Abkürzung "indecl." bekannt, die direkt nach dem Genus steht.

Bsp.: A wi o, s. n. inded. (Comm.) das Agio, Aufgeld.

Анд ан те, s. n. indecl. (Mus.) das Andante.

M 'a к и, s. m. indecl. (Zool. lemur) der Maki, Fuchsaffe.

Auch bei den Adjektiven bietet die erste Auflage des russisch-deutschen Wörterbuches von Pawlowsky kaum Informationen über deren Flexion und Komparation. Einzig einige unregelmäßige Komparationsformen sind als selbständige Lemmata aufgenommen worden.

Bsp.: $\quad$ М е льче, comp. feiner, kleiner; seichter, flacher.

M 'еньш е, comp. weniger; kleiner; [...].

П л о ш e, comp. schlechter; schlimmer.

П л о щ e, comp. flacher.

Sind schon die Informationen zur Flexion der Substantive und der Adjektive sehr dürttig. so ist die Situation bei den Verben noch unbefriedigender. Die erste Auflage des russischdeutschen Wörterbuches von Pawlowsky enthält keinerlei Hinweise auf die Flexion der 
russischen Verben. Weder bei den lemmatisierten Verben direkt, noch in dem Vorwort finden sich Himweise auf die Flexion. Auch unregelmäßige Verbformen werden nicht als selbständige Lemmata mit einem Verweis auf den Infinitiv aufgenommen.

Die für die Verben getroffene Aussage gitt leider auch für die Pronomina und die Numeralia, über deren Flexion mit Hilfe des Wörterbuches keine Informationen zu gewinnen sind.

\subsubsection{Bewertung der grammatischen Angaben}

Bei der Kodierung der Wortarten ist Pawlowsky systematisch vorgegangen. Er legte ihr ein traditionelles Wortartensystem zugrunde, das bereits in vielen Grammatiken verwandt wurde und bei den Benutzem als bekannt vorausgesetzt werden konnte. Trotz dieser Tatsache ist zu kritisieren, daß Pawhowsky darauf verzichtet hat, das von inm benutzte System innerhalb des Vorwortes zu enäutern. Daß dies den Benutzer vor unnötige Schwierigkeiten stellt und zudem auch noch den Anwendungswert der Systematik mindert, hat die Kategorisienung der Verben deutlich gezeigt.

Aus der Sicht des deutschsprachigen Benutzers unbefriedigend ist die Darstellung der Flexionsangaben im Wörterbuch. Pawlowsky verzichtet zwar nicht gänzlich auf Flexionshinweise, aber er geht in diesem Punkt wenig systematisch vor. Noch am besten informiert wird der Benutzer über die Flexion der Substantive, da auf einige Unregelmäßigkeiten direkt bei den Lemmata hingewiesen und implizit durch die Genusangabe auf die jeweilige Deklination verwiesen wird.

Ebenfalls akzeptabel ist die Situation bei den Adjektiven, da deren Flexion weitgehend regelmäßig ist, so daß die Wortartangabe als ausreichend betrachtet werden kann, zumal einige unregelmäßige Komparative als selbständige Lemmata aufgenommen uurden.

Als größter Mangel ist anzusehen, daß Pawlowsky bei den Verben und den Pronomina vollständig auf Flexionsangaben verzichtet, obwohl gerade bei diesen Wortarten besonders viele Schwierigkeiten auftreten. Das Fazit Mugdans, .daß die Angaben verschiedener Wörterbücher zu Fragen der Flexion vielfach uneinheitlich oder widersprüchlich sind, weil sie intuitiv und nicht empirisch gewonnen wurden, daß bei Art und Umfang der Kennzeichnung erhebliche Unterschiede bestehen und daß kein Wörterbuch konsequent vorgeht" (Mugdan, 1983, 233-234), kann nach der Untersuchung der Flexionsangaben in der ersten Auflage des Pawboskyschen Wörterbuches nur bestätigt werden.

\subsubsection{Diasystematische Markierungen}

Es könnte argumentiert werden, daß Markierungen im zweisprachigen Wörterbuch nicht nötig seien, da sich „im Idealfall [...] lexikalische Einheiten der Ausgangs- und der Zielspra- 
che im Rahmen der lexikographischen Aquivalenz nicht nur denotativ, sondern auch in ihrer Markierung so weit wie möglich entsprechen" (Wemer, 1991, 2800) solten. Da dieser Idealfall in den seltensten Fällen verwirklicht werden kann, bleibt die Markierung auch für den Autor von zweisprachigen Wörterbüchern wichtiges Hilfsmittel.

Pawlowsky bediente sich beim Abfassen seines Wörterbuches unterschiedlicher Markierungen, um den Wert seines Werkes für den Benutzer zu steigern. Da die diatechnischen Markierungen die weitaus umfangreichste und auch zahlenmäßig häufigste Gruppe bilden, werden sie an erster Stelle behandelt.

\subsubsection{Die diatechnischen Markierungen}

Laut Abkürzungsverzeichnis unterscheidet Pawlowsky insgesamt 154 verschiedene diatechnische Marker. Allerdings ist wiederum zu kritisieren, daß er bei der Erarbeitung des Abkürzungsverzeichnisses nicht die nötige Sorgfalt hat walten lassen, denn bereits unter den insgesamt 74 diatechnischen Markierungen in der Stichprobe sind sechs zu finden, die nicht im Verzeichnis erklärt werden.

Die einzeinen Markierungen werden unterschiedlich häufig benutzt. Besonders zahlreich sind Lemmata, die aus dem Bereich der Botanik und der Zoologie stammen. Da bei einer solchen Markierung fast immer auch die fachsprachliche Bezeichnung angegeben wird, könnte dies ein indirekter Hinweis auf die von Pawlowsky benutzten Quellen sein (vgl. 5.2, 162-163). Um ein Bild von der Reichhaltigkeit der diatechnischen Markierungen zu vermitteln, seien nun einige Beispiele angeführt.

Bsp.: AKT b, s. m. 1. (gerichtl.) die Acte, Verhandlungsschrift; 2. (Theat.) der Act. Aufzug; 3. (auf Schulen, Universitäten:) der Actus, die Schulfeierlichkeit.

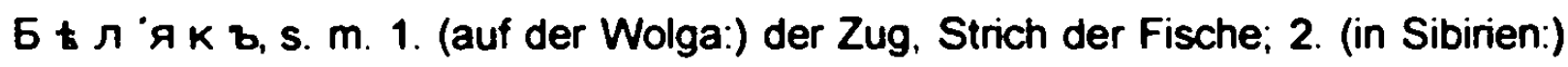
außerordentliche Abgabe an Pelzwerk; 3. (Schiffspr.) schäumende Woge; 4. (Jäg.) der weiße Hase; 5. (Bot. cytisus hirsutus) rauher Bohnenbaum.

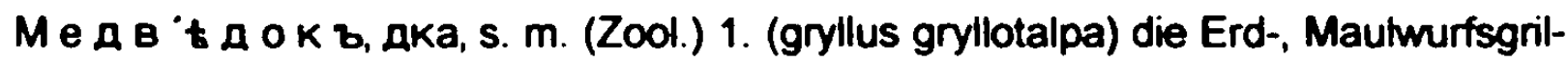
le. Ackerwerre; 2. (mustalpinus) die Maulwurfsratte; 3. junger Biber (in Kamtschatka).

О 6 в ариват ь, о6 вар ит ь, v. а. 1. abbrühen; [...]; 2. (Schuhm.) bepichen (den Faden, Draht); [...].

Пов р я ть, пов ьрить, v. a. 1. vergleichen (Rechnungen), controliren; $n$. и заклочать счёты (Kaufl.) Conto reguliren; 2. (Arithm.) die Probe machen; 3. (Münzw.) n. мон'еты, s. Юст'ировать; 4. vertrauen, anvertrauen, Einem, etwas; $[\ldots]$ 
С ливн о о и ('bй), 'ая, 'о, adj. 1. (Medc.) сл-aя 'ocna die Fließblattem; zusammenfließende Blattem; 2. aus verschiedenen Gefäßen zusammengegossen (wie z. B. die Nachbleibsel vom Wein etc.); 3. (Miner.) dicht, compact.

Durch die Beispiele wird deutlich, daß sämtliche Hauptwortarten markiert werden können, wobei der Großteil der Markierungen natürlich auf die Substantive entfällt, und daß sämtlichen Markienungen innerhalb der Mikrostruktur eine feste Position zugeteilt wird. Bezieht sich die Markierung auf die gesamte Bedeutungsangabe, so steht sie direkt nach den grammatischen Angaben. Bezieht sie sich nur auf einen Teil der Angaben, so erfolgt die Markierung direkt nach den arabischen Zifferm, die die einzelnen Bedeutungen voneinander trennen (vgl. 4.2.4, 110). Als diatopische Markierung betrachtet und an entsprechender Stelle erläutert (vgl. 4.2.3.5, 107) werden Angaben wie .auf der Wolga“ und „in Sibirien".

Neben der diatechnischen Markierung durch Abkürzungen kennzeichnet Pawlowsky auch einige Wörter durch den Gebrauch von ausgeschriebenen Wörtern, die in Klammern vor der Bedeutung des entsprechenden Lemma stehen.

Bsp.: M M T k a, s. f. 1. pop. die Mutter; 2. (bei Thieren:) das Weibchen; [...]; 3. (Anat. uterus) die Mutter, Gebărmutter, 4. (in Archangel, bei den Seefahrem:) der Compaß; [...].

M 'a T o 4 k a, s. f. 1. dim. das Mütterchen; (bei Thieren:) das Weibchen; 2. (am Ural, bei den Jägern:) der Compaß.

Der ebenfalls in Klammern stehende Ausoruck ,bei Thieren“ wird als nähere Erklärung betrachtet. Da die denotativen und die konnotativen Bedeutungen von Weibchen nicht deckungsgleich mit dem Lemma sind, muß der Benutzer durch nähere Erklärungen über die Verwendung der Bedeutung in Kenntnis gesetzt werden (vgl. 4.2.4, 110-111).

\subsubsection{Die diakonnotativen Markierungen}

Mit insgesamt drei Markierungen bilden die diakonnotativen Markierungen die zweitgrößte Gruppe im Wörterbuch. Mit Hiffe solcher Markierungen verwoist Pawbusky auf die liebkosende, die scherzhafte und die verächtliche Verwendung der in dieser Weise ausgezeichneten Lemmata.

Bsp.: Б р а т е ц ъ, тua, s. m. (liebkos.) Brüderchen; (in der Anrede auch:) mein Freund; [...].

Брат 'и uк a, s. f. (verächtl.) der Bruder. 
м ал чиикъ, s. m. 1. der Knabe; 2. der Diener, 3. (bei Kauff.) der Lehrling; (bei den Hanowerkem:) der Lehrbursch, Lehrling; Maльикъ cъ пальикъ (scherzh.) Einer von sehr kleinem Wuchse; kleiner Knipps, der Knirps, Däumling. Скрипчёнка, s. f. (verächtl.) schlechte Geige; die Bierfiedel.

\subsubsection{Die diachronischen Markierungen}

Laut Abkürzungsverzeichnis und durch die Stichprobe bestätigt kennzeichnet Pawlowsky nur Paläologismen. Dabei unterscheidet er mit ,veraltet" und ,ehedem" zwei unterschiedliche Zeitsphären, ohne näher darauf einzugehen, in welchem Sinne die beiden Kennzeichnungen gebraucht werden. Die Beispiele legen nahe, daß alle mit „ehedem" gekennzeichneten Lemmata Denotate aus der Geschichte bezeichnen, während die mit "veraltet" markierten Lemmata bereits zu dem Zeitpunkt der Abfassung des Wörterbuches im allgemeinen Sprachgebrauch nicht mehr üblich waren. Allerdings ist Schmidt nur zuzustimmen, wenn er empfiehlt, erstere nicht mit mißverständlichen Markierungen sondem durch „Angaben innerhalb der Bedeutungserklärungen“ (Schmidt, 1989, 659) näher zu beschreiben.

Bsp.: Алт 'ынникъ, s. m. 1. (ehed.) das Dreikopekenstück; [...].

Бр а з дн а, s. f. (veralt.) geackertes Feld.

Бу т урл ви ъ, s. m. (ehed.) die Beinschiene (am Panzer).

м ‘ м ич ъ, s. m. (veralt.) das Muttersöhnchen.

O' 6 лый, ая, oe, adv. [adj., C. B.], (veralt.) 1. dick, plump; 2. rund; [...].

ח or o c т b, s. m. 1. die Kirche nebst einem Kirchhofe dabei; eine Kirche mit Wohnungen für Kirchendiener und dazu gehörigen Ländereien; 2. (ehed.) der Dorf-, Amtsbezirk.

С ло 6 о д 'a, s. f. 1. die Slobode, Vorstadt; 2. das Dorf (nahe an der Stadt gelegen, und wo die Häuser eine Straße bilden); чёрная сл. (ehed.) ein aus Fronbauem bestehendes Dorf.

\subsubsection{Die diastratischen Markierungen}

Mit der Abkürzung „pop.”, die relativ häufig vorkommt, aber dennoch nicht im Abkürzungsverzeichnis entschlüsselt wird, markiert Pawlowsky den sozialen Status eines Lemmas. „Pop." bedeutet „populär und kennzeichnet all jene Wörter, die stilistisch unterhalb der Literatursprache anzuordnen sind. Ebenfalls stilistisch niedriger als die Literatursprache anzuordnen ist die Markierung „fam.", die für „familiär" steht. Nicht zu klären ist die Hierar- 
chie beider Kennzeichnungen. Daß es zwischen innen für Pawlowsky einen Unterschied gab, beweist das Beispiel, das mit beiden Markierungen bedacht wurde.

Bsp.: AHz, conj. pop. aber.

Арш инник ъ, s. m. der Ellenwaarenhändler, [...]; fam. der Ellenreiter.

Браньк`o, s. n. pop. der Zänker.

Бp b c Ka, s. f.(fam. pop.) die Mieze, Katze.

мелед 'а, s. f. 1. pop. langweilige Arbeit; 2. pop. die Saumseligkeit, das Zaudem; 3. das Ringet-, Grillenspiel.

$06{ }^{\circ} \mathrm{a}$ и $\mathrm{T} b$, v. a. pop. Einen beweiben, verheiraten; [...].

Повит уха, s. f. pop. die Hebamme.

CK о $о$ о B $^{\prime} \mathrm{T}_{\mathrm{T}}$, s. m. pop. flinker Bursche; Einer, der alles geschwind, aber obenhin macht.

\subsubsection{Die diatopischen Markierungen}

Als diatopische Markierung kann die vereinzelte Kennzeichnung von Lemmata mit der Abkürzung .prov.", die für "provinziell" steht, gedeutet werden. Allerdings muß bemängelt werden, daß diese Markierung sehr unspezifisch ist (vgl. Niebaum, 1989, 664), da sie keinen Hinweis darauf enthält, in welcher Gegend das Lemma in dieser Bedeutung verwendet wird.

Bsp.: Мерл ииа, s. f. prov. das Fell von gefallenen Schafen.

ח о в 't T b, s. f. prov. der Boden (über einem Schoppen etc.).

CKоp A a, s. f. prov. die Egge.

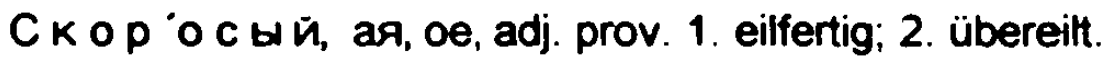

Wenn Pawlowsky auf die Gegend verweist, in der ein Lemma in dieser oder jener Bedeutung gebraucht wird, so benutzt er keine Abkürzung, sondem eine ausgeschriebene geographische Zuordnung, die in Klammern steht. Zu kritisieren ist allerdings, daß dieser Markierung keinen festen Platz innerhalb des Aufbaus der Mikrostruktur zugewiesen ist. In einigen Fällen steht sie - wie für Markierungen üblich - vor der Bedeutungsangabe, zuweilen folgt sie allerdings auch erst auf die Bedeutungsangabe und kann dann als nähere Erklärung (vgl. 4.2.4, 110-111) interpretiert werden.

Bsp.: Ap $6^{\circ}$ a, s. f. (in Astrachan U. Krimm) der zweirädenge Wagen.

5 เ лик ъ, s. m. 1. eine Art Granit (in Jekaterinburg); [...].

M ар а л в, s. m. der Hirsch (in Sibirien).

$0^{\circ} 6$ ерв-г ау п тманскій с у в (in Kurland:) das Oberhauptmannsgericht. 
Скиноп игія, s. f. (bei den Israeliten:) das Lauberhüttenfest.

\subsubsection{Diaintegrative Markierungen}

Als diaintegrative Markierung kann die Kennzeichnung aller genetisch aus dem Kirchenslavischen stammenden bzw. der Kirchensprache zugehörigen Lemmata mit der Abkürzung .sl." interpretiert werden.

Bsp.: Aнгелозр ачный, ая, ое, adj. (sl.) engelgleich.

Бр а ш ш о, s. n. (sl.) die Speise, das Essen.

Миз инец ъ, ниа, s. m. 1. der kleine Finger; 2. (sl.) der jüngste Sohn.

$06^{\circ}$ a 4 e, adv. (sl.) allein, übrigens.

Повинов 'ати, повин 'ути, v. а. (sl.) zum Gehorsam bringen.

С к в е рна, s. f. (sl.) die Unreinigkeit, Unsauberkeit; скв ерна пліоти и д’уха

(2. Cor. VII. 1.) die Befleckung des Fleisches und des Geistes.

\subsubsection{Abschließende Bemerkungen}

Pawlowsky bemüht sich, dem Benutzer seines Wörterbuches mit Hilfe von Markierungen Hinweise auf die Verwendungsbedingungen und die Anwendungsbereiche der ausgangssprachlichen Lemmata zu liefern. Sein Markierungssystem enthält sechs der von Hausmann vorgestelten acht diasystematischen Markierungen. Er verzichtet auf diafrequente und dianormative Markierungen, wobei letzteres als Beteg dafür dienen kann, daß es sein Ziel war, ein deskriptives und nicht ein präskriptives Wörterbuch zu verfassen. Da im Wörterbuch sehr differenzierte diatechnische Markierungen benutzt werden, konnte es zur damaligen Zeit als adäquates Hilfsmittel bei der Lekłüre fachsprachlicher Texte genutzt werden.

\subsection{4 Äquivalente}

Das zielsprachliche Äquivalent, das nun im Blickpunkt des Interesses stehen soll, ist der zentrale Informationsträger eines zweisprachigen Wörterbuches. Relativ problemlos für den Lexikographen sind diejenigen Fälle, bei denen Voll- oder Nulläquivalenz vorliegt, da bei ersteren eine 1:1-Entsprechung besteht und letztere durch eine beschreibende Definition erklärt werden. Für beide Fälle finden sich in der ersten Auflage des russisch-deutschen Wörterbuches Beispiele.

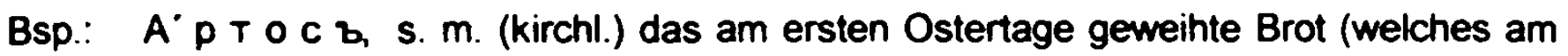
Sonnabend der Osterwoche in der Kirche ausgetheilt wird).

A $р$ × ив в, s. m. das Archiv. 
G y e p b, s. m. 1. halbverdecktes Wasserfahrzeug mit einem Maste; 2. eine Art Schlitten mit Segel (zum Fahren auf dem Eise).

Бур авить, v. a. bohren.

Ман ист a, s. f. (bei den Fischern auf der Wolga:) die Kinnlade vom Stör oder von der Beluga.

ма рин ов внный, ая, oe, adj. mariniert.

П о $6^{\text {' }}$ жник и, s. m. (bei den Kamtschadalen:) ein langer Riemen am Schiitten befestigt, der anstatt der Deichsel beim Fahren mit Hunden dient.

Повив альщица, s. f. die Hebamme.

Сл авильщикъ, s. m. (Einer, der zur Weihnachtszeit in den Häusem geistliche Lieder zu Ehren der Geburt Christi absingt:) der Weihnachtssänger, (etwa wie bei den Katholiken:) der Currendaner, Lauf-, Straßensänger.

Сл ивина, s. f. der Pflaumenbaum.

Die Beispiele machen deutlich, daß Nulläquivalenz sehr häufig bei ausgangssprachlichen Realien vorliegt, da es für sie natürlich keine Entsprechung in der Zielsprache geben kann. Volläquivalenz dagegen begegnet man häufig bei Fachtermini, die aus dem Griechischen oder dem Lateinischen in eine Reihe von Sprachen entlehnt wurden.

Eine zielsprachliche Definition erscheint nur dann notwendig, wenn kein zielsprachliches Áquivalent zur Verfügung steht. In der ersten Auflage des Pawlowskyschen Wörterbuches finden sich allerdings auch zahlreiche Beispiele, bei denen auf der zielsprachlichen Seite sowohl ein Äquivalent als auch eine zusätzliche Definition angefüht werden. Dies ist immer dann der Fall, wenn Pawlowsky berechtigte Zweifel daran haben konnte, daß dem Benutzer des Wörterbuches die Bedeutung trotz der Angabe des Äquivalents klar sein würde. Mit einer zusätzlichen Definition versehen sind nämlich zum einen Äquivalente, die ausgangssprachliche Realien bezeichnen, und zum anderen zumeist fachsprachliche Äquivalente, die im Deutschen durch ein Fremdwort repräsentiert werden.

Bsp.: A $\quad$ H 4 'о y $\mathbf{C}$ b, s. m. (zool. clupea s. engraulis encrasicolus) die Anschove, -vis (Art Sardellen).

6 y 3 a, s. f. die Busa (ein Getränk aus Buchweizen und Hafermehl).

мамер енец в, мамер инец в, нua, s. m. der Mamiering (ein Schlauch von Leder oder Segeltuch zum Ableiten der Wassers - auf Schiffen).

Сквозн Янка, s. f. (eine Molluske:) die Hyaläa.

Vor noch größere Schwierigkeiten wird der Lexikograph durch Lemmata gestellt, bei denen nur eine partielle Äquivalenz mit den zielsprachlichen Entsprechungen vorliegt. Um dem Benutzer die Suche nach dem korrekten Äquivalent zu erleichtern, bedient sich der 
Lexikgraph verschiedener bedeutungsdifferenzierender Mittel. Als implizite Mittel zur Bedeutungsdifferenzierung können Komma und Semikolon betrachtet werden. In der Regel trennt Pawlowsky zwei Äquivalente derselben Äquivalenzgruppe, die prinzipiell gegeneinander austauschbar sind, durch Kommata voneinander. Wenn die Áquivalente zwar der gleichen Bedeutungsgruppe zugeordnet, aber nicht durchgehend synonym gebraucht werden können, so kennzeichnet er dies durch die Abtrennung mit dem Semikolon.

Bsp.: Антип 'аті я, s. f. die Antipathie, Abneigung, der Widerwille (gegen etwas).

Брод 'яжничат т, s. n. [v. n., C. B.] sich herumtreiben; von einem Ort zum andern wandern; keinen festen Verbleib haben; vagabondiren.

$M$ a л ¿ $T$ b, v. n. kleiner werden, sich verkleinern; (vom Wasser in den Flüssen:) abnehmen.

$06^{\circ}$ ай od. $о 6^{\circ}$ ай ик в, s. m. pop. Einer, der etwas durch List erlangt, von Einem, der einem etwas ablugst: der Betrüger.

П ло д ор о дный, ая, ое, adj. Früchte tragend; fruchtbar.

Скв а жина, s. f. die Oeffnung, das Loch, die Spalte, der Riß; [...].

Bei polysemen Lemmata, deren Åquivalente semantisch nichts miteinander gemein haben, bedient sich Pawlowsky arabischer Ziffern, um die einzelnen Bedeutungen linear zu gliedem. Wenn eine noch feinere Untergliederung nötig wird, so werden die arabischen Ziffern mit Kleinbuchstaben kombiniert.

Bsp.: A р м як ъ, s. m. 1. eine Art Kamelot; 2. kameelhaarener Schlafrock.

G p a H b, s. f. 1. der Zank, Streit; die Schmährede; 2. (sI.) der Kampf, die Schlacht; [...]; 3. dünne, gewürfelte Leinwand; 4. (Bot. polemonium) das Sperrkraut; $[\ldots]$.

М е д в ћ дк а, s. f. 1. (Zimmert.) großer Hobel; 2. der Lastwagen mit Blockrädern; 3. (Artill.) der Handprotzwagen; 4. (Bot. meum athamanticum) die Bärwurz, der Bärenfenchel; 5. (zool.) s. Медв Łдокъ.

O 6 ле т a т b, о 6 ле т ' т b, 1. v. n. a. um etwas herumfliegen; b. herabfallen (von Blättern); c. im Fliegen Einem zuvorkommen; 2. v. a. durchfliegen (eine Gegend); [...].

С ле ${ }^{\prime}$ ' $a$, adv. 1. leicht, oberflächlich (berühren, antasten, verwunden); 2 . nebenbei (etwas erwähnen), [...].

Als explizites Mittel zur Bedeutungsdifferenzierung verwendet Pawlowsky nähere Erklärungen, die fast ausschließlich nach dem Äquivalent angeführt und formal vom Äquivalent durch Klammem abgegrenzt werden. Diese Art der Differenzierung findet dann Anwen- 
dung, wenn die Bedeutung des Áquivalents nur in eingeschränktem Rahmen für das entsprechende Lemma gilt.

Bsp.: A м в о н ъ, s. m. 1. das Lesepult (vor dem Altar); 2. erhabener Sitz (mitten in der Kirche, für Bischöfe).

Б y 6 p e r b, s. m. die Niere (bei Thieren).

M 'a з а т b, ма зн 'у T b, v. a. bestreichen (mit Theer, z. B. das Dach); schmieren (die Räder); einreiben (mit Salbe, Oel); [...].

О 6 жи и 'a тb, о 6 w'e 4 b, v. a. brennen (Ziegeln, Töpfergeschirre, Kalksteine); brennen, rösten, abtreiben (Metalle); ringsum anbrennen (einen Pfahl); [...].

ח or a w'a $\mathbf{b}$, nor a c ' $и$ т b, v. a. 1. auslöschen (die Lampe, das Fever); löschen (das Feuer, die Feuersbrunst); 2. fig. bändigen (Leidenschaften); 3. tilgen (Schulden).

I. СКл адывать, сложить, v. a. 1. ablegen, abnehmen (z. B. eine Last von den Schultem); 2. zusammenlegen (etwas aus mehreren Stücken; Wäsche Kleider z.); zusammen-, einbiegen, einschlagen, falten (einen Bogen Papier, Briefe); zusammenschlagen (den L'hombretisch); zusammenlegen, einschlagen (das Federmesser); [...].

Die Beispiele machen deutlich, daß Pawlowsky größten Wert auf eine differenzierte Darstellung der zielsprachlichen Übersetzungsäquivalente legte. Daß dies ein erklärtes Ziel bei der Abfassung seiner Wörterbücher war, wird schon in der Einladung zur Subscription auf das deutsch-russische Wörterbuch deutlich, in der der Autor diejenigen Wörterbücher kritisiert, die mehrere zielsprachliche Aquivalente anböten .ohne Anweisung darüber, in welchen Fällen namentlich jedes von ihnen gebraucht werden soll, so daß der Lernende für den gegebenen Satz irgend einen von diesen Ausárücken auf gut Glück wählt" (Pawlowsky, 1849, 2).

\subsubsection{Syntagmatik}

Die Kenntnis allein der semantischen Entsprechung eines ausgangssprachlichen Wortes ermöglicht dem Benutzer noch nicht die Bildung syntagmatisch korrekter Konstruktionen. Um dem Wörterbuchbenutzer vor allem bei der Textproduktion nützlich zu sein, muß ein Wörterbuch eine Reihe von syntagmatischen Informationen anbieten. Zu denken ist hier etwa an Kollokationen, das heißt an typische Verbindungen, die das Lemma mit anderen Wörtern eingeht, aber auch an Angaben zur Rektion der einzelnen Lexeme. Solche Informationen können entweder explizit hinter dem Lemma angeführt oder implizit anhand von Kollokationen und Beispielen verdeutlicht werden. 
Im Folgenden gilt es zu klären, an welcher Stelle und in welcher Form Pawlowsky syntagmatische Informationen in sein Wörterbuch aufgenommen hat. Der Übersichtlichkeit halber werden die unterschiedlichen Wortarten getrennt voneinander behandelt.

\subsubsection{Syntagmatische Informationen bei den Substantiven}

Bei den Substantiven werden syntagmatische informationen nur in äußerst seltenen Fällen explizit dargeboten (vgl. Bergenholtz, 1984, 28). Lediglich einige wenige Substantive, die einen Kasus regieren können, erhalten von Pawlowsky einen Verweis auf denselben.

Bsp.: Алк'ані е, s. f. (sl.) yer'o, die Gier, heißes Verlangen nach etwas.

$A^{\prime}$ Лчность, s. f. Къ чем'y die Gier, Gierigkeit, heftige Begierde, nach etwas.

м илованіе, м илованье, s. n. kor’o 1. die Zuneigung zu jmd.; die Liebkosung: 2. die Gnadenerweisung.

In allen anderen Fällen enthalten die Wörterbuchartikel der Substantive entweder gar keine syntagmatischen Informationen oder implizite Verweise auf ihren syntagmatischen Gebrauch durch Beispiele und Kollokationen. Die zahlenmäßig größere Gruppe bilden in der ersten Auflage des russisch-deutschen Wörterbuches Substantive ohne Verweis auf ihren syntagmatischen Gebrauch. Da hier nur die Hinweise auf die syntagmatische Verwendung von Interesse sind, kann auf Beispiele aus der ersten Gruppe verzichtet werden.

Bsp.: A м 6 'ар b, s. m. der Ambar, der Speicher, xr t6m an6. der Kornspeicher, die Kornklete, das Getreidemagazin; CKrianoum an6. der Waarenspeicher;

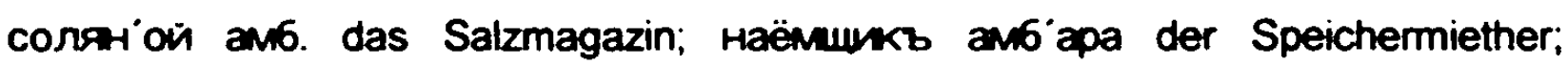
скл'адывать тов' ары въ ам6. die Waaren speichem, aufspeichem; [...].

Б у м 'a r a, s. f. 1. das Papier; nouroв aя 6. das Postpapier; 2. eine Schrift, ein Schreiben, die Ausfertigung; казёная 6 . gerichtliches Schreiben; заиил'ительая 6. die Vertheidigungsschrift; под'ать на ког'0-либо бумаг'у schriftlich über Jmd. Klagen; eine Klage über Jmd. einreichen; прив 'есть бум' arи Bb пор ядокъ die Papiere (Acten, Schriften) in Ordnung bringen; на бум'аrt schriftlich; schwarz auf weiß; 3. das Baumwollengarn; кp'aweнаa 6. gefärbtes B.; хлопч атая 6. die Baumwolle (zum Wattiren); чул'очная 6. die Strumpfbaumwolle.

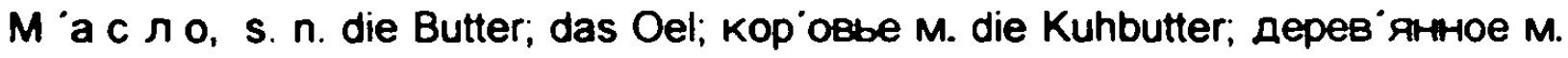

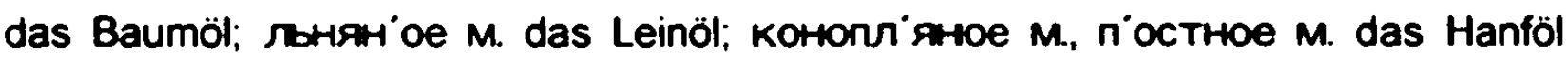
(Fastenöl); K’amehнoe, r'ophoe, yёрн-ое M. das Stein-, Bergöl, die Naphta; ky- 


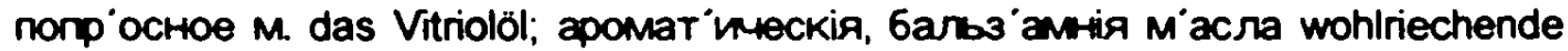
Oele; die Olitäten; торг youin̆ аромат 'илескими м' acлами der Olitätenhändler, -

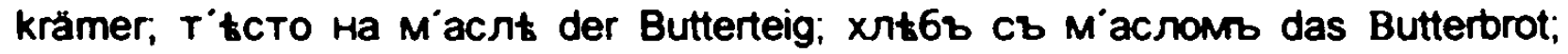
Kaxb no M'acлy fam. (Sprüctww.) es geht, wie geschmiert; M'acлoмb залм'ать пож' aps (Sprüchw.) Oel in's Feuer gießen; eine Sache noch gefährlicher machen; S. auch Кат'аться (вb M'acлt); S p rü chw. M'acso cavio to pog 'ится wer was haben will, muß die Mühe nicht scheuen; gebratene Tauben fliegen nicht in den Mund.

O 6 o p o t b, s. m. 1. die Wendung (der Sprache, Proceßsache); 06. crosb die Wortwendung; 2. der Umsatz (im Handel); Topr oвble o60p oты die Handelsunternehmungen, -spekulationen; им' вть калит ars вb o6op'ort sein Kapital im Handel umsetzen; s. auch Пуск`ать (капмт 'aתь въ 06.); 3. die Kehr-, Rückseite; die umgekehrte, linke Seite (eines Blattes, einer Münze); der Revers (einer Münze); Ha 060p отъ als Adv. auf die andere Seite gewendet; umgekehrt; взять сл ово на о6.

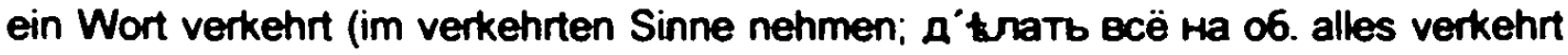
(in verkehrter Weise) machen; 4. der Rauchgang, -zug (in Oefen); nous o wecr'u 06-axъ д bva ein Ofen mit sechs Rauchzügen; [...].

C $\Omega$ о в о, s. n. 1. als Benennung des zwölften Buchstabens (C) des slavonischen

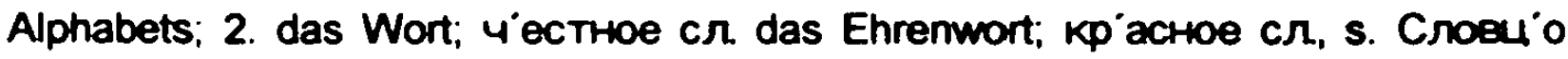
(кр'асное); л'агерное сл. (Milit.), s. Пар 'оль; Cл ово Б'owie das Wort Gottes; die heilige Schrift; no6'ители P'yсcкаro Сл'oвa Freunde der russischen Sprache; сл ово въ сліово wörtlich; worttreu; buchstäblich; genau; оть сліова до сліова

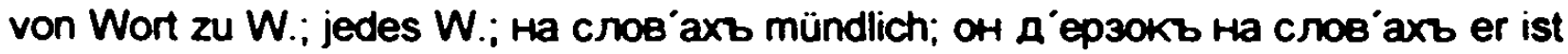
frech im Reden; словомв и д tromb mit Rath und That (z. B. Einem beistehen); сліовомв оd. одн ими сліовомв mit einem Worte; genug; kur; kurz gesagt; um nicht viele Worte zu vertieren; um nicht viel Redens zu machen; Hккт'о ни сліова Niemand sprach ein Wort; Alle schwiegen; дать сл oso sein Wort geben; versprechen; сдержн ать сліово sein Wort, sein Versprechen halten; ein Mann von Wort sein; orb he дасть MHt crioвa в'brosoputb (сказ'ать) er läßt mich nicht zu Wort kommen; 3. die Rede. Sprache; дарь слі овa die Rednergabe, das R-talent;

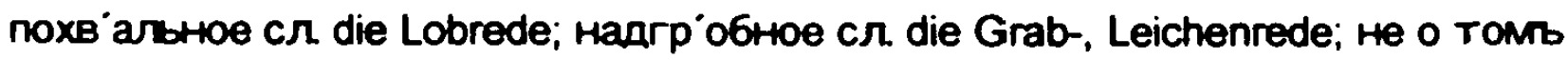
сліово es ist nicht davon die Rede; fern. (ehed.) сл ово и д $\mathbf{t}$ ло! Wort und That! 
(ein Ausdruck, der bei der Anklage eines sctweren Verbrechens gebraucht murde); 6ыть въ сл'овt (ehed.) unter Verantwortung stehen; Rede und Antwort geben müssen; с'удное сліово das Brustschild, Amtsschildlein (bei den jüdischen Hohenpriestem der Vorzeit); - S p r ü ch w. Д'авим сл'ово дерн' Ись, а не д'авим

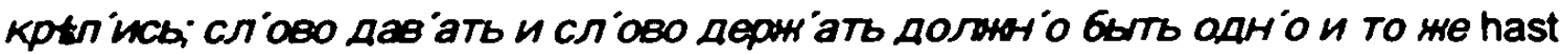
du dein Wort gegeben, so mußt du es auch halten; y 4'естнаго челов 'кка одн'

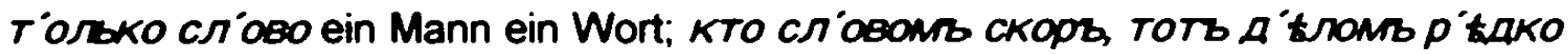

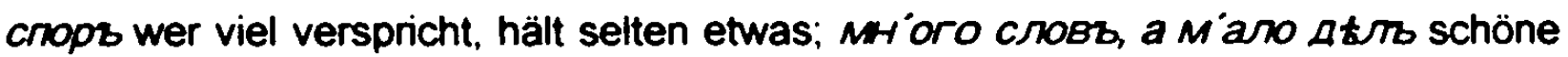
Worte ohne Werke; viele Worte, wenig Werke; viel Geschrei und wenig Wolle; the вC'яко сл'ово за $A^{\prime}$ ' в'O вромия и кст'ати сильн 'te письм'а и печ'aru ein gut Wort findet eine gute Statt; ein gut Wort richtet mehr als ein Fähnlein Lanzknechte; отъ уит vвыхъ словъ яз 'икъ не отс 'охнеть höfliche Worte machen die Zähne nicht stumpf, [...].

Die Beispiele machen deutlich, daß implizite Informationen zum syntagmatischen Gebrauch der Substantive nicht nur durch Kollokationen unterschiedlicher Art geliefert werden, sondern auch durch Aufnahme von ganzen Sätzen und Phraseologismen. Im Folgenden stehen jedoch nur die Kollokationen im Mittelpunkt des Interesses, denn den Beispielssätzen und den Phraseologismen ist ein eigener Unterpunkt gewidmet (vgl. 4.2.5.5, 121-122), der sich der Analyse der expliziten und der impliziten syntagmatischen Informationen bei den einzelnen Wortarten anschließt.

Bei der Untersuchung der Kollokationen stellt sich die Frage, ob Pawlowsky bei deren Anordnung einem bestimmten System gefolgt ist. Vergleicht man die Anordnung der Kollokationen in den Beispielen, so kommt man zu dem Schluß, daß Pawlowsky sich prinzipiell an eine systematische Folge hält. An erster Stelle werden Verbindungen der jeweiligen Substantive mit Adjektiven angeführt, wobei die Verbindung im Nominativ Singular steht. An zweiter Stelle folgen Verbindungen mit zwei Substantiven, wobei das Lemma im Nominativ und das zweite Substantiv im Genitiv steht. Die dritte Gruppe bilden SubstantivAdjektivkombinationen im Nominativ Plural. An vierter und an fünfter Stelle werden Verbindungen mit Verben und Präpositionalgefüge aufgelistet. Wenn Phraseologismen aufgenommen werden, so schließen sie den jeweiligen Wörtertuchartikel ab. Abschließend ist zu betonen, daß die eben vorgestellte Systematik in dieser Maximalausdehnung nicht in der Stichprobe vorkommt. Üblich ist vielmehr die Angabe von durchschnittlich zwei Kollokationen, die häufig auch nach dem gleichen syntagmatischen Prinzip gebildet sind. 


\subsubsection{Syntagmatische Informationen bei den Adjektiven}

In der Stichprobe gibt es nur sehr wenige Beispiele für Adjektive, die explizit mit einer Rektionsangabe versehen sind.

Bsp.: $A^{\prime}$ лчный, ая, oе, adj. 1. heißhungrig; 2. unersättlich; 3. fig. 'алmый къ чему gierig, habsüchtig.

м илостивный (st.), м илостивый, ая, $\infty$, adj. 1. къ ком'y herablassend, gegen Einen; leutselig; 6 ланенм милостивin (Matth. V. 7.) selig sind die Sanftmütigen; 2. gnädig, gütig; M. rосуд apd gnädiger Herr! mein H.I

О 6 и льны й, ая, $\infty$, adj. чtмъ Ueberfluß habend, reich an etwas; 06. з'олотомъ goldreich; 06. ист'оникъ reiche, ergiebige Quelle; 06-ая ж'атва reiche Ernte.

In allen anderen Fällen wird über den syntagmatischen Gebrauch der Adjektive nur implizit durch die Aufnahme von Kollokationen und Beispielssätzen informiert.

Bsp.: Ар 'ендный, ая, ое, adj. zur Arrende gehörig; ар. дох одъ die Einkünfte von der Artende; взять на ар ендное содерж' анie arrendiren, pachten, in Pacht nehmen; отд'ать на ар' ендное сод. verarrendiren, verpachten.

Бр 'анный, ая, oe, adj. 1. (sl.) kriegerisch; Kriegs-; Kampf-; 6p-ые кр'ики der Kriegslärm; 6p-te a'ocntxu die Kampfrüstung; 6p-oe вंon+ство kampfrüstiges Heer; schlachtfertiges H.; Ha 6p' a homb n'ont auf dem Kampfplatze; 2. schmähend: 6p-ыя слов'a die Schmäh-, Schimpfworte.

M 'е т к i й, aя, $\infty$, adj. sicher; genau; M-aя pyk'a sichere, geübte Hand; M. взг лядъ richtiger Blick; M. B'bытtрtль sicherer Schuß.

О 6 орон ительный, ая, ое, adj. vertheidigend, denfensiv; о6. 'уголь (Fortf.) der Streich-, Defensionswinkel; 06. co'rosъ das Schutzbündnis, die Defensivallianz; s. auch Наступ ателыни (и о6. со'юзъ); о6-ая вонн'a der Defensiv-, Defensionskrieg; о6-ое полож etie der Vertheidigungszustand, die Defensive; дернать себ'я въ 06-омв положеніи (Krgsw.) sich defensiv verhalten; пост' аеить се6'я въ о6-ое полон' die Defensive ergreifen.

П ло щ а дн о й ('bи), 'ая, 'ое, adj. 1. sich auf den Marktplatz beziehend; пл. ст'ароста der Marktvogt; пл. тов'ap々 die Marktwaare; 2. niedrig, gemein, pöbelhaft; пл-'ыя р'亡чи ungebührliche Reden; пл-'ыя н'овости die Altagsneuigkeiten; пл. враиъ der Afterarzt, Quaksalber, Charlatan, Marktschreier.

CK 'о p i h̆, as, oe, adj. geschwind, schnell, flink, rasch; cK. Mapuß der Eilmarsch; forcirter Marsch; cK. Ha n'omoubs gleich zur Hülfe bereit; cK. Ha rHtbs immer ge 
neigt zum Zome; sehr auffahrend; orb ckops H’a Hory er geht (läuft) sehr schnell; д' влать что на ск' орую р'yky etwas obenhin (überhin) machen.

Bei der Analyse der Kollokationen fällt auf, daß Pawbowsky fast ausschließlich Beispiele für den attributiven Gebrauch der jeweiligen Lemmata aufgenommen hat. Wünschenswert wäre es gewesen, wenn er den prädikativen Gebrauch der Adjektive mit mehr Beispielen belegt hätte. In der gesamten Stichprobe finden sich nur drei Einträge, die implizit Informationen zum prädikativen Gebrauch der Adjektive bereitstellen.

Bsp.: 6 о 'я р о в а ты й, adj. stolz, wie ein Vomehmer; онъ черезъ чуръ $60^{\circ}$ яровать er brüstet sich zu sehr, er macht sich zu vornehm.

П лохов А с ов атый, ая, ое, adj. pop. einfältig; онъ плохов 'совать еr ist etwas einfach, einfältig.

С к у чн й, ая, $о$, adj. 1. langweilig; lästig; cK. гость lästiger, überlästiger Gast; 2. traurig; ск-ое вр' емя traurige Zeit; что ты такъ ск'учен? warum bist du so traurig?

Auch bei den Adjektiven läßt sich ein Muster bei der Anordnung der Kollokationen erkennen, das allerdings nicht immer eingehalten wird. An erster Stelle werden in der Regel Verbindungen der jeweiligen Adjektive mit Substantiven angegeben, wobei diese im Nominativ Singular oder Plural stehen. An zweiter Stelle folgen Beispiele für die Kombination von Adjektiven mit Präpositionalgefügen. Daran anschließend werden Verbindungen mit Verben angeführt, auf die in seltenen Fällen Beispiele für die prädikative Verwendung der Adjektive folgen.

\subsubsection{Syntagmatische Informationen bei den Verben}

Die in der ersten Auflage des russisch-deutschen Wörterbuches lemmatisierten Verben sind die am konsequentesten mit expliziten Hinweisen auf ihren syntagmatischen Gebrauch versehene Wortart. Zum einen wird mit der Auszeichnung der Verben als aktiv bzw. neutral (vgl. Pkt. 4.2.2.1, 97) regelmäßig auf deren transitiven bzw. intransitiven Gebrauch verwiesen, zum anderen wird bei den intransitiven Verben häufig explizit auf die Rektion des Verbes hingewiesen, indem pronominale Wortgruppen in den entsprechenden Kasus angeschlossen werden. Darüber hinaus finden sich bei vielen Verben konkrete Beispiele, die über den syntagmatischen Gebrauch Aufschluß geben.

Bsp.: А д р ес о в а т b, v. a. adressieren; -cя, v. $r$. Къ ком'y sich wenden an Jemand; [...]. 


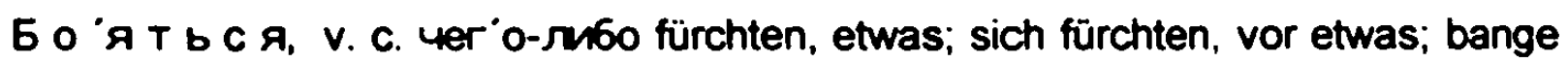
sein; 6. вод'ы sich vor Wasser fürchten; wasserscheu sein; 6. мущ инъ männerscheu sein; 9 " 9 Toro He $60^{\circ}$ 'مcb davor ist mir nicht bange.

мил ос ердовать, v. n. о комъ barmherzig, mitleidig sein, Mitleid haben, mit Jmd.

06 лич а ть, о 6 лич ит ь, v. a. 1. ког'0-либо въ чёмъ Einen überweisen, überführen einer Sache (eines Verbrechens); 2. обл. что beweisen, bekunden (z. B. Jmos. Talent); [...].

По 6 ы в 'а т b. v. n. (voll.) rat besuchen (einen Ort); $n$. y kor'o-תu6o besuchen, Einen.

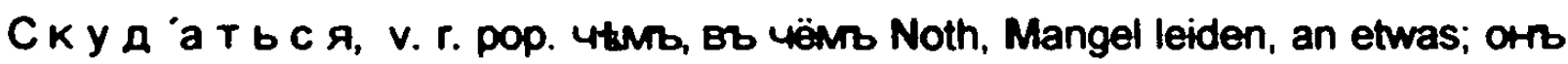
скуд'ается д 'енами es mangelt inm an Geld; es fehlt inm Geld; er hat kein G.

Die Beispiele machen deutlich, daß Pawlowsky sich auch bei der Erarbeitung des russisch-deutschen Wörterbuches an das bereits für das deutsch-russische Wörterbuch aufgestellte Prinzip hält, die Rektion des russischen Verbs immer dann anzugeben, wenn sie von derjenigen des entsprechenden deutschen Verbs abweicht (vgl. Pawlowsky, 1849, 10).

Neben den expliziten Hinweisen finden sich auch bei den Verben implizite Verweise auf inren syntagmatischen Gebrauch in Form von Kollokationen und Beispielssätzen. Allerdings ist festzustellen, daß, obwohl die Verben relativ konsequent mit syntagmatischen Angaben versehen wurden, die Zahl der Verben ohne implizite Hinweise immer noch gröBer ist als diejenige mit Verweisen.

Bsp.: Брос ат ься, 6 р о ситься (voll.) v. r. stürzen, hineinstürzen (z.B. in ein Haus); sich stürzen (in's Wasser); $6 p^{\circ}$ оситься на n'omous zur Hülfe eilen; $6 p$. на уумиу auf die Straße hinauseilen, hinausstürzen; 6р. на кол' trm sich auf die Knie werfen; auf die $\mathrm{Kn}$. fallen; niederknien; 6p. въ глаз ${ }^{\circ} \mathrm{a}$ in die Augen fallen; 6p. ком 'y-

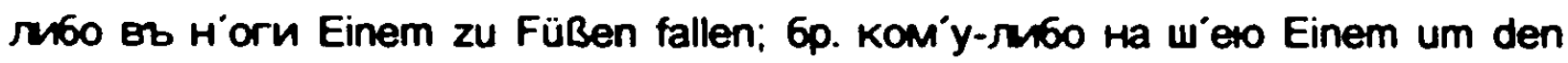
Hals f.; $6 p$. Ha kor'0-sm60 über einen herfallen, (Von Hunden - auch:) anfallen, Einen; 6рос' аться туд'а и скад'a, 6p. во всt ст'ороны sich hin und her werfen; hin und her laufen, rennen; $6 p^{\circ}$ оситься 6 бж ать anfangen zu laufen; davon laufen, losziehen; 6p. 3a Kturb въ nor' owo Einem nachsetzen; s. auch unt. Orpometb; кpoвs 60 осилась Bъ $r^{\circ}$ onoвy das Blut schoß (stieg) zum Kopfe. 
мет 'ать, метн'уть, v. a. werfen (Bomben etc.); schleudern (Steine); abschießen (Pfeile); M. икр'y (von Fischen:) den Laich absetzen; laichen; М. кот ятъ junge Katzen werfen; $M$. pyныёмb mit der Flinte exerciren; $M$. жр werfen; loosen; м. кровь zur Ader lassen; м. 'искри, s. И'скриться; м. К'арты (Kartsp.) die Bank halten; M. C'tho das Heu in Haufen werfen, zusammenwerfen; $M$. Bcë изъ оКн'a alles zum Fenster hinauswerfen; M. пंетлм (Schneid.) die Knopflöcher benähen, bewerfen; M. Bзоръ, 'ou, den Blick, die Augen werfen auf etwas; рвёть и м ечеть reißt und schmeißt (vom Sturmwinde, von zornigen Menschen); $3^{\circ}$ аяць м'ечеть пंетли (Jäg.) der Hase springt von der Fährte ab (wirft sich hin und her, damit seine Spur nicht bemerkt werde); вс'е, что есть въ печи, на столь меч $и$ tische auf, was du hast (was Küche und Keller vermögen); [...].

О 6 новл я ть, о 6 нов ить, v. а. 1. emeuem, wiedertherstellen (ein Gebäude); auch: eimweihen (eine Kirche); 2. zum ersten Mal gebrauchen; o6H. nviatbe ein neues Kleid zum ersten Mal anziehen; ein neues Kleid einweihen; 06H. Kap етy in einer neuen Kutsche zum ersten Mal ausfahren; seinen neuen Wagen einweihen; 3. von Neuem beleben; весн он с олнце обновліяеть прир оду die Sonne belebt im Frühling die Natur, [...].

Поги $6^{\circ}$ т т, пог и 6 нут ь, v. n. umkommen (z. B. auf der Reise); untergehen (von Schiffen); oнъ здtсь nor ' ибнеть er wird hier zu Grunde gehen, ganz verderben; orrs nor ' 6 b не из8 ' tстно rat man weiß nicht, wo er geblieben ist; er ist verschollen; otrb nor ${ }^{\circ} 6 \mathrm{~b} \mathrm{Bb}$ волнахъ er ist in der See ertrunken; OHb nor 'ибぬ es ist um ihn geschehen; cnac 'ите! norv6' aso rettet mich! ich bin vertoren.

Сл амывать, слом'ать, слом'ить, v. а. 1. abbrechen; zerbrechen; 2. niederreißen, abreißen, abtragen (ein Gebäude); 3. fig. слом ить ког'о-либо Einen mit Mühe bewegen, bereden, zu etwas; сломить чей нравъ Einen zahm, kirre machen; слом ить ш'ею den Hals brechen; слом'я $r^{\circ}$ олову über Hals und Kopf; orb no6tw'arb cлom a r'oлoвy er lief, was er konnte, als ob inm der Kopf brennt; [...].

Einen Ausnahmefall stellt das Verb 6aTb dar, da es relativ komplizierten syntagmatischen Regularitäten unterliegt. Wie das folgende Beispiel deutlich macht, hat sich Pawtowsky dafür entschieden, den Artikel einerseits mit syntagmatischen Erklärungen zu versehen, die dann durch Beispiele belegt werden, und inn andererseits auch nach syn- 
tagmatischen Gesichtspunkten zu untergliedern. Am Ende des Artikels werden dann unter den ferneren Beispielen Kollokationen angeführt, die sich nicht in die syntagmatische Systematik einordnen lassen.

Bsp.: $Б$ Бы т , v. n. 1. sein, a. mit dem Nomt., wenn dem Subjecte ein bleibendes Prädicat beigelegt wird, 2. В. он былт д'обрый челов zкъ er war ein guter Mensch;

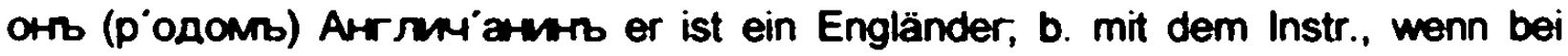
dem Subjecte ein nur angeeignetes, vorübergehendes Prädicat steht, z. B. utumb ты х'о4еub 6ыть? - yёы was willst du werden? - ein Gelehrter, orb 6ыль тогд' а мо имъ пом' ощинкомъ er war damals mein Gehülfe; 2. das Zeitw. 6ыть in Vertindung mit der Präp. y wird im Deutschen gewöhnlich durch $h$ a b e $n$ ausgedrückt; z. В. у мен'я есть ещё д'etribn ich habe noch Geld (übrig); y Her'o (anst. у нег'о есть) мн'ого друз'еn er hat viele Freunde; suep'a н'е было у нась гост'ей (gestern hatten wir keine Gäste) wir haben gestern keinen Besuch gehabt; 3. das Prät. $6^{\circ}$ bvo, wenn es einem Zeitworte angehängt ist, bezeichnet so viel als schon, beinahe, hätte, müssen, sollen, 2. В. я хот ұлъ-было сказ'ать ich wollte schon sagen; ich hätte beinahe gesagt; orr H'atoumb-6ыло пор'ядони капмт 'алт, да - er hatte schon ein ziemliches Kapital erworben, aber -; сход ить-было те6 einen Gang zu ihm gemacht haben können; онъ yriamb-6ыло, да удерж'ался за nep ила er wäre (beinahe) gefallen, wenn er nicht nach dem Geländer gegriffen hätte; - fernere Beispiele: какъ 6ыть? was macht man nun? быть такъ es mag sein; meinetwegen; такъ и быть es mag denn so sein, wenn es nicht anders ist; быть по сем'y es sei; dem sei also; чем'у быть, тог'о не миновать s. Mnнов ать; какъ ни есть gleichviel wie; darüberhin; то есть das ist: nämlich; есть и честые riюди es giebt auch (mitunter giebt es auch) ehrliche Leute; как бы то ніи было wie dem auch sein; 6'buлo 6ы т'олько чtмrb налть wenn man nur Mittel hätte (hat) zu leben; был'а не был'а auf gut Glück; и быль так'овъ, s. unt. Так'овъ; я Къ те6't сег'одня 6'yдy ich werde heute zu dir kommen; 'это непрем' t1 $1066^{\circ}$ удетъ das wird durchaus geschehen; das wird nicht ausbleiben; em 'y $6^{\circ}$ удеть $3^{\circ}$ а это в 'brоворь er wird dafür einen Verweis bekommen; 4то $6^{\circ}$ удеть, то $6^{\circ}$ yдетв es mag kommen, was da will; пусть 6 уддетъ nо тв' оeмy es mag so sein, wie du es willst; да $6^{\circ}$ yдетъ auf das geschehe; $6^{\circ}$ yдетъl das ist hinlänglich, hinreichend! genug! das reicht schon hin! $6^{\circ}$ yдетъ $^{\circ} 6^{\circ} t$ ! du wirst schon deinen 
Theil bekommen; не будь я здысь - wäre ich (zufällig) nicht hier gewesen, -; и будь я всег'о лмшёtrb und soltt' ich auch alles vertieren; und sei es auch, daß man mir Alles nimmt.

Es stellt sich nun die Frage, ob die Kollokationen und Beispiele willkürlich oder nach einer bestimmten Systematik angeordnet werden. Nach der Analyse der oben angeführten Beispiele läßt sich allenfalls feststellen, daß Kollokationen prinzipiell vor Beispielsätzen angeordnet sind, aber eine Systematik bei der Anordnung der Kollokationen selbst ist nicht zu erkennen.

\subsubsection{Syntagmatische Informationen bei den Prapositionen}

Reich mit syntagmatischen Angaben versehen hat Pawlowsky die Präpositionen. Die Wörterbuchartikel der Präpositionen untergliedert er nach deren syntagmatischen Regularitäten, wie die folgenden Beispiele eindrucksvoll belegen.

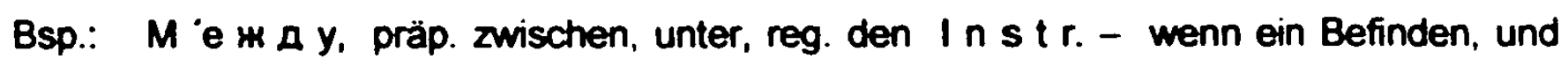
den Gent. - wenn eine Bewegung zwischen zwei oder mehreren Gegenständen bezeichnet wird, 2. В. немть м'ежду д'обрыми лодымі и unter guten Menschen leben; наход иться м. стр'ахомь и над'ендоно zwischen Furcht und Hoffnung schweben; дор' ora изеив аeтъ $M$. горъ der Weg schlängett sich zwischen Bergen; fern. M'ежау Ttмß inzwischen; unterdessen; während dessen; $M$. nр' o umb unter anderm; M. намм (6удь) ск' азан to unter uns gesagt; im Vertrauen $g$.

ח o, praep. auf, zu, bis, bis an, bis nach, bis über etc. regiert 1. den Dat. a. auf die Frage wor a uf? - Bei einer Bewegung auf der Oberfläche eines Gegenstandes, z. В. гул'ять n'о полю, n'o городу auf dem Felde, in der Stadt spazieren gehen; $6^{\circ}$ tгать no 'улмut auf der Straße herumlaufen; nлыть no ptk' $t$ auf dem Flusse fahren: $b$. auf die Frage $z u$ wie viel? no py6rio cъ K'aждаro von Jedem zu einem Rubel; no пят'и фуунтовъ zu fünf Pfund; $c$. auf die Frage wann? zu welcher Zeit? an welchem Tage steht nach no der Dat. Plur., z. B.

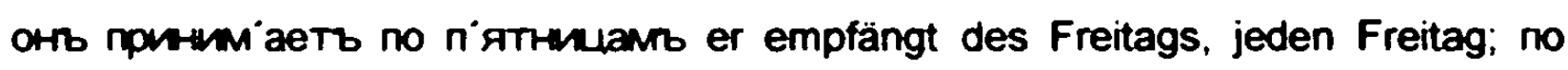
воскрес ендамъ an den Sonntagen, an jedem Sonntag; по пр аздникамъ an den

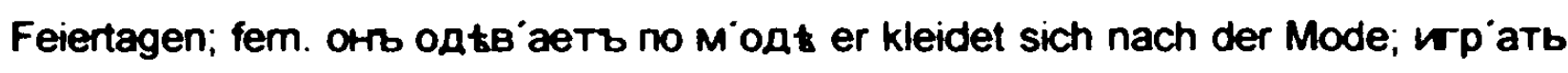
по нотамъ, по насліbukt nach Noten, nach Gehör spielen; узн ать ког'o no r'osocy Einen an der Stimme erkennen; - 2. den Accs. a. auf die Frage b is wie we it? wenn eine gewisse Grenze der Handlung bezeichnet wird und no so viel als 
до bis $z u$, bis a neißt, z. В. сто ять nо w'ею, no кол' thо вb вод't bis an den Hals, bis an den Knieen im Wasser stehen; orъ n'о уим въ дол 'axъ еr ist bis über die Ohren in Schulden; no 'это $M^{\circ}$ Łсто bis zu dieser Stelle; no c ie вр' емя bis zu dieser Zeit; bis jetzt; no n'epeoe unлjo R-вар"я bis zum ersten Januar, b. auf die Frage w o n a ch ? wenn die Präp. no (und zwar von dem gemeinem Manne) anstatt sa gebraucht wird, z. B. он'a nowria n'o воду, no дров a (anstatt за вод ${ }^{\circ}$ ок, за дров амм) sie ging nach Wasser, nach Holz; s. auch unt. Yrryck'atb, Пов анмваты. III. (im Sprüchw.); - 3. den Präp. auf die Frage w on a ch ? n a ch we $m$ ? wenn eine Handlung bezeichnet wird, die in Folge von etwas geschieht, s.

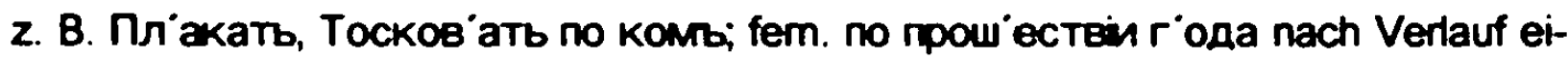
nes Jahres; no okorriarin pa6 otb nach der Beendigung der Arbeit; orro Bibctptrumb no Hënb er schoß nach ihm.

Cкв 0 3 b, praep. durch.

Der Aufbau der Wörterbuchartikel zu den Präpositionen kann als gelungen bezeichnet werden, da der Benutzer umfassend über die syntagmatischen Regularitäten der einzelnen Präpositionen informiert wird.

\subsubsection{Syntagmatische Informationen durch Beispielsatze und Phraseologismen}

Neben frei gebildeten Sätzen, wie sie beispielsweise in den Artikeln zu norи6ать und zu ckymbin zu finden sind, hat Paulowsky auch Zitate aus der Bibel und aus der russischen Literatur sowie Sprichwörter aufgenommen, um dem Benutzer Informationen über den syntagmatischen Gebrauch einzelner Lemmata bereitzustellen.

Bsp.: A y $\quad$ с а т b, v. n. Einem zurufen, au schreien; -cя, v. r. einander zuschreien, au zurufen; $S$ prü chw. каког'o аукнется, таког'o и отклікнжется wie man in den Wald schreit, so schallt es wieder heraus; wie du rufest in den Wald, die Stimme dir entgegen schallt; wie man fragt, so wird man berichtet.

Б р о д ит ь, 1. v. п. а. herumstreifen, -gehen, -wandern; онь д олто по

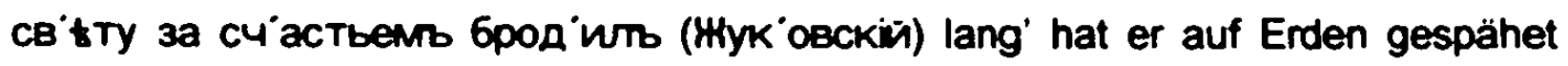
nach Glück; [...].

$6 p$ io $x$ 0, s. n. der Unterleib, Bauch, Wanst; [...]; Sprüchw. ha 6p roxt шёлкъ, хоть въ 6р гохь щёлкъ Alles auf dem Leibe und Nichts im Leibe; Sammt (od. Gold) am Kragen, Hunger (od. Kleie) im Magen; goldene Treffen und, nichts zu essen; Dickthun ist sein Leben, zwei Pfennige sein Vermögen; roл'oarнe $6 p^{\circ}$ 'охо 
yw'en tнe un'terb der hungrige Bauch hat keine Ohren; dem Hungrigen ist nicht

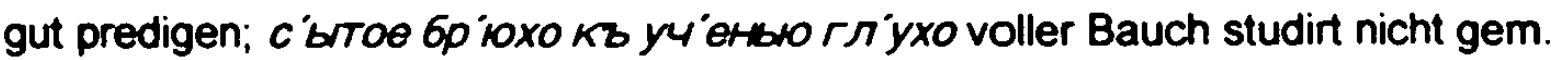

Б у й с т в о, s. n. 1. der Ungestüm; die Frechheit, Gewaltthätigkeit; 2. (sI.) die Unwissenheit, Thorheit; спаст'и $6^{\circ}$ yйствомъ пр оповыди (I. Cor. 1. 21.) durch thörichte Predigt selig machen.

Ma 'я T b, v. a. pop. ermüden, erschöpfen; -cя v. r. schmachten, verschmachten; sich abplagen; а я ещё жв у и м'аось (Долтор 'уковъ) und ich? ich lebe noch und placke mich.

М и л о, adv. lieb, angenehm; S p r ü с h w. дорого да міило (дёшево да

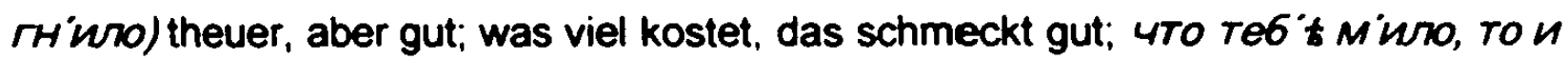
M-t $A^{\prime}$ 'oporo was dem Einen recht, ist dem Andern billig.

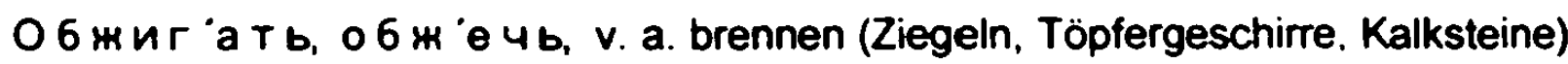
[...]; - cя, v. r. utmß sich verbrennen, an etwas; fig. auch: übel anlaufen, wobei; v. p. gebrannt werden, angebrannt w. etc. S p r ü chw. обжёгшись на молок't (od. Ha молом' '), ст'анешь дуть и н'а воду (оd. И на вод ииу); кто на молок't обнёrся, дууетъ ина воду verbranntes Kind scheut das Fever, gebrühtes Kind scheut auch das kalte Wasser, durch Schaden wird man klug (vorsichtig).

О 6 лек'а т b, о 6 л'е 4 b, v. a. 1. bekleiden; 2. umgeben; einhüllen; -cя, v. r. sich anziehen, sich ankleiden; (sl.) вb лtnoт'y o6 лек' аться sich ausschmücken; да облеч емся и во 'о6разъ Не6" еснаго (I. Cor. XV. 49) so werden wir auch das Bild des Himmlischen tragen.

П о в † д а т b, v. а. erzählen; mittheilen; пов ұждь ц'еркви (Matth: XVIII. 17.) sage es der Gemeinde; не6ес'а пов tдають сл'аву Б'онiо (Psalm XIX. 17.) die

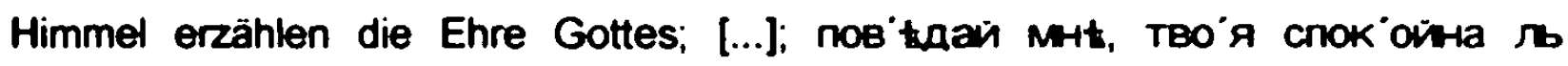
голов' a (Б'атюuковъ) nun sage mir, ob du auch ruhig bist; [...].

СКлон'я Haupt); senken, herabsenken; [...]; и вождь и р.атнки чел'о склоніил въ прахъ (Б'атюиковъ) und Feldherr und Soldaten senkten tief das Haupt; 2. bewegen, bereden, überreden, willig machen, geneigt m., zu etwas. Einen;

पто 6'удто с'амым крокод иламь.

Всьхъ м'илостей тво ихъ 30'иламъ, 
Всегд' а склон яешься прост'ить. (Дерн авинг.)

Als ob du selbst den Krokodillen,

All' deiner Gnad' Zoilen

Stets zu verzeihen bist geneigt:

3. Gramm. abändern, beugen, decliniren; [...].

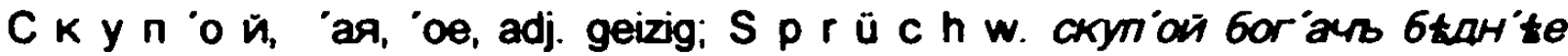
Hinularo der Geizige ist ein reicher Bettler; Geiz ist die größte Armuth; ckyn'ony

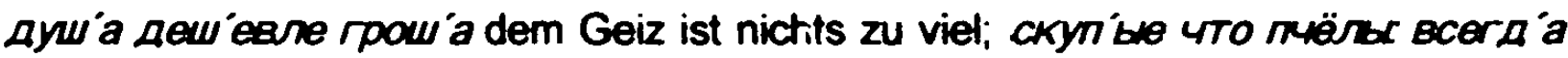

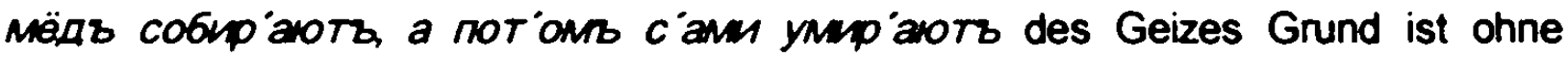
Schlund; je mehr der Geizige hat, je weniger wird er satt; ckyn ble yмм 'aorz, a 口't TKи сунаук' ' отrnp aotz auf den Sparer folgt der Zehrer.

Der Wert der Zitate für die Textproduktion oder die Textrezeption ist als relativ gering einzuschätzen, da man sich kaum Situationen vorstellen kann, in denen diese sehr spezifischen Konstruktionen Anwendung finden könnten. Für den Benutzer sinnvoller wäre ein Verzicht auf die Zitate zugunsten weiterer Kollokationen gewesen. Positiv zu bewerten ist dagegen die Aufnahme der Sprictwörter, da diese dem Kulturwortschatz einer Sprache angehören und deshalb meist keine 1:1-Übersetzung möglich ist.

\subsubsection{Zusammenfassung}

Durch die Analyse wurde deutlich, daß bereits die erste Auflage des russisch-deutschen Wörterbuches über eine relativ komplexe Mikrostruktur verfügt. Um die Untersuchung abzurunden, soll nun noch angeführt werden, wie die einzelnen Wörterbuchartikel aufgebaut sind. Vorgestellt wird der Aufbau eines einfachen Wörterbuchartikels, bei dem keine Bedeutungsdifferenzierung durch arabische Ziffem vorliegt, denn der Aufbau der komplexen, d. $h$. durch arabische Ziffern in unterschiedliche Bedeutungen aufgespaltenen Wörterbuchartikel ergibt sich aus der Aneinanderreihung mehrerer einfacher Wörterbuchartikel.

An erster Stelle direkt hinter dem Lemma steht in der ersten Auflage des untersuchten Wörterbuches in einigen seltenen Fällen der Verweis auf die Flexion. Im Anschluß daran findet sich die Angabe zu den Wortarten, die obligatorischer Bestandteil eines Artikels ist. Gefolgt wird diese Angabe gegebenenfalls von Markierungen und expliziten Angaben zu der Rektion, wobei über ihre Reihenfolge keine Aussage getroffen werden kann, da in der Stichprobe keine Beispiele enthalten sind, die sowohl eine Markierung als auch eine explizite Angabe zur Rektion aufwiesen. An nächster Stelle steht mit den Äquivalenten das wichtigste Element eines zweisprachigen Wörterbuches. Auf die Äquivalentangaben folgen in einigen Fällen die Kollokationen, wobei eine interne Systematik bei der Anordnung der 
Kollokationen nur in Ansätzen zu erkennen ist. Nach den Kollokationen als Abschluß des Artikels positioniert sind Beispielssätze und Phraseologismen.

Ein einfacher Wörterbuchartikel besteht demnach in seiner Maximalausdehnung aus folgenden Elementen: Lemma + (Flexionsangabe) + Wortartangabe + (Markierung) + (Rektion) +Ãquivalent(e) + (Kollokationen $)+($ Zitate $)+$ (Phraseologismen $)$.

Allerdings findet sich in der Stichprobe kein einziges Beispiel für die maximale Mikrostruktur. Vielmehr bilden solche Artikel die Mehrzahl, die nur aus den obligatorischen Elementen Lemma, Wortartangabe und Äquivalent(e) bestehen.

\subsection{Die Mikrostruktur der zweiten Auflage des russisch-deutschen Wörterbuches}

Als Bezugspunkt bei der Analyse der Mikrostruktur der zweiten Auflage des russischdeutschen Wörterbuches von Pawlowsky dienen die Erkenntnisse aus der Untersuchung der ersten Auflage. Ziel dieses Abschnittes ist es, die Veränderungen herauszuarbeiten, die Nikolič und Asmuss bei der Überarbeitung des Wörterbuches vorgenommen haben. Um den Rahmen der Arbeit nicht zu überschreiten, wird auf diejenigen Phänomene, die in der zweiten Auflage unverändert beibehalten wurden, nur in begründeten Ausnahmefällen eingegangen.

\subsubsection{Phonetische Informationen}

Bei der Präsentation von phonetischen Informationen haben Nikolič und Asmuss keine nennenswerten Veränderungen vorgenommen. Beibehalten wurde die durchgehende Akzentuierung der zwei- und der mehrsilbigen Lemmata sowie der Kollokationen und Beispiele. Hinweise auf die jeweiligen Akzentparadigmen der flektierbaren Wortarten, deren Fehlen schon in der ersten Auflage kritisiert wurde, finden sich auch in der zweiten Auflage nur in sehr eingeschränkter Form. Implizite Informationen zu Akzentparadigmen finden sich bei einigen unregelmäßigen Verben, deren Konjugationsparadigmen im Vorwort als Musterbeispiele angeführt werden (vgl. Pawlowsky, 1879, VII). Da diese Verben unter 4.3.2.2 (127128) ausführlich behandelt werden, sei für entsprechende Beispiele auf diesen Punkt verwiesen. Außerdem wird bei einigen Substantiven auf ihre Flexion und damit implizit auch auf ihr Akzentparadigma hingewiesen, worauf ebenfalls an entsprechender Stelle weiter eingegangen wird (vgl. 4.3.2.2, 125-126). 


\subsubsection{Grammatische Angaben}

\subsubsection{Die Wortarten}

Auch bei der Kategorisierung des lemmatisierten Wortschatzes hat Nikoliz die von Pawlowsky gewählte Praxis übernommen, sämtliche Lemmata mit einem Verweis auf die Wortarten zu versehen. Prinzipiell beibehalten hat Nikoliz nicht nur die von Pawlowsky definierte Wortartenkonzeption, sondem auch die von diesem festgelegten Abkürzungen, was sich an der Markierung der neu aufgenommenen Lemmata zeigt. Im Gegensatz zur ersten Auflage werden in der zweiten Auflage die einzelnen Kürzel im Abkürzungsverzeichnis aufgeschlüsselt (vgl. Pawtowsky, 1879, V), wodurch ihr Nutzen im Vergleich mit der ersten Auflage bedeutend erhöht werden konnte. Eine zusätzliche Erläuterung der einzelnen Abkürzungen in einer Kurzgrammatik fehtt jedoch auch in der zweiten Auflage. Sie hätte den Wert dieser Angaben für den Benutzer deutlich gesteigert, da beispielsweise die Kategorisienung der Verben weit über die bloße Wortart hinausgehende Informationen enthält, die bei den Benutzern nicht ohne weiteres als bekannt vorausgesetzt werden können.

\subsubsection{Angaben zur Flexion}

Deutlich verbessert präsentieren sich in der zweiten Auflage des russisch-deutschen Wörterbuches die gründlich überarbeiteten Flexionsangaben. Beschränken sich die Veränderungen bei den Substantiven und Adjektiven noch auf wenige Teilbereiche, so sind die Angaben zur Konjugation der Verben vollständig überarbeitet und im Vergleich mit der ersten Auflage enorm verbessert worden.

Zusätzlich zu den bereits in der ersten Auflage mit der Genitivform lemmatisierten Substantiven, die innerhalb der Flexion einen flüchtigen Vokal aufweisen, wurden in die zweite Auflage zahlreiche abgeleitete Maskulina mit der Genitivform aufgenommen, die innerhalb des Paradigmas den Akzent wechseln.

Bsp.: Mariurr, $4^{\circ}$ a s. m. eine Art Schafe (in der Krimm).

Mact'rokb, K'a s. m. der Meister, [...].

O6ерт 'yнъ, H'a s. m. der Zauberer, Währwolf.

O6rivub, w'a s. m. runder Klotz.

Плотикъ, K’a s. m. (Bot. Linaria vulgaris) das Leinkraut, der Frauen-, Marienflachs, das Löwenmaul.

Nentchb s. f. [...]; - $\mathrm{CH}^{\circ} \mathrm{SKZ}, \mathrm{K}^{\circ}$ a s. m. 1. der Schimmelpilz; 2. verschimmelter Gegenstand; [...]. 
Cқо6к'aph, p'a s. m. hölzerner Humpen, die Trinkschale (mit zwei Henkeln), kleines Zuberchen (mit einem Deckel, zu Butter).

Cкоnepд ин, н’a s. m. ein Spiel (bei welchem Stöcke zusammengebogen und aus der Hand geschnellt werden, um zu sehen, wessen Stock weiter fliegt).

Die bisher zitierten Beispiele wurden alle erst von Nikolič in das Wörterbuch aufgenommen. Daß aber auch der bereits vorhandene Wortschatz im Hinblick auf die Flexionsangaben überarbeitet worden ist, zeigen folgende Beispiele, die zwar schon in der ersten Aufiage lemmatisiert sind, aber dort noch keinen Verweis auf die Genitivform enthalten.

Bsp.: Ma' 9 Kb, K’a s. m. 1. die Feuerbake, der Leuchtthurm; 2. das Zeichen, die Warthe, der Warthurm; 3. (Maur.) die Streckerschicht (Schicht querliegender Mauersteine); 4. der Schattenriß; 5. betrügerischer Händler.

Плотъ, т’a s. m. 1. der Prahm, das Floß, die Fähre, der Waschprahm; 2. gewisse Anzahl mit einander vertundener Balken (die auf dem Flusse gefiößt werden); der FIOB, Holzfloß; [...].

Сквозніикъ, к’a s. m. 1. jede durchsichtige, klare Frucht; [...]; 2. ein Mensch von durchdringendem Verstande; fam. durchtriebener Schelm; 3. der Zugwind; [...].

Nicht verbessent hat Nikolic die Angaben zur Deklination und zur Komparation der Adjektive. Die einzige Veränderung betrifft die Angabe der unterschiedlichen Endungen, auf die Nikolič laut Vorwort verzichtet (vgl. Pawlowsky, 1879, V), wenn die femininen und die neutralen Endungen regelmäßig auf -as und -oe gebildet werden. Aus Platzgründen erscheint es durchaus sinnvoll, diese in der ersten Auflage noch angegebenen Endungen zu streichen. Allerdings hält sich Nikolič nicht streng an das von ihm postulierte Prinzip, da bei einigen Gruppen von Adjektiven die abweichenden Endungen aufgenommen wurden, bei den lemmatisierten Possessivadjektiven mit besonderer Deklination aber sowohl auf Hinweise auf die Deklination als auch auf die Aufnahme der femininen und der neutralen Endung verzichtet wurde.

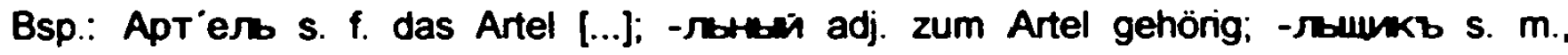
-лыцица s. f. 1. der Artelwirth, die -in; [...]; -льщиковъ adj. dem A-wirth gehörig; [...]; -лыииивиь adj. der A-wirthin gehörig; -иирій, 4ья, use adj. den Gliedern eines A. zukommend.

Б'yдоика s. f. dim. das Wächterhäuschen; [...]; -4rkxosъ adj. den Wächter, Polizeiwächter betreffend; -чимій, ья, be adj. den Wächtern, Polizeidienern eigenthümlich; - Wächterhäuschen-. 
Meдв 't|lab s. m. 1. (Zool. Urus) der Bär; [...]; -дesъ adj. Bären-; [...]; -дuubrrb adj.

Bärinnen-; -н aù̆, bя, be adj. jungen Bären eigenthümlich, eigen; [...].

Mit der Aufnahme von Flexionshinweisen für die Verben hat Nikolič einen der größten Schwachpunkte der ersten Auflage behoben. In der zweiten Auflage des russischdeutschen Wörterbuches finden unterschiedliche Verfahren zur Flexionsangabe bei den Verben Amwendung. An erster Stelle stehen im Vorwort aufgeführte Konjugationsregeln, die die Bildung der regelmäßigen Verbformen ertäutern (vgl. Pawlowsky, 1879, VII). Nikolic unterscheidet in den „Paradigmen für die Conjugation der russischen Zeitwörter" vier unterschiedliche Konjugationsklassen, die weitgehend identisch sind mit den fünf noch heute produktiven Verbalklassen des Russischen. Abweichend von der heute üblichen Einteilung (vgl. Mulisch, 1993, 103), werden in der zweiten Auflage des Pawlowskyschen Wörterbuches Verben mit den Infinitivstămmen auf -aTb, -9Tb und - $\mathbf{k}$ Tb nicht als zwei Klassen, sondem nur als eine Klasse angesehen. Alle im Wörterbuch lemmatisierten Verben, die ihre Verbalformen nach den regelmäßigen Konjugationsregeln bilden, wurden ohne weiteren Kommentar nur mit ihrer Infintivform aufgenommen.

Bsp.: Arлывать, гліать v. n. versteinem, zu Stein werden; [...].

Eop tTb v. n. mit Nadelholz bewachsen.

Mapakов"aTb v. a. 1. etwas oberfiächlich wissen, radebrechen; 2. s. Mopokos'aTb.

$06038^{\circ}$ tкrнуть (voll.) v. n. entkräften, kraftlos werden, ermatten, ermüden; [...].

CK’asmib v. a. entblößen (die Zähne); [...].

Um die Formen der unregelmäßigen Verben zu erklären, bedient sich Nikolič eines Kodesystems (vgl. Mugdan, 1983, 219), wobei mit Hilfe von arabischen Ziffem auf eine Position einer Liste mit Verben verwiesen wird, deren Konjugation im Vorwort angeführt ist (vgl. Pawlowsky, 1879, VI). Die auf die Erläuterungen zur regelmäßigen Formenbildung folgende Tabelle beschreibt die Konjugationsmuster von folgenden 31 Verben: 1. БpaTb, 2.

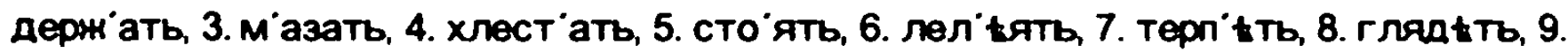
пол оть, 10. треп ать, 11. вод ить, 12. тер еть, 13. бер еиь, 14. класть, 15. пеиь, 16. нест и, 17. уред ить, 18. хлопот'ать, 19. колот ить, 20. прос ить, 21. воз ить, 22.

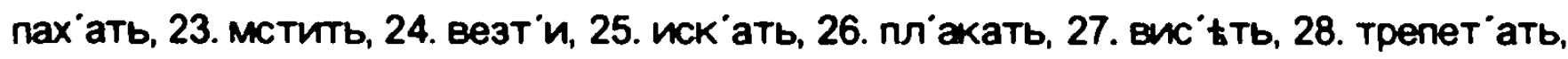
29. пис'ать, 30. верт' +ть, 31. мыть.

Die einzelnen Verben in der Tabelle lassen sich in verschiedene Teilgruppen untergliedern. Die erste Gruppe von Verben gehört zu der von Nikolic unter Punkt vier vorgestelten produktiven Verbalklasse mit Infinitiv auf -ить. Einige dieser Verben vollziehen in der 1. Person Präsens bzw. Futur im Stamm einen Konsonantenwechsel. Endet der Stamm auf 
einen Labial, so wird dieser in der 1. Person Singular um ein $/ \Omega /$ ergänzt. Da Nikolic bereits im Paradigma für die regelmäßige Formenbildung auf dieses Phänomen hinweist, muß die Aufnahme des Verbes Tepn $¥ T \mathrm{Th}$, das bis auf den Konsonantenwechsel regelmäßig konjugiert wird, als überflüssig kritisiert werden. Doch der Konsonantenwechsel erfolgt auch bei Verben, deren Infintivstamm auf einen Dental endet. Ist dies der Fall, so wird in der 1. Person Singular Präsens bzw. Futur der Dental durch einen Zischlaut ersetzt. Da Nikolič auf diesen zweiten Konsonantenwechsel nicht innerhalb der regelmäßigen Formenbildung eingeht, ist es nur konsequent, daß sich Beispiele für diesen Konsonantenwechsel in der Tabelle der unregelmäßigen Verben finden. $\mathrm{Zu}$ dieser Gruppe von Verben zählen folgende Vertreter: Глядьть, вод'ить, учред'ить, колот'ить, прос'ить, воз ить und мстить, sowie die den unproduktiven Verbalklassen (vgl. Mulisch, 1993, 120) zuzurechnenden Infinitive anc 't to und Bept'etb.

Alle nun folgenden Gruppen gehören zu den unproduktiven Verbalklassen. Die größte Gruppe bilden die Verben auf -atb (vgl. Mulisch, 1993, 119), zu deren erster Teilgruppe Verben zähten, deren Präsens- bzw. Futurformen immer den Konsonantenwechsel aufweisen. Dies ist bei den Verben м'азать, хлест'ать, трел'ать, хлопот'ать, пах'ать, иск'ать, n' акать, трепет'ать und пмс'ать der Fall. Die zweite Teilgruppe bilden Verben, die wie 6patb im Präsensstamm ein flüchtiges e oder o aufweisen. Trotz des Infinitivstammes auf -a- werden nach der zweiten Konjugation konjugiert einige unproduktive Verben, deren Präsensstamm auf lj/ oder Zischlaut endet. Beispielhaft für diese Gruppe von Verben hat Nikolic die Infintive дерн 'ать und сто 'ять in die Tabelle aufgenommen.

Eine weitere Gruppe der unproduktiven Verbalklassen bilden Verben mit besonderen Infinitivausgängen und solche mit einer Veränderung im Präsensstamm. In der Konjugationstabelle der zweiten Auflage des russisch-deutschen Wörterbuches zählen hierzu fol-

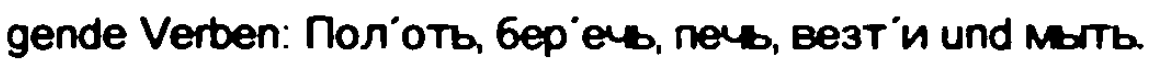

Beı der Analyse der Verben in der Stichprobe fält auf, daß auf insgesamt 16 Codeziffern, was gut der Hälfte aller Ziffern entspricht, keine Eintragungen und auf weitere fünf Ziffern weniger als fünf Eintragungen entfallen. Nur die Codeziffern, die auf den Konsonantenwechsel in der 1. Person Singular Präsens bzw. Futur verweisen, werden im Wörterbuch häufig verwendet.

Bsp.: Бурд tть 8. v. n. für sich hinbrummen, in den Bart brummen.

Epex arie s. n. [...]; - $x^{\prime}$ aтb 22. v. n. 1. kläffen, belfern, bellen; 2. fig. schreien; zanken; schimpfen; keifen, lügen; [...].

Mapyд’a s. c. [...]; -р'удить 11. v. n. zögern, langsam etw. betreiben; [..]. 
Маст ика s. f. [...]; -т'ить 23. v. a. mit wohlriechendem Oel beschmieren, damit einölen; [...].

Obanaм утить 19. (voll.) v. a. 1. anführen, betrügen, beschwatzen; 2. betăuben, benebeln.

Обобрест $и, 60^{\circ}$ есть 14. (voll.) watend umgehen, umwaten.

O6eзрим \& t t Tb 30. (voll.) v. n. ohne Merkmal, ohne Merkzeichen bleiben.

Побормот'ать 18. (voll.) v. n. etwas murmeln.

nosuc t ts 27 . (voll.) v. n. eine Zeitlang här.gen.

CK'ena [...]; -nंatb 10. v. a. spalten, spleißen, schleißen.

Ск'уксить 20. (voll.) v. a. in die Faust nehmen; fig. stehlen, heimlich wegschleppen.

II. Сл анивать, voll. сліазить 21. (voll.) v. n. klettem, hinaufklettern; hinklettern und zurückkehren.

Bei denjenigen Verben, deren Konjugation weder durch die allgemeinen Regeln, noch durch das Kodesystem hinreichend erklärt wird, verweist Nikolič direkt bei der lemmatisierten Einheit auf die Stammformen des Verbes.

Bsp.: Брить (praes. $6 p^{\circ}$ tю, $6 p^{\circ}$ teub) v. a. barbieren, rasiren; [...].

Etrm (praes. я есмь, ты ес и, онь есть, мы есміы, вы ест'е, они суть; prät. 9 6ыть; fut. я 6'yдy) v. n. sein, [...].

6twb s. f. [...]; -жатb (praes. 6tr y, 6tw kub, 6tr yTb) v. n. 1. laufen, rennen; 2. 6. OTъ kor'o vor Einem fliehen; Einen meiden, vermeiden; 3. entlaufen, flüchten, desertiren; 4. (von Farben:) verschießen, ablassen; 5. (von der Zeit) enteilen, entfliehen, entfliegen, verfließen, verstreichen; (vom Wasser) laufen, rinnen, fließen, strömen; [...].

O68 orumb (voll., fut. -rimo, ëub) v. a. beklagen, beweinen, bejammem.

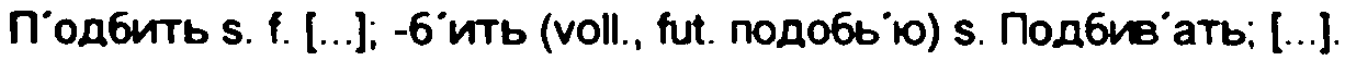

Cқресть (praes. ckpe6'y) v. a. schaben, kratzen, abkratzen; [...].

Слать (praes. шло) v. a. schicken, senden; [...].

Obwohl positiv hervorzuheben ist, daß Nikolič sich dazu entschlossen hat, überhaupt Flexionshinweise für die Verben aufzunehmen, so ist das von inm gewählte System doch nicht von Kritik auszunehmen. Zum einen ist die systematische Dreiteilung der Himweise nicht besonders benutzerfreundlich, zum anderen funktioniert das System nicht einmal lükkenlos, wie folgende Beispiele belegen. 
Bsp.: Бор Оть v. a. bezwingen, übenwältigen, niederwerfen, zu Boden strecken; -cя v. r. ringen, kämpfen, pop. sich balgen.

Eperriatie s. n. [...]; - - 'atb v. n. klirren, klappem, klimpern.

Брнозж анrie, -Hbe s. n. [...]; -ж; ать v. n. brummen, murren, knurren.

Mep 'өть (praes. мpy, мpёub, мруть) v. n. sterben.

Mесть 1. s. m. [...]; 2. 33. v. a. fegen, kehren (mit dem Besen); [...].

Met'arie s. n. [...]; -T'ать v. a. werfen (Bomben etc.); schleudern (Steine); abschießen (Pfeile); [...].

Плыть v. n. 1. schwimmen; [...]; 2. segeln [...]; 3. fließen [...]; 4. überlaufen [...].

Cкриmb s. m. [...]; -nंtть v. n. knarren.

Im Fall von meperb hätte anstelle der Angabe von Verbalformen ein bloßer Verweis auf das zwölfte Verb der Tabelle genügt, das dort als Muster für Verben mit verkürztem Präsensstamm angeführt wird. Dieser Fall kann allerdings nicht als gravierender Fehler betrachtet werden, da der Benutzer sowohl auf diese, als auch auf die andere, der Systematik entsprechenden Weise zu der korrekten Verbalform geleitet wird. Dies gilt auch für das Verb ckpun'亡Tb, denn hier wäre zwar ein Verweis auf das siebte Verb der Tabelle zu erwarten gewesen, das als Muster für den Konsonantenwechsel in der ersten Person Singular Präsens bzw. Futur ausgewählt wurde, allerdings ist dieses Beispiel sowieso überflüssig. da Nikolič das eben genannte Phänomen bereits bei den allgemeinen Konjugationsregein beschreibt.

In allen anderen Fällen hat das Fehlen von Codeziffern oder Verbalformen allerdings schwerwiegende Folgen, da der Benutzer aufgrund der im Vorwort vorgestellten Systematik scheinbar korrekte Formen bilden kann, die tatsächlich nicht den Verhältnissen der sprachlichen Wirklichkeit entsprechen. Bei dem Verb 600'0Tb ist die Wahrscheinlichkeit noch relativ groß, daß der gewissenhafte Benutzer aufgrund des ungewohnten Infinitivstanıms im Vorwort nachschlägt und erkennt, daß hier der Verweis auf das in der Tabelle an der neunten Stelle stehende Verb пол'оть fehit. Bei den Beispielen Gperriatb, 6рнозн ать und мет'ать allerdings kann als sicher gelten, daß der des Russischen noch nicht mächtige Benutzer die Verbalformen nach der für diese Verben nicht geltenden Regel eins des Paradigmas für die Konjugation der russischen Zeitwörter bildet, die besagt, daß „die Zeitwörter, welche sich im Infinitiv auf aTb, яTb und $\mathrm{z}$ Tb endigen, [...] das Tb des Infinitivs im Präsens in 10 , eub, етъ, eNB, ете, юTъ" (Pawlowsky, 1879, VI) verwandeln. Die Bildung der falschen Formen hätte mit den Mitteln der von Nikolič gewählten Systematik verhindert werden können, indem bei den ersten beiden Verben auf das zweite Verb der Tabelle und für das letzte Verb auf das 18 . Verb hingewiesen worden wäre. 
Da .ganz unregelmäßig sich bildende Verbalformen [...] bei den Infinitiven der betreffenden Zeitwörter selbst angegeben" (Pawlowsky, 1879, VII) werden sollen, ist es unerklärlich, daß das Vert nлытb ohne weiteren Kommentar aufgenommen wurde, zählt es doch aufgrund der besonderen Stammverhältnisse zu eben jenen Verben. Unverständlich bleibt auch der Verweis auf die Codeziffer 33 im Falle von мectb, da die Tabelle nur 31 Verben umfaßt. Da das nach denselben Regeln zu konjugierende nrectb ebenfalls mit 33 markiert ist, scheint es wahrscheinlich, daß die Tabelle ursprünglich zumindest ebenso viele Verben enthalten hat.

Bedenkt man außerdem, daß der größte Teil der Codeziffem auf das regelmäßige Phänomen des Konsonantenwechsels bei der V. Klasse der produktiven Verbalklassen hinweist, so erscheint das System der Codeziffern unnötig. Da neun Zehntel der russischen Verben zu den produktiven Verbalklassen gehören (vgl. Mulisch, 1993, 119) und der Verweis auf die Verbalformen direkt bei dem lemmatisierten Verb ohnehin eine weitere Option bei der Darstellung der verbalen Flexionsformen ist, wäre es sinnvoller gewesen, die Benutzerfreundlichkeit durch den Verzicht auf das Codesystem zu ertöhen, das den Benutzer zum Nachschlagen an unterschiedlichen Stellen zwingt.

\subsubsection{Diasystematische Angaben}

Schon für die erste Auflage des russisch-deutschen Wörterbuches wurde festgestellt, daß der Autor großen Wert auf die Markierung des lemmatisierten Wortschatzes gelegt hat. Dies gilt auch für den Bearbeiter der zweiten Auflage, der Art und Zahl der Markierungen deutlich erhöht hat.

\subsubsection{Diatechnische Markienungen}

In der Stichprobe murden 107 verschiedene diatechnische Markierungen gefunden. Vergleicht man diese Zahl mit derjenigen in der Stichprobe aus der ersten Auflage, so ist festzustellen, daß insgesamt 33 Markierungen hinzugekommen sind. Da der größte Teil der neu hinzugekommenen Markierungen zwar nicht in der Stichprobe der ersten Auflage. wohl aber schion im Abkürzungsverzeichnis des von Pawlowsky erarbeiteten Wörterbuches zu finden ist, steht fest, daß Nikolič bei der Überarbeitung des Wörterbuches sorgfältig auf die Markierung der Lemmata geachtet hat. Dies zeigt sich zum einen an den bei Pawlowsky noch ohne Markierung lemmatisierten Einheiten, die in der zweiten Auflage mit einer diatechnischen Markierung versehen wurden.

Bsp.: Arрам анты, овъ pl. m. (Posam.) Agrements, Zieraten, (geflochtene) Verzierungen (an Frauenkleidern oder Fenstervorhängen).

Брод 'оKъ, дK'a s. m. (Schm.) das Locheisen. 
Mesknyllct'osfie s. n. [...]; -ctp'ovie s. n. (Buchdr.) die Durchschießlinie, der

Druckschuß, die Zwischenzeilenweite; [...].

O6r'aca s. f. (Seew.) ein Flußfahrzeug, die Barke (auf der Dwina).

Ckо6riouka s. f. (Conch. Dolabella) die Beilschnecke.

Zum anderen wird es auch dadurch deutlich, daß ein großer Teil der neu aufgenommenen Lemmata mit einer diatechnischen Markierung versehen wurde.

Bsp.: Araßsматолить s. m. (Min.) der Agalmatolith, Bildstein (chinesischer Speckstein, der zu Bildschnitzereien verwandt wird).

Бyux arb s. m. (Bot. Sambucus racemosa) der Traubenholunder.

Map aarb S. m. (Jäg.) die Hirschkuh.

O6мір(ш)щ'аться, voll. -(ш)щиться v. n. (Krctw.) der Secte (der Altgläubigen in der griech. Kirche) abtrünnig werden, sich verweltlichen.

חлодъ s. m. [...]; -дохран илище s. n. 1. (Med.) die Mutter, Gebärmutter, das Gebärorgan; 2. (Bot.) die Fruchtkapsel; [...].

CKB useps s. m. (Mech.) das Quetschwerk.

Zu kritisieren ist allerdings auch Nikolič, da er bei der Erstellung des Abkürzungsverzeichnisses nicht die erforderliche Sorgfalt hat walten lassen. So kommen einerseits einige Abkürzungen nicht in der im Verzeichnis ausgewiesenen Form vor, andere in der Stichprobe nachgewiesene diatechnischen Markierungen fehlen in der Tabelle des Vorwortes vötlig.

\subsubsection{Diakonnotative Markierungen}

Zusätzlich zu den bereits von Pawlowsky benutzten diakonnotativen Markierungen, die den liebkosenden, den scherzhaften und den verächtlichen Gebrauch einiger Lemmata charakterisieren, hat Nikoliž eine weitere Markierung eingeführt, die mit der Abkürzung .iron." die ironische Verwendung einzelner Lemmata anzeigt. Auffällig ist allerdings, daß nur neu aufgenommene Lemmata sowie erst durch Nikoliž eingeführte Bedeutungen mit einer solchen Markierung versehen wurden.

Bsp.: Mak'apъ s. m. 1. s. Mak'apin̆; 2. Spitzname für die Rjäsaner; 3. iron. die Mücke.

Maraxäll s. m. 1. eine Pelzmütze mit Ohrklappen; der Ueberwurf, (über die Schultern geworfene) Ueberrock; 3. iron. der Watschelnde, mit den Armen Schlenkernde; [...].

O6ар "oturbcя (voll.) v. r. iron. Baron werden, groß thun.

O6M trrb s. m. [...]; -HOKъ, HKa S. m. 1. untergeschobenes Kind; iron. uneheliches Kind, der Findling; dummes, ungezogenes, mißgestaltetes Kind; [...]. 
Cковор одиика s. f. [...]; -дница s. f. 1. der Eierkuchen; 2. iron. die Wirthin, Köchin; [...].

Cладком ордый, aro (als Subst.) iron. das Süß-, Leckermaul.

Слив онское вин iron. zusammengegossene Ueberbleibsel (pl.) von Wein. schlechtes Getränk.

Weiterhin ist bemerkenswert, daß nur die bereits in der ersten Auflage mit den anderen diakonnotativen Markierungen versehenen Lemmata diese auch in der zweiten Auflage autweisen. Bei neu aufgenommenen Lemmata ooer Bedeutungen kennzeichnet Nikolič die diakonnotative Verwendung nicht mehr durch Abkürzungen.

Bsp.: Бусурм анъь s. m. (der Spott- u. Schimpfname zunächst für jeden) Ungläubigen; (also) der Muselmann, Muhamedaner, Moslem; (dann:) der Türke, der Asiate; (dann aber auch für jeden) Ausländer (u. jeden nicht zur griechischen Kirche Gehörenden); [...]; -M'ałckī̆ adj. (in verächtlichem Sinne) muhamedanisch, muselmännisch, fremdländisch; [...].

Бtд ить 11. v. а. [...]; -д'vuka (Kosewort zu 6ta'a, mit denselben Bedeutungen).

Etrigrka, -righouka s. f. 1. die Blondine; 2. Kosewort für weiße Thiere; [...].

Cкор onyura s. f. (Schmeichehwort) die milchgebende Kuh.

\subsubsection{Diachronische Markierungen}

Keine qualitativen Veränderungen hat Nikolič bei den diachronischen Markierungen vorgenommen. Da die zweite Auflage immerhin zwanzig Jahre nach der ersten Auflage erschienen ist, wäre eine Verändenung bei der Quantität der Paläologismen fast zu enwarten gewesen. Doch Nikoliz hat sämtliche bereits von Pawlowsky aufgenommenen und von diesem mit ,veraltet" bzw. mit "ehedem" markienten Lemmata in die zweite Auflage übernommen. Zusätzlich hat er weitere, in der ersten Auflage noch nicht verzeichnete Paläologismen bzw. dort noch nicht verzeichnete veraltete Bedeutungen in das von ihm überarbeitete Wörterbuch aufgenommen.

Bsp.: A we conj. (veralt.) wenn, sofern, falls; wenn anders.

Apxi атеръ s. m. (veralt.) der Ober-, Leibarzt.

Ep orwkz s. m. 1. der Gehamischte; 2. (ehed.) der Waffenschmied, Hamischer, Plattner; [...].

B'brro s. n. (veralt.) das Vermögen, Hab und Gut.

Maн ить v. a. 1. winken (mit der Hand:); 2. locken; 3. (veralt.) zögern; [...].

O'6ma s. f. 1. (veralt.) ein Ackermaß (5 Dessjätinen gleich); 2. die Deichselarme (pl.) des Hakenpflugs. 
O'60nortb s. f. [...]; +tbe s. n. 1. der Schüsselrand; 2. der Wiesenrand; 3. (veralt.) die Vorstadt; 4. coll. feuchte Wiesen.

Mriouka s. f. 1. die Schale, Mulde; 2. die Lampe (zu Illuminationen); irdene Schale (mit Fett gefüllt); 3. (Metalli.) der Probirtiegel; 4. (veralt.) die Salzabgabe.

Пов олынкъ s. m. (ehed.) der Freizügler (im atten Nowgorod); [...].

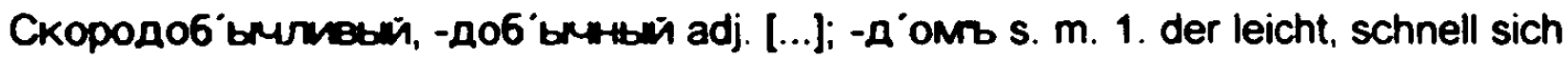
Ansiedelnde, auch der Ansiedler im Allgemeinen; 2. (ehed.) ein Stadtheil in Moskau; [...].

\subsubsection{Diastratische und diaintegrative Markienungen}

Da Nikolič bei der Überarbeitung der ersten Auflage weder bei den diastratischen, noch bei den diaintegrativen Markienungen qualitative Veränderungen vorgenommen hat, werden diese für die zweite Auflage in einem Unterpunkt behandelt.

Prozentual am wenigsten verändert hat Nikolič bei dem aus dem Kirchenslavischen ererbten Wortschatz. In der Stichprobe finden sich zusätzlich zu den bereits von Pawlowsky lemmatisierten Einheiten nur einige wenige neu aufgenommene Lemmata.

Bsp.: A інтей, A нтій s. m. (sl.) der Antichrist.

O6 омикв [...]; -use s. n. (sl.) die Augenhöhle.

Mozher a'a adv. (sl.) damals; zu der Zeit, wo.

Deutlich häufiger als noch in der ersten Auflage tritt dagegen die diastratische Markierung „pop." auf, die die im Volk gebräuchliche Verwendung bestimmter Lemmata kennzeichnet. Dies liegt zum einen daran, daß Nikolič zusätzliche in diesem Sinne gebrauchte Bedeutungen einzelnen Lemmata hinzugefügt hat, zum anderen aber vor allem daran, daß er zahlreiche neue Einträge aufgenommen hat. Stellvertretend für die neu aufgenommenen Lemmata seien hier die im Volk gebräuchlichen Tagesbezeichnungen aufgeführt.

Bsp.: Ar astи-коров' атниud; Ar asbu-roneнn' ухи pop. Name des 5. Februar.

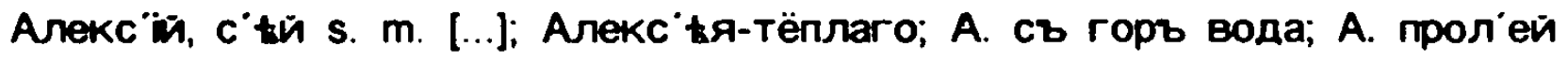
Kyeu' urb Name des 17. März, als Beginn des Frühlings-Thauwetters.

Мавры-моліоницы оd. разс адницы рор. Name für den 3. Mai (an welchem Tage die jungen Kohlpflanzen in die Beete verpflanzt werden und die Bauerfn, C.B.] zum ersten Mal Milchgries essen.

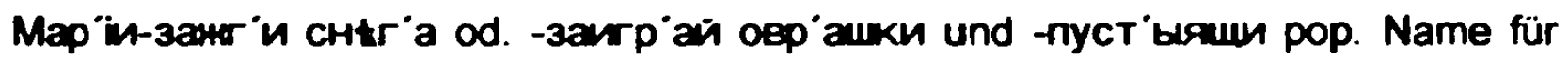
den 1. April; -c илиныb p'ocb pop. Name für den 22. Juli. 


\subsubsection{Diatopische Markienungen}

Nahezu unverändert bleibt auch in der zweiten Auflage die Verwendung von diatopischen Markierungen. Die bereits in der ersten Auflage als zu ungenau kritisierte Markierung bestimmter Lemmata als .provinziell wurde auch von Nikolic beibehalten. In der Stichprobe der zweiten Auflage finden sich nur wenige neu aufgenommene Lemmata oder Bedeutungen, die zusätzlich zu den aus der ersten Auflage übernommenen Lemmata mit einem Verweis auf ihren provinziellen Gebrauch versehen wurden.

Bsp.: Map yuka s. f. 1. s. Mapaжi a; 2. dim. von Map ï; 3. prov. das Zehnkopekenstück.

$06^{\circ}$ oub, щ'y prov. das Gemüse.

Mo6ep eus 13. (voll.) [...]; prov. gastlich aufnehmen, bewirthen; [...].

Mor'ona s. f. 1. das Wetter; die Witterung; [...]; 2. der Sturm, Wind; das Unwetter,

Schneegestöber, [...]; 3. coll. prov. lärmende, lustige junge Burschen pl.; [...].

Neu eingeführt wurde von Nikoliz eine diatopische Markierung auf der zielsprachlichen Seite des Wörterbuches. All jene neu aufgenommenen deutschen Entsprechungen, die nur regional in den Ostseeprovinzen verbreitet waren, wurden mit der Markierung .Osts." versehen. Da das Wörterbuch in jenem Raum entstanden ist und überarbeitet wurde, ist es nicht erstaunlich, daß zahlreiche regional beschränkt gebrauchte Entsprechungen ihren Weg in das Wörterbuch gefunden haben.

Bsp.: A'peummкъ s. m. grobkörniger Kiessand; kleine Kieselsteine, (Osts.) Gravel.

Ep'ara s. f. 1. (in Branntweinbrennereien:) der Meisch, die Meische, (Osts.) die Brage; [...].

Бредн якъ s. m. [...]; -дов икъ s. m. der Bastschuh, (Osts.) die Pastel (aus Weidenbast); [...].

Mapx aruia s. f. [...]; -x’ebb s. m. (Bot. Daucus carota) die Möhre, Mohr-, Gelbrübe. (Osts.) die Burkane.

Мел узина s. f. die Spreu, das Kaff; (Osts.) Sieblis.

0\%6менъ [...]; -менев анtie s. n. 1. das Abgränzen, Setzen der Grenzsteine; 2. die Aus-, Vermessung (eines Landstūcks; (Osts.) Regulinung (der Landbesitzlichkeit); $[\ldots]$.

\subsection{4 Äquivalente}

Die bisherige Analyse der Mikrostruktur der zweiten Auflage des russisch-deutschen Wörterbuches hat schon gezeigt, daß Nikoliz auch den Bereich der zielsprachlichen Äquivalente sorgfältig überarbeitet hat. Bei den einzelnen Wörterbuchartikeln differiert der Grad der Überarbeitung. Ein gewisser Anteil von Artikeln wurde unverändert übernommen. Dazu 


\section{6}

zăhlen die Beispiele, die unter 4.2 .4 (108-109) für Volläquivalenz angegeben wurden, aber auch der größte Teil der sehr gut gegliederten Wörterbuchartikel zu den Präpositionen (vgl. 4.2.5.4, 120-121). Ein weiterer Teil der bereits von Pawlowsky lemmatisierten Einheiten wurde mit vollständig veränderten zielsprachlichen Entsprechungen in die zweite Auflage übernommen. Belegt werden kann dies beispielweise mit den unterschiedlichen zielsprachlichen Entsprechungen bei dem Verb о6кл'адываться, das in der ersten Auflage mit .belegt werden" und .eingefaßt werden" übersetzt wird, für das in der zweiten Auflage dagegen folgende Áquivalente angeboten werden.

Bsp.: II. O6krianbsatb, voll. o6kriactb v. a. [...]; -cя v. r. 1. $4^{\circ}$ turb sich umlegen, umgeben mit Etwas (z. B. mit Büchern); 2. sich be-, umwölken (vom Himmel); 3. sich bemachen.

Außerdem hat Nikolič natürlich zahireiche Lemmata neu in das Wörterbuch aufgenommen und viele der aus der ersten Auflage übernommenen Einheiten auf der zielsprachlichen Seite um weitere, von Pawlowsky nicht berücksichtigte Bedeutungen ergänzt.

Wichtig ist es, zu betonen, daß Nikolic die von Pawlowsky gewählte Systematik zur Unterscheidung der Bedeutungen polysemer Lemmata ohne Veränderung übernommen hat (vgl. 4.2.4, 109-111). Auch in der zweiten Auflage werden verschiedenartige Aquivalente durch Kommata, Semikola, arabische Ziffern und Kleinbuchstaben getrennt und die Bedeutungsdifferenzierung durch nähere Erklärungen vorgenommen, wenn russische Einheiten nicht vollständig deckungsgleich mit ihren deutschen Entsprechungen gebraucht werden können.

Im folgenden werden entweder Beispiele angeführt, die von Nikolič neu aufgenommen wurden, oder solche, deren zielsprachlicher Teil von Nikolič in erheblicher Form erweitert wurde. Lemmata oder Lemmabestandteile, die in der zweiten Auflage erstmalig auftreten, werden durch eine Unterstreichung kenntlich gemacht, um sie von den anderen Beispielen zu unterscheiden.

Bsp.: $A 6^{\circ}$ asb, $a 6^{\circ}$ acb s. m. [...]; $-3^{\circ}$ a s. f., der (für die Donaufischer) gefährliche Ostwind; 2. ein dummer Muselmann; 3. (im Kaukasus) das eingebrannte Pferdezeichen; [...] Арт'ель s. f. [...]; -лыuикъ s. m., -roumua s. f. 1. der Artelwirth, die -in; 2. (als Mitglied eines Artels:) Artelschtschik, (im Allgemeinen:) der Handlanger bei der Börse, beim Pack- $u$. Zollhause, in den Speichern, auf den Bahnhöfen etc.; Arbeiter in den Geschäftslokalen der Kleinhändler; Comptoirdiener in den Comptoiren der Großhändler; entspricht zum Theil dem deutschen Markthelfer, [...]. 
Evr'a s. f. [...]; - $r^{\circ} a n$ s. m. 1. das Oberkleid eines Großfürsten (in alter Zeit); 2. unverschnittener Stier, 3. die Rohrdommel (Ardea stellaris); 4. das Arbeitskleid einer Bäurin; 5. der Hebebaum, die Brechstange.

$5^{\circ}+$ r תостb s. f. [...]; -r rsen adj. 1. flüchtig, entlaufen; 2. schnell, unbeständig, flüchtig, oberflächlich; 3. scharf, [...].

Maunnarb s. m. 1. die Fabrik; auch: die Theergrube, The[e, C. B.]rbrennerei, -schwelerei; [...]; 2. das Spielhaus; 3. das Kartenspiel, Würfelspiel; 4. der Platz, Ort, die Lichtung (im Walde), Lichte; 5. der Sammelplatz; 6. die Jägerhütte; 7. alter Todtenhügel, Kurgan (in Südrußland).

M'atka s. f. 1. pop. die Mutter, [...]; 2. (bei Thieren:) das Weibchen; [...]; 3. (Anat. Uterus) die Mutter, Gebärmutter, 4. (in Archangel, bei den Seefahrern:) der Compaß; 5. (Bergw.) рудн ая м. die Erz-, Metallmutter, 6. (Schloss.) м. для нарызки der Bankenbohrer, Originalbohrer; [...]; 7. der Fruchtboden (in Blüthen); 8. die natürlichen Pocken, Blattern; 9. pop. die Essigmutter, 10. (bei gewissen Kinderspielen:) der Anführer, die Spitze; 11. unterster Boden od. Kasten eines Brunnens; 12. der Ursprung, die Quelle; 13. der Mittet-, Schwerpunkt; 14. eine mit Beeren bewachsene Stelle (im Walde); 15. der Hanf; 16. der Tragbalken; [...].

Q63 apurb (voll.) v. a. 1. das Verlangen nach etw., die Lust zu etwas enwecken; 2. behexen; 3. ausdörren, versengen; [...].

06rion̈ s. m. 1. das Glatteis; 2. Ueberschwemmungen ausgesetztes, unter Wasser stehendes Stück Land; 3. das Aufwasser; 4. pop. der Hagel; 5. die Gußnaht (Metallgießerei); [...].

П'овихъ s. m. [...]; lockern; 3 . aus der rechten Lage bringen, verrücken; [...].

Mor'orß s. m. 1. das Nachsetzen; die Hast. Eile; 2. ohne Aufenthalt zurückgelegte Strecke; 3. coll. die Nachsetzenden, Verfolgenden pl.; 4. die Träber; (beim Branntweinbrennen), wässeriger, übel riechender Branntwein; der Bodensatz; 5. die Achselschnur (als Epaulette), Tuch-Epaulette; Schulter-, Achselklappe; das Schultergehenk, -gehänge, Bandelier, 6. die Schiene, Klammer, Krampe; 7. der Spielraum; 8. Kloben (einer Blockrolle), 9. späte Triebe (pl.) des Getreides (nach Spätregen); 9. das Austreiben (des Viehes).

Ckоросов'атьй, -p'ocbin adj. prov. 1. eilfertig; 2. übereilt; 3. heftig, jähzomig, auffahrend; 4. unvertráglich, streitsüchtig. 
Скyл'a s. f. 1. der Backenknochen, das Backenbein (hervorstehendes); 2. (Anat.) der Kiefer; [...]; 3. (Medc.) die Geschwulst (im Gesicht, im Nacken); 4. (Seew.) der Bug (am Schiffe); 5. fig. pop. der Geizhals, der Knauser, [...].

\subsubsection{Syntagmatik}

Da die Überarbeitung der ersten Auflage des russisch-deutschen Wörterbuches durch Nikolic auf dem Gebiet der Syntagmatik vor allem quantitative Veränderungen mit sich gebracht hat, erscheint es sinnvoll, diesen Punkt nicht nach den Wortarten, sondern nach der Art der Hinweise zu untergliedern. In einem ersten Punkt werden die expliziten Informationen zu den syntaktischen Regularitäten aller Wortarten abgehandelt, und in einem weiteren Unterpunkt soll auf die impliziten Hinweise eingegangen werden.

\subsubsection{Explizite Informationen zur Syntagmatik}

Bei den Substantiven, den Adjektiven und den Präpositionen hat Nikoliz zwar die von Pawlowsky eingeführten expliziten Hinweise auf den syntaktischen Gebrauch (vgl. 4.2.5.1, $112 ; 4.2 .5 .2,115 ; 4.2 .5 .4,120-121)$ übernommen, aber keines der von inm neu aufgenommenen Lemmata mit einem solchen Himweis versehen.

Explizit auf den syntaktischen Gebrauch hingewiesen wird demnach auch in der zweiten Auflage vor allem bei den Verben, wobei Nikoliž zusătzlich zu den aus der ersten Auflage übemommenen Fällen (vgl. 4.2.5.3. 116-117) zum Teil auch bei neu aufgenommenen Verben, deren Rektion nicht von der des deutschen Verbs abweicht, auf diese hinweist.

Bsp.: O6картёныть (voll.) v. a. kor'o Einem im Kartenspiel sein Geld abgewinnen.

O6кyn'atbcя, voll. -n iиться v. r. Ha yënb sich beim Kauf versehen, sich Schaden thun, sich verkaufen.

Пов олмть (voll.) v. n. pop. wollen, wünschen, geruhen, belieben; n. kом'y uто Einem etwas erlauben; n. ком'у въ чёмъ Einen verwöhnen, inm seinen Willen lassen; [...].

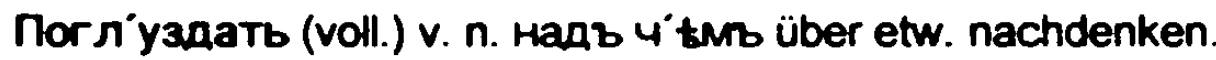

\subsubsection{Implizite Informationen zur Syntagmatik}

Schon in der ersten Auflage murde mit Hilfe von Kollokationen und Beispielssätzen implizit auf den syntaktischen Gebrauch einzelner Lemmata hingewiesen. Dieses Verfahren wurde grundsätzlich auch von Nikoliz beibehalten, der Veränderungen nur auf der quantitativen Ebene vornahm.

Vergleicht man die Kollokationen in der zweiten Auflage mit denjenigen der ersten, so ist festzustellen, daß Nikoliž den größten Teil der von Pawlowsky ausgewählten typischen 
Verbindungen übernommen hat. Darüber hinaus hat er zahlreiche neue Kollokationen aufgenommen, die hauptsächlich bei schon lemmatisierten Einheiten, in selteneren Fällen aber auch bei neu aufgenommenen Lemmata zu finden sind. Bei den Beispielen sind wieder die von Nikolič neu aufgenommenen Lemmata bzw. Lemmabestandteile durch Unterstreichung hervorgehoben.

Bsp.: Aвар "in adj. [...]; -p iя (auch -p'eя) s. f. (Seew., Comm.) die Avarie. Havarie. Haferei; а. м'алая die kleine Havarie, das Lootsen-, Anker- und Hafengeld; a. простая и ч'астная die einfache oder besondere, particuläre Havarie; a. 6олыш'ая и 'о6щая die gemeinsame $H$. oder Havarie grosse; a. вза'имнаro Bpen'a die Havarie des gegenseitigen Schadens, durch Collision entstandene Haverie.

Agosia s. c. [...]; -oebun, -OBb adj. höllisch, teuflisch; 'anceo cтяa' arbe der Hölle Eigenthum; врат'a 'адовы die Höllenpforte, Pforte der Hölle; [...].

Бр езанть, -ться v. impers. U. $n$. dämmern (am Morgen), anfangen zu tagen; чyтb

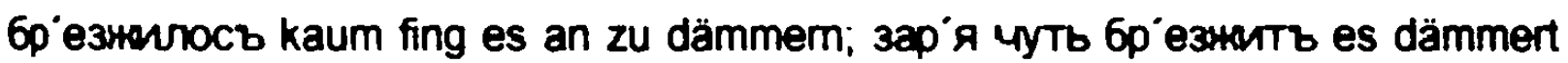

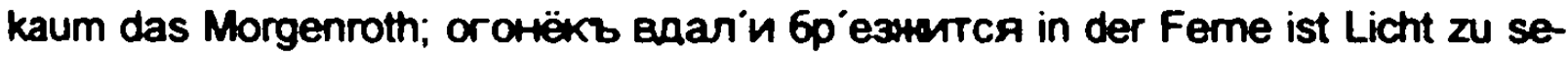
hen.

Буер'акъ s. m. [...]; -р'амий adj. Schluchten-, 2. В. 6+ная крутизн'а der steile Abfall der Schlucht; 6-ная вод’a das Wasser im Hohlweg; 6-ья тр аat die Steppengräser, dem Steppengras ähnliche Pflanzen.

M'aunta s. f. die Maschine; еинтор ьзная M. die Schrauben-Schneidemaschine, der Schrauben-Schneidestuhl; водоліиная рудн иная м. die Umtriebsm.; водоліивная м'ашина die Kunst, das Schöpfgebäu; die Sack-, Haspelpumpe, Bulgenkunst; ворс илыная м. die Rauhmaschine; вр убовая M. die Schrämmmaschine; das Pumpenwerk, hydraulisches P., Wasserwerk; rpy6orpqn' иlotas M. die Vorspinnm.; rpy6очес' алыная M. die Vorkratzm.; М. двойн' aro д' ћйствія doppetwirkende Maschine; дp06 ' илыная м. die Eisensteindruckm.; М. духов ая die kalorische. Heißeluftmaschine; камнемётная $M$. die Steinwurfmaschine; $M$. коловр'атная rotirende Maschine; мет'ателыная M. die Wurfmaschine; мот'алыная M. das Windebrett, die Wickelm.; M. н'изкаго давл' tнія die Niederdruckmaschine; napoв'ая $M$. die Dampf-, Feuermaschine; $M$. паров 'ая ғыс'окаго давл'енія die Hochdruckmaschine; подъёмная м. die Winde. Hebe-, Hakenwin- 
de. Hebemaschine, der Hebekrahn; noдъёмная м для ор yдї die Geschützwin-

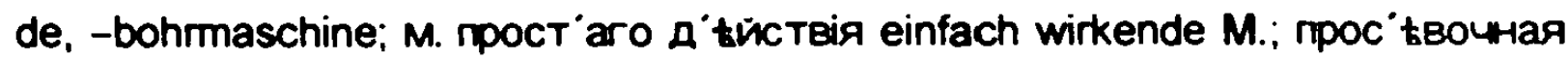
$M$ der Erzdurchwurf; сотряс ательная $M$. die Erschütterungsm.; $M$. ср едняго дазл' енія die Mitteldruckmaschine; M. Cъ 6arahc "upoms die Balanciermaschine;

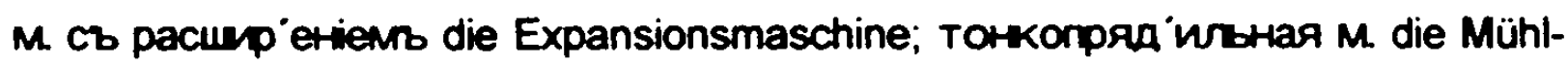
spulmaschine; штамв'алыная M. das Stampfwerk; M. Для штампв анія cen-uiosuxъ nуль die Kugelpresse, Kugelpreßmaschine; uв eйraя M. die Nähmaschine; M. Bbc'okaro дasrietiя die Hochdruck-, Hochdruckdampfm.; M. crom araç die M. macht Stücken; [...].

O6езс' удить 11., voll. zu -с унивать v. a. 1. Ohne Rechtsverfahren, ohne gerichtliches Verfahren verurtheilen; 2. Einem etwas Uebles nachreden; 3. verurtheilen, tadeln, kritisiren, verdammen, afterreden; не обезс удьте на угощ' еніи ich bitte damit fürlieb nehmen zu wollen (eine Höflichkeitsformel nach stattgehabter Bewirthung).

O6m arrb s. m. 1. der Betrug, die Betrügerei; enas'atbca въ 0. in die Falle gehen; sich betrügen, täuschen lassen; 2. die Täuschung, das Blendwerk, die lllusion; ort 'meckī o. die optische Täuschung; die T. der Augen; 0. 3p trig das Falschsehen, die Gesichtstäuschung; 0. 0604 qiя die Geruchstäuschung; 0. чувствъ die Sinnestäuschung; [...].

Criaska s. f. 1. (Zool. Sylvia) die Grasmücke; c.-nepecm tuka das Müllerchen, Weißkehichen; с. пестротр удая die Sperbergrasmücke; с. полев ая grave Grasmücke; c. сад овая Garten-Grasmücke; c. чёрношап очная der Mönch, Schwarzkopf; с. евpon ейскій портн 'ой der Schneidervogel, Cistenfänger; 2. der Lobgesang.

Cланы s. f. 1. das Aus-, Untergebreitete; die Unterlage; nодн оныая с. der Fußteppich; 2. gestreckter Lauf, der Schnelllauf, die Carriere (des Pferdes); 3. niedriges, krüppeliges Holz, das Knieholz; 4. zarte Vegetation; verkrüppeltes Wachsthum; 5. валіить слі аныo ohne Unterschied, durcheinander legen, werfen.

Obwohl bei einigen Lemmata die Mikrostruktur erheblich durch Kollokationen emweitert wurde, dominieren auch in der zweiten Auflage immer noch die Wörterbuchartikel ohne Himweise auf syntaktische Regularitäten. Prozentual gesehen, hat sich sogar der Anteil an Artikein mit Kollokationen in der Stichprobe von durchschnittlich $11 \%$ in der ersten Auflage 
auf nur noch ca. $8 \%$ in der zweiten Auflage verringert, da Nikoliz bei vielen der neu lemmatisierten Einheiten auf die Aufinahme von syntagmatischen Himweisen verzichtet hat.

Ebenfalls zu kritisieren ist, daß der Benutzer in den seltensten Fällen umfassend über die syntagmatischen Regularitāten der jeweiligen Lemmata informient wird, da die ausgewählten Verbindungen, wie das Beispiel maun-1a eindrucksvoll beweist, meist nur ein einziges syntaktisches Phänomen beschreiben.

Die einzige qualitative Veränderung, die Nikolič bei der Überarbeitung des Bereiches der Syntagmatik vorgenommen hat, betriff die Zitate aus der Literatur, die er ersatzlos gestrichen hat. Praktisch unverändert übernommen hat er dagegen den größten Teil der von Pawlowsky aufgenommenen Sprictwörter und die biblischen Zitate.

\subsubsection{Zusammenfassung}

Verglichen mit den von Nikolič eingeführten Veränderungen in der Makrostruktur des Wörterbuches (vgl. 3.2.5, 85), sind diejenigen in der Mikrostruktur als marginal zu betrachten, da Nikolič den Aufbau der Wörterbuchartikel unverändert von Pawbursky übemommen hat.

Qualitativ verbessert murden von Nikolič lediglich die Flexionshimweise bei den Verben. obwohl die von inm gewählte Systematik aufgrund ihrer Kompliziertheit als wenig benutzerfreundlich kritisiert werden muB. Da die Mikrostruktur ansonsten ausschließlich auf der quantitativen Ebene verändent wurde, solte allein der Zusatz "wesentlich vermehrt des Deckblattes der zweiten Auflage auf die Mikrostruktur bezogen werden, denn die Aussage "vollstándig umgearbeitet" trifft nur auf die Makrostruktur der von Nikolic erarbeiteten Auflage zu.

\subsection{Die Mikrostruktur der dritten Auflage des russisch-deutschen Worterbuches von Pawlowsky}

Abschließend wird nun auch die Mikrostruktur der dritten Auflage einer ausführlichen Analyse unterzogen. Dies geschieht auf der Basis der Ergebnisse der Analyse der Mikrostruktur der zweiten Auflage, so daß hier nur Phänomene erwähnt werden, die als Ergebnis der Überarbeitung der Mikrostruktur der zweiten Auflage zu werten sind.

\subsubsection{Phonetische Angaben}

Auch die Bearbeiter der dritten Auflage weisen nicht auf die korrekte Aussprache phonetisch komplizierter Stichwörter hin, sondern geben nur die jeweilige Akzentstelle bei zwei- und mehrsilbigen Lemmata und Kollokationsteilen an. Allerdings wurden die einzelnen Buchstaben des russischen Alphabets, die seit der zweiten Auflage lemmatisien sind, 
in einigen Fällen mit mehr oder minder ausführlichen allgemeingültigen Ausspracheregeln versehen.

Bsp.: A, a, der erste Buchstabe und Vocal des russischen Alphabets, wird wie das deutsche a ausgesprochen, ausgenommen im Genitiv der Adjectiva und adjectivischen Pronomina auf -aro, wo es wie o od. e lautet, z. B. Hëstraro (-owa) od. xop owaro (-wa); in unbetonten Silben wird es überhaupt undeutlich ausgesprochen, namentlich nach den Zischlauten $(*, 4, w, w)$ in unbetonten Silben zu Anfang $u$. in der Mitte eines Wortes beinahe wie e: жar ŁTb, щад ить, und in der 3. Person pl. der Zeitwörter wie englisch a: $\Delta^{\prime}$ epHatb, сліbuatb.

6, 6 zweiter Buchstabe des russischen Alphabets, dem deutschen b entsprechend; [...]. Es wird wie $n$ ausgesprochen vor den harten Consonanten $K, C, T, x, u, ~ 4, w, u$, z. B. 'общество die Gesellschaft, und wie ein b od. wie p am Ende eines Wortes, z. B. תo6b die Stim. [...].

$r, r$, vierter Buchstabe des russischen Alphabets, den deutschen Buchstaben $g, h$, $k$ u. ch entsprechend: wie $g$ in rp'y6tu grob, wie $h$ in $\Gamma^{\prime}$ ocnoди o Gott! wie $k$ (im Auslaute) in твор 0 or (twar ok) die Käsemilch, wie ch in תërkin leicht; außerdem wie w im Genitiv, resp. Accusativ, des Masculinums der Pronomina und Adjectiva, $z$. B. Hkor'o (nikaw'o) niemandes od. niemand, xop'owaro (char'oschawo) des guten od. den guten. $[\ldots]$.

O, o, fünfzehnter Buchstabe des russischen Alphabets, klingt im Volksmunde gegen Norden u. Osten von Moskau wie das o im Deutschen, in der maßgebenden Aussprache von Moskau jedoch ist es, wenn unbetont, sehr kurz u. geht mehr in den A-Laut über. [...].

\subsubsection{Die grammatischen Angaben}

\subsubsection{Wortarten}

Auch die Bearbeiter der dritten Auflage haben die von Pawlowsky gewählte Systematik zur Kennzeichnung der Wortarten im wesentlichen beibehalten. Neu hinzugekommen ist lediglich oine weitere Subkategorie bei den Substantiven, denn zusätzlich zu den Kollektiva, den Diminutiva und den Augmentativa (vgl. 4.2.2.1.94) werden nun auch die Nomina propria mit einer speziellen Abkürzung versehen. 
Bsp.: Ar'aza s. f. 1. [...]; 2. n. pr. f. (gr. Mythl.) die Tochter des Kadmus, Mutter des Pentheus, Königs von Theben.

Бр ейтонъ n. pr. m. Brighton, Seestadt an der Südküste Großbritanniens.

M'axeurb n. pr. m. Name einer bösen Gottheit (in der heidnischen Zeit).

Плут 'orrb n. pr. m. Pluto.

Criazkosb n. pr. m. Austerlitz (Mähren).

\subsubsection{Flexion}

Die Verbesserungen im Bereich der Flexion, die auf die Bearbeiter der dritten Auflage zurückzuführen sind, betreffen die Substantive und die Verben. Bei den Substantiven wurden nur marginale Verbesserungen innerhalb des bekannten Systems vorgenommen, die Flexionsangaben der Verben wurden dagegen komplett umgearbeitet.

Zusätzlich zu den Substantivgruppen, die in der ersten (vgl. 4.2.2.2, 101-102) und der zweiten Auflage (vgl. 4.3.2.2, 125-126) mit Hinweisen auf ihre Flexion versehen wurden, wird nun in den Wörterbuchartikeln auch die besondere Deklination der Substantive vermerkt, die junge Lebewesen bezeichnen. Weiterhin wird in der dritten Auflage nicht nur, wie in der zweiten Auflage, auf den flüchtigen Vokal in den obliquen Kasus, sondern teilweise auch auf die unregelmäßige Pluralbildung hingewiesen. Allerdings finden sich auch viele zu dieser Gruppe zählende Lemmata, bei denen ein Himweis auf die unregelmäßigen Pluralformen fehit.

Bsp.: Бо gl|purb s. m. [...]; -рченокъ, Hкa s. m. (pl. -puata, puatb) der Junker, [...].

Б уйілла, -ло [...]; -лёнокъ, Hка (pl. -ліята, -л'ятъ) s. m. das Büffelkalb; [...].

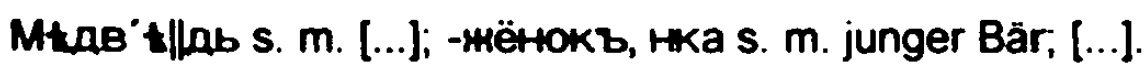

Ebenfalls neu aufgenommen wurde der Verweis auf die Stammveränderung im Plural bei den maskulinen Personenbezeichnungen, die mit dem Suffix -ями- bzw. -aнmb gebildet werden

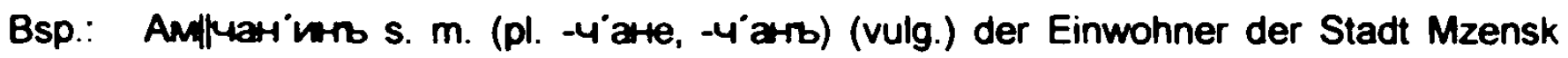
(vulg. AnY eHCKъ).

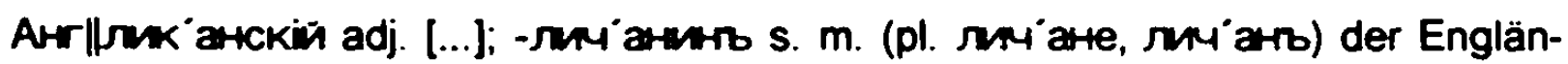
der; [...].

Doch auch hier lassen sich zahlreiche Beispiele finden, bei denen nicht auf die Pluralformen hingewiesen wird.

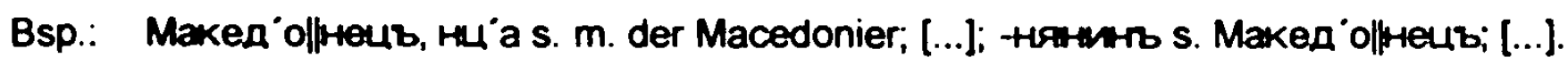

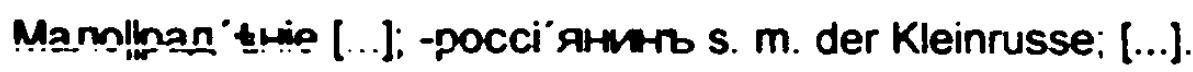

Слаңван иньь s. m. der Slave; [...]; [...]. 
Es fălt auf, daß die Angaben zur unregelmäßigen Pluralbildung dieser Substantivgruppen nicht konsequent bei allen entsprechenden Lemmata angeführt wurden. Dies legt die Vermutung nahe, daß die Überarbeitung des Wörterbuches auf mehrere Schultern verteilt war, so daß das Vorhandensein bzw. das Fehlen der unregelmäßigen Pluralformen als Abstimmungsfehler interpretiert werden kann. Diese Hypothese murde anhand aller im Грамматикаскиі словарь von A. A. Zaliznjak (1980) verzeichneten Substantive überprüft, die mit den Suffixen und -anurb bzw. -amb gebildet werden.

Von den insgesamt 76 Lemmata der ersten Gruppe im Wörterbuch von Zaliznjak sind 52 auch im Pawlowskyschen Wörterbuch lemmatisiert. Allerdings wird nur bei 13 Substantiven explizit auf die unregelmäßigen Pluralformen hingewiesen, bei den übrigen 39 Lemmata fehtt ein solcher. Ordnet man die Substantive nun den Anfangsbuchstaben nach, so ist festzustellen, daß die relevanten Eintragungen unter den Buchstaben 6, Y, 4 und 4 mit dem Hinweis auf die unregelmäßigen Pluralformen aufgenommen wurden. Ein solcher Hinweis fehtt hingegen bei sämtlichen tatsächlich in der dritten Auflage lemmatisierten Einheiten unter den Buchstaben B, A, 3, K, Л, O, C, T und щ. Dieses Ergebnis untermavert die These, daß die Arbeit am Wörterbuch buchstabenweise aufgeteilt wurde.

Weiter bestätigt wird diese These durch die Substantive, die mit dem Suffix -9an-b bzw. -arm-b gebildet werden und der Personenbezeichnung dienen. Von den insgesamt 114 bei Zaliznjak verzeichneten Substantiven lassen sich 63 auch in der dritten Auflage des Pawlowskyschen Wörterbuches nachweisen. Bei der Gruppierung nach den Anfangsbuchstaben fallt wiederum sofort auf, daß sämtliche Eintragungen unter den Buchstaben $A$, $\Phi$ und $X$ die entsprechenden Piuralformen aufweisen, die in allen anderen Fällen fehlen.

Allerdings gibt es auch Fälle, bei denen sowohl Substantive mit als auch solche ohne Verweis auf die Pluralbildung innerhalb eines Buchstabens auftreten. Da in diesen Fällen jedoch nur jeweils ein Lemma mit dem Verweis versehen wurde, zahireiche Lemmata dagegen ohne einen solchen aufgeführt sind, kann dies nicht als Widerspruch zu der oben aufgestelten These gewertet werden. Wahrscheinlicher ist es, daß in diesen wenigen Fällen der Hinweis auf die unregelmäßige Pluralbildung bereits in den Quellen vorhanden war und von dort in das Wörterbuch übernommen wurde.

Um ein vielfaches benutzerfreundlicher gestalteten die Bearbeiter der dritten Auflage die Flexionsangaben bei den Verben. Zum einen wurden zahlreiche Verbformen als Verweislemmata in die dritte Auflage des Wörterbuches aufgenommen, zum zweiten wurde die bei der Analyse der Mikrostruktur der zweiten Auflage als zu komplizient und zu ungenau kritisierte dreigeteilte Systematik (vgl. 4.3.2.2, 129-131) gestrichen und durch die Angabe der entsprechenden Verbformen direkt bei dem jeweiligen Lemma ersetzt. 
Bsp.: Aсcимn|lл ировать (-лiирую) v. a. assimilieren, ähnlich machen; [...].

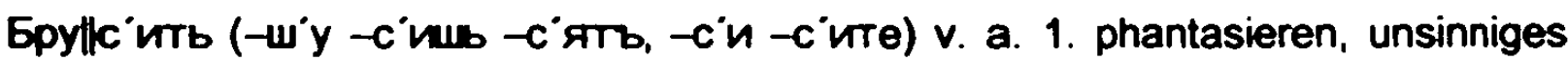
Zeug zusammenreden, lügen; 2 . Steine brechen und vierkantig behauen; [...].

M'alзать (-жу -жешь -жуть, -жь -ньте), -зызать, -зну'уть v. a. bestreichen (mit Theer, z. B. das Dach), schmieren (die Räder), einreiben (mit Salbe, Fett, Oel); $[\ldots]$.

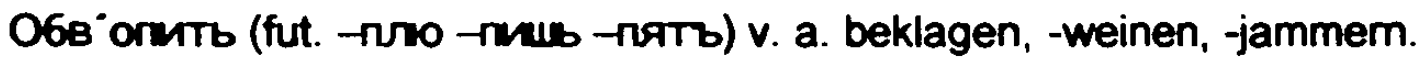

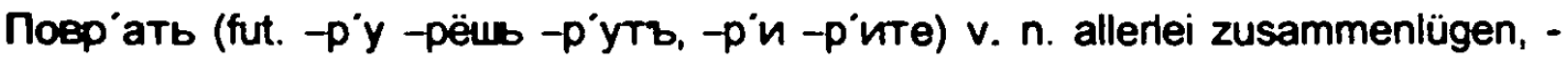
plaudem.

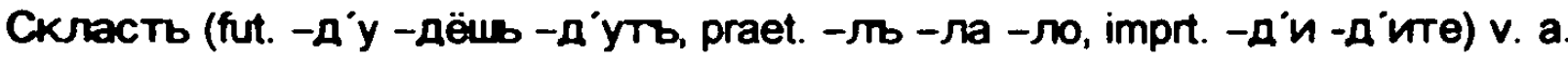

1. s. Cкriaдывать; 2. aufbauen, -führen (ein Haus), errichten (einen Rauchfang).

Allerdings ist auch dieses System nicht lückenlos, wie sich an den bereits bei der Analyse der Mikrostruktur der zweiten Auflage angeführten Verben zeigen läßt (vgl. 4.3.2.2, 129130). Denn nur bei den Verben 6ороть, метать und nлытrb wird auf die unregelmäßigen Konjugationsformen hingewiesen. Бренмать und брнознать sind ohne weitere Angaben lemmatisiert.

Bsp.: Бор' 에tb (6op' zwingen, überwältigen, niederwerfen, zu Boden strecken; [...].

Брен1|н arie s. n. [...]; -4 atb v. n. klirren, klappern, klimpern.

Epro3|r'a s. c. [...]; -ж'ать v. n. 1. brummen, murren, knurren; 2. aufdringen, zusetzen; 3. klingen, tönen, klimpern.

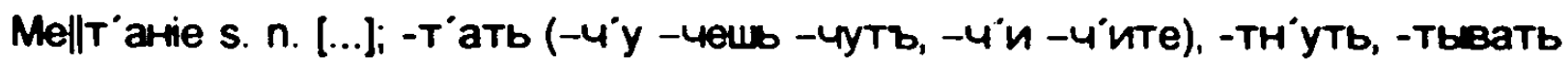
v. a. 1. werfen (Bomben etc.), schleudern (Steine), abschießen (Pfeile); [...].

Пльшстіи [...]; -ть (-в'у -вёшь -в'утъ, -ви -вите) v. n. (плыть unterscheidet sich in den gleichen Bedeutungen 1. u. 2. von nл авaтb durch ein bestimmtes Ziel) 1. schwimmen; 2. segeln (von Schiffen), fahren; [...]; 3. fließen (von Lichtern, Harz); [...]; 4. überlaufen (z. B. aus der Kasserolle).

Unerklärlich ist allerdings, weshalb die Bearbeiter der dritten Auflage die allgemeinen Angaben zur Bildung der regelmäßigen Verbformen ersatzlos gestrichen haben. Denn nun ist zu beklagen, daß der Benutzer über die Formenbildung von regelmäßigen Verben nicht mehr durch das Wörterbuch informiert wird, sondern auf andere Hilfsmittel zurückgreifen muß. 


\subsubsection{Diasystematische Angaben}

\subsubsection{Diatechnische und diakonnotative Markierungen}

Da der Vergleich der diatechnischen und der diakonnotativen Markierungen der dritten Auflage mit denjenigen der zweiten Auflage des russisch-deutschen Wörterbuches von Pawlowsky keine oder nur geringe Veränderungen ergeben hat, werden diese Markierungen in einem Unterpunkt behandelt. Wie schon in den vorangehenden Auflagen (vgl. 4.2.3.1, 104-105; 4.3.3.1, 131-132), so wurde auch in der dritten Auflage großen Wert darauf gelegt, den fachsprachlichen Wortschatz in einer angemessenen Form darzustellen. Neben den aus der zweiten Auflage übernommenen diatechnisch markierten Einheiten finden sich auch neu aufgenommene Lemmata bzw. neu berücksichtigte Bedeutungen, bei denen auf den fachsprachlichen Gebrauch verwiesen wird. Da die Zahl der diatechnischen Markierungen in der dritten Auflage deshalb mit 111 Markierungen in der relevanten Stichprobe nahezu unverändert hoch ist, nur einige wenige neue Markierungen hinzugekommen sind und im Verlauf dieses Unterpunktes zahlreiche Beispiele für diatechnische Markierungen (vgl. 4.4.3.3, 149) auftreten, wird hier auf die Angabe von zusätzlichen Beispielen verzichtet. Positiv ist die Überarbeitung des Abkürzungsverzeichnisses hervorzuheben, die die Zahl der dort ungenau oder überhaupt nicht aufgeführten diatechnischen Markierungen deutlich verringert hat.

Unverändert bleibt die Zahl der diakonnotativen Markierungen in der dritten Auflage. Markiert werden Lemmata und Bedeutungen, die liebkosend, scherzhaft, verächtlich und ironisch gebraucht werden.

\subsubsection{Diachronische Markierungen}

Qualitativ unverändert ist die Situation der diachronischen Markierungen in der dritten Auflage, denn auch dort werden nur Paläologismen mit einer Markierung hervorgehoben. Da die dritte Auflage 41 Jahre nach der ersten Auflage erschienen ist und Nikolič alle als veraltet markierten Lemmata ohne Veränderung in die zweite Auflage übernommen hat, könnte man erwarten, daß sich anhand der Paläologismen der Sprachwandel dokumentieren läßt. Zum einen dürften einige der 1859 bereits veralteten Lemmata 1900 gar nicht mehr gebräuchlich gewesen sein, zum anderen waren manche der in der ersten Auflage gebräuchlichen Lemmata 1900 vermutlich schon veraltet. Der Vergleich der jeweils mit veraltet markierten Lemmata in der zweiten Auflage mit denjenigen der dritten Auflage ergab eınige Veränderungen 
Die erste Gruppe bilden Lemmata wie алаборъ, 6раздна, матрель, о6ада, плtновати und скалмна, die in der zweiten Auflage als veraltet charakterisiert und von den Bearbeitem der dritten Auflage nicht in diese übernommen wurden.

Eine weitere, deuttich umfangreichere Gruppe bilden Lemmata, die in der zweiten Auflage noch unmarkiert aufgenommen worden waren und dann von den Bearbeitern der dritten Auflage einen Verweis auf ihren veralteten Gebrauch erhalten haben.

Bsp.: $\quad A 6^{\circ}$ d conj. (veralt.) 1. daß, damit; 2. wenn etwa.

Amra6 allcb (veralt.) s. m. persischer Brokat; [...].

Бо\|ст'и (-д'у -дёшь -д утъ) v. а. (veralt.) mit den Hörnern stoßen.

Б'yдa s. f. (veralt.) 1. das Gebäude, Bauwerk, die Baude; 2. Todtengewölbe; 3. eine Art Fabrik für Soda, Theer, Salpeter; 4. n. pr. f. ungarischer Name für Ofen, Hauptstadt von Ungarn.

Meд yua s. f. (veralt.) der Honig-, Methkeller.

Метыль, л'я s. m. 1. (Zool. Ephemera) die Eintagsfliege; 2. (veralt.) der Schmetterling; 3. (veralt.) der Eiter, Schleim.

$06^{\circ}$ entün adj. (veralt.) leibeigen.

'Облить v. a. (veralt.) ein Zeichen aufbrennen, brandmarken.

CKup6b s. f. (veralt.) das Bündel, Flachsbündel.

Ckop'a s. f. (veralt.) die (unbearbeitete) Thierhaut, das Thierfell; das Rauchwerk.

Es darf an dieser Stelle aber nicht unerwähnt bleiben, daß eine fast gleich große Gruppe solche Paläologismen bilden, die aus der zweiten Auflage unverändert in die dritte Auflage übernommen wurden.

Bsp.: 'Awe conj. wenn, sofern, falls; wenn anders.

Apxi'atepъ s. m. (veralt.) der Ober-, Leibarzt.

Б'ыто S. n. (veralt.) das Vermögen, Hab und Gut.

Манать'я s. f. 1. (veralt.) die Mönchskutte; 2. (NordrußI.) der abgetragene Ueberrock.

M'alluexa [...]; - veumarb s. m. (veralt.) der Sohn der Stiefmutter.

'O6ma s. f. 1. (veralt. u. NordrußI.) ein variierendes Ackermaß (bald 5, bald 15 Dessjätinen gleich); [...].

Пов oдie s. $n$. (veralt.) die Ueberschwemmung

กorpe6 armue s. n. (veralt.) der Gottesacker, Kirchhof; [...].

Ckлаןlaъ s. m. 1. [...]; 7. (veralt.) der Vertrag, die Abmachung; 8. (veralt., WestrußI.) die Zusammenkunft, Versammlung; [...]. 


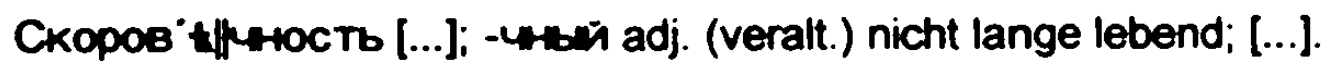

Bedenkt man nun, daß ein großer Teil der Paläologismen unverändert übernommen wurde, und berücksichtigt man außerdem, daß ein Teil des erst in der dritten Auflage als veraltet markierten Wortschatzes vermutlich vorher schon veraltet war, ohne daß er als sotcher von Nikolix markiert worden ist, so scheint es nur sehr bedingt möglich, anhand der Paläologismen Aussagen über den Sprachwandel zu treffen.

\subsubsection{Diastratische Markierungen}

Die diastratischen Markierungen wurden in der dritten Auflage des russisch-deutschen Wörterbuches von Pawlowsky komplett überarbeitet, wobei das Ergebnis dieses Prozesses so heterogen ist, daß dadurch wiederum die These von den unterschiedlichen Bearbeitern dieser Auflage gestützt wird (vgl. 4.4.2.2, 144). In der Stichprobe der zweiten Auflage finden sich insgesamt 155 Lemmata bzw. Bedeutungen, bei denen mit der Markierung .pop." auf deren volkssprachlichen Gebrauch verwiesen wird. Insgesamt 27 davon werden von den Bearbeitern der dritten Auflage durch die Kennzeichnung ihres Gebrauchs als .vulgär auf eine stilistisch niedrigere Ebene gesetzt. Von dieser Abwertung betroffen sind insbesondere die Lemmata bei den Buchstaben $A$ und $E$ in der Stichprobe, denn 9 von 13 bzw. 7 von 8 Lemmata haben anstelle eines Verweises auf den volkssprachlichen Gebrauch nun einen Himweis auf ihre vulgäre Verwendung erhalten.

Bsp.: Arb conj. (vulg.) aber, jedoch.

Ap alsa s. f. (vulg.) eine Menge; [...].

Б'ypllkarie s. n. [...]; -Кать, -Kнуть v. a. (vulg.) 1. werfen, daß es saust; schwingen, daß es schwirt; 2. murmeln, in den Bart brummen; [...].

Б'yrops s. m. (vulg.) 1. das Hab und Gut, die Habseligkeiten, Hausgeräthe; 2. der

Rumpelkram, das Gerümpel; 3. das Eingeweide; 4. Fieberphantasien; 5. der Lärm, das Getöse.

Als Konsequenz daraus ergibt sich, daß bei den ersten beiden Buchstaben der Stichprobe die Zahl der in die dritte Auflage ohne Markierung übernommenen Lemmata im Vergleich zu den anderen Buchstaben sehr gering ist. Gibt es bei den Buchstaben $A$ und 6 nur zwei bzw. gar kein Lemma, das durch das Streichen der Markierung stilistisch aufgewertet wurde, so finden sich unter dem Buchstaben $M 17$ von 30 , bei $O 11$ von 58, bei $\Pi 11$ von 37 und unter $C$ sogar 7 von 9 Lemmata, die nach der Überarbeitung aufgrund des Fehlens einer Markierung in den stilistisch neutral gebrauchten Wortschatz eingeordnet werden müssen. 
Bsp.: Mellnyн inua s. f. 1. (Zool. Alosa vulgaris) die Alfe, der Maifisch; 2. die Biene, Arbeiterbiene; 3. (prov.) die Erdhummel; 4. der Honigthau; 5. (Bot. Pulmonaria officinalis) gemeines Lungenkraut; 6. (Spiraea ulmaria) die Ulmenspierstaude, das Mädelsüß, Wurmkraut; [...].

O6riolMrb s. m. 1. s. O6rionka; 2. das Ge-, Zerbrochene, Bruchstück; die Bruchstelle; [...]; 3. der Abhang, -sturz; 4. (veralt.) der Absatz, Vorsprung an einer Stadtmauer; 5. (Archit.) das Profil, der Durchschnitt des Gesimses; 6. der Lümmel, plumper Kerl; 7. (Schimpfw.) der Satan, Teufel; 8. der Hausgeist, Kobold; 9. das Fieber, [...].

Mo6p'alkwa s. f. 1. der Wortwechsel; 2. die Weise zu schimpfen, das Schimpfwort; [...].

Cky\|r'a s. f. 1. der Backenknochen, das -bein (hervorstehendes); 2. (Anat.) der Kiefer, [...]; 3. (Seew.) der Bug (am Schiffe); 4. (Süd- u. WestrußI.) die Geschwulst im Gesicht, auf dem Halse od. geschwollene Drüsen; 5. der Geizhals, der Knauser, [...].

Obwohl die Mehrheit dieser Beispiele eine Vielzahl von Markierungen enthält und einige dieser Markierungen an anderer Stelle anstelle des Verweises auf den volkstümlichen Sprachgebrauch verwendet werden, so sind doch die in der zweiten Auflage stilistisch niedrig angesetzten Bedeutungen "Biene", .Lümmel" und "Geizhals" gemäß der dritten Auflage neutral verwendbar.

Der weitaus größte Teil der in der zweiten Auflage diastratisch markierten Lemmata wurde in der dritten Auflage mit einer diatopischen Markierung versehen. Auffällig ist, daß diese Methode vor allem bei den Buchstaben $M, O$ und $\Pi$ der Stichprobe Anwendung gefunden hat, was wiederum im Einklang mit der These steht, daß unterschiedliche Bearbeiter an der Neufassung des Wörterbuches beteiligt waren. Der größere Teil der in der zweiten Auflage als im Volk gebräuchlich bezeichneten Lemmata wurde nun mit der bereits als zu unspezifisch kritisierten (vgl. 4.2.3.5, 107) diatopischen Markierung .provinziell" vom neutralen Wortschatz abgegrenzt.

Bsp.: Mep 'екать v. a. (prov.) 1. muthmaßen, errathen; 2. ein wenig begreifen; 3. phantasieren, irre reden.

O6ariuxa s. f. (prov.) eine Art Mehlsuppe, dünner Mehlbrei aus Roggen- oder Gerstenmehl mit Milch od. Butter.

Morop'az*e adv. (prov.) besser, mehr. 
Der andere Teil wurde mit den neu eingeführten Arealbezeichnungen (vgl. 4.4.3.5, 152153) jeweils einer bestimmten Sprachregion innerhalb des Gesamtsystems zugeordnet.

Bsp.: Marдpoв ать (-p'yo) v. n. (Süd- u. Westrußl.) wandern, reisen.

O6вешн ять V. n. 1. (NordrußI.) gegen den Frühling hin (in Folge Erschöpfung der Wintervorräthe) Mangel leiden; [...].

O6m on s. m. pl. (WestrußI.) die Deichselarme, die Gabeldeichsel am Hakenpfluge.

Пos'ofps s. m. (Sibir.) der Strick, Riemen, zum Um- od. Anbinden; [...].

Пог 'a-1никъ [...]; +ka s. f. 1. unsauberes, -flätiges, -reines Frauenzimmer; 2. die Ungläubige, -christin; 3. schlechter, ungenießbarer Pilz, überh. der Giftpilz; bes. (Agaricus comatus) der Mist-, Krötenschwamm; 4. (Zool. Colymbus) der Seetaucher, Steißfuß; 5. (prov.) die Maus; 6. (SüdrußI.) das Fieber, [...].

Als Fazit der Untersuchung der diastratischen Markierungen ergibt sich, daß die Bearbeiter der dritten Auflage auf die Markierung der im Volk gebräuchlichen Lemmata verzichtet haben. Die vormals so markierten Lemmata wurden entweder auf einer stilistisch noch tiefer liegenden Sprachschicht als vulgär gebräuchlich gekennzeichnet oder mit einer diatopischen Markierung im besten Fall der Gegend zugewiesen, in der sie gebräuchlich waren. Ein geringerer Teil wurde durch das Streichen der Markierung von den Bearbeitern der dritten Auflage in den stilistisch neutralen Bereich erhoben.

\subsubsection{Diaintegrative Markierungen}

Die Bearbeiter der dritten Auflage haben zusätzlich zu der bereits aus den ersten beiden Auflagen bekannten Markierung "sl." für aus dem Kirchenslavischen stammende Lemmata zahireiche weitere Markierungen eingeführt, die den Benutzer über die Herkunftssprache der entsprechenden Lemmata unterrichten. Die Informationen zur Etymologie einiger Lemmata sind in der Stichprobe nicht nur unterschiedlich umfangreich, sondem auch unterschiedlich häufig verteilt. Auffällig ist, daß die etymologischen Hinweise besonders häufig bei den ersten drei Buchstaben der Stichprobe auftreten und daß bei den letzten drei Buchstaben keine derartigen Hinweise nachgewiesen werden konnten. Diese Tatsache kann als weiterer Beleg dafür gedeutet werden, daß vermutlich unterschiedliche Bearbeiter für die jeweiligen Buchstaben zuständig waren.

Bsp.: Абаж уръ s. m. (franz. abat-jour) 1. das Schrägfenster, die Jalousie, der Fensterschirm; 2. der Lampenschirm.

Ariek\|topb (aus dem Griech. in's Ksl. übergegangen) der Hahn; [...]. 
Av'arrb (aus dem Arab.) 1. die Verzeihung, Begnadigung; 2. der Geizhals, Knauser.

Ac'eñ s. m., ac'eñka s. f. (engl. I say) (vulg.) der Engländer, die -in.

Брет'ель s. f. (franz. bretelle, echt russisch подт'яннка) das Tragband, der Hosenträger, die Achselbänder.

Epllotto s. f., -Он'я s. f. (altd.) die Brünne, der Harnisch, Panzer.

Epynßs s. m. (engl.) ein Brougham, kleine zweisitzige Kutsche.

Markи\|lров ать (-p'yю) v. n. (franz. manquer) fehlen, versäumen.

метранпі анъ s. m. (franz. metteur en pages) (Buchdr.) der Formatbildner.

Es wurden bewußt Beispiele aus unterschiedlichen Gebersprachen gewählt, um ein möglichst voliständiges Bild der Entlehnungen zu zeichnen. Tatsächlich stammt aber der größte Teil der Fremowörter aus dem Französischen, was auf den großen Einfluß des Französischen auf die russische Literatursprache zu dieser Zeit zurückzưühren ist.

Praktisch unverändert übernommen wurden von den Bearbeitern der dritten Auflage die laut Nikoliž aus dem Kirchenslavischen stammenden Lemmata. Da auch Nikolic diese von Pawlowsky übernommen hatte, ergibt sich die Konsequenz, daß die Gruppe der aus dem Kirchenslavischen stammenden Lemmata als bisher einzige direkt auf Pawlowsky zurückgeht.

\subsubsection{Diatopische Markierungen}

Die Angaben zur regionalen Verbreitung der Lemmata sind in der dritten Auflage von deutlich höherer Qualität und somit von größerem Wert für den Benutzer als die in den vorhergegangenen Auflagen. Dies liegt vor allem daran, daß die in den ersten beiden Auflagen überwiegend verwendete sehr unspezifische Markierung "provinziell" in der dritten Auflage häufig durch neu eingeführte Markierungen ersetzt wurde, die die regionale Verbreitung der jeweiligen Lemmata deutlich spezifizieren.

Die Autoren der dritten Auflage des russisch-deutschen Wörterbuches unterscheiden drei verschiedene Ebenen bei der Markierung des regional gebrauchten Wortschatzes. Auf der ersten Ebene sind diejenigen Lemmata anzusiedeln, die weiterhin als „provinziell" gekennzeichnet werden.

Bsp.: Аrieй s. m. (prov.) das Pflanzenöl, Hanföl.

$Б^{\prime}$ y\|6енъ, 6на s. m. [...]; -6'енить v. n. 1. (prov.) die Glocken läuten; 2. fig. prügeln, durchwalken; 3. о чёмъ (vulg.) ausposaunen, verbreiten; [...].

M'an adj. (prov.) muthig, fröhlich (vom Charakter). 
'O6mopoкъ s. m. 1. die Ohnmacht; 2. der Höhen-, Heerrauch; 3. der Schlingel, Wildfang, Schelm; 4. (prov.) der Sinnenwahn, das Wahn-, Trugbild, Phantasiegebilde; 5. (prov.) der Hexenmeister, Schwarzkünstler.

Mor olfrb s. m. 1. das Verfolgen, Nachsetzen; die Hast, Eile; 2. ohne Aufenthalt zurückgelegte Strecke; 3. (beim Destillieren) der letzte, wässerige, übel riechende Branntwein (zum nochmaligen Abziehen); 4. der Tragriemen, das Schultergehenk, Bandelier, 5. die Tuchepaulette (mit der Regimentsnummer), die Schulter-, Achselklappe; 6. die Stange, Schiene, der Bogen (worauf sich etw. bewegt); 7. der Spielraum der Auf- und Abbewegung; 8. (Wolga) günstiger Wind; 9. (prov.) das Holzfoß; 10. (OstrußI.) ein Komplex von beiläufig 250 Angelhaken für den Fischfang im Winter (unter dem Eise); 11. (prov.) die Viehtrift, -weide; 12. (prov.) späte Triebe des Getreides (nach Spätregen); [...].

Ско॥б ить [...]; -6к'apь, p'a s. m. 1. (prov.) hölzerner Humpen, großes Trinkgefäß mit zwei Henkeln; 2. (Archang.) kleiner Zuber mit einem Deckel (zu Butter).

Auf einer zweiten Ebene wird das russische Sprachgebiet in sechs Regionen unterteilt und werden diejenigen Lemmata markiert, die in Nord-, in Süd-, in West- und in Ostrußland sowie in Sibirien bzw. in Ostsibirien gebräuchlich sind.

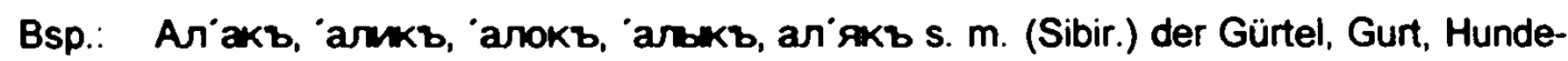
gurt aus Hirsch-od. Rennthierleder.

Ari aps s. m. (Ostsib.) ein von Feldern umgebenes Wäldchen, die Waldinsel.

Max итра s. f. (West- u. SüdrußI.) großer, breiter Topf (zum Zerreiben von Mohn, Tabak).

Ma'alfuetie s. n. [...]; -4итb v. n. (vulg.) 1. undeutlich scheinen, sich unklar zeigen, schimmern; 2. sich kümmerlich durchhelfen; [...]; 3. Kleinhändler sein; 4. (OstrußI.) zaudern, zögem; v. a. 1. etw. in der Luft hin u. her bewegen, Zeichen geben; 2. (prov.) lallen; 3. (Sibir.) eine wenig verstehen (eine Sprache); 4 . beim Handeln übervortheilen, betrügen; [...].

O6де|lp uxa s. f. (NordrußI.) weiblicher Badstubengeist; [...].

O6mariaxtatb v. a. (OstrußI., Sibir.) trauen (ein Paar); [...].

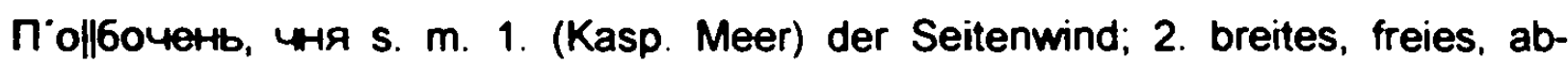
schüssiges Ufer; 3. (Sibir.) einer der beiden Quersäcke des Saumthieres; 4. (Sibir.) die einseitige Fußfessel (für die Pferde); [...].

Понfr oда s. f. [...]; -год иться v. rc. (Süd- u. WestrußI.) sich vertragen, sich einigen; v. n. (Sibir.) sich finden, sich vorfinden; [...]. 
Ckpy\|tr s. m. [...]; -тa s. f. 1. s. Ckpyч'eHie; 2. die Vorbereitung. Ausrüstung (zu den Thierfängen); das Rüstzeug, Geräth, Zubehör für den Thierfang; 3. (NordrußI.) das Gewand; das Festkleid; der Kopfputz (der Neuvermählten); 4. (NordrußI.) die Mitgift; [...].

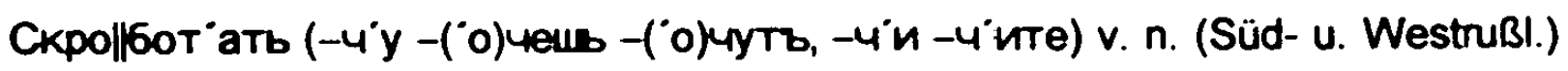
scharren, durch Scharren ein Geräusch hervorbringen; [...].

Die dritte Ebene bilden Lemmata, die nur in einem regional eng begrenzten Raum Anwendung finden, auf den dann explizit hingewiesen wird.

Bsp.: $5^{\circ}$ olluka s. f. 1. das Faß, die Tonne; [...]; 2. ein Flüssigkeitsmaß $=40$ Wedro; [...]; 3. (im Pskowsch. G.) eine Art Winde zum Ausziehen von Netzen; [...].

Mar' gllpъ s. m. 1. der Maler, Zimmermaler, Putzmaurer, 2. (Petersburg) der Tapetenankleber; [...].

Mерекайло s. n. (Kamtschatka) die Thorheit, der Unsinn, Wahnsinn.

Обледев онить v. а. 1. (Ostrußl.) niedermachen, zu Boden strecken; 2. (Moskau) übers Ohr hauen, übertölpeln, -listen; 3. (prov.) blamieren beschämen, in Schmach bringen.

$06^{\circ}$ ой s. m. 1. s. O6n' arie; 2 das vom Winde abgeschlagene, herabgefallene Obst: 3. Flachs- od. Hanfreste vom Hecheln; 4. (Perm) der erste, noch unreine Bodensatz in der Salzpfanne.

חoaw'atb v. a. (Orenburg) etw. zu sich nehmen.

ח'o803ъ s. m. (Wjatka) der Gottesacker, Kirchhof.

CK'aфa s. f. (Cherson) ein Instrument (altes Sensenstück) zum Abschaben der Schaffelle.

Cковоlpoд'a s. f. [...]; -p’oдникъ s. m. 1. der Stiel zur Pfanne (zum Umkehren derselben od. zum Abnehmen vom Dreifuß), die Pfannengabel; 2. der Hebel zum Aufziehen des Schleusengatters; 3. (Wologda) ein Eierkuchen mit Milch; (Smolensk. Kursk) ein auf der Pfanne gebackener Fladen aus Roggenmehl; [...].

Auffällig sind hier ein weiteres Mal sowohl die quantitative als auch die qualitative Verteilung der Markierungen innerhalb der Stichprobe. Bei den Buchstaben $A$ und $\bar{B}$ ist die Zahl der Markierungen mit 29 bzw. 8, insgesamt gesehen, relativ gering. Prozentual gesehen, kommt hier die unspezifische Markierung „provinziell“ am häufigsten vor. Gar nicht vertreten sind bei diesen Buchstaben Lemmata, die mit einem Hinweis auf die Regionen West-, Ost-, Süd- oder Nordrußland versehen worden wären.

Bei den Buchstaben $M, O$ und $\Pi$ häufen sich die diatopischen Markierungen, wobei die größte Gruppe mit 129, 158 bzw. 185 Eintragungen jeweils die unspezifischen Markierun- 
gen bilden, gefolgt von den an zweiter Stelle stehenden regional begrenzt benutzten Markierungen. Relativ gering ist dagegen in diesem Teil der Stichprobe die Zahl der Markierungen, die ein regional eng begrenztes Gebiet auszeichnen. Bei dem Buchstaben $\mathrm{C}$ kehrt sich dieses Ergebnis um. Stärkste Gruppe sind hier mit 120 Markierungen die auf der dritten Ebene angesiedelten Markierungen, die auf ein kleines geographisches Gebiet verweisen. An letzter Stelle steht dagegen die unspezifische diatopische Markierung "provinziell“. Obwohl natürlich zu berücksichtigen ist, daß die quantitative Größe durch die unterschiedliche Zahl der markierten Lemmata innerhalb dieser Buchstaben verzert wurde, so sind doch die Unterschiede in der Art der Markierung auffällig. Die heterogene Verteilung der unterschiedlichen Markierungen in der Stichprobe kann als weiteres Indiz für die These gedeutet werden, daß unterschiedliche Bearbeiter für die Überarbeitung der Auflage verantwortlich zeichneten.

\subsection{4 Åquivalente}

Wie schon bei der zweiten Auflage, so beschränken sich auch in der dritten Auflage die im Bereich der Äquivalente vorgenommenen Veränderungen zumeist auf quantitative Aspekte. Die von Pawlowsky eingeführte Systematik zur Differenzierung der Bedeutungen von polysemen Lemmata (vgl. 4.2.4, 110-111) wurde von den Bearbeitern der dritten Auflage unverändert übernommen. Im Vergleich mit der ersten und der zweiten Auflage wurde allerdings die Anzahl der polysemen Lemmata deutlich erhöht. indem die Bearbeiter dieser Auflage zahlreiche Bedeutungen in das Wörterbuch aufgenommen haben, die von ihren Vorgängem nicht lemmatisiert worden waren. Da ein Großteil der neu aufgenommenen Bedeutungen aus dem fachsprachlichen bzw. aus dem regional und zum Teil sogar nur aus dem dialektal gebräuchlichen Wortschatz stammt. kann die dritte Auflage des Pawtowskyschen Wörterbuches häufig sogar anstelle eines entsprechenden Fachwörterbuches gebraucht werden.

Bsp.: Ar arm|l3 s. m. (griech.) 1. die Zerlegung eines Ganzen in seine Bestandtheile; 2. (Chem.) die Zerlegung eines Körpers in seine Theile; [...]; 3. (Mathm.) die Buchstabenrechnung und ihre Anwendung in der Geometrie auf endliche und unendliche Größen: [...]; 4. (Philos.) die Zerlegung eines Begriffes in seine Merkmale; 5. die Inhaltsangabe einer Schrift nach ihren Hauptpunkten; 6. (Gram.) Zergliederung eines od. mehrerer Sätze nach ihren etymologischen od. syntaktischen Bestandtheilen; [...].

Btria\|kb s. m. 1. ein sauberer Mensch, Stutzer; 2. ein nicht arbeitender, zarter Mensch; 3. (auf der Wolga) der Zug, Strich der Fische; 4. (in Sibirien) außerordentli- 
che Abgabe an Pelzwerk; 5. (Schifff.) die schäumende Woge, Schaumwelle, (pl.) d. Schäfchen; 6. (Jäg.) der weiße Hase (Zool. Lepus variabilis); 7. (Bot. Cytisus hirsutus) rauher Bohnenbaum; auch (Bot. Trifolium montanum) weißer Bergklee; 8. (Gerb.) eine Vorrichtung zum Walken; 9. die weiße Kugel b. Ballotement; 10. (prov.) weißlicher, kalkhaltiger Erdboden; 11. der Leinenkittel; 12. d. Fußbekleidung a. weiBem Leder, [...].

M'umapa s. f. 1. (Nord- u. Ostruß1.) allerhand Kieinigkeiten, das Lumpenzeug, der Plunder, Quark; 2. das Geschmeiß, Ungeziefer; 3. der Unsinn, dummes Zeug, die Albernheit; 4. (Smolensk) der Schnittkohl.

O6ol|лоч Waaren); [...]; 3. (Anat., Naturg.) das Häutchen, die Membran; [...]; 4. (prov.) die Bettdecke; 5. (prov.) der Ueberrock; 6. (Nordrußl.) die Kleidung übh.; [...].

Mor'ollctb s. m. 1. die Dorfkirchengemeinde, das Kirchspiel; 2. eine Kirche nebst Wohnhäusern für den Geistlichen u. die Kirchendiener, sammt den dazu gehörigen Ländereien; die Kirche mit einem Kirchhofe; 3. (prov.) der Kirch-, Friedhof, 4. (Orenburg) einzeln stehendes (vom Dorfe weit entferntes) Einkehrhaus; 5. (Nordruß1.) lappländisches Dorf, [...].

Cковоl|poд’a s. f. 1. die Pfanne, Bratpfanne; 2. (Hüttw.) gußeiserner Behälter für den überflüssigen Rohstein beim Schmelzen; 3. (Buchdr.) der Waschstein, das -faß (zum Abwaschen der Typen); 4. erste Garbenschicht eines Getreideschobers; 5. (Jaroslaw) die Wölbung des russ. Ofens; 6. (Archang.) die flache Krippe; 7. (Zool. Solea vulgaris) gemeine Seezunge; 8. pl. die Cymbeln, Becken, Metallteller; [...].

\subsubsection{Syntagmatik}

\subsubsection{Explizite Informationen}

Bei der Überarbeitung des Wörterbuches haben die Autoren der dritten Auflage auf dem Gebiet der Syntagmatik praktisch keine Veränderungen vorgenommen. Interessant ist allerdings, daß die von Pawlowsky eingeführte Kategorisierung der Verben (vgl. 4.2.2.1, 9598) zwar übernommen wurde, aber trotzdem zahlreiche, zum Teil neu aufgenommene transitive Verben in der dritten Auflage erstmalig mit einem expliziten Rektionshinweis versehen wurden. Dadurch wird offensichtlich, daß zumindest ein Teil der Bearbeiter dem Benutzer des Wörterbuches offenbar nicht zugetraut hat, die komplizierte Kategorisierung 
korrekt zu entschlüsseln, denn diese Angaben sind überflüssig, da Verba activa immer das Objekt im Akkusativ aufweisen.

Bsp.: O6ese ${ }^{\circ}$ ollsutb v. a. kor'o jmd. seiner Freiheit (des freien Willens), seiner Selbständigkeit berauben, inn willenlos machen; [...].

$06{ }^{\circ}{ }^{\circ}$ tимть v. a. kor'o 1. (Nord- u. Ostrußl.) jmdm. das Leben verkürzen; jmd. abquälen, ausmergeln (ein Pferd); 2. jmd. zum Krüppel schlagen, machen, ins Unglück stürzen; 3. (prov.) jmd. unglücklich machen, ins Unglück stürzen; [...].

חо6t|pнn'atb v. a. kor'o über jmd. siegen, den Sieg davon tragen, jmd. besiegen, überwinden; [...].

II. По|l由' анывать, -воз ить v. а. kor'o jmd. dann u. wann herumfahren, etw. nach u. nach wohin verführen.

Слиз'ить v. a. imprs. (WestrußI.) kor'o jmdm. übel machen, Uebelkeit erregen.

\subsubsection{Implizite Informationen zur Syntagmatik}

Obwohl auch in der dritten Auflage die Mikrostruktur von Lemmata dominiert wird, denen keine Kollokationen zur Seite gestelt werden, so hat sich doch, prozentual gesehen, die Zahl der Kollokationen in der dritten Auflage erheblich erhöht. Zusätzlich zu den aus der zweiten Auflage übernommenen Kollokationen haben die Bearbeiter der dritten Auflage sowohl bereits von Pawlowsky oder Nikolič lemmatisierte Einheiten als auch von innen selbst aufgenommene Lemmata mit Kollokationen versehen. Diese quantitative Verbesserung ist dem Wert des Wörterbuches sicherlich nicht abträglich, es bleibt aber zu kritisieren, daß die Qualität der impliziten Informationen zur Syntagmatik nicht erhöht wurde. Gerade bei den Lemmata, deren Mikrostruktur reich an Kollokationen ist, fällt auf, daß die Beispiele in den meisten Fällen nur eine einzige syntagmatische Konstruktion wiedergeben. Sowohl bei den Adjektiven als auch bei den Substantiven dominieren Konstruktionen zwischen Substantiven und attributiv gebrauchten Adjektiven. Dies beweist das folgende Berspiel eindrucksvoll.

Bsp.: Бумаlira s. f. 1. das Papier; почт'овая 6. das Postpapier; чертённая 6. Zeichenp.; печатная 6. Druckp.; обёрточная 6. Umschlagp., Makulaturp.; nропускн'ая, цћд илыная, оd. 6юв'арная 6. Löschp., Filtrierp.; прозр'аиная 6. Pausp.; нажд ачная 6. Schmirgelp.; 6. 6 итая Papier maché; гербов ая 6. Stempelp.; аль6 ом-ая 6. Albump.; альбум иная 6. Albuminp.; безкон еиная 6. Rollenp.; 6утыличная 6. Bouteillenp.; в'атманская чертённая 6. Whatmanszeichenp.; восков'ая 6. Wachsp.; газ'етная 6. Zeitungsp.; карт'онная 6. (n'aака) Pappe; К'артошая 6. Kartenp.; карт узная 6. Cartonp.; карт. с'иняя 6. blaue 
Carton-Aktendeckel; кліћтчатая чертённая 6. quadriert liniertes Zeichenp.; конв ертная 6. Couvertp.; котмров алыная 6. Kоріегр.; лиёваная 6. liniiertes P.; маисовая 6. Maisp.; мундшт учная 6. Mundstückp.; нотная 6. Notenp.; нотная 'узкая прод'ольная 6. Hochfoliop.; нотн. шир'окая попер'еиная 6. Querfoliop.; nanup осная 6. Papyrosp., Cigarettenp.; nehok' овая 6. Hanfp.; noзол'оная 6. Goldp.; посеребрёная 6. Silberpapier, nepr' аментная 6. Pergamentp.; пес'оиная 6. Sandp.; п'исчая 6. Schreibp.; пис4. графлённая 6. liniiertes Schreibp.; пис4. кліŁтчатая 6. quadriert liniiertes Schreibp.; рак'етная 6. Raketenhülsenp., Doppelp.; peakт'vвная 6. Reagensp., Reaktionsp., Probierp.; Hе6р'истая 6. P. mit Wasserlinien, geripptes P.; ро'яльрая 6. Royalp.; с'ахарная 6. Zuckerp.; свинц'овая 6. Bleip. od. Staniol; стекл яная 6. Glasp.; 6. подъ caфь 'an Maroquinp., Saffianp.; coл ом тиснёная 6. gepresstes P.; т'ортная 6. Kuchenp.; хим ииеская 6. Pflanzenp.; uвtтн ая 6. buntes, farbiges P.; 4айая 6. Theep.; шёлковая 6. Seidenp.; эст`амная 6. Kupferstichp.; 2. eine Schrift, ein Schreiben, die Ausfertigung; [...].

Da der Großteil dieser freien Syntagmen für den Benutzer des Wörterbuches gleich welcher Muttersprache ad hoc bildbar ist, ist die Aufnahme dieser Einheiten insbesondere in diesem Ausmaß als unnötig zu kritisieren (vgl. Kromann/Riiber/Rosbach, 1984, 207).

Doch innerhalb der Stichprobe finden sich auch einige Beispiele, bei denen in der Mikrostruktur mehr oder weniger umfassend über die syntagmatischen Möglichkeiten des jeweiligen Lemmas informiert wird.

Bsp.: Ap'encrb s. m. 1. der Arrest, die Haft, Inhaftierung; дом' aurin a. der Haus-, Stubenarrest; содерж ать подъ а-омъ unter Arrest, in Haft halten; посад ить подъ a. s. Арестов'ать 1; в'ылустить изъ-nодъ а-a aus der Haft befreien, entlassen; вз' '9тіе подъ а. die Verhaftung; в'екселының a. die Wechselhaft; а. долынк'a die Execution gegen die Person des Schuldners; [...].

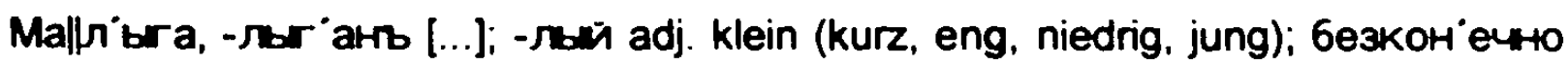
M. unendlich klein, infinitisimal; м-ое исл о kleine Zahl, geringe Anzahl; м. ходъ (Masch.) kalter Gang; Mamb M ara M' (von einer Kinderreihe gebraucht) einer kleiner wie der andere; въ M-омъ в иat im Kleinen; Cъ M-ыхъ летъ von KIndheit an; canor' $и$ M-H masib die Stiefel sind mir zu klein, zu eng; 6езъ M-aro пять apu' urb es fehtt wenig auf fünf Arschin, beinahe fünf Arschin; M. $60^{\circ}$ яpu-b eine bei Hochzeiten fungierende Person: der Gehülfe des Hochzeitsmarschalls od. der 


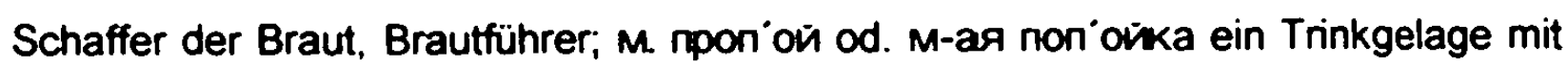
dem Brautwerber, der das Getränk selbst mitbringt; M-ое смотр Łніе оd. М-ыя смотр ины die Zusage der Braut, Verlobung, das Verlöbniß; [...].

O6ollp'otъ s. m. 1. s. O6op ausarie; 2. die Rückkehr, -kunft; 6ыть Bъ o. zurück sein; 3. die Wendung; кругов'ой o. die ganze W.; о. на пр'аво rechts um; о. Ha

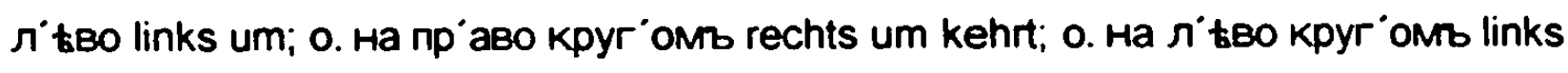
um kehrt; о. винт'a die Schraubenwindung; o. konec'a die Umdrehung; o. p’tum die Rede-, Wortwendung; д'єло пр иняло скв'ерный о. die Sache nahm eine schlimme Wendung; 4. die Tour, парах одъ д traeтъ три 0-a das Dampfschiff macht drei Touren; 5. der Umsatz (im Handel); д'енены о-t der Geldumsatz; торr'osse o-t die Handelsunternehmungen, -spekulationen; им'tть капмт'arb Bъ 0- $t$ sein Kapital im Umlauf haben; пуститься въ о-b sich in Spekulationen einlassen; 6. die Kehr-, Rückseite, die umgekehrte, linke Seite (eines Blattes), der Revers (einer Münze); на o. auf die andere Seite gewendet, umgekehrt; д всё на о. alles verkehrt (in verkehrter Weise) machen; 7. der Rauchgang, -zug (im Ofen); печs о пят'и о-ахъ ein Ofen mit fünf Rauchzügen; 8. (prov.) das zweite Pflügen des Neulandes; [...].

Mollnap' etrie s. n. [...]; -д'арокъ, pka s. m. das Geschenk, die Schenkung, das Angebinde (am Geburts-, Namenstage); п. кр'естнику das Pathengeld; п. ко дню

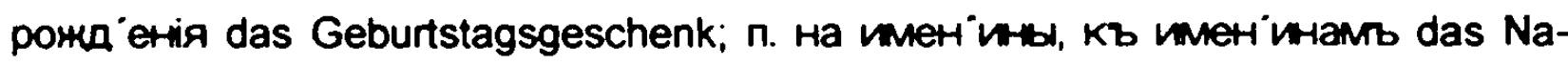
menstagsgeschenk; п. на пр'аздникъ, къ пр'азднику, пр аздниный п. das Feiertagsgeschenk, die Festgabe; ронд ественскій п., п. на ёлку das Weihnachts-, Christgeschenk, die Christbescherung; св'ane6ның n. das Hochzeit-, Brautgeschenk; получить что въ п. etw. als Geschenk (geschenkt) bekommen, erhalten: дать ком у что въ п. jmdm. ein Geschenk womit machen, etw. schenken; [...].

Besonders wichtig für den deutschsprachigen Benutzer sind die impliziten Informationen zur Syntagmatik durch die in ein Wörterbuch aufgenommenen Phraseologismen, da diese zumeist nicht direkt in die Muttersprache übertragen werden können. Diesen Bereich haben die Bearbeiter der dritten Auflage sorgfältig erweitert, was sich insbesondere daran zeigt, daß sie zahlreiche Phraseologismen neu in das Wörterbuch aufgenommen haben. Vergleicht man die Entsprechungen der sowohl in der zweiten als auch in der dritten Auflage enthaltenen Phraseologismen, so fällt auf, daß sich die Bearbeiter der dritten Auflage 
darum bemüht haben, keine direkten Übersetzungen anzugeben, sondern deutsche Entsprechungen für das jeweilige Sprichwort zu finden.

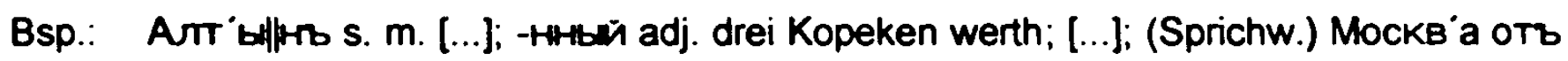
а-ой свьч и загор' єласъ kleine Ursachen, große Wirkungen; K'аждая коп' өйка а-ьмъ гвоздёмъ приб ита der kluge Mensch berechnet jeden Kopeken; [...].

Epa|t so s. f. der Zank, das Gezänk, der Streit, der Wortwechsel; die Schmährede; (Sprichw.) 6езъ 6p'ани не нитьё ohne Zank kein Leben, was sich liebt, das neckt sich; 6. на ворот'у не віиснеть и въ 6ок'у не боліить Schmähreden verweht der Wind; 2. der Kampf, die Schlacht; [...]; 3. gemusterte Leinwand; 4. (Bot. Polemonium) das Sperrkraut; [...].

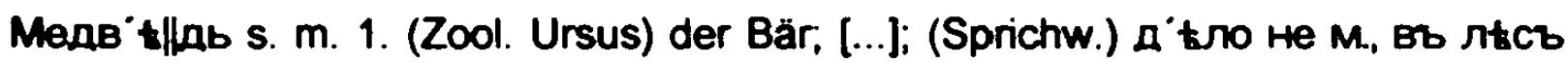
не уйдёть Arbeit ist kein Hase; два м-я въ одн ои берл ог не унив утся zwеi Hähne taugen nicht auf einem Mist; не уб' ивъ М-я, ик уры не продав ай man muß die Haut nicht verkaufen, ehe der Bär gestochen ist; м. пл яueть, а шыr' анъь д'еги берёть der eine hat die Mühe, der andere den Lohn; въ лtс' у и м. архимандр итъ im Reiche der Blinden ist der Einäugige König od. in einem Schafstall kann auch ein Kalb König sein; [...]; 2. fig. der Brummbart, Murrkopf; 3. ein Getränk aus Kaffee U. Rum; der Punsch mit Ei od. Sahne; 4. lang liegende Waare, der Ladenhüter, 5. die Chausseewalze; [...].

Плох on adj. schlecht, gering; fahrlässig, saumselig; [...]; (Sprichw.) y n-'oro м'астера таков'а и пмл'а od. кто льн'ивъ съ сох ой, том'у всё годъ n. dem faulen Arbeiter ist jedes Beil zu stumpf od. faule Bauern finden keinen guten Acker; самъ плохъ, не дасть Богъ Sankt Niklas beschert wohl die Kuh, aber nicht den Strick dazu; n. то[тъ, С. В.] воръ, что 'около се6'я огре6' aeтъ kluger Dieb hält rein sein Nest; [...].

Сл аakiм̈ adj. süß; schmackhaft, wohlschmeckend; fig. angenehm, lieblich; [...]; (Sprichw.) не вкус 'ивъ r'optкаго, не вид'ать (не узн'аешь) и с-aro hast du Lust zum Süßen, laß dich Bitteres nicht verdrießen; r'optкимъ быть - pacnлю'ють, c-имъ быть - прог лот'ять sei nicht so süß, daß man dich verschlucke, $u$. nicht so bitter, daß man dich ausspeie; [...]. 


\subsubsection{Fazit}

Dominierten nach der Überarbeitung des Wörterbuches durch Nikolič auf der mikrostrukturellen Ebene noch die quantitativen Veränderungen, so sind in der dritten Auflage zusätzlich zu den Erweiterungen auch zahlreiche qualitative Verbesserungen zu verzeichnen. Hierzu zählen beispielsweise die nun rudimentär vorhandenen Ausspracheregeln bei den einzelnen Buchstaben und das verbesserte System zur Angabe der Flexion der Verben. Bei den nun auch vorhandenen Hinweisen auf die Gebersprachen bestimmter Lemmata und bei der Aufnahme und der Markierung des nur regional gebräuchlichen Wortschatzes fiel auf, daß diese Informationen innerhalb der Stichprobe sehr heterogen verteilt sind. Faßt man die einzelnen Ergebnisse zusammen, so ist der Schluß zulässig, daß zwei oder mehr Bearbeiter für die dritte Auflage des russisch-deutschen Wörterbuches von Pawlowsky verantwortlich gewesen sind. Denn innerhalb der Buchstaben A und $\mathbf{E}$ der Stichprobe wird zum einen die ganze Bandbreite der unregelmäßigen Pluralformen angegeben, zum anderen wird dort insbesondere auf die etymologische Herkunft bestimmter Lemmata hingewiesen. Außerdem erfolgte fast ausschließlich hier eine stilistische Abwertung der in der zweiten Auflage als "populär" gebräuchlich markierten Lemmata, wobei gleichzeitig nur die diatopische Markierung .provinziell" nachgewiesen werden konnte.

Bei den Buchstaben $M, O$ und $\Pi$ dagegen fehlen neben den Flexionshinweisen bei den mit den Suffixen -анни-я/-ян-ъъ bzw. -ёнокъ gebildeten Substantiven auch Hinweise auf die Etymologie entlehnter Lemmata. Außerdem treten vor allem dort die auf einer zweiten Ebene angesiedelten diatopischen Markierungen auf, die auf ein regional begrenztes, aber flächenmäßig relativ großes Verwendungsgebiet hinweisen. Auffällig ist weiterhin, daß signifikant häufig eine Umwertung der in der zweiten Auflage mit der diastratischen Markierung „populär versehenen Lemmata vorgenommen wurde, die nun oft mit diatopischen Markierungen gekennzeichnet werden.

Betrachtet man die Entwicklung der Mikrostruktur in den drei Auflagen, so ist deutlich zu erkennen, daß das Bestreben, das angeführte Sprachmaterial unter Berücksichtigung der zeitlichen, der räumlichen und der sozialen Dimension zu beschreiben, von Auflage zu Auflage zugenommen hat. Als Konsequenz daraus ergibt sich, daß die Mikrostruktur der dritten Auflage innerhalb des Wörterbuches die umfangreichste ist. Allerdings wurde der Aufbau der Mikrostruktur durch die Nachfolger Pawlowskys nicht verändert, so daß die allgemeine Struktur der Wörterbuchartikel innerhalb der drei Auflagen gleich ist. 


\section{Die Quellen des Wörterbuches}

\subsection{Vorbemerkungen}

In diesem Kapitel soll die Frage geklärt werden, welche Quellen Pawlowsky und seine Nachfolger bei der Arbeit an dem Wörterbuch benutzt haben. Prinzipiell stehen dem Lexikographen unterschiedliche Arten von Quellen zur Verfügung. Für die frühen lexikographischen Arbeiten wurden hauptsächlich Primärquellen ausgewertet, später bezog man sich der Einfachheit halber vor allem auf Sekundärquellen. Es ist zu vermuten, daß für das russisch-deutsche Wörterbuch von Pawlowsky hauptsächlich der zweite Quellentypus zu Hilfe genommen wurde, so daß im folgenden insbesondere früher veröffentlichte Wörterbücher auf ihren Quellenwert für das Pawlowskysche Wörterbuch überprüft werden sollen. Natürlich kann nicht ausgeschlossen werden, daß insbesondere Pawiowsky, aber auch seine Nachfolger Primärquellen bei der Erstellung des Wörterbuches herangezogen haben. $\mathrm{Da}$ sich aber weder in den einzelnen Auflagen des Wörterbuches, noch in der zeitgenössischen Sekundärliteratur Hinweise auf Primärquellen finden lassen, ist es im Rahmen dieser Arbeit nicht möglich, auf eventuell benutzte Primärquellen zu verweisen.

Am schwierigsten gestaltet sich die Suche nach den Quellen für die erste und die dritte Auflage des Wörterbuches, da weder in den Vorworten der beiden Auflagen, noch in anderen Schriften auf die benutzten Quellen hingewiesen wird. Deutlich einfacher zu beantworten ist die Frage nach den Quellen, die die Autoren der zweiten Auflage benutzt haben, denn sie nennen ihre Vorbilder an mehreren Stellen.

\subsection{Quellen der ersten Auflage des russisch-deutschen Wörterbuches}

Da die erste Auflage des russisch-deutschen Wörterbuches von Pawlowsky im Jahr 1859 erschienen ist, kommen prinzipiell alle vor diesem Zeitpunkt veröffentlichten ein- und zweisprachigen Wörterbücher als potentielle Quellen in Frage. In einem ersten Schritt wurden die jeweils in Betracht kommenden einsprachigen russischen Wörterbücher überprüft, um dann in einem zweiten Schritt etwaige Spezialwörterbücher heranzuziehen, wobei durch die Wortfelder, die nicht aus den allgemeinen Wörterbüchern stammen, Rückschlüsse auf die Art der Spezialwörterbücher gezogen werden sollen.

Um die Frage nach den von Pawlowsky benutzten Quellen zu klären, wurde die schon aus den vorangehenden Kapiteln bekannte Stichprobe in den unterschiedlichsten Wörterbüchern gegengeprüft. Da die einsprachigen Wörterbücher der Akademie sehr häufig als Quellengrundlage für zweisprachige Wörterbücher verwendet wurden (vgl. Eismann, 1991, 
3075), lag es nahe, zuerst zu prüfen, ob der 1847 erschienene Cловарь Lеркованолаванскаго и русскаго языка (vgl. 1.1.4, 8) von Pawlowsky ausgewertet worden ist.

Der Vergleich der Stichprobe aus der ersten Auflage mit den entsprechenderi Passagen aus dem Akademiewörterbuch hat ergeben, daß Pawlowsky jenes Werk offensichtlich als Quelle benutzt hat. Beweisen läßt sich dies anhand unterschiedlicher Merkmale, die sich in beiden Wörterbüchem finden. Für sich betrachtet noch wenig aussagekräftig ist, daß Pawlowsky das von A. Ch. Vostokov ausgearbeitete Wortartensystem ohne Veränderung übernommen hat, dessen ungewöhnliche Verbklassifizierung bereits vorgestellt wurde ( $\mathrm{vgl}$. 4.2.2.1, 96-98). Da sich dies in den folgenden Beispielen zeigt, wird darauf verzichtet, gesondert Beispiele anzuführen.

Schon stärker wiegt die Tatsache, daß sich sämtliche Flexionshinweise aus der ersten Auflage des russisch-deutschen Wörterbuches im Akademiewörterbuch nachweisen lassen. Allerdings wurden von Pawlowsky nicht alle Flexionshinweise aus dem Akademiewörterbuch übernommen, obwohl sie für den fremdsprachigen Benutzer von wesentlich größerer Bedeutung als für den Muttersprachler sind.

Bsp.: Aнкерокъ, рка, 'анкерочекъ, wa s. m. dim. das Ankerchen, Fäßchen; [...].

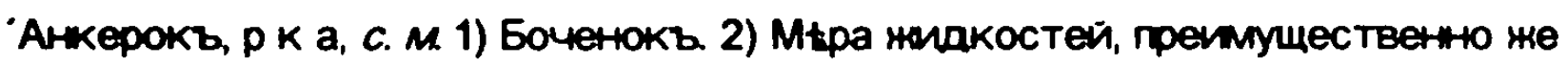
винная.

Auch bei der Realien aus Flora und Fauna beschreibenden Lexik verstecken sich zumindest Hinweise darauf, daß Pawlowsky bei der Erarbeitung seines Wörterbuches auf das Akademiewörterbuch zurückgegriffen hat, denn die lateinischen Entsprechungen sind in den meisten Fällen in beiden Wörterbüchern identisch. Allerdings ist diese Übereinstimmung weniger aussagekräftig als die noch folgenden Entsprechungen, da die lateinischen Bezeichnungen international gebräuchlich sind und waren. so daß Pawiowsky in diesem Fall auch auf andere Quellen zurückgegriffen haben könnte.

Bsp.: Ан 'ис z, s. m. (Bot. pimpinella anisum) der Anis.

Arinç, a, c. M. Pimpinella Anisum, pacterie.

Б уииволъ, S. m. (Zool. bos bubalus) der Büffel, Büffelochs.

Б'уйволь, а, С. м. Bos bubalus, нивотное изъ рода воловъ.

M А в в д ок в, дKa, s. m. (Zool.) 1. (gryllus gryllotalpa) die Erd-, Maulwurfsgrille, Ackerwerre; 2. (mus talpinus) die Maulwurfsratte; 3. junger Biber (in Kamtschatka). 
Медв tдокъ, д к а, с. м. 1) Gryllus gryllotalpa, насқкомое, прннадлежащее къ роду свериковъ. 2) Mus talpinus, звьрокъ, принадленашій къ роду кротовъ. 3) Молодой 6оберъ въ Камиаткћ.

$\Pi \pi \hbar ш$ 'анка, s. f. (Zool. motacilla leucomella) eine Art Bachstelzen.

Плtш'ана, и, с. ж. Motacilla leucomella, птима, принадлежащая къ роду трясогузокъ.

Ск`амникъ, s. m. (Bot. onoclea) die rärberochsenzunge.

СК' ам-икъ, a, c. M. Onoclea, папоротникъ.

Bei denjenigen Lemmata, die keine direkte zielsprachliche Entsprechung haben und deren Bedeutung durch eine Definition umschrieben werden muß, wird recht deutlich, daß das Akademiewörterbuch als Vorlage benutzt worden ist; denn die Erklärung im Pawlowskyschen Wörterbuch ist zumeist eine Übersetzung der Umschreibung aus dem Akademiewörterbuch.

Bsp.: Ap T ${ }^{\circ} c_{b}$, s. m. (kirchl.) das am ersten Ostertage geweihte Brot (welches am Sonnabend der Osterwoche in der Kirche ausgetheilt wird).

Артосъ, a, c. м. Квасный хлt6b, освянаемыи вь переый ден Пасхи и раздро6 ляемый въ суб6оту свћт лой седьмишы, для раздачи народу.

Брод ильщикъ, s. m. (in Kamtschatka:) Einer, der den Weg für die Zobelfänger bahnt.

Брод ильиикъ, а, с. м. Въ Камиатке: прокладикъ дорогъ для соболмнахъ ловиовъ.

Ман 'иста, s. f. (bei den Fischern auf der Wolga:) die Kinnlade vom Stör oder von der Beluga.

Ман иста, Ы, с. ж. У Волнскихъ рыбаковъ:

O 6 л 'a c a, s. f. eine Barke auf der Dwina.

O6r аса,

П० 6 औникъ, S. m. (bei den Kamtschadalen:) ein langer Riemen am Schiitten befestigt, der anstatt der Deichsel beim Fahren mit Hunden dient.

По6 ннанкъ, а, с. м. Долтій ремен, укрtпляемый посреди головяшекъ у саней, слунашій въ Нtкоторыхъ мtстахъ Сибири и въ Камиаткt, гдt tздять на собакахъ, вместо дышла. 
Скл адни, ей, s. m. pl. zwei oder mehrere Brettchen mit Heiligenbildern, zum Zusammenschlagen eingerichtet.

Cкліаднм, е й, с. м. м.. Двt или 6олtе доски съ изображеніями святыхъ, сдыланые такимъ образомь, что одна съ другой можетъ складываться.

Daß das Akademiewörterbuch die Grundlage für Pawlowskys Arbeit bildete, wird bei den Markierungen offensichtlich. Der größte Teil der Markierungen in der ersten Auflage des Pawlowskyschen Wörterbuches wurde entweder direkt aus dem Akademiewörterbuch übernommen oder aber aus den dortigen Bedeutungsumschreibungen abgeleitet.

Bsp.: A м 6 р а з ур a, s. f. 1. (Fortf.) die Embrasur, die Schießscharte; 2. (Archit.) die Embrasur, Fenstervertiefung.

Амбраз ура, Ы, с. ж. 1) Форт. Отверстіе въ насыми землянаго бруствера или въ каменныхъ и деревянныхъ стынахъ, для помыщенія дула артиллерійскато орудія. 2) Архит. Оконная владина внутри комнатъ; заломи.

Б р а $з$ дн 'a, s. f. (veralt.) geackertes Feld.

Браздніа, 'ы, с. ж. Стар. Воздыланне поле.

М a ${ }^{\prime}$ y $x$ a, s. f. pop. die jüngste Tochter.

Маліуха, и, с. ж. Простон. Меныая дочь или меныная сестра.

O 6 M ë T b, s. m. 1. die Einfassung (der Knopflöcher); 2. (Jäg.) großes Netz zum Zobelfange; 3. (Miner.) 06M. K06 anstoвbй der Kobaltbeschlag.

Обм етъ, а, с. м. 1) То, чtмъ обметано что нибудъ. 2) Охот. сьть для ловлм co6олей. 3) Мнн. O6меть кобальтовьи, зн. цвьть, или плева на кобальть.

По 6 е р 'ежник ъ, s. m. 1. prov. der längs dem Ufer wehende Wind: (auf dem weißen Meere:) der Nordwest; 2. (ehed.) der Strandwächter.

Побер ениккъ, а, с. м. 1) О6л. Вьтръ, дуюшій отъ берега. 2) У Бьломорцевъ: с вверо-западныи румбъ комласа. 3) Стар. Береговый странъ, сбориикъ поберенной пошлины.

Сковор о дишка, s. f. (verächtl.) schlechte Pfanne.

Сковор одиика, и, с.ж. ун. слова с ко в о р о д 'а.

Bei der Gegenüberstellung der Mikrostruktur der beiden Wörterbücher wird besonders deutlich, daß Pawlowsky das Akademiewörterbuch als Quelle benutzt hat, denn der Artike- 
laufbau und die Bedeutungsangaben bei polysemen Lemmata weisen große Ähnlichkeiten auf.

Bsp.: A к в а р е л в, s. f. 1. das Aquarell, die Aquarell-, Wasserfarbenmalerei; 2. das Aquarellgemälde.

Аквар' ель, и, с. ж. Худ. 1) Hивогись на бумагt водаными красками. 2) Рисунокъ сдьланыи такими же красками.

Б außerordentliche Abgabe an Pelzwerk; 3. (Schffspr.) schäumende Woge; 4. (Jäg.) der weiße Hase; 5. (Bot. cytisus hirsutus) rauher Bohnenbaum.

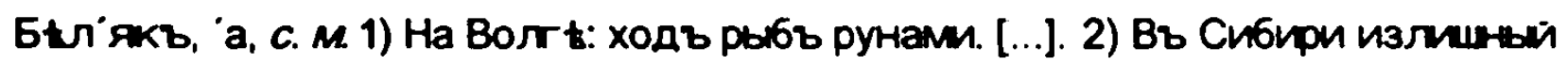
сверхъ ясака поборъ. 3) Мор. Бтлый воль. 4) Охот. Обыкновеный 6tлый заяиъ.

M метліка.

Метл'а, 'ы, с. ж. 1) Пукъ прутьевъ, прихрылле кй къ деерку и слунашіи аля сменія пыти и сору. [...]. 2) Въ просторtчіи: хвость кометы. 3) Растеніе. Meтлика Motrusa.

06 w 'и r b, s. m. 1. s. O6tar'arie; 2. die Brandstelle (am Körper); 3. ein Brand (Ziegeln, Dachpfannen etc.).

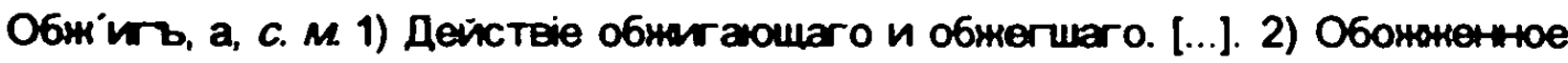
мtсто на тьлt; ожега. [...]. 3) Колмество кирпией, кровелынй черепмшы, изразиовь и тому подобнаго, обонаныхь въ одной пеии однми пріемомъ.

П о в инность, s. f. 1. das Geständnis seiner Schuld: прин есть n. Geständnis thun, ablegen; 2. die Ergebenheit, der Gehorsam; 3. die Pflichtigkeit, Dienstbarkeit; земск'ія пов иности die Landesstever; городск" ія Stadtabgaben; 6'apum n. die Gehorchsleistung, Frohne; рекр'утская n. die Rekrutenpflichtigkeit.

Пов инность, и, с. ж. 1) Признаніе своей вины или приступленіе. Поности повиность 2) Покорность, послушаніе. 3) Плата въ казну съ домовъ и земељ, и исполненіе друтихъ общественыхь и мірскихъ обязаннотей. Земккія поеи ности. Горскіе пови ности. 
CKу у 'ат b, скуп ит b, v. a. 1. auf-, zusammenkaufen; 2. (veralt.) loskaufen, befreien; ск. ког' о-либо съ прав ежа, съ прав ежу Einen loskaufen (von der Execution befreien, indem man seine Schulden bezahit); [...].

Скупіать, n 'a ю, n 'a е ш ь; с к у п и т ь, гл. a. 1) Покупать въ разныхъ мыстахъ и у разныхъ людей. [...]. 2) Стар. Выкупать, избавлять, освобождать. [...]. - Скупать съ правежа: Стар. зн. избавлять оть взысканія, заплативъ долть. [...].

Daß das Akademiewörterbuch für Pawlowsky eine wichtige Quellengrundlage gewesen ist, zeigt sich am deutlichsten im syntagmatischen Bereich, denn aus der Vorlage stammen nicht nur zahlreiche Kollokationen des Pawlowskyschen Wörterbuches, sondern auch die meisten Bibelzitate, viele Zitate aus der Belletristik und einige Sprichwörter.

Bsp.: A л $ф$ a, das Alpha; das A (der Griechen); aзъ есмь 'anфa и oм era (Joh. Offenb. I. 8.) ich bin das $A$ und das $O$, das Alpha und das Omega.

'Aлфа, ы, с. ж. Названіе первой греческой букви, означанщей въ иносказателынмъ смысль начало. Азъ есмь алфа и омега, т. е. начало и конецъ. Anok. 1.8.

A p ен д a, s. f. 1. die Arrende, Pacht; отд atb на ар енду verarrendiren, verpachten (ein Gut); взять на ар енду arrendiren, pachten, in Pacht nehmen; 2. die Arrende (ein auf gewisse Jahre Allerhöchst verliehenes Gut).

Ар енда, ы, с. ж. 1) Платежъ помћиику оть арендатора, съ землм илм деревн; откуть, кортома. Отдать, взять на аренау. 2) Uмtнiе, жалуемое Государемъ на опредьленное время кому либо во владыніе. Пожаловать, полуить аренау. Пользоваться аренцок.

Бр е д ить, v. п. abgeschmacktes Zeug reden; fasein; 6p. во cHt im Schlafe reden; 6p. Bъ rop $94 \times t$ während des Fiebers phantasieren; $6 p$. на $98^{\circ}$ y im Wachen (wachend) träumen.

Бр едить, 6 р енжу, 6 р е д ишь; с 6 р е дить, гл. ср. Произносить рьчи, не имьющія связи. Бредить во снь, въ горячке, онъ и на яву бредитъ.

Б у у ка ли, pi. m. pop. große, hervorstehende Augen; die Glotzaugen; что ты 6'уркалами-то похліопываешь? (фонъ-В'изинъ) was blinzst du so mit deinen großen Augen? 
Б'уркалм, о в в, с. ср. мн. Простон. Болышіе глаза. Что ты буркалами-то похronbzaeus? Фон Buз. Bъ Hедорослt.

M а р т 'о в с кій, ая, ое, adj. März-; м-ое пंивo das Märzbier; M-ie 'утренки die Morgenfröste im März.

Март овскій, а я, о е пр. 1) Бываншій въ Мартt. Мартовскіө утрөткки 2) Заготовляемий въ Марть. Мартовское пиво.

О 6 е з в 'ян скій, ая, $\infty$, adj. den Affen eigen, ähnlich; о6-ія ухв атки die Affenmanieren; 06. OKr 'anъ rML'a das Affengesicht.

Обезъ'янскій, а я, о е, пр. 1) Свойственый обезъянами Обезълккія ухватки. 2) Похоній на обезъянъ. Обезъянский окладъ лмиа.

O $6 \mathrm{H}^{\circ} \mathrm{O}$ щ b, adv. (sl.) in der Nacht; $06 \mathrm{H}$. вс10 тр ундашеся (Luc. V. 5.) wir haben die ganze Nacht gearbeitet.

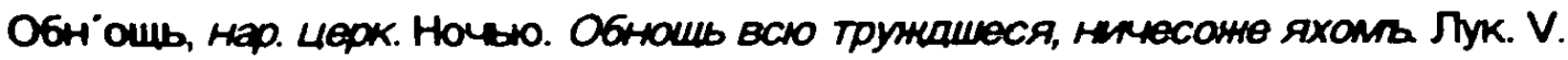
5. [...].

П о в а л в, s. m. 1. die Seuche; п. на скоть die Viehseuche; лежать пов аломъ an der Seuche liegen (von Mehreren); 2. der Sturz, Einsturz; п. сн tra die herabgestürzte Schneemasse; die Lawine; - Ha n. Alle, ohne Ausnahme; Bcю негрі ятельскую с илу положить на п. den Feind aufs Haupt (total) geschlagen; полож'ить всњхъ на п. Alle niedermachen.

Пов аль, а, с. м. 1) Паденъ, моръ. Поваль на скотъ, на лошадей - Ленать повалопи, зн. быть многив въ одно время въ повалыной 6олtзн. Въ

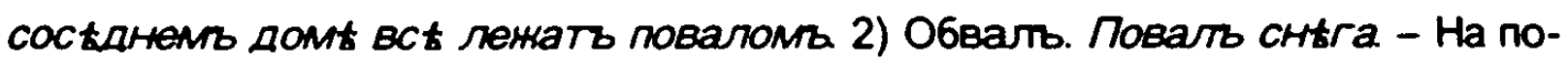
вать, нар. Зн. На голову, всьхъ до одного. Всіо непріятельскую силу на повалт полонили.

По в 'о й, s. m. 1. s. Повив' arie; 2. (sl.) das Tuch, Leichentuch; Sp rüchw. He $p^{\prime}$ 'ana 6 'a6a noв 'or, p'ana nok'or wenn nur Ruhe im Land ist.

Пов ой, а, с. м. 1) Отправленіе повивалынаго дыла; повиваніе. [...]. 2) Lерк. Пелена, обвязка, обвивка. [...]. - Посл. Не рада баба повою, рада покою, зн. желаеть не столько выгодъ, сколько покою. 
Скв 'ерна, s. f. (sl.) die Unreinigkeit, Unsauberkeit; скв'ерна пл'оти и д'уха (2. Cor. VII. 1.) die Befleckung des Fleisches und des Geistes.

Скв'ерна, ы, с. ж. Неистота, гнусность чего либо. Оистимв себе оть всякія сквер плоти и духа 2. Кор. VII. 1.

СК у чны й ая, oe, adj. 1. langweilig; lästig; СК. гость lästiger, überlästiger Gast; 2. traurig; CK-ое вр'емя traurige Zeit; что ты такъ ск'ученъ? warum bist du so traurig?

Ску унй, а я, о е, - 4 ен b, чна, о пр. 1) Производяай, примняошій скуку. Скушые гости. Скуиная книга. Скунное время. 2) Чувствующй скуку, невеселый. Что ты такъ скученъ?

Die eben angeführten qualitativen Übereinstimmungen belegen eindeutig, daß Pawlowsky das Akademiewörterbuch von 1847 als Quellengrundlage benutzt hat. Bei einem rein quantitativen Vergleich wird deutlich, daß das Akademiewörterbuch sogar die maßgebliche Quelle für das russisch-deutsche Wörterbuch von Pawlowsky gewesen ist. denn nur ca. $20 \%$ der Lemmata aus der Stichprobe lassen sich nicht im Akademiewörterbuch belegen.

Nun stellt sich die Frage, aus welchen Quellen die noch verbleibenden 20 Prozent stammen. Auf der makrostrukturellen Ebene fält auf, daß ein Großteil der nicht im Akademiewörterbuch belegten Lemmata in den Bereich Fremowörter und fachsprachliche Termini gehört. Dies läßt darauf schließen, daß Pawlowsky vermutlich einsprachige Spezialwörterbücher als weitere Hilfsmittel herangezogen hat.

Auch auf der mikrostrukturellen Ebene gibt es Hinweise, die auf die Benutzung weiterer Quellen deuten. So finden sich neben den aus dem Akademiewörterbuch übernommenen Kollokationen in der ersten Auflage des russisch-deutschen Wörterbuches auch einige, die aus anderen Quellen stammen müssen, da sich zwar das Lemma, nicht aber die Kollokation im Akademiewörterbuch nachweisen läßt. Als Quelle für diese Kollokationen kommen entweder zweisprachige Wörterbücher oder Primärquellen in Betracht.

Da die meisten Sprichwörter nicht aus dem Akademiewörterbuch stammen, ist zu vermuten, daß Pawlowsky weitere Wörterbücher oder Primärquellen für diesen Teilbereich der Syntagmatik benutzt hat. Darauf deutet auch die Darstellung der Verben in der ersten Auflage hin, die häufig von der im Akademiewörterbuch abweicht.

Um weitere Quellen herauszufinden, wurde der Wortschatz, der sich in der ersten Auflage des Pawlowskyschen Wörterbuches, nicht aber im Akademiewörterbuch belegen läßt. in unterschiedlichen Wörterbüchern gegengeprüft. 
Der Vergleich einiger in Frage kommender Wörterbücher mit der ersten Auflage des Pawlowskyschen Wörterbuches erbrachte keine signifikanten Übereinstimmungen, so daß die Frage nach weiteren Quellen unbeantwortet bleiben muß. Allerdings können folgende zweisprachige Wörterbücher definitiv als Quellengrundlage ausgeschlossen werden: Das von Jacob Rodde verfaßte russisch-deutsche Wörterbuch (vgl. Rodde, 1784a), das 1800 erschienene Vollstándige russisch-deutsche Wörterbuch von Johann Heym (vgl. Heym, 1800) sowie das 1842 von J. A. E. Schmidt veröffentlichte russisch-deutsche Taschenworrterbuch (vgl. Schmidt, 1842).

Ebenfalls ohne positives Ergebnis endete die Überprüfung zweier Spezialwörterbücher. Die Gegenprüfung der botanischen Lexik der Stichprobe im botanischen Wörterbuch von Annenkov (vgl. Annenkov, 1859), dessen Vorläufer bereits 1858 veröffentlicht wurde, erbrachte einige Übereinstimmungen. Da aber die übereinstimmenden Lemmata auch im Akademiewörterbuch von $1847 \mathrm{zu}$ finden sind und der größte Teil der nur im botanischen Wörterbuch berücksichtigten Lemmata in der ersten Auflage des russisch-deutschen Wörterbuchs fehlt, kann das Wörterbuch als Quelle ausgeschlossen werden. Dies gitt auch für das Fremdwortwörterbuch von Janovskij (vgl. Janovskij, 1803). Einige wenige der nicht aus dem Akademiewörterbuch stammenden Lemmata sind zwar im Janovskijschen Wörterbuch lemmatisiert, allerdings ist ihre Zahl zum einen sehr gering, zum anderen sind die Übereinstimmungen in der Mikrostruktur bei diesen Lemmata nicht hinreichend signifikant.

Abschließend bleibt nur zu vermuten, daß Pawtowsky entweder zweisprachige Wörterbücher für seine Arbeit ausgewertet hat, die heute in Vergessenheit geraten sind, oder daß er auf von ihm selbst zusammengetragene Primärquellen zurückgegriffen hat, deren Vorhandensein nach so langer Zeit und in der sctwierigen Quellensituation nicht mehr nachzuweisen ist.

\subsection{Quellen der zweiten Auflage des russisch-deutschen Wörterbuches}

Die Frage nach den Quellen der zweiten Auflage des russisch-deutschen Wörterbuches von Pawlowsky ist deutlich einfacher zu beantworten als bei der ersten Auflage, da mehrere explizite Hinweise auf die von Nikolič benutzten Quellen im Wörterbuch enthalten sind. Zum einen enthält das Vorwort der zweiten Auflage eine Fußnote, die besagt, daß das russische Wörterbuch von Dal' (vgl. Dal', 1863-1866) als Muster gewählt wurde (vgl. Pawiowsky, 1879, M), zum anderen finden sich in der Stichprobe unter dem Buchstaben 5 einige Beispiele, bei denen direkt auf die Quellen Akademiewörterbuch (A. W.) (vgl. Slovar', 1847) und Dal'sches Wörterbuch (D.) verwiesen wird.

Bsp.: Боров'euъ, вu'a s. m. [...]; -в'nkъ (Bot. Boletus A. W.: edulis, D. bovinus) der Borowik, eßbare Fichtenpilz; [...]. 
Bops s. m. 1. der Fichten- u. Tannenwald, der Nadelw., Hochw., Föhrenw., (eigentl.:) der Forst; 2. (ehed.) die Auflage, Abgabe, Steuer; [...]; 3. (Chem.) das Boron, der Boraxstoff, 4. (Bot. A. W. Panicum miliaceum) die Flatterhirse; (D. U. A. W. Milium effusum) das Hirsengras, die Waldhirse; [...].

Ep'ara s. f. 1. (in Branntweinbrennereien:) der Meisch, die Meische, (Osts.) die Brage; 2. das Hirsenbier (nach A. W.); (nach D. richtiger: das vom Brauer aus jedem Malz und Mehl meist mit Hopfen gebraute) Bier, (Bauer-, Krug-, Stoos-, Dünn- Halbbier).

Брит окъ, тк'а; 6ритъ s. m. A. W.: der obere Theil (die Aehren), D.: der untere Theil (die Schnittfläche) einer Korngabe.

Der Vergleich der Stichprobe aus der zweiten Auflage mit den entsprechenden Abschnitten des Dal'schen Wörterbuches hat ergeben, daß Dal' als maßgebliche Quelle bei der Überarbeitung der ersten Auflage des Wörterbuches gedient hat. Daß Nikoliz mit Hilfe des Dal'schen Wörterbuches sowohl die Mikrostruktur als auch die Makrostruktur der zweiten Auflage erheblich erweitert hat, wird anhand der folgenden Beispiele gezeigt.

Bei der Analyse der Makrostruktur wurde festgestellt (vgl. 3.2.3.3, 77), daß Nikolič den Lemmabestand in der zweiten Auflage im Vergleich mit demjenigen der ersten Auflage nahezu verdoppelt hat. Der größte Teil der erst in die zweite Auflage aufgenommenen Lemmata stammt aus dem Dal'schen Wörterbuch.

Bsp.: A6 a3b, a6 acz s. m. der Abas (eine persische Silbermünze; in Grusien Bezeichnung für 20 Kopeken Silb.); $-3^{\prime}$ a s. f. der (für die Donaufischer) gefährliche Ostwind; 2. ein dummer Muselmann; 3. (im Kaukasus) das eingebrannte Pferdezeichen; [...].

А6 азъ, а6 асъ м квк. персидская серебрн. монета, около 20 коп.|l Восковой шарикъ, отъ церковной свъчи, привьшиваемый закавкаскими христіанами,

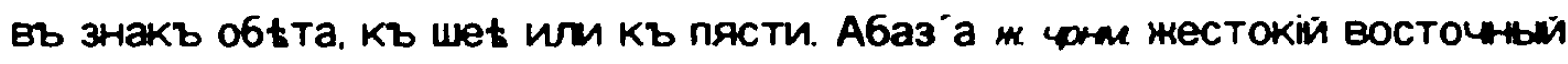
вьтеръ, отъ кавкаскаго берега, опасный для дунайскихъ рыбаковъ.|l Бран. бестолковый бусурманин. Эхъ вы, абаза нtмая! || Конское тавро, извьстное на Кавказћ, вьроятно оть названя горскаго племени.

6'basa s. f. der Schweif; der weibliche Haarschopf; $-3^{\circ} \mathbf{b}$ pl. 1. die zudringliche Schmeichelei; 2. Name des 13. Juni.

Btus08'anbe s. $n$. das Toll-, Wildwerden (des Viehes von Bremsen während der Mitte des Sommers); $-30 B^{\circ}{ }^{\prime}$ Tb v. a. schmerzhaft, empfindlich schlagen; v. n. rasen, wild werden von Hitze und Insekten (vom Vieh); $-308^{\circ}$ on wild, toll geworden; 
$-3^{\prime}$ yнß s. m. 1. ein unverschämter Buhler; 2. der Hieb mit der Peitsche, mit der Karbatsche.

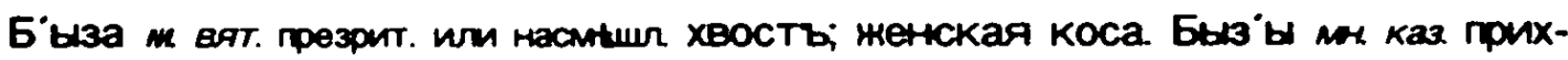
востниманые, лесть, подаакиваные. [...]川 День 13. Іюня; [...]. Быз унъ ми вата бестьній волокита. || Бызуны, ударь плетыю, хлыстомы. [...]. Бызов ать, бу-

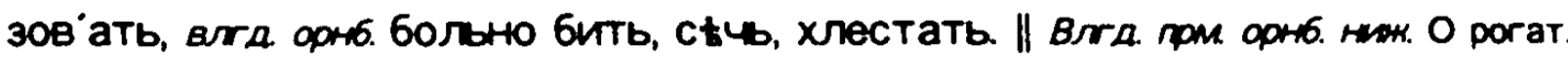
скоть: 6узыкать, 6зырить, 6tситься вь лtтніе жары, сь половины Іюня по третью недыло Іюля, оть моики, оводовъ и червей, [...]. Бызов аные скота, тоже, 6зик, какъ дtйстеіе, и какъ пора. Бызов ой скоть, 6ызуоній.

Minnerbll s. m. (Seew.) die Mittelrippe (auf den Schiffen); - $\Delta^{\circ}$ eKr S. m. das Mittel-, Zwischendeck, zweites Deck; „unarr ayro s. m. das Mittelspann, die -spante.

Мидель (средиа) морс. 6'олышая иирина кора6ля, и миделышанг'ауть, среднее им самое широкое ребро, отруга. Миделын екъ средняя палуба (6атарея) трехдечнаго кора6ля.

O6езс удить 11., voll. zu -сліушизать v. а. 1. ohne Rechtsverfahren, ohne gerichtliches Verfahren verurtheilen; 2. Einem etwas Uebles nachreden; 3. verurtheilen, tadeln, kritisiren, verdammen, afterreden; не обезс уаьте на утои еніи ісы bitte damit fürtieb nehmen zu wollen (eine Höflichkeitsformel nach stattgehabter Bewithung).

Обезс 'унивать, обезс удить кого, не давать суда, обеинит $6 е 3$ суда; || о6винять, осуждать, порицать, охаять, охуждать, особн заг лазно, беславить. Не обезсудьте на утощеніи, на словт, не осудите, извинте. [...].

Пов олить (voll.) v. n. pop. wollen, wünschen, geruhen, belieben; п. ком'у что Einem etw. erlauben; n. Koм'y въ чёмв Einen verwöhnen, ihm seinen Willen lassen; $[\ldots]$.

Пов олить сtв захотьть, похотьть, пожелать; потребовать, приказать. [...]. ॥ Кому. что, соизволить, позволить, дозволить, разрьшить, дать въ чемь воло; [...]. || Поволить кому, вь чемь, помиреолить, потакать, послаблять, поблажать, дать потачку. [...].

Cланы s. f. 1. das Aus-, Untergebreitete; die Unterlage; подн он-ая с. der Fußteppich; 2. gestreckter Lauf, der Schnelllauf, die Carrière (des Pferdes); 3. niedri- 
ges, krüppeliges Holz, das Knieholz; 4. zarte Vegetation; verkrüppeltes Wachsthum; 5. валіить сл аныю ohne Unterschied, durcheinander legen, werfen.

Стлать, менtе праилын слать и стеліить что, по(на)стилать, Класть что плоское, пластомь, всьмъ полотнищемъ илм плашмя. [...]. Стлань, слань ж. все что пост лано, настлан, что стелется, всякая настилка и постика; [...]; подножная сланы, коверъ, половикъ; [...]. || Самая быктрая побьнка лошади, скаиь, во весь духъ, опоръ [...]. || Бндная древесная растителынсть, сланецъ, ёрникъ. \| Валить сланьк, сподрядъ, 6езъ разбору, все, лоскомь, Hanoeamo [...].

Die Verdoppelung des Lemmabestandes der ersten Auflage ist neben den gänzlich neu aufgenommenen Lemmata hauptsächlich dem Umstand zu verdanken, daß Nikolič mit Hilfe des Dal'schen Wörterbuches die Zahl der zu einem Wortfeld gehörenden Lemmata deutlich erhöht hat. Nachvollziehbar wird dies an folgenden Beispielen, wobei zuerst aus der ersten und dann aus der zweiten Auflage des Pawlowskyschen Wörterbuches zitiert und dann an dritter Stelle die Quellengrundlage angeführt wird.

Bsp.: Арж анецъ, ниа, арж енецъ, ниа, s. Ржанеци

Аржан ецъ, -жанецъ, -жен ецъ, -жен икъ s. m. (Bot. Alopecurus) der Wasserfuchsschwanz; -жан inua s. f. (Phleum pratense) das gemeine Lieschgras, Thimoteusgras; der Roggen, das mit Roggen bestandene Feld; -жан иue s. $n$. das Roggenfeld; -жанka der Brachvogel, die Feldschnepfe; -жar on adj. Roggen-; -женіикв s. m. der Wegerich; -женик овый, -жен иновын adj. Süßkraut-; -жен ина s. f. das Roggenstroh; -жен истьй adj. Wegerich-; -жен уха s. f. das Roggenbrot; -жinue s. n. die Roggenstoppel, das Roggenstoppelfeld.

Аржан ецъ, аржен ецъ, арнен икъ, м орнан ецъ, рнаникъ, растеніе изъ семейства злаковъ, похожее на рожь, Alopecorus geniculatus: Phleum, разныхъ видовъ, весьма схонихъ; полевикъ, палоинкъ вла, сьянецъ, тимофей, сивуха, сивунъ; это хорошее сьно, еслм трава молода, называемое арженик овымь, аржен иновымь. Однородные съ этими злаки назызакоть: глашникъ, батлачикъ?, сталыная-трава, рьзунъ; а пырей (Triticum repens), нер алко смұшизають со рнанцомъ. || Арнен икъ? ват. подороноикъ, попутникъ, узиъ, Plantago. Аржен истое сtно, ptзучее, съ примысью аржанца. Аржан ица ж. ржан ица, тоне, рнанецъ; |l ржаное поле, ронъ на корно пен твр. || Поле съ котораго ронъ снята, рнмще. ржаное жниво тмб. || Ржамая солома

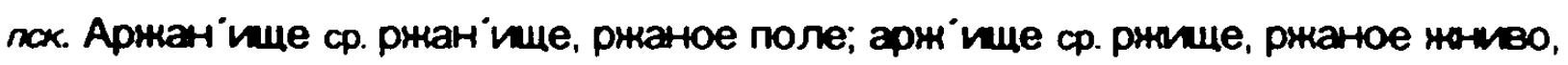


поле съ котораго рожь снята. Аржан ой, оржаной, ржан ой. [...]. Аржен уха w. рнаной xлt6z [...]. Арнен ина ж. рнанина, ржаная солома. Арнканка н. рнағка, полевой коротконогій куликъ, сивка, сивикъ, Charadrius.

Бо 'я ринъ, s. m. (pl. 60'яpa u. 60\%яе, в) der Bojar, Große, Vomehme.

Б о я и и ьс я, v. c. den Großen, Vomehmen spielen.

Бо я рич ъ, s. m. der Sohn eines Bojaren.

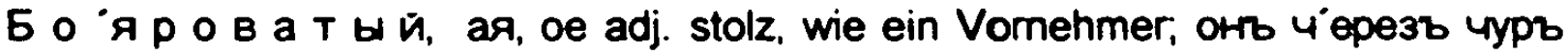
$60^{\circ}$ яpoвatb er brüstet sich zu sehr, er macht sich zu vornehm.

Бо ярская снить, (Bot.) s. Воліодушка.

Бо я яская спесь, (Bot.) s. Горицв tтb.

Бо 'я р ск і й, ая, ое, adj. vomehm; s. auch Б'арскій; 6-іе д'ьти, 6-іе сыны (ehed.) die Kriegsleute (Besitzer von kleinen Gütem, die als Kriegsleute dienten, nöthigenfalls aber auch Civildienste verrichteten).

Б $0^{\circ}$ я р с т в 0, s. n. (ehed.) die Bojarenwürde.

Бо я р ст вовать, v. n. groß, vornehm leben.

Бо ярщина, s. Б’ аринна.

Бо Я рыня, S. Б'арына.

Б о ярышники, s. m. (Bot. crataegus oxyacantha) der Mehibeerstrauch, Mehl-, Hage-, Weißdorn; 6. 6' блый Сиб' ирскій (cr. s. pyrus aria) der Mehlbeerstrauch; 6. кленоліитный (cr. s. pyrus torminalis) der Elsbaum, Elsbeerbaum, Darmbeerbaum.

Бо Я рышня, s. Б' арышня.

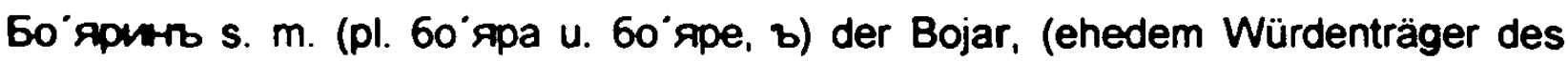
Reichs, vomehme Standespersonen), Große, Vomehme; 6rivain̆ 6. (ehed. der dem Zaren zunächststehende, sein Vertrauen genießende Bojar, etwa:) Kammerbojar; св ойственые $60^{\circ}$ яpe die zu Bojaren emobene Verwandten der Zarin; -pnновъ adj. dem Bojar gehörend; -pинyuka s. f. das Bojarensöhnchen; -pиться v. c. den großen, vomehmen Herm spielen; -phrb s. m. der Bojarensohn; -pka s. f. 1. die ätteste der vier Brautjungfern bei einer Hochzeit; 2. eine verarmte Edelfrau; -pнияать v. n. den großen Herm spielen; -роватьй adj. stolz, hochmüthig: -pokъ, pKa s. m. der verarmte Edelmann; Habenichts; -pcku adv. vornehm, herrschaftlich; -рскій adj. 1. vornehm; 6-іе д ьти, 6-іe сьн'ы (ehad.) die Kriegsleute (Besitzer von kleinen Gütern, die Kriegsdienste, nöthigenfalls aber auch Civildienste verrichteten); etwa das altdeutsche: Degen; 2. (Bot.) 6-ая снить (Bopleurum) 
das Hasenohr; 6-aя cntcb (Lychnis chalcedonica) die Feuemelke, brennende Liebe; -рство s. n. (ehed.) die Bojarenwürde; -рствовать v. n. groß, vornehm leben;

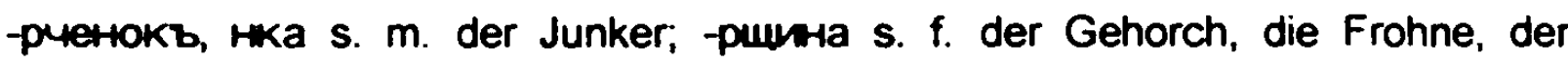
Frohndienst: -pd s. m. pl. beim Bräutigam mit männlichen Gästen zugebrachter Vorabend einer Hochzeit; -ptrb adj. der Bojarin gehörig; -рыня, davon dim. -ptoka s. f. die Frau, Edelfrau; -pturnkъ s. m. (Bot. Crataegus oxyacanthai) der Mehlbeerstrauch, Mehl-, Hage-, Weißdorn; 6. $6^{\circ}$ tлый си6 ' ирскій (Cr. S. pyrus aria) der Mehlbeerbaum; 6. krenоліистнын (Cr. s. pyrus torminalis) der Elsbaum, Elsbeerbaum, Darmbeerbaum; -pturmua s. f. ein Schmetterling; die Wasserjungfer; Libelle; -ptuня s. f. das Fräulein, Edelfräulein.

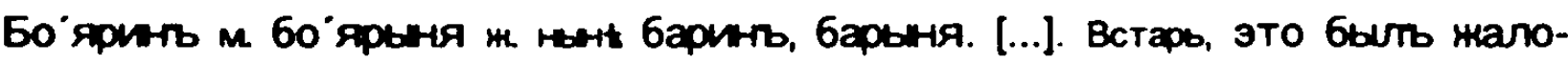
ваны санъ; велыможа, знатнћйшее сословіе въ государствы; блиный бояринд, комнатный, что нынt камер, приблиненыи Къ царю. [...]. Бояре свойстве состояние въ родствћ съ царицей, въ свойств' ' съ царемъ. [...]; 60' ярка ж. пск. стариая изъ четьрехъ друнекъ невћсты. Бо'яры мн. пск. вечерь у нениха, во время дывишника, прощалынй вечеръ, канунъ свадьбы; и гости эти, одна холостень, мушины, зовутся боярами Бо яринуико и 60"ярынка, ласкателыне, лобовное умалені. Бо яриенокъ $M$.

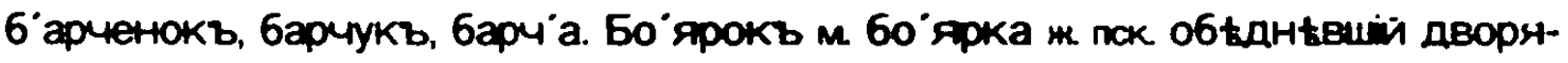

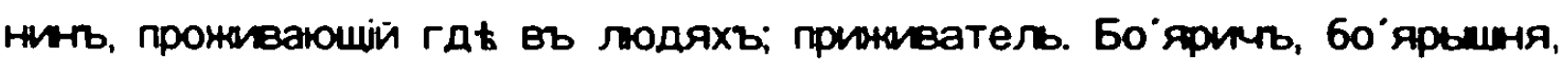

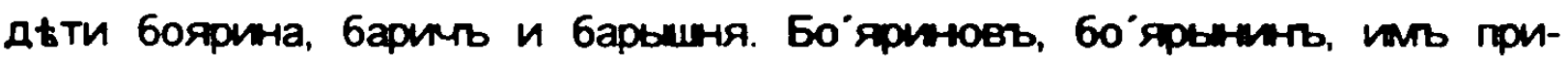
надлнащ: 60"ярскій, барскій, относяшийя до боярина. [...]. Боярскія дьти, стар. сословіе мелкихъ дворянъ, обязаныхъ военою слунбою. Боярскаяспесь, барская спесь, раст. татарское мыло, огнеи цвћтокъ Lychnis chalcedonica. Барская-снить, растеніе Bupleurum. Бо яроватьй, пріемами своими подобныи боярину, ваннынй, велмиавый. Бо'ярство ср. барство, 6оярское состояніе, бытъ, званіе, достоинтво; || собраніе людей этого званія. [...]. Бо'ярствовать, управлать, нить бояриномь. Бо'ярнинать, 6о'ярить, 60\%ямться, приммать на себя видъ барина, нелать казаться имь. [...]. Бо яриина, 60 'яршина ж. баршина, Т'яга, паншина, половниковая ра6ота на помьшика, владылына. Бо ярышикъ, кустовое ятодное деревио Crataegus; C. Oxyacantha et monogyna, 6оярка, глодъ, барыня, глудина, глогъ, талон'о; С. melanocarpa, черииллодъ; С. Pyracantha, машковое-дерево, мушмула; C. 


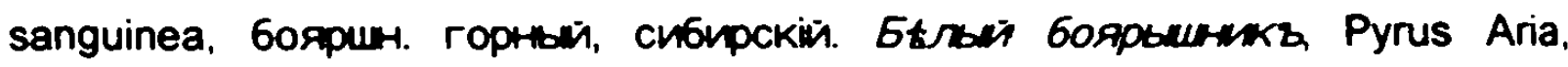
муное дерево. [...]. Бо ярыиниа стар. мотылекъ, бабока; цВытистая стрекоза, зеленыи коромысель.

M е ло чн 'о मे ('bй), 'ая, 'оe, adj. geningfügig, unbedeutend; м. челов' kleinlicher Mensch; der Kleinigkeitskrämer; $M$ - bе счёты kleine Rechnungen; $M$-'ая л'авка die Kram-, Hökerbude; fern. S. Прод'ана (мелон'ая), Тов'арь, Торгъ, Торгов ецъ (мелоині'

$M$ 'e ло чь, s. f. unbedeutende Sachen, Kleinigkeiten.

м'елочь s. f. coll. unbedeutende Sachen, Kleinigkeiten; рудн иная м. das Klei-

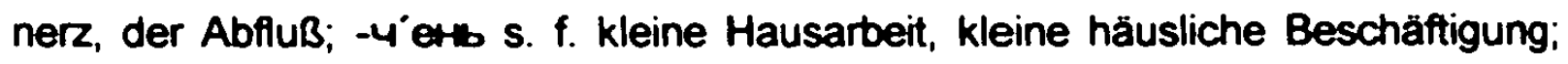
-4 inxa s. f. die Kleinhändlerin, Hökerin, das Marktweib; -uikrb s. m. 1. der Kleinhändler, Hökerer, 2. kleinlicher Mensch, Kleinigkeitskrämer, -4ivua s. f. 1. s. Mesоч ixха; 2. kleinliches Frauenzimmer, - wi matb v. n. 1. Kleinhandel treiben, hökern; 2. fig. kleinlich sein, Kleinigkeiten Einem vorenthalten; -4німество s. $n$. der Kleinhandel; 2. fig. die Kleinigkeitskrämerei; - $4{ }^{\circ}$ on adj. geringfügig, unbedeutend; м. челов 'tкъ kleinlicher Mensch; der Kleinigkeitskrämer, м- ве счёты kleine Rechnungen; M-'ая r'aeka die Kram-, Hökerbude; M-'ая прод'ажа, Topr'oвля der Kleinhandel, Detailverkauf; M. Topr'oвeuß der Kleinhändler, Kleinkrämer; - - ность s. f. die Kleinlichkeit; -4'yxa s. Мелочиха.

Мелкіи [...]. М'елоиь ж. все что не крупно ити сравителын не велико; вешишы, всякая всяима, небольиі, неваныные предметы; $\|$ [...]. Мелоч ень ж. каз. мелоч; мелкія работы по хозайству. Мелонной, къ мелоч относяашіся. Мелоная продажа, дробная илм розниная; - ліака, торгующая по мелочамъ, по малымв частямв. Мелочнй человыкъ, пустяный, заниманоиіися мелоиным дылами. М'елоиность ж. свойство мелоинаго человька. Мелонникъ м. Hinца ж. мелочой торговецъ; -человыкъ. Мөлочиха, -ч'уха, базарная торговка. [...]. Мелочничать, торговать мелочами, занмматься мелоинми, пустыми дыламм, придираться къ мелочамъ. Мелочнімество, торговла мелочь; || щепетилынсть, нитоныыя придирки, занятія. [...].

O 6 их о д b, s. m. der Bedarf; для cBoer'o o6ux'ona zu eigenem Bedarf (z. B. etwas anschaffen); для дом' ашняго о6их ода zum Hausbedarf. 
O6ux'ons s. m. 1. das Hauswesen, die Wirthschaft, Einnichtung; 2. die Ausbeute, Verarbeitung; 3. der Bedarf; a was anschaffen); для дом'ашнято обих ода zum Hausbedarf, zum Hausgebrauch; -дить 11. (voll.) s. О6их анивать; -дка s. f. s. О6их одъ; -дливость s.

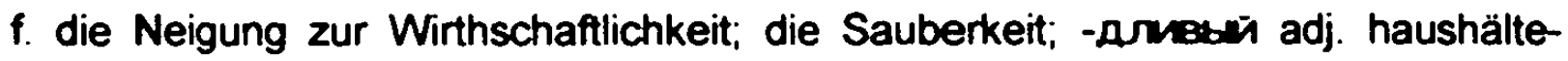
risch; Ordnung, Sauberkeit liebend; -дникъ s. m. guter Wirth, guter Meister; -дница s. f. häusliche, wirthschaftliche Frau; gute Hausfrau; -дность s. f. 1. O6их одлвость; 2. die Altäglichkeit, Gewohnheit, Sitte und Brauch; -дный adj. 1. zum Hauswesen, zum Hausbedarf, zum täglichen Gebrauch erforderlich, dienend; Bedarfs-; 2. gewöhnlich, altäglich, gebräuchlich; 3. wirthschaftlich, ordentlich; -дчизость s. f. das Efforderniß eines wirthschaftlichen Sinnes; -дивзии adj. einen wirthschaftlichen Sinn erfordernd, verlangend; wirthschaftlich, gem Ordnung haftend; -дчикъ s. m. der Hausfreund, Stammgast, täglicher Gast, täglicher Besucher, -дunua s. f. die H-din.

O6их анизать, обих одить что [...]. O6их аниванье ал. о6их оненье окн. о6их одъ м. о6их одка ж. о6. днйств. по гл. \| Обих одъ, хозяйство, домашнее или ремесленое, промысловое, вь зм. дtла и предмета его, всьхъ принадленностей. [...]. || O6иходъ, текушая потребность, потре6ленье, расходъ. [...]. O6иходның, къ обиходу относящс. [...]. \| Нетразднимнй, буднияй, ежеденнй, ежедневнии, объ оденды. || Хозяйственый, порядливый, опрятныи, чистоплотный. Обиходная, обиходливая хозяика, порядливая, опрятная. [..]. Обих одивыи, обиходливыи; \| требователынй. взыскателынй по обиходу, по иктоть и опрятности. Обих одность ж. своЙство обиходнаго, опрятность; обих одЛивость наклонНость, охота Къ обиходности; обиходчивость, требователыность по сему. [...]. Обих одникъ, заботлмвын хозямн; \| мастеръ, старателыный и опытныи уходчикъ, [..]. Обиходикв $M$ кандодневнй гость, всегдаиніи посьтитель, товарищъ, сотрудникъ, всегда бываюиіи въ домь, но не нивущй въ немъ. [...]. Обих одница ж. добрая, опрятная хозяика, путная хлопотунья, вытомойница, скотидомка. [...].

По 6 о чны й, ая, ое, adj. 1. nicht zur Hauptsache gehörig; Neben-; n-oe обсто ятельство der Nebenumstand; 2. (Geneal.) n-ая л'инія die Neben-, Seiten- 
. Collaterallinie; п-ая ліинія родств а; родств'о п-ой ліи-іи der Collateralerbe; 3. nicht in der Ehe erzeugt; unehelich.

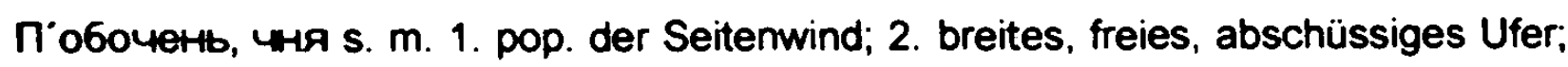

3. einer der beiden Quersäcke des Saumthieres; 4. die Fußfessel; -6 '0 s. m. pop. der Nachbar; $-6^{\circ}$ ouma s. f. 1. die Seite; 2. das Geländer; 3. pop. die Leiterstange (der Wagenleitern, des Schlittenkastens); 4. die Landzunge (in einem Flusse), lange Sandbank; 5. der Rain, Feldrain; 6. der Seitenstoß; -6'04kи pl. s. m. die Flachsbündel; $-6^{\circ}$ о nicht zur Hauptsache gehörig; Neben-; n-aя ліуна der Nebenmond; n-oe c'ол-це die Nebensonne; n-oе обсто'ятельство der Nebenumstand; 2. (Geneal.) n-ая л'инія die Neben-, Seiten-, Collaterallinie; n-ая ліинія родств'а; родств'о п-ой rinin der Collateralerbe; 3. nicht in der Ehe erzeugt; unehelich.

По6 о й, все что въ 6оку, въ сторонt, не на прямомв пути, не прямо передъ чtмr; 6оковой. [...]. \| Стороній, постороній, не прямо идуиій къ дtлу; эпизодъ. [...]. По6 оина, вобще бокъ, боковая сторона; вдолыая. ॥

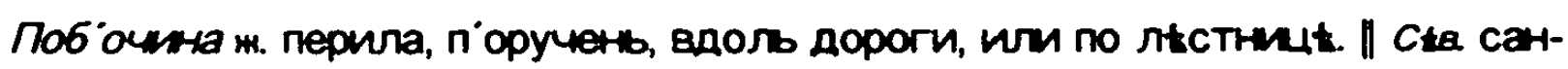
ная грядка, продолынй верхній брусъ; теленяая обшиека, доски, лубья. ॥ волнс вдолыная по рtкь коса, отмељ, долтая мель, вдоль русла, 'обокъ съ

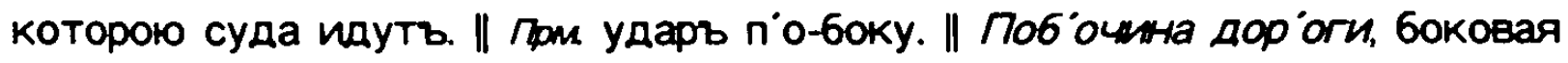
полоса, ил ровъ съ валомъ; незапаханая вдоль дороги полоса [...]. По6'очень пск. твр. сосьдъ. П'обочень м касп. боковой вьтеръ для судна,

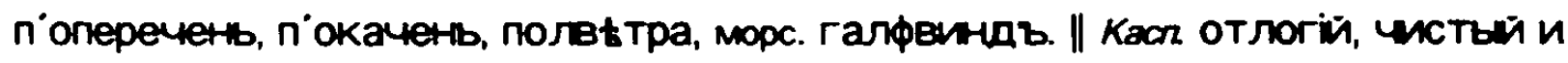
uмрокій берегъ моря? \| Сиб. конскій выокъ, одинъ изъ двухъ мАшковъ, сумь, чемодановъ илм яинковъ, по о6t ст'ороны сыдла; п'обонм, переметная сума, или || сиб. однобокія конскія пута, на переднюю и заднюю ногу.

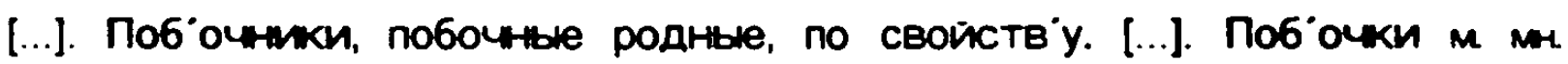
Лоняные сн опики, 6абки.

Neben der Ausdehnung der Makrostrukur durch neu aufgenommene Lemmata hat Nikoliz aber auch die Mikrostruktur der von Pawlowsky übernommenen Lemmata mit Hilfe des Dal'schen Wörterbuches erheblich enweitert. Dies ist vor allem dadurch geschehen, daß Nikoliz in der ersten Auflage lemmatisierte Einheiten um weitere, aus dem Dal'schen Wörterbuch stammende Bedeutungen und einige Bedeutungen um auf Dal'zurückgehende Kollokationen ergänzt hat. Zuerst wird das jeweilige Beispiel aus der ersten Aufiage zitiert. 
dann folgen die entsprechenden Einträge aus der zweiten Auflage des Pawlowskyschen Wörterbuches und aus dem Dal'schen Wörterbuch.

Bsp.: А д 'амова голов а (Bot.), s. Mamapar'opъ.

An'aмъ s. m. Adam; -мова голов’a 1. der Todtenkopf; 2. populäre Bezeichnung verschiedener Pflanzen; 3. der Alraun oder die Zauberwurzel; 4. ein Abendschmetterling; [...].

An амь, [...]. Адамова-голова, мертвая голова т. е. человьческій черетъ; II тропинеское растеніе мандрагоръ, Mandragora offic. или Atropa Mandragora, изъ сем. пасленовыхъ. \| вят. растн. Cypripedium Calceolus, кукуикиысап онки. || Самый большой сумереинив, 6абочка мертвая-голова, Sphinx Caput mortuum, на спинt коеи видится изображеніе человынескаго черепа. $[\ldots]$.

Б у 3 a, s. f. die Busa (ein Getränk aus Buchweizen- und Hafermehl).

Буз'a s. f. 1. die Busa (ein Getränk aus Buchweizen- und Hafermehl); 2. das Stein-, Bergsalz; 3. der Apfetwein.

Буз а ж. каменая илм горная сољ, [...]. Буз а ж. сусло, молодое пиво илм 6рага, неуходившаяся, солодковатая. \|| Особый напитокъ, густой и мутный, родъ пшетнаго квасу; [...]. \|| Я6ло й или грушевый Квасъ, сидръ. [...].

M 'a T K a, s. f. 1. pop. die Mutter; 2. (bei Thieren:) das Weibchen; пиеліиная м. die Mutterbiene; 3. (Anat. uterus) die Mutter, Gebärmutter, 4. (in Archangel, bei den Seefahrem:) der Compaß; - fern. рудн'ая м. die Erz-, Metallmutter; винтов'ая м. die Schraubenmutter; сказ'ать пр'авду м'атку, s. Пр'авда (am Schluß); S p r ü c h w. л'асковое тел'я двь м'атки сосётъ, s. unt. Л'асковый.

M'atka s. f. 1. pop. die Mutter; fig. сказ'ать пр аaдy M'atky die reine Wahrheit heraussagen, reinen Wein einschenken; 2. (bei Thieren:) das Weibchen; пчеліиная м. die Mutterbiene, Bienenkönigin, der Weißel; 3. (Anat. Uterus) die Mutter, Gebärmutter; 4. (in Archangel, bei den Seefahrern:) der Compaß; 5. (Bergw.) рудн'ая м. die Erz-, Metallmutter, 6. (Schloss.) м. для нарызки der Bankenbohrer, Originalbohrer; (Mech.) винтов'ая M. die Schraubenmutter; M. подъёмаго винт'а die Nichtschraubenmutter, м. вст'авленная въ под ушку die Sohlenmutter; 7. der Fruchtboden (in Blüthen); 8. die natürlichen Pocken. Blattern; 9. pop. die Essigmutter; 10. (bei gewissen Kinderspielen:) der Anführer, die Spitze; 11. unterster Boden od. Kasten eines Brunnens; 12. der Ursprung, die 
Quelle; 13. der Mittel-, Schwerpunkt; 14. eine mit Beeren bewachsene Stelle (im Walde); 15. der Hanf; 16. der Tragbalken; [...].

мать ж. м'ати цок. и сьв. М'атерь, [...]. М'атка, кромы прямаго значенья матеpи: || 6аба, нениина; || самка, всякое нивотное женск. полу; кобыль, на конСК. заводы, такне зовуть матками У пель, въ каждомь рою одна царица, или матка, осталыныя дылятся на трутней (самцовъ) и рабочмхъ, батраковъ. || Во многихъ итрахъ, осо6. гды дылятся на два стана, предводителм называются матками: 6ыть на маткахъ || Женская утро6а, черево, та часть, Въ коей вынашивается дытеныи. || У растенй, плодн икъ, гды принмается цвь тен, производя плодъ и сьмя; || [...]. || вга. прмродная оспа. || Старый или густой уксусъ, отсьдъ, влмваемый въ смьсъ, изъ коей дьлають уксусъ. \| [...]. || Исподній сру6ъ или яиикъ въ колодиt, на самом днt, насылаемый перскомь. II Источикъ чему либо, мьсто рождены, происхожденья, корен; || середка, средина, средоточе, остіе, чентръ, особ. центрь тянести. \|

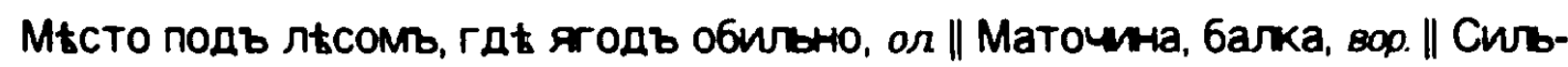
ная, сплошная оспа. [...].

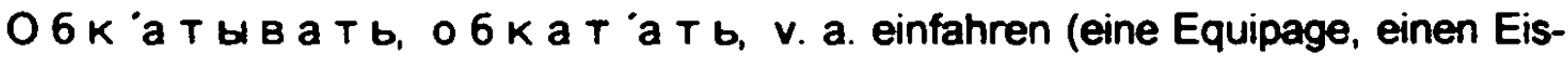
berg); [...].

I. O6K'атьвать, voll., обкат 'ать v. a. 1. einfahren (eine Equipage, einen Eisberg); 2. einrollen, hin und her rollen, durch Hin- und Herrollen abrunden; о. битк' $и$ Bb сухар яхъ Cotelets in Reibbrod einrollen; 3. befahren; о. весь $r^{\circ}$ ородъ durch die ganze Stadt fahren, überall in der ganzen Stadt umherfahren.

O(6)火'атьвать, обкат'ать что [...]. || O6катать 6итк'и въ сухаряхв, к'олобы въ мукt, смоланой комъ въ песк., обвалять, в'ьвалять. [...]. || Обкатать весь городъ катая, валяя на лошадяхъ, объtхать городъ, перебьвать во мноruxъ Mtctaxъ. [...].

П о г 'о н b, s. m. 1. das Nachsetzen; die Nachsetzenden; 2. die Träber (beim Branntweinbrennen); der Bodensatz; 3. die Achselschnur (als Epaulette).

Mor'orr s. m. 1. das Nachsetzen; die Hast, Eile; 2. ohne Aufenthalt zurückgelegte Strecke; 3. coll. die Nachsetzenden, Verfolgenden pl.; 4. die Träber; (beim Branntweinbrennen), wässeriger, übel riechender Branntwein; der Bodensatz; 5. die Achselschnur (als Epaulette), Tuch-Epaulette; Schulter, Achselklappe; das Schultergehenk, -gehänge, Bandelier; 6. die Schiene, Klammer, Krampe; 7 der Spielraum; 
8. KJoben (einer Blockrolle); 9. späte Triebe (pl.) des Getreides (nach Spätregen); 9. das Austreiben (des Viehes).

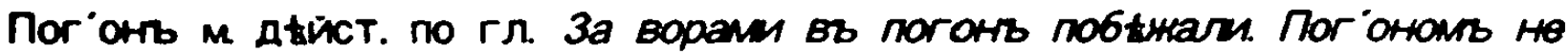
подспорииь, торопя, спнша. [...]. I| Перегонъ, перетздъ не кормя. Въ одинь

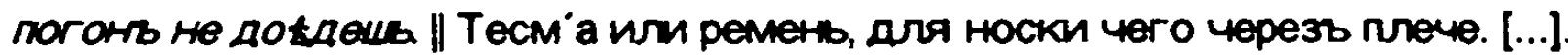
|| Полоса, нашиваемя на пл еча военнаго мундира. [...]. || Погонъ, пруть или полоса, по коей ходить что либо, рельсь, и || самый просторь, разбнгі, пространство для двиненья взадь и впередъ: [...]. || Погонда каз поздніе

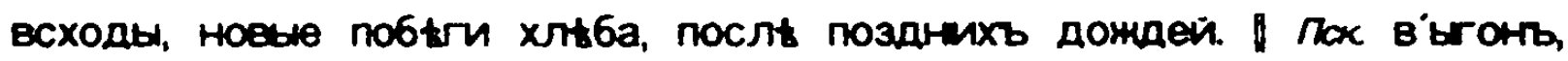
поск отина. [...].

C k y л a, s. f. 1. das Backenbein (hervorstehendes); 2. fig. pop. der Geizhals, Knauser.

Cқyria s. f. 1. der Backenknochen, das Backenbein (hervorstehendes); 2. (Anat.) der Kiefer, в ерхняя c. der Oberkiefer, Backenknochen; н' fer, Kinnbacken; 3. (Medc.) die Geschwulst (im Gesicht, im Nacken); 4. (Seew.) der Bug (am Schiffe); 5. fig. pop. der Geizhals, der Knauser; [...].

Скуліа ж. челость; наяя скула, салазки, сысала; вероняя скула или скулыная кость; она выдается подъ глазомъ, переходя кь уху въ скульную ауту, и скулами зовуть эту костяную вылукость надъ щеками, округ лую въ кавказкомь племени, и плоскую, иирокую въ азіатскомь. [...]. II Cкуліа судна, боковая часть носу, 6ылуклость Парахадв 6аркы скулу просаяиль. || Cкула, ож и зал. линная простудная 6ольњн, 6оль и опухоль въ тинь, на шен, пухлыя нелөзы, заушниа ир. такне вередъ, иррей [...]. || " Cкула, скупецъ, скрага. [...].

Der Vergleich der Stichprobe aus der zweiten Auflage mit den entsprechenden Passagen aus dem Dal'schen Wörterbuch hat ergeben, daß jenes für Nikoliž zwar die maßgebliche, nicht aber die einzige Quellengrundlage gewesen ist. Nicht aus dem Dal'schen Wörterbuch stammen die neu aufgenommenen Toponymika und Anthroponyme sowie zahlreiche Pflanzenbezeichnungen. Es ist deshalb zu vermuten, daß Nikolic ebenso wie Pawlowsky zweisprachige Wörterbücher und Spezialwörterbücher als ergänzende Hilfsmittel herangezogen hat.

Die Untersuchung der Pflanzenbezeichnungen in der Stichprobe hat ergeben, daß das botanische Worterbuch von Annekov (1859) als Quelle ausgewertet worden ist. Dies belegen folgende Beispiele. 
Bsp.: Map yнa s. f. (Bot. Matricaria chamomilla) die Kamille, das Mutterkraut, gemeiner Romey.

857. Matricaria Ch a m om ill a L. - Pomauka (Antr.), Pomerb תtkapckin (Maлор. Макс.), Сосонка ( Tan6. Меу. FI. Nr. 163), Моргунъ (Мей. Бот. Сл. II. 310). - Румия текъ, Маруна (Пал) [...].

Kamille, Mutterkraut, Hermel, Gemeiner Romey $(H \neq M)[\ldots]$.

Marioks, YK'a s. m. (Bot. Papaver hoeas) wilder Mohn, der Kornmohn, die Feuertlume. Klapperrose.

962. P a paver Rhoe as L. - [...], Marokb (Mar Makc.) [...].

Wilder Mohn, Kommohn, Feuerblume, Schnallen, Klatschrose, RanunketMohn, Fallblume, Klapperrosen (HtM) [...].

O6 ${ }^{\circ}$ epsu-ka s. f. (A. Bot. Solanum melongena) die Ejerpflanze.

1350. Solanum Melongena L. - [...], O6ерзика (Лол) [...].

Eierpflanze $(H t M)[\ldots]$

O6op' nourb, hua s. m. (Bot. Oxalis acetosella) der Saverklee, Buchampfer.

940. Oxalis A ceto sell a L. - [...]. O6opmenb (Wied. u. Web. Beschr. p. 247) $[\ldots]$.

Sauerklee, Käs und Brod, Buchampfer (HtM) [...].

Повелivka s. f. (Bot. Galium aparine) kletterndes Labkraut, das Klebkraut, das Zaunreis; (Polygonum convolvulus) die Buch-. Schwarzwinde; n. noлeв'as (Galium mollugo) weißes Labkraut.

624. G a li um A p a rine L. - [...], Повелмка (Bat. Mey. FI. Nr. 242), [...].

Kletterndes Labkraut, Klebkraut, Zaunreis, Kleber $(H \neq M)$ [...].

626. G a li u m M oll u g o L. - [...], Повелмка полевая, [...].

Weisses Labkraut $(H \neq M)[\ldots]$.

1055. Polygonum C onvolvulus L. - Повелmka, [...].

Schwarzwinde, Buchwinde (HtM) [...].

Повитель s. f. (Bot. Convolvulus anvensis) die Winde, Acker-, Feldwinde; (Cuscuta) die Flachsseide; (Polygonum dumetorum) die Vogelzunge, Heidelwinde; п. жёлтая (Lysimachia nummularia) das Eget-, Pfennigkraut. Wiesengeld. 
448. C onvolvulus arvens is L. - [...]. Повелмиа, Поемтељь (Bор. Тар. Фл. Nr. 265, Tam6.) [...].

Winde, Ackerwinde, Feldwinde (Ht/M) [...].

488. C u s c u t a разлин. алд. - Повелица, Повелика, Повитель (Вор. Тар. Фл. Nr. 162), [...].

Flachsseide, Seide $(H t M)$ [...].

1056. P ol y go num du m e to r u m L. - Поеитель (Bop. Tap. Фл. Nr. 285), [...].

Vogelzunge. Heidelwinde.

841. L y s im a chia N u m m u l a ri a L. [...], Поеитељь желтая (Bop. Tap. Фл Nr. 346), [...].

Egelkraut, Pfennigkraut, Wiesengeld $(H: M)[\ldots]$.

CK'иnetpъ s. m. [...]; c. L'арскій (Bot. Lilium martagon) die Martagonlilie, der Türkenbund; (Verbascum thapsus) die gemeine Wollblume, die Neumannskraft; [...].

803. Liliu m Martag on L. - [...], Llapcкin̆ ckиnetps (Cnm6. Beitr. zur Pf. IX. Lief. p. 116), [...].

Berglilie, Goldwurz, Martagon-Lilie, Gelbwurz, Türkenbund (HtM) [...].

1527. Verbascum Thapsus L. et thapsiforme L. $-[\ldots]$. Lapckin cKunetpr, [...].

Neumannskraft $(H \notin M)[\ldots]$.

CK'yukъ s. m. (Bot. Campanula glomerata) gehäufte Glockenblume, das Zäpfleinkraut.

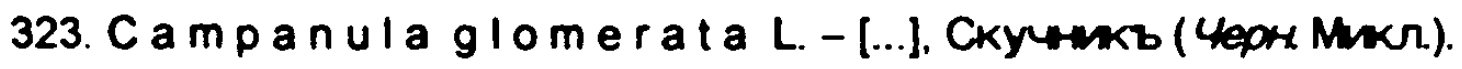

Zäpfleinkraut (H太M).

\subsection{Quellen der dritten Auflage des russisch-deutschen Worterbuches}

Die Untersuchung der Stichprobe aus der dritten Auflage im Hinblick auf die von den Autoren benutzten Quellen hat kein einheitliches Bild ergeben. Auch hier deuten die Ergebnisse darauf hin, daß mehrere Bearbeiter für unterschiedliche Teile des Wörterbuches verantwortich gewesen sind (vgl. 4.4.2.2. 144; 4.4.3.5, 153-154). Hinsichtlich der Art der benutzten Quellen und der Intensität der Ausnutzung derselben läßt sich die Stichprobe dreiteilen. Die erste Gruppe bildet die Stichprobe aus den Buchstaben A und 5 , die zweite 
Gruppe umfaßt Abschnitte der Buchstaben $M, O$ und $\Pi$, und die dritte Gruppe bildet die Stichprobe aus dem Buchstaben C.

Die Frage nach den der dritten Auflage zugrundeliegenden Quellen, wird der Übersichtlichkeit halber für jede Gruppe einzeln beantwortet, wobei jedoch auch immer ein Vergleich mit den anderen Gruppen angestellt wird.

Bei der ersten Gruppe ist besonders auffällig, daß die zwischen 1880 und 1882 veröffentlichte zweite Auflage des Dal'schen Wörterbuches (vgl. Dal', 1880-1882) nicht als maßgebliche Quelle genutzt worden ist. Es finden sich zwar sowohl auf makrostruktureller als auch auf mikrostruktureller Ebene ettiche Eintragungen, die aus dem Dal'schen Wörterbuch stammen, sie sind allerdings, verglichen mit den nicht aus diesem Wörterbuch stammenden Einheiten, zahlenmäßig eher gering.

Bei den Beispielen, die belegen, daß das Dal'sche Wörterbuch als Quelle benutzt worden ist, wird zuerst der jeweilige Eintrag aus der zweiten Auflage zitiert, darauf folgt die entsprechende Stelle aus der dritten Auflage und zum Schluß die Quellengrundlage. An erster Stelle stehen Beispiele, die belegen, daß mit Hilfe des Dal'schen Wörterbuches die nischenalphabetische Makrostrukur des Wörterbuches emvitert wurde, anschließend werden Beispiele angeführt, die untermauem, daß die zweite Auflage des Dal'schen Wörterbuches auch zur Erweiterung der Mikrostruktur benutzt worden ist.

Bsp.: Aprym entr s. m. das Argument, der Beweis.

Aprylli 'енть s. m. das Argument, der Beweis; -мент' aunig s. f. die Beweisführung, Schlußfolgerung; -мент'ировать (-мент'ирую) v. n. einen Beweis führen (vgl. Док'азывать, Д'оводъ).

Аргуміенть м лат. примиа, доказательство, убнжденіе, доводы Аргумент ировать что, доказывать, излагать доказателын, доводить. Аргумент аиія, доводъ, доказательное разсунденіе.

\section{Lemmalücke}

Брун ¿ ть v. n. 1. klingen, tönen, summen; klirren, klimpem; 2. dick werden, anschwellen; 3. grau, weiß werden; 4. reifen, reif werden.

Бру(山, e)н'tтb [...], звенtть, звучать, жунокать; гудыть, гудить, бренчать; извлекать илм издавать звукъ. [...]. I| Налмваться, пухнуть, грубнуть; зрьть, pattb, cntтb. [...]. Ctatsb, nлastTb, 6tлtтb, [...]. 
An'амь [...]; -мова голов'а 1. der Todtenkopf; 2. populäre Bezeichnung verschiedener Pflanzen; 3. der Alraun oder die Zauberwurzel; 4. ein Abendschmetterling; [...].

An alhmb [...];-мова голов a 1. der Todtenkopf, ein Abendfalter (Zool. Sphinx caput mortuum); 2. Bezeichnung verschiedener Pflanzen: a. (Bot. Eryngium campestre) die Feldmannstreu, das Elendkraut, die Damendistel; b. (Nicandra physaloides) der Männersieg, die Giftbeere; c. (Cypripedium calceolus) der Frauenschuh; d. (Atropa mandragora) die Alraunwurzel, der Schlafapfel, das Galgenmännlein; e. (Sibir.) (Centaurea scabiosa) die Bergflockenblume, Eisenwurzel; [...].

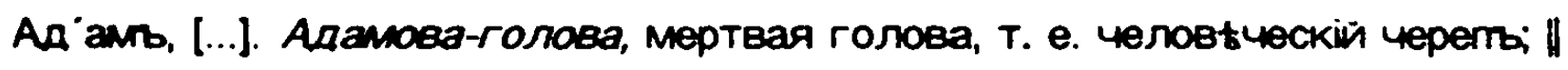
тротимеское растеніе мандрагорь, Mandragora offic. um Atropa Mandragora. изъ сем. пасленовыхъ. \| Растн. черный-осотъ, Centaurea scabiosa,

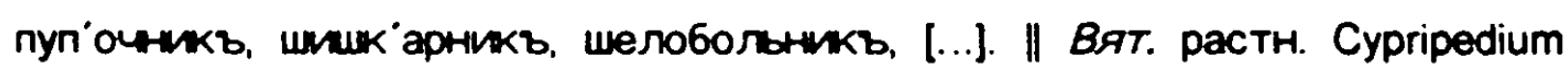
calceolus, кукуикиы-саліония \& Самый болыиой сумереинкв, бабоика мертвая-голова, Sphinx Caput mortuum, на стикь которой видньется изобранненіе челов tиескато черепа. [...].

Б'ykвa s. f. der Buchstabe; [...].

Б'yk|ka s. f. der Buchstabe; гліасная 6. der Vokal; cor riachaя 6. der Konsonant; губн'ая 6. der Lippenlaut; нёбная 6. der Gaumenlaut; горт'аная 6. der Kehllaut; стронная, рядоваая, м'алая 6. der kleine Buchstabe; кр асная, прописная 6. der große Buchstabe; [...].

Б' уква ж. одинь изъ началыныхъ знаковъ грамоты, письмености, изъ комхъ составлаются слоги и слов а; писым Я. Буквы гласныя, согласныя; губныя, небныя, гортаныся ир. Стр очныя букеы, рядовыя, малыс, употребляемыя Bъ письмы сплошы; красныя, прописныя, 6ольия, началыныя, переая буква оть строк иили послt точки. [...].

Die neu aufgenommenen Lemmata und Bedeutungen, die nicht aus dem Dal'schen Wörterbuch stammen, lassen sich größtenteils den Fachsprachen zuordnen, was darauf hindeutet, daß möglicherweise Spezialwörterbücher ausgewertet worden sind. Außerdem weisen die Eintragungen aus der griechischen Mythologie und die Eintragungen zu bekannten Persönlichkeiten eventuell auf eine enzyklopädische Quelle hin.

Da die Autoren des Pawlowskyschen Wörterbuches aber insbesondere die großen einsprachigen Wörterbücher als Quelle ausgewertet haben, lag es nahe, vor den Spezialwörterbüchern zuerst den ersten Teilband des unter der Leitung von Ja. K. Grot erarbeiteten 
Akademiewörterbuches (vgl. Pkt. 1.1.4, 10) auf seinen Quellenwert für den ersten Teil der Stichprobe zu überprüfen. Der Vergleich der Stichprobe mit den entsprechenden Passagen des Wörterbuches von Grot (vgl. Slovar', 1891) ergab, daß dieses Wörterbuch sowohl zur Erweiterung der Makrostruktur als auch zur Ausdehnung der Mikrostruktur als maßgebliche Quelle herangezogen worden ist. Da die meisten Beispiele eine Erweiterung der Makrostruktur belegen, was bedeutet, daß in der zweiten Auflage des Pawlowskyschen Wörterbuches Lemmalücken vorliegen, wurde der entsprechende Abschnitt aus der zweiten Auflage des Pawlowskyschen Worterbuches in dieser und der folgenden Beispielgruppe nur dann aufgeführt, wenn es sich um eine mikrostrukturelle Ausdehnung handelt.

Bsp.: Afl6 6 ing 6 adj. von weißem groben Tuch.

A/16 Bb OKH'O (Redensart in Südrußland von etw. Dünnem, Durchsichtigem, weil dort, namentlich an der persischen Grenze, solches Zeug statt der Fensterscheiben gebraucht wird).

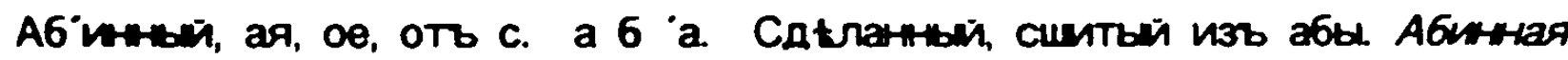

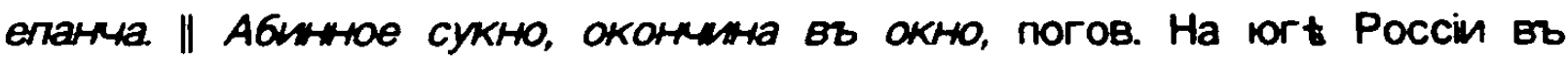
Hнкоторыхь деревняхь употребляоть емнсто оконыхь стеколь

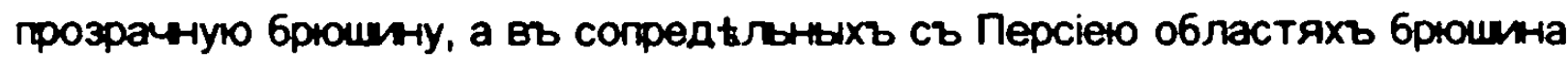
замtняется иногда абою; оттуда эта поговорка, означамая что-нбудь сквозне, płaKое, какъ абине сукно.

Lemmalücke.

Aap'acz s. m. bucharisches und persisches halbseidenes Zeug mit welligen bunten Streifen auf einfarbigem Grunde, zu Schlafröcken gebraucht.

Адр 'ясъ, а, м (тат.). Бухарская и персидская полушелковая ткан съ волнстыми, пестрыми узорами по одинакому поло, идушая на халаты и архалуки. $[\ldots]$.

Lemmalücke.

Ararp'ekъ s. $n$. inded. (franz. à la greque) ein Muster, bestehend aus einer od. zwei in rechten Winkeln sich biegenden fortlaufenden Linien, wie man es nicht nur auf altgriechischen Gewändem u. etruskischen Vasen, sondern auch auf älteren chinesischen Denkmälern findet.

Aлатр 'екъ, носкл ( $\phi$ р. à la greque). Узоръ изъ одной или двухъ загибаюиихся подъ прямыми уг лами непрерывныхъ лмній, встрычаемый не только на 
древнетреческихъ одеждахъ и этрусскихъ вазахъ, но и на болtе старыхъ КИтайскихъ памятникахъ.

\section{Lemmalücke.}

Epakoffi amie s. n. [...]; ваный part. praet. ps. brackiert, ausgeschieden; 6p. тов аръ Wrackwaare, Brack; 6-ая ліошағы ausrangiertes Regimentspferd, das untauglich geworden $u$. an Privatpersonen verkauft ist; [...].

Брак ова й, ая. ое; -анъ, ана, о, страд. прич. гл. 6 р ак о в а т ь. Браковамнын товары. || Бракованкая лошады, полковая, оказавшаяся негодною и потому проданная въ частныя руки.

Брусн inxa s. f. (Bot. Vaecinium vitis idaea) die Preißel-, Preisel-, (Ost.) Strickbeere: [...]; -сніица, -німина, -сніика dim. s. Брусніика; [...].

Брусніица s. f. 1. s. Брусн имита; 2. eine längliche Blechdose, in wetcher zugleich mit Wasser der Schleifstein zum Wetzen der Sensen und Sicheln aufbewahrt wird; diese Dose hängt gewöhnlich am Gürtel des Măhers; 3. das Schleiforettchen für Sensen u. Sichein.

1. Брусн йа, b, жо то же что 6 р у сн 'ика.

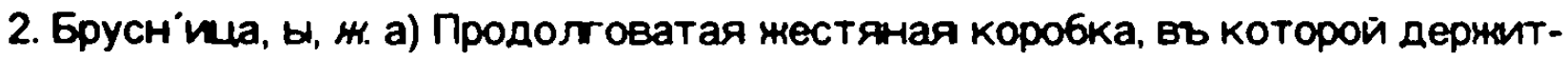

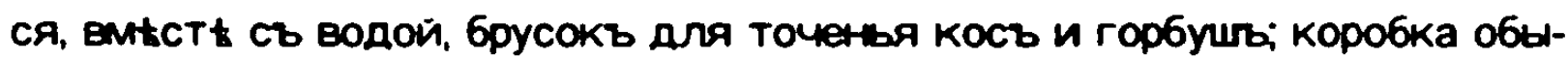
Кновенн привьиивается Къ поясу косиа торикоми. 6) Дощечка въ виды маленкой лопаты, о6литая варомъ и употребляемая для тоиеныя косъ и горбушъ. [...].

Auffällig ist, daß auch ein großer Teil derjenigen Lemmata, die eigentlich auf die Benutzung von Spezialwörterbüchern bzw. von Enzyklopädien hinweisen (vgl. Pkt. 5.3, 180), aus dem Grotschen Wörterbuch stammen, was darauf zurückzuführen ist, daß dieser Autor neben den einschlägigen Wörterbüchern auch unterschiedlichen Fachgebieten zugehörige Spezialliteratur ausgewertet hat (vgl. Sorokoletov, 1998, 216-220).

Bsp.: Lemmalücke.

Arriapb s. m. (Bot. Antiaris toxicaria) der Antiar, Antschar, Giftbaum, Upas.

Aн4іаръ, а, м. (малайск. антіаръ). Ядовитое дерево Antiaris toxicaria, о которомь суиествуеть много 6аснословныхь разказовь Сокъ его туземиы употреблато для отравленія стрыль. Отечество о. Ява. Упасъ, I'Upas de Java. 
Аoн inat pl. f. die Aeoniden.

Аон иды n. pr. f. pl. 1. (griech. Mythl.) die Aoniden, aonischen Schwestern; die in Aonien (Böotien) verehrten Musen; 2. der erste russ. Almanach, herausgegeben von Karamsin (1796-1799).

Аон иды, дъ, мн. же (по имен области Аотіи, уасти Беоті). Музы, которымв поклонялись на горахъ Аонім. "Аон'иды Карамзин'а, переы русскій альманахи, который онъ издавать въ концt прошлаго столtтія (1796-1799).

Lemmalūcke.

Арист"архъ 1. n. pr. m. ein griechischer Grammatiker um 150 v. Chr.; 2. der Kritiker, gelehrter, pedantischer Kritiker.

Арист' архъ, а, м (има низиаго около 150 лtть до P. X. греческаго грамматика, установившаго тексть Гомера и признавшаго многія мыста Иліады и Одиссеи подлонони). Критикъ, Въ особенности уиен; критикъпеданть, неуклонно руководящийя въ оцtнкt произведеніл однанды установленым, хотя 6 уне и устарылыми правилами Исти тей таланть

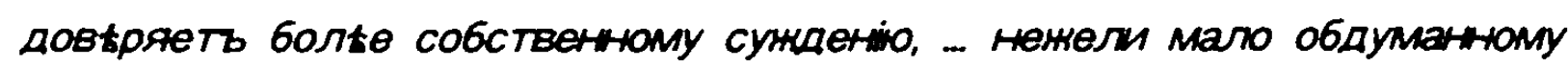
pturerio zanncrodz apuctapxosb.

Пуиек.

Eylr'opъ, rp’a s. m. der Hügel; der Haufen; [..].

Bylf'opł, rp'a s. m. 1. der Hügel; 2. der Haufen; 3. (Bergw.) ein regelrechter Salzhaufen der Salzseen und Saizbergwerken; 4. (Eisbn.) eine Anhöhe am Ende des Ausgangsgeleises neben der Rangierstation; [...].

Буг'оръ, rр'a, м (тюрк. 6огри горбъ; сраен. Htм. Bühel и Buck возвышеность).

1. Неболышои холмъ. [...]. 2. Всякое небольше возеышеніе на поверхности. [...]. 3. Горн. Груда солм праеилыной формы при соляныхъ озерахъ и копяхъ. 4. Жел-дор. Возвышеніе, устрамваемое у конца вытянног пути, подлt copтирово най станиін.

\section{Lemmalücke.}

Б' уры s. m. pl. die Boers, holländische Kolonisten in Sũdafrika. Farmer, die 1835 eine unabhängige Kolonie gegründet haben.

Б'уры, овъ, мн. м. (гол. ьое крестьлинъ). Голландскіе колонисты въ юнной Африкt, фермеры, основавине тамъ въ 1835 г. независимую колонію. 
Lemmalücke.

Буст opka s. f. (Zool. Sorex) die Spitzmaus.

Буст орка, И, ж. Звtрекъ Sorex, похожіи на мыиь.

Da von dem Grotschen Wörterbuch nur die beiden ersten Teilbände, die von A bis D reichen, veröffentlicht werden konnten (vgl. 1.1.4, 10), scheidet das Werk als Quelle für die anderen beiden Gruppen der Stichprobe selbstverständlich aus, so daß sich der zweite und der dritte Teil der Stichprobe wieder auf das Dal'sche Wörterbuch als maßgebliche Quelle stützen. In beiden Teilen wurde sownhl die Makrostruktur als auch die Mikrostruktur mit Hilfe dieser Quellengrundlage enweitert. Der Aufbau der Beispiele erfolgt analog zu den Beispielen des ersten Teils. Das bedeutet, daß zuerst Beispiele für die Erweiterung der Makrostruktur und dann solche für die Ausdehnung der Mikrostruktur angeführt werden.

Bsp.: Lemmalücke.

Max yilxa s. f. coll. die Trester von Mohn, Hanf, Senfkömem etc.; -xosłñ adj. daraus bestehend, dazu gehörig.

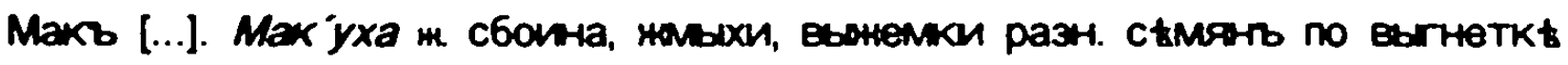
масла. Мак'уха маковая, гориндая, конолляная [...]. Мак'уховын, къ ней относяuincя. [...].

O6л truваться, voll. Ніиться, Н яться v. n. faul werden.

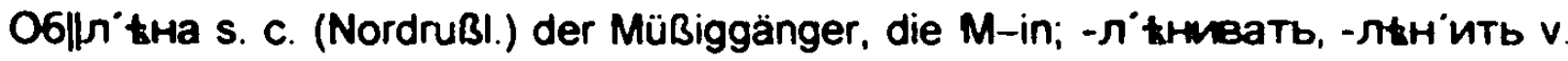

a. faul, träge. lässig machen; -ліниваться, -льнииься faul, träge werden; -лінний adj. müßiggängerisch; -лtн'oxa s. c. der Faulpelz, die Faulenzerin;

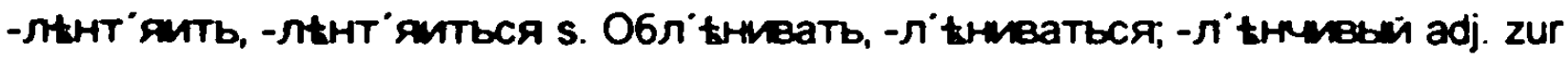
Faulheit geneigt; -лtнtb s. f. 1. die Faulheit; 2. der Faulpelz; -лtн atbca s. 06л' тниваться.

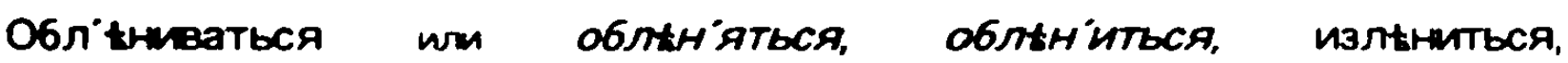

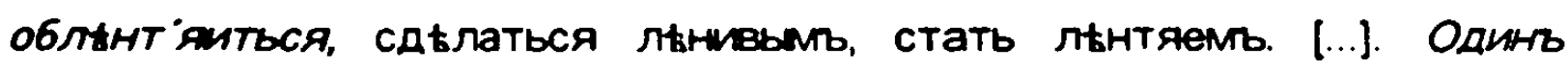

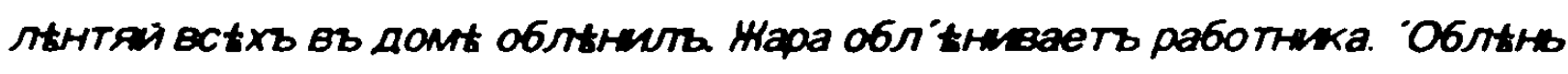
налала, лtнь. II Эка 'о6лtны шляется! лtнтяй, о6лtн'оха о6. Народь все

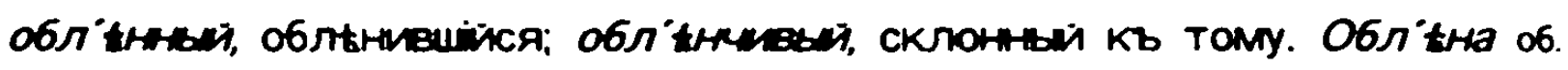
apx. 06 תtнивuincя человtкъ.

\section{Lemmalücke.}

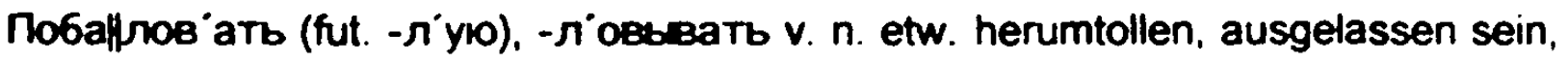
Muthwillen treiben; v. a. ein wenig verwöhnen, -ziehen (Kinder); einen kleinen Gefal- 
len erweisen; -лов аться s. Побалов'ать v. n.; -л'овка s. f. die Verwöhnung, zu große Nachsicht; -л овbать s. Побалов'атb.

Побал овывать, по6'алов'ать Я вину, ты сыницку таки побаліовываешь. Orb и самв побал'овываеть, пошалмваеть. Побаловать собаку, и полно, надо чтобъ слушалась. Побаловаль съ собакой, а она полу оторвала!

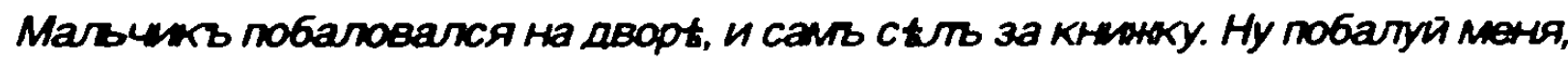
подари платочекъ! Побал овка, баловство, повадка.

\section{Lemmalücke.}

Cқар/M axъ s. m. (Ostsib.) felsiges Ufer (eines kleineren Flusses); -мак'и s. m. pl. (SüdrußI.) das Felsgerölle.

Скарм'акъ во-сиб. береговой утесъ, скалистый береть рники. Скармах ' скальё он. ск'ели, каменистые обрыеы, розсыли.

Меже умка [...]; - умиокъ, мка s. m. 1. s. Менцау умокъ; 2. ein großes Boot (zum Salzführen auf der Kama); 3. schmales Beil; [...].

мене|l'улокъ [...]; -'умокъ, мка S. m. 1. das Mittelding; челов'tкъ M. ein Mensch von mittlerer Statur od. von wenig Verstand; TOB ${ }^{\circ}$ aps $M$. die Mittelgattung einer Waare (Borsten, Flachs etc.); 2. (von Thieren) der Bastard, Mischling; 3. eine Barke auf der Wolga, Kama, die annähernd 70,000 Pud trägt: 4 . schmales Beil; 5. ein mittelgroßer Löffel; 6. grobes Schrot; 7. eine Art Kaviar mit mäßigem Salzgehalt; [...].

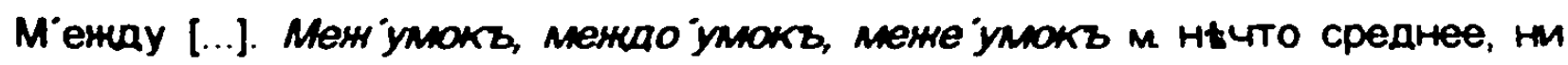
туда, ни сюда, все, что не принадленить ни къ тому, ни къ другому сорту, разбору, разряау. [...]. Человыкъ меже умокъ, среднято роста, либо средственаго ума, недо'умокъ, поло'умокъ. \| Лошакъ меже умокъ, ыродокъ, тумакъ, ублодокъ. Соболь мене умокъ, нм собољь, нм куница. || Барка меже умокъ, 25-30 саж. дл., 5-8 имр., подымаеть до 70 т. пуд., волжская ладыя, по Камt. || [...]. || Нуоке лонка средней велимны (см. лонка). || Топоръ,

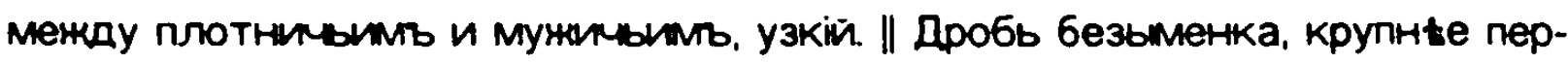
ваго номера. II Икра средняго засола, между паюсног и малосолыною. [...].

O6ebk'atb, voll. -B'bukнyTb v. $n$. sich nach und nach gewöhnen, an etwas

'O6/lacs s. m., artie s. n. die Gewöhnung, Gewohnheit; - atb(cя), -B buxнyтb(cя) v. n. sich nach $u$. nach an etw. (Ungewohntes od. Widerliches) ge- 
wöhnen; (Sprichw.) 06в'bkнеub, такъ и въ an'y нmer'o (eig. ist man's gewohnt, so ist es auch in der Hölle erträglich) es kommt alles auf die Gewohnheit an.

O6еык'ать, 06в 'ькнуть, обыкать, пріобыкать, привыкать, свыкаться. Обеын

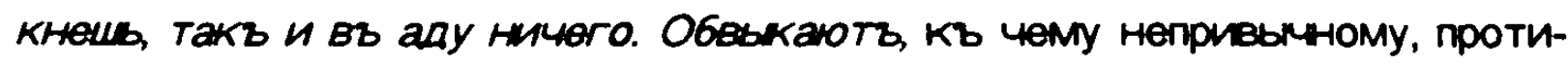

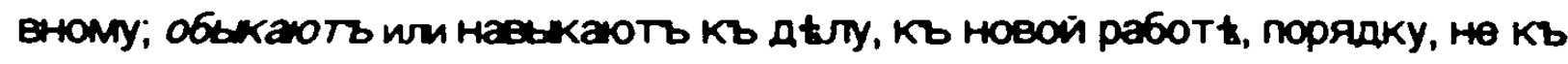

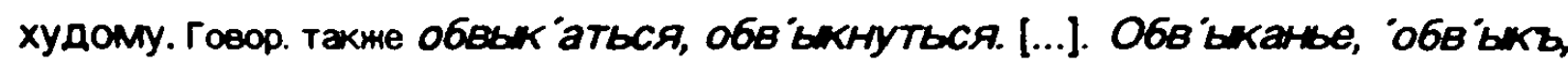

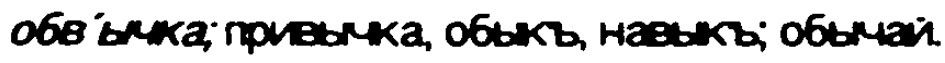

Пог'остыи [...]; -r'octb s. m. 1. die Kirche nebst einem Kirchhofe dabei; eine Kirche mit Wohnungen für Kirchendiener und dazu gehörigen Ländereien; 2. (ehed.) der Dorf-, Amtsbezirk.

Mor'ollctb s. m. 1. die Dorfkirchengemeinde, das Kirchspiel; 2. eine Kirche nebst Wohnhäusern für den Geistlichen u. die Kirchendiener, sammt den dazu gehörigen Ländereien; die Kirche mit einem Kirchhofe; 3. (prov.) der Kirch-, Friedhof; 4. (Orenburg) einzeln stehendes (vom Dorf weit entferntes) Einkehrhaus; 5. (NordrußI.) lappländisches Dorf; [...].

Пог'ость м нег. приходъ сельскій, нtсколько деревен, подъ обиимв управленемь и одного прихода; волость; отдылын стояная на церковной

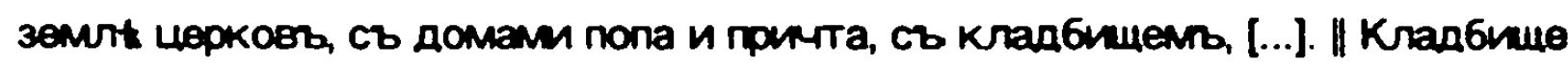
съ церковыо вообще; ярс. орл. всякое кладбище, бонья-нива; церковны

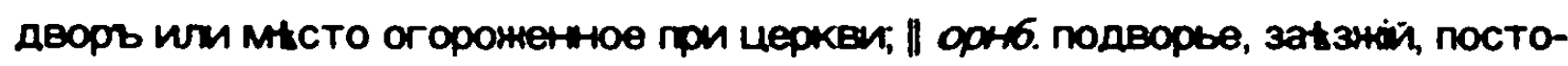
ялый дворъ на отиибt, вдалекь отъ селеній, одинокій, תerbe. [...].

Ckomb s. m. 1. s. CK' ormule; 2. die Gemeindeversammlung; 3. Angesammeltes, Erspartes; 4. der Aufruhr, die Emporung; ck onows in Gemeinschaft, nach gemeinschaftlicher Verabredung.

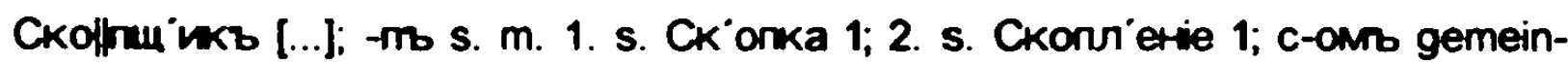
schaftlich, zusammen, nach gemeinschaftlicher Verabredung; c. pa6 oumxb der Arbeiterstrike; 3. s. CK'onmue; 4. das Angesammelte. Ersparte; pl. Vorräthe; мол о с-ы die Milchprodukte; 5. die geheime Zusammenkunft, -rottung, Versctwobrung; der Aufruhr, 6. (Archang., Nowgorod) die Versammlung der Dorfgemeinde: 7. (Twer) die Kräutersammlung, der -thee (zum Aufguß).

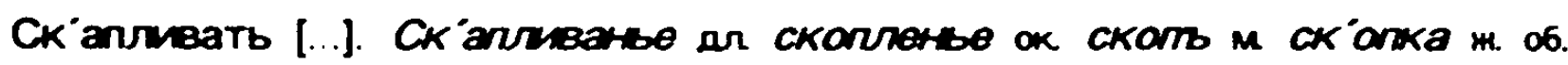

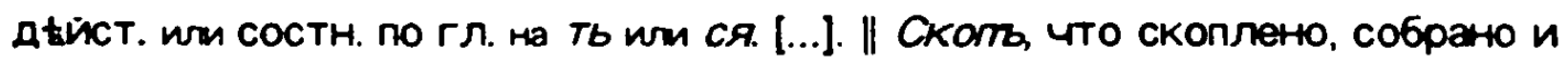




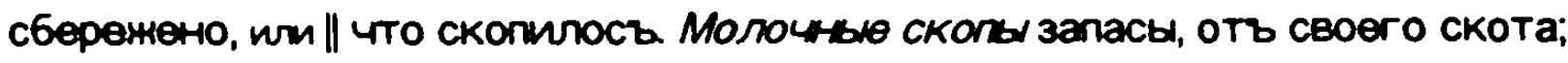
молоко или сливки, сметана, твороть и сыры, простокваша и варенець, масло [...]. || Тер. сборныя тр авы, для настойки вина и водКИ, для леченын. || Cкоть ил ск отище, толла, ватага, сборище народа, лода; 6ол вь зн скоплетья съ дурнымъ умысломъ; || скоть, заговоръ, крамолы, злоумыленная стамка. [...], стар. Cкоть рабочихz, стамка противь хозяина. [...]. || Cкоть арх. Hвr. cK' огка, арх. с6оръ, сходка, мipъ на сходкt; на думt. [...].

Allerdings unterscheiden sich der zweite und der dritte Teil der Stichprobe hinsichtlich der Intensităt der Auswertung der Quelle insbesondere im mikrostrukturellen Bereich. Kennzeichnend für die zweite Gruppe innerhalb der Stichprobe ist, daß zahlreiche Lemmata und Bedeutungen mit einer diatopischen Markierung versehen wurden, die zwar aus dem Dal'schen Wörterbuch abgeleitet, aber nicht direkt von dort übemommen wurde. Das bedeutet, daß die diatopische Markierung in diesem Teil der dritten Auflage des Pawlowskyschen Wörterbuches hăufig regional weniger eng begrenzt ist als in der Quellenvorlage, da die genaue Ortsangabe bei Dal' häufig durch grobere Regionalangaben ersetzt murde (vgl. 4.4.3.5, 151-152). Dies verdeutlichen folgende Beispiele, wobei die Quellenangabe immer auf den entsprechenden Abschnitt aus der dritten Auflage des Pawlowskyschen Wörtertuches folgt.

Bsp.: Melpн a [...]; -w axb s. m. (prov.) 1. der Nachbar, Grenzbewohner, 2. der Landmesser, 3. der Südwestwind; 4. der Grenzstreifen.

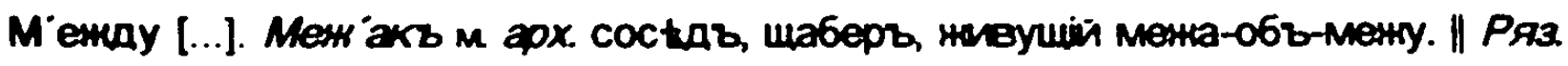

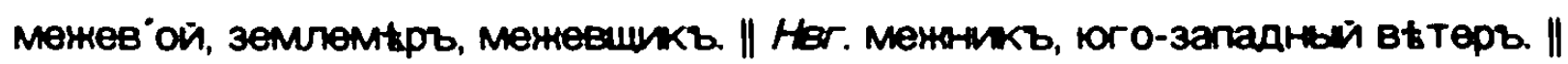
Межако ит меня икз, менная полоса; мена, образуоная не черту, а полосу, 06лі огъ, о6ложекъ, затущеная полоса мень двухъ полей, nauetb. [...].

$06 e s 8^{\circ}$ tuntb v. a. kor'o 1. (Nord- u. OstrußI.) jindm. das Leben verkürzen; jmd. abquălen, ausmergeln (ein Pferd); 2. jmod. zum Krüppel schlagen, machen; 3. (prov.) jind. unglücklich machen, ins Unglück stürzen; [...].

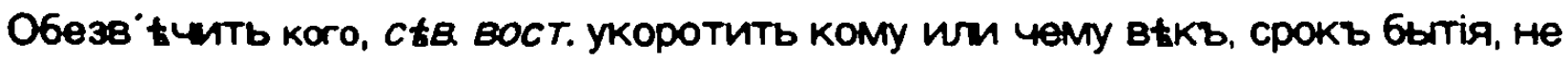
дать донить выка; замуить, замаять, изнурить. Oбезвьчали коня моего! \| Прибить, избить, изувьиить, искалtиить; \| пск. обидtть, обмануть и

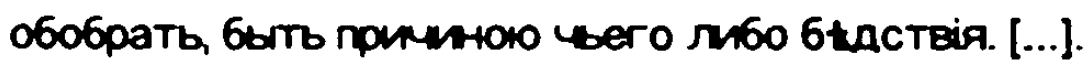

Пhать v. a. (prov.) antreiben; v. n. (prov.) gehen, vorwärts gehen, schreiten.

Пнать кого, мск. погонять, нудить $\|$ - кудв, кстр. брести, идти, ташиться; [...]. 
Der Bearbeiter, der unter anderem für die dritte Teilgruppe der Stichprobe zuständig war, hält sich am exaktesten an die maßgebliche Quelle, denn er hat die genauen Ortsangaben bei den nur regional gebräuchlichen Lemmata in der Mehrzahl der Fälle unverändert von Dal' übemommen.

Bsp.: CK'ała s. f. (Cherson) ein instrument (altes Sensenstück) zum Abschaben der Schaffelle.

Ск'афа, херс. орудіе, сдыланне изъ старой косы дия оскабливанія оөины.

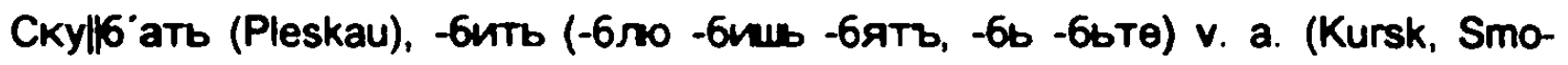
lensk) zausen (Haare), rupfen (Vögel, Federn); [...].

Скубт'и гак. ск'убить кур. смл. пск. скубст'и сар. скуб ать пск. драть за волоса; uипать птицу. [...].

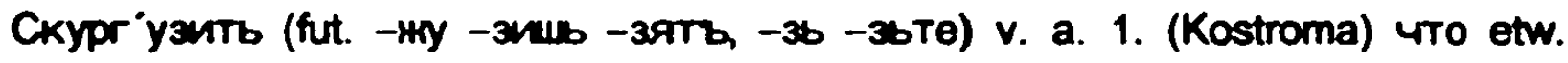
obenhin zusammenpfuschen; 2. (Tambow) kor'o jmd. anführen, prellen; -cя v. r. 1. (Sibir.) sich zusammenkrümmen; 2. (Tambow) sich irren.

Скург узить что, Кстр. сдылать кой-какъ; | кого, тм6. обмануть, надуть. -ся,

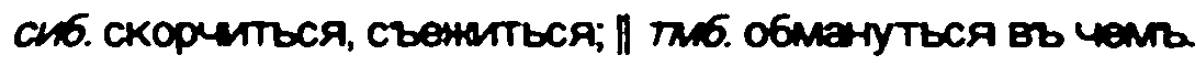

\subsection{Fazit}

Ziel des Kapitels über die dem russisch-deutschen Wöterbuch von Pawlowsky zugrundeliegenden Quellen war es, zumindest die wichtigsten Sekundärquellen der unterschiedlichen Auflagen zu finden. Dieses Ziet wurde für alle drei Auflagen erreicht.

Pawlowsky stützte sich bei der Schaffung seines Wörterbuches hauptsächlich auf das gut 10 Jahre zuvor veröffentlichte einsprachige Wörterbuch der Akademie, dessen Bedeutung laut Jachnow nicht nur "in der Auswahl des Materials, sondern in der Art der explikativen, stilistischen und grammatischen Aufbereitung des Materials" lag, "die nunmehr eine gründliche sprachwissenschaftliche Reflexion erkennen" (Jachnow, 1990, 2312) lasse. Da sich Pawlowsky nicht nur am inhalt der Vorlage. sondem auch an dessen Autbau und Präsentation orientierte, ist es nicht erstaunlich, daß die erste Auflage des Pawlowskyschen Wörterbuches um ein vielfaches komplexer aufgebaut ist als die Mehrzahl seiner zweisprachigen Vorgänger.

Auch Nikolix, der die zweite Auflage des Wörterbuches erarbeitet hat, benutzte die Ergebnisse der zeitgenössischen einsprachigen Lexikographie zur Verbesserung und Erweiterung des Wörterbuches. Als maßgebliche Quelle diente ihm das als Gegenentuurf zur 
Akademielexikographie konzipierte Wörterbuch von Dal', dessen Schwerpunkt erstmals auf der gesprochenen Sprache lag.

Das Ziel, mit Hilfe der neuesten Erkenntnisse der zeitgenössischen einsprachigen Lexikographie den Wert des zweisprachigen Wörterbuches zu erhöhen, spiegelt sich auch in der dritten Auflage des Wörterbuches wider, für die neben dem Dal'schen Wörterbuch auch der damals bereits veröffentlichte Teil des jüngsten Werkes der Akademielexikographie als maßgebliche Quelle herangezogen wurde.

Auffällig ist, daß als Vorbilder für das Pawlowskysche Wörterbuch nicht etwa früher erschienene zweisprachige Wörterbücher gedient haben, sondem daß hauptsächlich auf die Ergebnisse der einsprachigen Lexikographie zurückgegriffen worden ist. Auch wegen der umfangreichen Quellen, die den unterschiedlichen Auflagen als Vorlagen dienten, erstaunt es kaum, daß das Pawlowskysche Wörterbuch einem Großteil seiner russisch-deutschen Vorgänger, aber auch vielen Nachfolgem überlegen ist und deshalb „als hervorragende Leistung" gilt (Baumann, 1969, 127), die "noch heute [...] von deutschen Übersetzern genutz" (Eismann, 1991, 3077) wird. 


\section{SchluB}

Betrachtet man die Erzeugnisse der russisch-deutschen Lexikographie aus der metalexikographischen Perspektive, so ist zu konstatieren, daß „die Landkarten der historischen Wörterbuchforschung mit weißen Flecken übersät sind" (Papachristos, 1990, V). Als weiBer Fleck mußte bis jetzt auch das russisch-deutsche Wörterbuch von Pawbusky gelten, dessen Bedeutung in der Slavistik zwar oftmals anerkannt murde (vgl. Baster, 1987, 59; Baumann, 1969, 126-127; Bielfeldt, 1956, 19), ohne daß diese Hochschătzung allerdings eine genauere Untersuchung des Wörterbuches nach sich gezogen hätte.

Um diesen Mißstand zu beheben, wurde in der vorliegenden Arbeit eine metalexikographische Einzeluntersuchung des russisch-deutschen Wörterbuches von Pawlowsky durchgeführt, die einen Beitrag für die in der Forschung bisher recht stiefmütterlich behandelte Geschichte der russisch-deutschen Lexikographie leisten soll.

Um einen geeigneten Rahmen für die Analyse zu schaffen, wurde ein Überblick über die Entwicklung der russischen und der russisch-deutschen Lexikographie sowie über die Entstehung der noch jungen Disziplin Metalexikographie vorangestellt. Daran anschließend erfolgte die Analyse des Wörterbuches, deren Ergebnisse im folgenden zusammengefaßt werden.

Auch für d e n Pawlowsky gilt, wie für viele andere Wörterbücher, daß sich neben dem Autor der ersten Auflage eine Reihe weiterer, heute zu Unrecht in Vergessenheit geratener Mănner in den Dienst dieses Werkes gestellt haben. Zu nennen ist hier an erster Stetle Pawlowskys Neffe Ivan Nikolič, der, unterstützt durch Napoleon Asmuß, für die zweite Auflage des Wörterbuches verantwortlich gewesen ist. Nicht durch namentliche Nennung geehrt werden können die leider noch immer unbekannten Autoren der dritten Auflage des Wörterbuches. Durch die Analyse wurde aber immerhin deutlich, daß mindestens drei Personen an der heute meist gebräuchlichen und mehrfach nachgedruckten dritten Auflage mitgearbeitet haben.

Die Analyse der einzelnen Auflagen hat gezeigt, daß das Wörterbuch auf einem qualitativ hohen Niveau verfaßt worden ist. Das Bestreben, den russischen Wortschatz unter Berücksichtigung der zeitlichen, der räumlichen und der sozialen Dimension zu beschreiben, trat von Auflage zu Auflage immer stärker in den Vordergrund. Im Vergleich mit anderen zweisprachigen Wörterbüchem zeichnet sich das untersuchte Werk insbesondere dadurch aus, daß in hohem Maße die Terminologie vieler Fachbereiche sowie die Lexik der Umgangssprache und der Dialekte berücksichtigt worden ist. Gerade dieser Aspekt macht deutlich, weshalb das Wörterbuch bis heute seinen Wert als kulturelle Vermittlungsinstanz besitzt, denn zahlreiche Lemmata und Bedeutungen finden sich in keinem anderen zwei- 
sprachigen Wörterbuch früherer oder heutiger Zeit. Das Wörterbuch ist deshalb bis heute für die deutsche Slavistik ein unentbehrliches Hilfsmittel, etwa bei Arbeiten über die russische Folklore (vgl. Böhler, 1998) oder über die russischen Dialekte.

Die Tatsache, daß das Pawlowskysche Wörterbuch für die Slavistik bis heute von bedeutendem Wert ist, liegt aber auch darin begründet, daß dieses Werk, vom konzeptionellen Standpunkt aus betrachtet, einem hohen Standard gerecht wird. Bereits Pawlowsky legte größten Wert darauf, die Aquivalentangaben systemhaft zu gliedern, um dem Benutzer das Auffinden der jeweils richtigen Entsprechungen zu erleichtern. Dieses Prinzip wurde von seinen Nachfolgern nicht nur beibehalten, sondern auch, wann immer dies nötig schien, verbessert. Immer differenzierter wurde auch das System der Markierungen, das dem Benutzer - insbesondere in der dritten Auflage - bei vielen Lemmata eine genaue Zuordnung zu bestimmten Gebrauchssphären ermöglicht.

Auf der makrostrukturellen Ebene muß in diesem Zusammenhang auch das von Nikolič eingeführte nischenalphabetische Anordnungsprinzip Erwăhnung finden, das die Präsentation einer größeren Zahl von Lemmata auf einem kleineren Raum ermöglichte.

Die hohe Qualităt der einzelnen Auflagen liegt aber auch darin begründet, daß die Autoren des Wörterbuches größten Wert darauf legten, die jeweils aktuellsten Hervorbringungen der russischen einsprachigen Lexikographie als Quellen für ihr zweisprachiges Wörterbuch auszuwerten. Diese Vorgehensweise verdeutlicht eindrucksvoll, daß die zweisprachige Lexikographie nicht isoliert von der einsprachigen Lexikographie betrachtet werden solte, da zwischen beiden Richtungen ein reger Austausch stattfindet.

Abschließend werden nun einige Ergebnisse der Untersuchung noch einmal komprimiert tabellarisch vorgestellt, um einen schnellen Überblick über die Entwicklung des russischdeutschen Wörterbuches von Pawlowsky zu ermöglichen. 


\begin{tabular}{|c|c|c|c|}
\hline & 1. Auflage & 2. Auflege & 3. Auflage \\
\hline AUTOR(EN) & $\begin{array}{l}\text { Iwan Pawlowsky } \\
(1800-1869)\end{array}$ & $\begin{array}{l}\text { Ivan Nikolix (1820- } \\
\text { 1879): } \\
\text { Napoteon Asmuß } \\
(1805-1878)\end{array}$ & $\begin{array}{c}\text { unbekannt; mindestens } \\
\text { drei unterschiedlicne } \\
\text { Autoren }\end{array}$ \\
\hline $\begin{array}{l}\text { MAKROSTRUKTUR } \\
\text { 1. Publikations- } \\
\text { geschichte }\end{array}$ & 1859 & 1879 & $\begin{array}{l}1900 \text { (1. Abdruck) } \\
1911 \text { (2. Abdruck) } \\
1923 \text { (3. Abdruck) } \\
1952 \text { (1. Nactrdruck) } \\
1960 \text { (2. Nachdruck) } \\
1972 \text { (3. Nactruck) }\end{array}$ \\
\hline 2. Stichprobengroße & 5.159 Lemmata & 11.015 Lemmata & 13.647 Lemmata \\
\hline $\begin{array}{l}\text { 3. geschatzte Lemma- } \\
\text { zahl }\end{array}$ & $60.000-70.000$ & 140.000 & $180.000-190.000$ \\
\hline 4. Anordnungsprinzip & glattalphabetisch & nischenalphabetisch & nischenalphabetisch \\
\hline $\begin{array}{l}\text { MIKROSTRUKTUR } \\
\text { 1. Wortarten }\end{array}$ & $\begin{array}{l}\text { systematisch klassifi- } \\
\text { ziert (ohne Schlüssel) }\end{array}$ & $\begin{array}{l}\text { systematisch klassifi- } \\
\text { ziert (mit Schlüssel) }\end{array}$ & $\begin{array}{c}\text { systematisch klassifiziert } \\
\text { (mit Schlüssel) }\end{array}$ \\
\hline 2. Flexionsangaben & rudimentär vorthanden & $\begin{array}{l}\text { für die Verben zufrio- } \\
\text { denstellend }\end{array}$ & $\begin{array}{l}\text { für die Verben ausrei- } \\
\text { chend }\end{array}$ \\
\hline $\begin{array}{l}\text { 3. diasystematische } \\
\text { Markierungen }\end{array}$ & vorhanden & $\begin{array}{l}\text { Anstieg bei den dia- } \\
\text { tectmischen Markienun- } \\
\text { gen }\end{array}$ & $\begin{array}{l}\text { deuttich verbesserte } \\
\text { Markierung des regional } \\
\text { beschränkt gebrauchten } \\
\text { Wortschatzes }\end{array}$ \\
\hline 4. Aquivalente & $\begin{array}{l}\text { differenzierte Darstel- } \\
\text { lung der Aquivalente }\end{array}$ & $\begin{array}{l}\text { differenzierte Dar- } \\
\text { stellung der Aqui- } \\
\text { valente: überarbeitet } \\
\text { und enweitent }\end{array}$ & $\begin{array}{l}\text { differenzierte Darstellung } \\
\text { der Aquivalente; überar- } \\
\text { beitet und erheblich or- } \\
\text { weitert }\end{array}$ \\
\hline $\begin{array}{l}\text { 5. syntagmatische } \\
\text { Informationen }\end{array}$ & $\begin{array}{l}\text { explizite } u \text {. implizite } \\
\text { Informationen vorthan- } \\
\text { den }\end{array}$ & $\begin{array}{l}\text { implizite Informationen } \\
\text { enweitent }\end{array}$ & $\begin{array}{l}\text { implizite Informationen } \\
\text { weiter erthoht }\end{array}$ \\
\hline QUELLEN & Slovar, 1847 & $\begin{array}{l}\text { Dal', 1863-1866; Slo- } \\
\text { var', } 1847\end{array}$ & $\begin{array}{l}\text { Slovar,1891; Dal',1880- } \\
1882\end{array}$ \\
\hline
\end{tabular}

Abb. 2: Ergebnisse der metalexikographischen Analyse des russisch-deutschen Wörterbuches von Pawlowsky

Zum Schluß bleibt festzuhalten, daß die Ziele, die zu Beginn der Arbeit formuliert wurden, erreicht worden sind und daß das Worterbuch von Pawlowsky zurecht zum Gegenstand einer eingehenden Untersuchung gemacht worden ist. Es ist gelungen, aus einer terra incognita ein zumindest teilweise erforschtes Gebiet zu machen. Zu wünschen bleibt, daß weitere zweisprachige Wörterbücher in ähnlicher Weise untersucht werden, denn nur auf einer solchen Grundlage wird es möglich sein, die längst überfällige Geschichte der russisch-deutschen Lexikographie zu schreiben. 


\section{Literaturverzeichnis}

1. Bibliographien

AAV, Y.: 1977, Russian Dictionaries. Dictionaries and Glossaries printed in Russia 16271917, Zug.

BIRKENMAYER, W.; MOHL, I.: 1990, Bibliographie zur russischen Fachsprache, Tübingen.

LEWANSKI, R.: 1972, A Bibliography of Slavic Dictionaries, Volume III, 2nd Revised and Enlarged Edition, Bologna.

MÜLLER, K.-H.: 1965, Bibliographie der Fachwörterbücher mit deutschen und russischen Aquivalenten, Leipzig.

STANKIEWICZ, E.: 1984, Grammars and Dictionaries of the Slavic Languages from Middle Ages up to 1850. An Annotated Bibliography, Berlin, New York, Amsterdam.

ZAUNMÜLLER, W.: 1958, Bibliographisches Handbuch der Sprachwörterbücher. Ein internationales Verzeichnis von 5600 Wörterbüchem der Jahre 1460-1958 für mehr als 500 Sprachen und Dialekte, Stuttgart.

ZGUSTA, L.: 1988, Lexicography today, an Annotated Bibliography of the Theory of Lexicography, Tübingen.

ВИНОГРАДОВ, В.В.: 1966, Словари изданые в СССР. Библиотрафинекий указатель 1918-1962, Москва.

ВИНОГРАДОВ, В.В. (Hg.): 1954, Библиографияескии указатель литературы по русскому языкознанио с 1825 no 1880 год. Выпуск II. Лексиколотия и лексикоrрaina, Москва.

ВОМПЕРСКИЙ, В.П.: 1986, Словари XVIII. века, Москва.

КАУФМАН, И.И: 1955, Русские биотрафиеские и биобиблиотрафинаские словари, Mockвa.

\section{Worterbicher}

ADELUNG, J. C.: 1970, Grammatisch-kritisches Wörterbuch der Hochdeutschen Mundart mit bestăndiger Vergleichung der übrigen Mundarten, besonders aber der Oberdeutschen, zweite vermehrte und verbesserte Ausgabe, Leipzig 1793-1801, mit einer Einführung und Bibliographie von Helmut Henne, Hildesheim (Reprint).

BIELFELDT, H.H.: 1983, Deutsch-Russisches Wörterbuch, Berlin.

BIELFELDT, H.H.: 1958, Russisch-Deutsches Wörterbuch, Berlin.

BIRKFELLNER, G. (Hg.): 1984, Teutsches und russisches Dictionarium, Wien.

BLATTNER, K.: 1906, Taschenwörterbuch der russischen und deutschen Sprache, BertinSchöneberg, St. Petersburg, Moskau.

DIETZE, J. (Hg.): 1978, Christoph Schmidt, gen. Phiseldek, Kurzes russisch-teutsches und teutsch-russisches Wörterbuch, Halle.

FALOWSKI, A. (Hg.): 1994, "Ein Rusch Boeck...". Ein Russisch-Deutsches anonymes Wörter- und Gesprächsbuch aus dem XVI. Jahrhundert, Köln, Weimar, Wien.

GÜNTHER, E.: 1999, Das deutsch-russische Sprachbuch des Heinrich Newenburgk von 1629. Einführung, sprachliche Analysen, Text, Faksimile, Frankfurt, Berlin.

HAMMERICH, L.L.; JACOBSON, R. (Hg.): Tönnies Fenne's Low German Manual of Spoken Russian, Pskov 1607, Copenhagen.

Vol. I: 1961, Facsimile Copy, Copenhagen.

Vol. II: 1970, Transliteration and Translation, Copenhagen.

Vol. III: 1985, Russian-LowGerman Glossary, Copenhagen

Vol. IV: 1986, Mittelniederdeutsch-neuhochdeutsches Wörterbuch, Copenhagen

HEYM, J.: 1800, Vollständiges Russisch-Deutsches Wörterbuch nach dem grossen Wörterbuche der Russischen Akademie bearbeitet von Johann Heym, Rus- 
sisch-kaiserlichem Hofrath, Professor und Unterbibliothekar der Kaiserlichen Moskowischen Universităt, Riga und Leipzig.

KLUETING, H. (Hg.): 1978, Das Leidener russisch-deutsche Gesprächswörtertuch von ca. 1730 ("Christian Gottlieb Wolf-Lexikon"), Amsterdam.

LENSTROEM, N.: 1891, Russisch-deutsches und deutsch-russisches Wörterbuch, neue, durchgängig revidierte und vermehrte Autlage, Sondershausen.

LUNDEN, S.S.: 1972, The Trondheim Russian-German MS Vocabulary. A Contribution to 17th Century Russian Lexicography, Oslo, Bergen, Tromsö.

PANZER, B.: 1989, A.-E. Sellius, Vocabularium Russo-Germanicum (1707) und Russorum Formulae Loquendi. Kritische Textausgabe der Handschrift Sign. Miscell D $4^{0} 55$ der Ratsbücherei Lüneburg mit kyrillischer Interpretation der russischen Wörter sowie Indices der deutschen und russischen Wörter mit Stellenverweis, Frankfurt, Bern, New York.

PAWLOWSKY, I.Ja: 1974, Russisch-Deutsches Wöterbuch, dritte, vollstăndig neubearbeitete, berichtigte und vermehrte Auflage, fotomechanischer Nachdruck der 3. Auflage, Riga, 1911, zwei Bănde, Leipzig.

PAWLOWSKY, I.Ja: 1960, Russisch-Deutsches Wörterbuch, dritte, vollstăndig neubearbeitete, berichtigte und vermehrte Auflage, fotomechanischer Nachdruck der 3. Auflage, Riga, 1911, zwei Bănde, Leipzig.

PAWLOWSKY, I.Ja: 1952, Russisch-Deutsches Wörterbuch, dritte, vollstăndig neubearbeitete, berichtigte und vermehrte Auflage, fotomechanischer Nachdruck der 3. Auflage, Riga 1911, zwei Bānde, Leipzig.

PAWLOWSKY, I.Ja: 1923, I.Ja. Pawlowsky's Russisch-Deutsches Wörterbuch, dritte, vollständig neu bearbeitete, berichtigte und vermehrte Auflage, dritter Abdruck, Riga.

PAWLOWSKY, I.Ja: 1922, Deutsch-Russisches Wörterbuch, vierte gänzlich umgearbeitete und sehr vermehrte Auflage, zweiter Abdruck, Riga.

PAWLOWSKY, I.Ja: 1911a, Deutsch-Russisches Wörterbuch, vierte gănzlich umgearbeitete und sehr vermehrte Auflage, Riga.

PAWLOWSKY, I.Ja: 1911, I. Ja. Pawlowsky's Russisch-Deutsches Wörterbuch, dritte, vollständig neu bearbeitete, berichtigte und vermehrte Aurlage, zweiter Abdruck, Riga.

PAWLOWSKY, I.Ja.: 1902, I. Pawlowsky's Deutsch-Russisches Wörterbuch, dritte, umgearbeitete und wesentlich vermehrte Auflage, dritter Abdruck, Riga.

PAWLOWSKY, I.Ja.: 1900, I.Ja. Pawlowsky's Russisch-Deutsches Wörterbuch, dritte, vollstăndig neu bearbeitete, berichtigte und vermehrte Auflage, Riga.

PAWLOWSKY, I.Ja.: 1900a, I. Pawlowsky's Deutsch-Russisches Wörterbuch, dritte, umgearbeitete und wesentlich vermehrte Auflage, zweiter Abdruck, Riga.

PAWLOWSKY, I.Ja.: 1888, Deutsch-Russisches Worterbuch, dritte, umgearbeitete und wesentlich vermehrte Auflage, Riga.

PAWLOWSKY, I.Ja.: 1879, I. Pawlowsky's Russisch-Deutsches Worterbuch, zweite Auflage, vollständig umgearbeitet und wesentlich vermehrt von I. Nikolitsch und $\mathrm{N}$. Asmuß, Riga.

PAWLOWSKY, I.Ja.: 1867, Vollständiges Deutsch-Russisches Worterbuch, 2. Auflage, Riga.

PAWLOWSKY, I.Ja.: 1859, Vollständiges Russisch-Deutsches Wörterbuch, zwei Bănde, Riga.

PAWLOWSKY, I.Ja.: 1856, Vollständiges Deutsch-Russisches Wörterbuch, erstellt von Iwan Pawlowsky, Lektor der russischen Sprache an der Universităt Dorpat, zwei Bände, Riga.

PFAU, KF.: 1890, Biographisches Lexikon des deutschen Buchhandels der Gegenwart. RODDE, J.: 1784, Deutsch-russisches Wörterbuch, Riga. 
SCHMIDT, J.A.E.: 1844, Vollständiges Russisch-Deutsches und Deutsch-Russisches Wörterbuch zum Gebrauch beider Nationen, zweite gänzlich umgearbeitete Stereotypausgabe, Leipzig.

SCHMIDT, J. A. E.: 1842, Neues Russisch-Deutsches und Deutsch-Russisches Taschenwörterbuch, Stereotypausgabe, Leipzig.

SCHOLZ, B; FREIDHOF, G.; KOSTA, P. (Hg.): 1982-1983, Weismanns Petersburger Lexikon von 1731, Band I-III, München.

AHНEHКОВъ, Н.: 1859, Ботанияскіи словарь или собраніе названіи какъ русскихъ такъ и многихъ иностраныхъ растенй на языкахъ латинскомъ, русскомь, нtмецкомъ, французскомъ и другихъ, употребляемыхъ разлиыми племенaмm, обитаюиими въ Россій, Москва.

АПРЕСЯН, Ю.Д; БОГУСЛАВСКАЯ, О.Ю.; ЛЕВОНТИНА, И.Б.; УРЫСОН, Е.В.; ГЛОВИНСКАЯ, М.Я.; КРЫЛОВА, Т.В.: 1997, Новый объАсните Лный словарь синонимов русского языка, переый выпуск, Москва.

ДАЛЬ, В. И.: 1863-1866, Толковый словаръ живаго велмкорускаго языка, т. 1-4, Москва.

ДАЛЬ, В. И.: 1880-1882, Толковый словарь нмваго велмкорускаго языка, второе издане, исправленное и знаиителын умноненнее по рукотиси автора, Т. 1-4, Москва.

ЗАЛИЗНЯК, А.А: 1980, Грамматинеский словарь русского языка, словоизменене, издание второе, стереотипное, Москва.

ЛЕВИЦКІЙ, Г.В.: 1903, Біографиюскій словарь профессоровъ и преподавателей Императорскаг о Юрьевскаго, 6ыеuаго Дерптскаго университета, Т. II, Юрьевъ

ЛЕПИНГ, А.А.; СТРАХОВАЯ, Н.Л.; ЛЕЙН, К; ЕККЕРТ, П.: 1976, РУссКОНЕМЕИИй словарь, издане седымое, исправле и дополн но, Москва.

ЛЕПИНГ, А.А; СТРАХОВАЯ, Н.П.: 1960, Руссконемеикий словарь, издание четвертое, стереотипное, Москва.

ЛОХОВИЦ А.Б.: 1943, РуссконемеЧкий словарь, Москва.

МЕЛЬЧУК, И.А; ЖОЛКОВСКИЙ, А.К: 1984, ТоЛково-Комбинаторный словарь современого русского языка: опыты семантико-синтаксинеского описания русской лексики, Wien.

НИКОНОВА, О.Н.: 1973, Русско-немеикий словары, изданме шестое, стереотипное, MOCKвa.

НИКОНОВА, О.Н.: 1963, Руссконемецкий словарь, издание четвертое, перера6отанНое И дополненно, Москва.

ОЖЕГОВ, С.И.; ШВЕДОВА, Н.Ю.: 1992, Толковый словарь русского языка, Москва.

РОДДЕ, Я.: 1784а, Российской лексикон по алфавиту изданыи Яковом Родде секретарем и переводиком при магистратћ российско императорскаго города Purn, Pura.

[Slovar, 1891] СЛОВАРЬ русскаго языка, 1891, составлей Вторымъ отдыленіемъ Императорской Академій Наукъ, выпускъ первый: А-Втас, С. Петербургъ.

[Slovar, 1847] СЛОВАРЬ церковно-славянскаго и русскаго языка, 1847, составленный Вторымъ отдыленіемъ Императорской Акадаммм Наукъ, т. I-IV, С. Петербургъ.

ФАЛОВСКИЙ, А; ВИТКОВСКИЙ, В. (Hg.): 1992, .Ein Russisch Buch" Tомаса Uрове. Русско-немеикий словарь и разговорник XV. 8., часть 1: Веедение. Фотокопим, Краков.

ФАЛОВСКИЙ, А; ВИТКОВСКИЙ, В. (Нg.): 1997, .Ein Russisch Buch“ Томаса Щрове. Руссконемецкии словарь и разговорник XV. В., часть 2: Комментарим. Индекс, Краков. 
ЦвиЛЛИНГ, М.Я.: 2000, Русско-немеикий словары, четвертое издание, стереотипHое, Москва.

ЯНОВСКИЙ, М.: 1803, Новый словотолкователь расположеный по алфавиту, часть переая, С. Петербург.

\section{Quellen}

MINISTERIUM der Volksaufklärung: Vom Curator des Dorpatschen Lehrbezirks an das Conseil der Kaiserlichen Universität Dorpat, Dorpat am 24ten November 1838, Nr. 2202.

\section{Sekundärliteratur}

ALEKSEEV, M.P.: 1974, Thomas Schrowe und das Russischbuch von 1546. In: ALEKSEEV, M.P.: 1974, Zur Geschichte russisch-europäischer Literaturtraditionen, Aufsätze aus vier Jahrzehnten, Bertin, 21-31 und 344-348.

ANDERS, M.: 1988, Balten in Bayern und Bayern im Baltikum, Pfaffenhofen.

ARD, J.: 1982, The Use of Bilingual Dictionaries by ESL Students while Writing. In: I.T.L. Review of Applied Linguistics, 1982, 58, 1-22.

BAHDER V., E.: 1941, Russische Sprachlehre, Hamburg.

BALTISCHES BIOGRAPHISCHES ARCHIV, 1995, Mikroficheausgabe, München.

BARENBAUM, I.: 1991, Geschichte des Buchhandels in Rußland und der Sowjetunion, Wiesbaden.

BASLER, F.: 1987, Russischunterricht in drei Jahrhunderten, Berlin.

BAUMANN. H.: 1977, Lehrmittel des Russischen für Deutsche im 19. Jahrhundert. In: Zeitschrift für Slawistik, 1977, XXII, 244-249.

BAUMANN, H.: 1969, Zur Geschichte der für Deutsche gedruckten Lehrmittel des Russischen (1731-1945), Habil.schrift, Jena.

BAUNEBJERG HANSEN. G.: 1990, Artikelstruktur im zweisprachigen Wörterbuch. Überlegungen zur Darbietung von Übersetzungsäquivalenten im Wörterbuchartikel. Tübingen.

BÉJOINT, H.; THOIRON. P. (Hg.): 1996, Les dictionnaires bilingues, Louvain-la-Neuve.

BÉJOINT, H.: 1981. The Foreign Student's Use of Monolingual English Dictionaries: A Study of Language Needs and Reference Skills. In: Applied Linguistics, 1981, 2, 207 220.

BENSON, M.: 1995, A Step Forward in Russian Lexicography. In: Slavic and East European Joumal, 39, 1, 431-435.

BERGENHOLTZ, H.; MOGENSEN, J.: 1995, Geschichte der Lexikographie mit Deutsch und Dänisch. In: WIEGAND, H. E. (Hg.): Studien zur zweisprachigen Lexikographie mit Deutsch II. 1995, 191-222.

BERGENHOLTZ, H.; MUGDAN, J.: 1985, Lexikographie und Grammatik. Akten des Essener Kolloquiums zur Grammatik im Wörterbuch, 28.-30.6.1984, Tübingen.

BERGENHOLTZ, H.: 1984, Grammatik im Wörterbuch: Syntax. In: STUDIEN V, 1984, 146.

BERGENHOLTZ, H.: 1984a. Grammatik im Wörterbuch: Wortarten. In: STUDIEN IV. 1984a, 19-72.

BERGENHOLTZ, H.; MUGDAN, J.: 1982, Grammatik im Wörterbuch: Probleme und Aufgaben. In: STUDIEN II, 1982, 17-36.

BERKOV, P.N.: 1958, Deutsch-russische kulturelle Beziehungen im 18. Jahriundert. In: Winter, E. (Hg.): 1958, 64-85.

BIELFELDT, H.H.: 1956, Fragen des russisch-deutschen Wörterbuches. In: Zeitschrift für Slawistik, 2, 1956, 19-34.

BOHLER, C.: 1998, Das Russisch-Deutsche Wörterbuch von Pawtowsky als ethnographische Quelle, Göttingen. (Unveröffentlichte Magisterarbeit) 
BORST, A.: 1963, Der Turmbau von Babel. Geschichte der Meinungen über Ursprung und Vielfalt der Sprachen und Völker, Bd. IV: Schlüsse und Übersichten, Stuttgart.

BUCHHOLTZ, A.: 1899, Geschichte der Juden in Riga bis zur Begründung der Rigischen Hebräergemeinde im Jahr 1842, Riga.

BUCHHOLTZ, A.: 1890, Geschichte der Buchdruckerkunst in Riga 1588-1888. Festschrift der Buchdrucker Rigas zur Erinnerung an die vor 300 Jahren erfolgte Einführung der Buchdruckerkunst in Riga, Riga.

CORBETT, G. G.: 1991, Gender, Cambridge.

DEUBNER, P.: 1998, Von Riga bis Köln. Kurze Geschichte der Familie Deubner als Buchhändler und Verleger, Köln.

DTV-LEXIKON, 1976, ein Konversationslexikon in 20 Bänden, Bd. 4: Deut-Einq, München. DUBOIS, J. u. C.: 1971, Introduction à la lexicographie: le dictionnaire, Paris.

DUDA, W:: 1986, Ein „aktives“ russisch-deutsches Wörterbuch für deutschsprachige Benutzer? Anmerkungen zu Šcerbas Wörterbuchtypologie. In: GÜNTHER (Hg.): 1986 , 9-15.

DUDA, W.; FRENZEL, M.; WOLLER, E.; ZIMMERMANN, T.: 1986, zu einer Theorie der zweisprachigen Lexikographie, Überlegungen zu einem neuen russisch-deutschen Wörterbuch, Berlin.

ECKERT, R.: 1990, Die Phraseologie in Christoph Schmidts kurzem russisch-teutschen und teutsch-russischen Wörterbuch. In: Zeitschrift für Slawistik, 35, 1990, 805-810.

EISMANN, W:: 1991, Die zweisprachige Lexikographie mit Russisch. In: WÖRTERBÜCHER, Bd. 3, 1991, 3068-3085.

FEJER, R.: 1995, Zur Geschichte der deutsch-ungarischen und ungarisch-deutschen Lexikographie von der Jahrhundertwende bis zum Ende des Zweiten Weltkrieges, Tübingen.

FRACZEK, A: 1999, Zur Geschichte der deutsch-polnischen und polnisch-deutschen Lexikographie (1772-1868), Tübingen.

GERNENTZ, H.J. (Hg.): 1988, Untersuchungen zum Russisch-niederdeutschen Gesprächsbuch des Tönnies Fenne, Pskov 1607. Ein Beitrag zur deutschen Sprachgeschichte, Berlin.

GLEASON, H.A: 1962, The Relation of Lexicon and Grammar. In: HOUSEHOLDER, F.W.; SAPORTA, S. (Hg.): 1962, 85-102.

GÜNTHER, E.: 1986, Beiträge zur Lexikographie slawischer Sprachen, Berlin.

GÜNTHER, E.: 1964, Zwei russische Gesprächsbücher aus dem 17. Jahrhundert, Dissertation, Berlin.

HAAS, M.: 1962. What Belongs in the Bilingual Dictionary? In: HOUSEHOLDER, F.W.; SAPORTA, S. (Hg.): 1962, 45-50.

HARTENSTEIN, K.: 1999, Konzeptionen der sowjetischen und russischen Semantik. In: JACHNOW, H. (Hg.): 1999, 910-953.

HARTENSTEIN, K.: 1981, das erklärend-kombinatorische Wörterbuch im 'smysl-tekst'Modell. Studien zu den lexikologischen Grundlagen der Bedeutungsexplikation und ihrer lexikographischen Verwendbarkeit, München.

HARTMANN, R.R.K.: 1987, Wozu Wörterbücher? Die Benutzungsforschung in der zweisprachigen Lexikographie. In: Lebende Sprachen, 1987, 4, 154-156.

HARTMANN; R.R.K. (Hg.): 1984, LEXeter '83 Proceedings. Papers from the Intemational Conference on Lexicography at Exeter, 9-12 September 1983, Tübingen.

HARTMANN, R.R.K.: 1983, The Bilingual Leamer's Dictionary and its Uses. In: Multilingua, 1983, 2, 195-201.

HAUSMANN, F.: 1991, Spezifische Bauteile und Strukturen zweisprachiger Wörterbücher: eine Übersicht. In: WÖRTERBÜCHER, Bd. 3, 1991, 2729-2769.

HAUSMANN, F.: 1989, Pour une histoire de la mètalexicographie. In: WORTERBÜCHER, Bd. 1, 1989, 216-224.

HAUSMANN, F.: 1989a, Kleine Geschichte der Metalexikographie. In: WIEGAND, H.E. (Hg.): 1989a, 75-109. 
HAUSMANN, F.: 1989b, Die Markierung im allgemeinen einsprachigen Wörterbuch: eine Übersicht. In: WORTERBÜCHER, Bd. 1, 1989, 649-657.

HAUSMANN, F.: 1988, Grundprobleme des zweiprachigen Worterbuchs. In: HYLDGAARD-JENSEN, K.; ZETTERSTEN, A. (Hg.): 1988, 137-154.

HAUSMANN, F.: 1986, Wörterbuch und Wahrheit. Zur Rezeption des Worterbuchs der deutschen Gegenwartssprache in der Bundesrepublik. In: MALIGE-KLAPPENBACH, H.: 1986, Das .Wörterbuch der deutschen Gegenwartssprache", Berichte, Dokumentation und Diskussion, Tübingen, 175-192.

HAUSMANN, F.: 1977, Einführung in die Benutzung der neufranzösischen Wörterbücher, Tübingen.

HENNE, H.: 1972, Semantik und Lexikographie. Untersuchungen zur lexikalischen Kodifikation der deutschen Sprache. Berlin.

HENNE, H.: 1970, Einführung und Bibliographie. In: ADELUNG, J. C.: 1970, I-XXI.

HOLLANDER, B.: 1927, Geschichte der Literärisch-practischen Bürgerverbindung in Riga 1802-1927, Festschrift zum 125-jährigen Jubiläum, Riga.

HOUSEHOLDER, F.W.; SAPORTA, S. (Hg.): 1962, Problems in Lexicography. Report of the Conference on Lexicography Held at Indiana University 11./12. 11. 1960, Bloomington.

HYLDGAARD-JENSEN, K.; PEDERSEN, V.H. (Hg.): 1994. Symposium on Lexicography V. Proceedings of the Sixth International Symposium on Lexicography May 7-9, 1992 at the University of Copenhagen, Tübingen.

HYLDGAARD-JENSEN, K.; ZETTERSTEN, A. (Hg.): 1992. Symposium on Lexicography V. Proceedings of the Fifth International Symposium on Lexicography May 3-5, 1990 at the University of Copenhagen, Tübingen.

HYLDGAARD-JENSEN, K.; ZETTERSTEN, A. (Hg.): 1988a, Symposium on Lexicography IV. Proceedings of the Fourth International Symposium on Lexicography April 20-22, 1988 at the University of Copenhagen, Tübingen.

HYLDGAARD-JENSEN, K.; ZETTERSTEN, A. (Hg.): 1988, Symposium on Lexicography III. Proceedings of the Third International Symposium on Lexicography May 14-16. 1986 at the University of Copenhagen, Tübingen.

HYLDGAARD-JENSEN, K.: ZETTERSTEN, A. (Hg.): 1985, Symposium on Lexicography II, Proceedings of the Second International Symposium on Lexicography May 16-17. 1984 at the University of Copenhagen, Tübingen.

HYLDGAARD-JENSEN. K. ( $\mathrm{Hg}$.$) : 1983, Proceedings of the Symposium on Lexicography:$ September 1-2, 1982 at the University of Copenhagen. Hildesheim.

IANUCCI. J.: 1962, Meaning Discrimination in Bilingual Dictionaries. In: HOUSEHOLDER, F.W.; SAPORTA, S. (Hg.): 1962, 201-216.

ISACENKO, A.: 1980, Geschichte der russischen Sprache. Heidelberg.

JACHNOW, H. (Hg.): 1999, Handbuch der spractwissenschaftlichen Russistik und ihrer Grenzdisziplinen, Wiesbaden.

JACHNOW, H.: 1990. Russische Lexikographie. In: WORTERBÜCHER, Bd. 1, 1989, 2309-2329.

JAGIĆ, V.: 1892, Bibliographisches. In: Archiv für Slavische Philologie, 14, 1892, 613-636.

JEANNIN, P.: 1973, Der Lübecker Tónnies Fonne - ein Pionier der Slawistik. In: Hansische Geschichtsblätter, 91, 1973, 50-53.

JELITTE, H.; KONOVALOV, V.N.; NIKOLAEV, G.A.; SAFIULLIN, Ja.G. (Hg.): 1994. Deutsch-russische Sprach- und Literaturbeziehungen im 18. und 19. Jahrhundert. Frankfurt.

JOHANSEN, P.: 1955, Fragment eines niederdeutsch-russischen Sprachführers (1551). In: Zeitschrift für Slavische Philologie, 23, 1955, 275-283.

KEIPERT, H: 1992, Wörterbücher. Dictionaries. Dictionnaires. Ein intemationales Handbuch zur Lexikographie [...]. Hrsg. von Franz Josef Hausmann, Oskar Reichmann, Herbert Ernst Wiegand, Ladislav Zgusta. Bd. 1-3. Berlin. New York: Walter de 
Gruyter 1989-1991. In Zeitschrift für Slavische Philologie, Sonderdruck, LII, 2, 1992, 380-393.

KEIPERT; H.: 1987, Cellarius in Rußland. In: Russian Linguistios, 11, 1987, 297-317.

KOERNER, W.: 1891, Ueber russische Schrift, Aussprache und Orthographie. In: LENSTROEM, N., 1891, I-XVI.

KOPENHAGENER BEITRÄGE zur Germanistischen Linguistik, 1977, 12, Kopenhagen.

KRAUS, W.; STIEBER, Z. (Hg.): 1969, Slawisch-Deutsche Wechselbeziehungen in Sprache, Literatur und Kultur, Berlin.

KRINGS, H.-P.: 1986, Was in den Köpfen von Übersetzern vorgeht. Eine empirische Studie zur Struktur des Übersetzungsprozesses an fortgeschrittenen Französischlemern. Tübingen.

KROMANN, H.; RIIBER, T.; ROSBACH, P.: 1991, Principles of Bilingual Lexicography. In: WORTERBÜCHER, Bd. 3, 1991, 2711-2728.

KROMANN, H.; RIIBER, T.; ROSBACH, P.: 1984, Üborlegungen zu Grundfragen der zweisprachigen Lexikographie. In: STUDIEN V, 1984, 159-238.

LANDAU, S.: 1984, Dictionaries: the Art and Craft of Lexicography, New York.

LEHFELDT, W.: 1990, Zur Stellung des Russisch-Deutschen Wörterbuchs von I.Ja. Pavlovskij in der russischen Lexikographie des 19. Jahrhunderts. In. Wiener Slawistischer Amanach, 25/26, 1990, 275-289.

LENZ, W.: 1970, Deutschbaltisches biographisches Archiv 1700-1960, Berlin.

LORCK, C.: 1883, Geschichte des Vereins der Buchhändler zu Leipzig während der ersten 50 Jahre seines Bestehens 1833-1882, Festschrift, Leipzig.

LUNDEN, S.S.: 1991, Panzer, Baldur: A-E. Sellius, Vocabularium Russo-Germanicum (1707) und Russorum Formulae Loquendi; Kritische Textausgabe der Handschrift Sign. Miscell D 4055 der Ratsbücherei Lüneburg mit kyrillischer Interpretation der russischen Wörter sowie Indices der deutschen und russischen Wörter mit Stellenvenweis, Frankfurt 1989. In: Russian Linguistics, 15, 1991, 297-298.

LUNDEN, S.S.: 1980, Das Leidener russisch-deutsche Gesprächswörterbuch von ca. 1730 ('Christian Gottlieb Wolf-Lexicon'), hrg. von Harm Klueting, Amsterdam 1978. In: Russian Linguistics, 5, 1980, 91-93.

LUNDEN, S.S.: 1975, J.A. Comenius and Russian Lexicography. In: Russian Linguistics, 2. 1975, 47-60.

MAI, E. U. J.: 1969, Die deutsch-russischen und russisch-deutschen Factwörterbücher aus der Zeit von 1850-1917 in ihrer ökonomisch-politischen Bedingtheit. In: KRAUS, W.; STIEBER, Z. (Hg.): 1969, 110-119.

MALKIEL, Y.: 1962, A Typological Classification of Dictionaries on the Basis of Distinctive Features. In: HOUSEHOLDER, F.W.; SAPORTA, S. (Hg.): 1962, 3-24.

MARELLO, C.: 1989, Dizionari bilingui; con schede sui dizionari italiani per francese, inglese, spagnolo, tedesco, Bologna.

MEDER, G.: 1992, Zum Stand der deutsch-(serbo)kroatischen/(serbo)kroatisch-deutschen Lexikographie: die wichtigsten Wörterbücher. In: HYLDGAARD-JENSEN. K:; ZETTERSTEN, A.(Hg.): 1992, 159-173.

MEL'ĊUK, I.A.: 1982, Towards a Language of Linguistics. A System of Formal Notions for Theoretical Morphology, München.

METTIG. C.: 1883, Zur Geschichte der rigaschen Gewerbe im 13. und 14. Jahrhundert, Riga.

MIKKELSEN, H. K.: 1992, What Did Scerba actually Mean by .Active" and .Passive“ Dictionaries? in: HYLDGAARD-JENSEN, K.; ZETTERSTEN, A. (Hg.). 1992, 25-40.

MOGENSEN, J.; PEDERSEN, V.; ZETTERSTEN, A. (Hg.): 2000, Symposium on Lexicography IX. Proceedings of the Ninth International Symposium on Lexicography April 23-25, 1998 at the University of Copenhagen, Tübingen.

MORÁN, M.: 1993, Wörterbuchkritik im spanischen Sprachraum. In: Lexicographica. Internationales Jahrbuch für Lexikographie, 9, 91-117. 
MORMILE, M.: 1993, Storia dei dizionari bilingui italo-francesi: La lessicografia italofrancese dalle origini al 1900, Fasano.

MÜHLSCHLEGEL, U.: 2000, Enciclopedia, vocabulario, dictionario. Spanische und portugiesische Lexikographie im 17. und 18. Jahrhundert, Frankfurt.

MÜLLER, O.: 1999, Lexikographie. In: JACHNOW, H. (Hg.): 1999, 290-320.

MUGDAN, J.: 1992, On the Typology of Bilingual Dictionaries. In: HYLDGAARD-JENSEN, K; ZETTERSTEN, A. (Hg.): 1992, 17-24.

MUGDAN, J.: 1992a, Zur Typologie zweisprachiger Wöterbücher. In: MEDER, G.; DORNER, A. (Hg.): 1992, Worte, Wörter, Wörterbicher. Lexikographische Beiträge zum Essener Linguistischen Kolloquium, Tübingen, 25-48.

MUGDAN, J.: 1983, Grammatik im Wörterbuch: Floxion. In: STUDIEN III, 1983, 179-237.

MULSCH, H.: 1993, Handbuch der russischen Gegenwartssprache, Leipzig, Berlin, München.

NAMENTLICHE ANZEIGE der Lettern und andern Typen, wetche gegerwwartig in der Steffenhagenschen Buchdruckerei befindlich sind, 1809, Mitau.

NIEBAUM, H.: 1989, Diatopische Markierungen im allgemeinen einsprachigen Wörterbuch. In: WORTERBÜCHER. Bd. 1, 1989, 662-668.

O'CONNOR, D.: 1990, A History of Italien and English Bilingual Dictionaries, Firenze.

PANZER, B.: 1992, Sellius' Vocabularium Russo-Germanicum und die frühe deutschrussische Lexikographie. In: HYLDGAARD-JENSEN, K.; ZETTERSTEN, A.: 1992. 189-200.

PAPACHRISTOS, E.: 1990, Die deutsch-neugriechische Lexikographie von 1796 bis 1909, Tübingen.

PAWLOWSKY, I.Ja.: 1857/1981, Kurzgefasste slavonische Grammatik für Deutsche, mit einer Einleitung von Dietrich Gerhardt, Tübingen.

PAWLOWSKY, I.: 1849, Einladung zur Subscription auf ein vollständiges deutschrussisches Wörterbuch, Dorpat.

PAWLOWSKY, I.Ja.: 1838, Russische Sprachlehre für Deutsche, Dorpat.

PAWLOWSKY, I.Ja.: 1838a. Theoretisch-practischer Cursus der russischen Sprache, Dorpat.

PFUHL, E.: 1895, Weitere Fortschritte in der Flachsgewinnung, Riga.

POELCHAU, A.: 1918, Der Vertag von Johann Friedrich Hartknoch, Buchhåndler und Verleger, Mitau 1762-1767, Riga 1767-1804. Ein bibliographischer Versuch, Riga.

QUEMADA, B.: 1967, Les dictionnaires du français modeme 1539-1863. Etude sur leur histoire, leurs types et leurs méthods, Paris.

RAECKE, J.: 1972. Untersuchung zur Entwicklung der Nominalkomposition im Russischen seit 1917, München.

REY-DEBOVE, J.: 1971, Etude linguistique et sémiotique des dictionnaires français contemporains, Den Haag.

RIPFEL, M.: WIEGAND, H.E.: 1988, Wörterbuchbenutzungsforschung. Ein kritischer Bericht. In: STUDIEN VI.2, $1988,491-520$.

RIPFEL, M.: 1989, Wörterbuchkritik. Eine empirische Analyse von Wörterbuchrezensionen, Tübingen.

SCHAEDER, B.: 1987, Germanistische Lexikographie, Tübingen.

SCHMIDT, G.: 1989, Diachronische Markierungen im allgemeinen einsprachigen Wörterbuch. In: WORTERBÜCHER, Bd. 1, 1989, 657-661.

SWANSON, D. C.: 1962, Recommendations on the Selection of Entries for a Bilingual Dictionary. In: HOUSEHOLDER, F.W.; SAPORTA, S.(Hg.): 1962, 63-77.

STEINER, R.: 1970, Two Centuries of Spanish and English Bilingual Lexicography (15901800), The Hague.

[STUDIEN I] WIEGAND, H. E. (Hg.): 1981, Studien zur Neuhochdeutschen Lexikographie I, Hildesheim.

[STUDIEN II] WIEGAND, H.E. (Hg.): 1982, Studien zur Neuhochdeutschen Lexikographie II, Hildesheim. 
[STUDIEN III] WIEGAND, H.E. (Hg.): 1983, Studien zur Neuhochdeutschen Lexikographie III, Hildesheim.

[STUDIEN IM] WIEGAND, H.E. (Hg.): 1984a, Studien zur Nouhochdeutschen Lexikographie IV, Hildesheim.

[STUDIEN V] WIEGAND, H.E. (Hg.): 1984, Studien zur Neuhochdeutschen Lexikographie V. Hildesheim.

[STUDIEN V.1] WIEGAND, H. E. (Hg.): 1986, Studien zur Neuhochdeutschen Lexikographie $V_{1}$ 1. Teilband, Hildesheim.

[STUDIEN V.2] WIEGAND, H. E. (Hg.): 1988, Studien zur Neuhochdeutschen Lexikographie VI, 2. Teilband, Hildesheim.

VRTANEN, P.: 1993, Zur Geschichte der finnisch-deutschen Lexikographie 1888-1991, Studien zur Makrostruktur, Tübingen.

WAHRIG, G.: 1983, Gesammelte Schriften. Hrsg. und zusammengestelt von E. Wahrig. mit einem Geleitwort von H. Eggers, Tübingen.

WEINREICH, U.: 1962, Lexicographical Definition in Descriptive Semantics. In: HOUSEHOLDER, F.W.; SAPORTA. S. (Hg.): 1962, 25-44.

WEISS, D.: 1999, Sowjetische Sprachmodelle und ihre Weiterführung. In: JACHNOW, H. (Hg.): 1999, 873-909.

WERNER, R.: 1991, Die Markierungen im zweisprachigen Wörterbuch. In: WORTERBÜCHER, Bd. 3, 1991, 2796-2803.

WERNER, R.: 1990, Studien zur Neuhochdeutschen Lexikographie. Hrsg. von Herbert Emst Wiegand. In: Lexicographica, 1990, 6, 267-284.

WERNER, R.: 1982, Zur Reihenfolge der Definitionen bzw. Übersetzungsäquivalente im Wörterbuchartikel (mit besonderer Berücksichtigung spanischer Beispiele). In: Lebende Sprachen, 4, 1982, 150-156.

WIEGAND, H.E. (Hg.): 2000, Wörterbücher in der Diskussion IV. Vorträge aus dem Heidelberger Lexikographischen Kolloquium, Tübingen.

WIEGAND, H.E.: 1998, Wörterbuchforschung. Untersuchungen zur Wörterbuchbenutzung, zur Theorie, Geschichte, Kritik und Automatisierung der Lexikographie, 1. Teilband, Berlin.

WIEGAND, H.E. (Hg.): 1998a, Wörterbücher in der Diskussion III. Vorträge aus dem Heidelberger Lexikographischen Kolloquium, Tübingen.

WIEGAND, H.E. (Hg.): 1996, Wörterbücher in der Diskussion II. Vorträge aus dem Heidelberger Lexikographischen Kolloquium, Tübingen.

WIEGAND, H. E. : 1993, Geleitwort. In: VRTANEN, 1993, 5-7.

WIEGAND, H.E. $(\mathrm{Hg}$.$) : 1989a. Wörterbücher in der Diskussion I. Vorträge aus dem Hei-$ delberger Lexikographischen Kolloquium, Tübingen.

WIEGAND, H.E.: 1989. Aspekte der Makrostruktur im aligemeinen einsprachigen Wörterbuch: alphabetische Anordnungsformen und inre Probleme. In: WORTERBÜCHER, Bd. 1. 1989, 371-409.

WIEGAND, H.E.: 1985, Fragen zur Grammatik in Wörterbuchbenutzungsprotokollen. Ein Beitrag zur empinischen Erforschung der Benutzung einsprachiger Wörtertücher. In: BERGENHOLTZ, H.; MUGDAN, J.: 1985, 20-98.

WINTER, E. (Hg.): 1958, Die deutsch-russische Begegnung und Leonhard Euler. Beiträge zu den Beziehungen zwischen der deutschen und der russischen Wissenschaft und Kultur im 18. Jahrhundert, Bentin.

[WORTERBÜCHER, 1989] HAUSMANN, F.; REICHMANN, O.; WIEGAND, H.E.; ZGUSTA. L.: 1989, Worterbücher, Dictionaries, Dictionnaires. Ein Internationales Handbuch zur Lexikographie, Bd. 1, Berlin.

[WORTERBÜCHER, 1990] HAUSMANN, F.; REICHMANN, O.; WIEGAND, H.E.; ZGUSTA, L.: 1990, Wörterbücher, Dictionaries, Dictionnaires. Ein Internationales Handbuch zur Lexikographie, Bd. 2, Bertin. 
[WORTERBÜCHER, 1991] HAUSMANN, F.; REICHMANN, O.; WIEGAND, H.E.; ZGUSTA, L.: 1991, Wörtertücher, Dictionaries, Dictionnaires. Ein Intemationales Handbuch zur Lexikographie, Bd. 3, Berlin.

WOLNY, H.: 1954, Geschichte des russisch-deutschen Wörterbuches. Hausarbeit für die Wissenschaftliche Lehrerprüfung, Bertin.

WOLSKI, W. (Hg.): 1982, Aspekte der sowjetrussischen Lexikographie. Übersetzungen, Abstracts, bibliographische Angaben, Tübingen.

YÜEKSEKKAYA, H.: 1998, die deutsch-türkische Lexikographie: metalexikographische Untersuchung der allgemeinen großen Wörterbücher, Tübingen.

ZETTERSTEN, A.; MOGENSEN, J.; PEDERSEN, V.H. (Hg.): 1999, Symposium on Lexicography VII, Proceedings of the Eight International Symposium on Lexicography May 2-4, 1996 at the University of Copenhagen, Tübingen.

ZETTERSTEN, A.; PEDERSEN, V.H. (Hg.): 1996, Symposium on Lexicography VI, Proceedings of the Seventh International Symposium on Lexicography May 5-6, 1994 at the University of Copenhagen, Tübingen.

ZGUSTA, L.: 1992, History, Languages and Lexicographers, Tübingen.

ZGUSTA, L.: 1985, Probleme des Worterbuchs, Darmstadt.

ZGUSTA, L. (Hg.): 1980, Theory and Method in Lexicography, Western and non-Western Perspectives, Columbia.

ZGUSTA, L.: 1971, Manual of lexicography, The Hague.

AЛЕКСЕЕВ, М.П.: 1968, Словари иностраных языков в русском азбуковнке XVI века, Лeнинтрад.

АЛРЕСЯН, 1О. Д: 1995, Из6раные труды. Том 1: Лексинская семантика, том 2: Интегралы ое описане языка и системая лексикография, Москва.

БАБКИH, АM:: 1965, Лексикотрафинеская традииия и пути его обновления. In: Известия Академим Наук СССР, Серия литературы и языка, Bd. XXIV, Cепт.OKT., 1965, 396-404.

БАБКИН, АМ: 1964, Лексикографиеская разработка русской фразеолоти, Ленитрад.

БАБКИН, АМ: 1960, По вопросам русской лексикологи и лексикографим. In: Лексикографиеский с6орник, 4, 1960, 3-14.

БEPE3ИНА, О.:: 1980, Два тематинасих лексикона нанала XVIII В (Сравнтельная характеристика). In: КУТИНА, Л.Л.; БИРЖАКОВА, Е.Е. (Hg.): 1980, 6-22.

БЕРКОВ, В.П.: 1996, Двуязынная лексикография, С. Петербург.

БЕРКОВ, В.П.: 1977, Слово в двуязын+ом словаре, Таллин.

БEРКОВ, В. П.: 1973, Вопросы двуязынй лексикографм, Ленмтрад.

БИРЖАКОВА, Е.Э.: 1977. Лексикографинеске истоини и их использование в словаре русского языка XVIII в. In: Проблемы историнеской лексикографим, 1977, Jethirpan.

БУллич, С.К: 1904, Очерк историм языкознания в Росим, С. Петербург. Nachdruck und Nachwort von $\mathrm{H}$. Keipert, München 1989

ВинОГРАДОВ, В.В.: 1977, Избраные труды: Лексикология и лексикография, MOCKвa.

ВИНОГРАДОВ, В.В.: 1977а, Толковые словари русского языка. In: Виноградов, В.В.: 1977, 206-242.

ВИНОГРАДОВ, В.В.: 19776, О некоторых вопросах теори русской лексикографим. In: Bиноградов, B.B.: 1977, 243-264.

ВИНОГРАДОВ, В.В.: 1966, Семнадцатитомны академинский словарь современного русского литературного языка и его значене аля современо языкознания. In: Вопросы Языкознания, 6. 1966, 3-26.

ГРАММАТИКА русского языка, 1960. том 1: фонетика и морфология, МосКва. 
ДЕНИСОВ, П.Н.; МОРКОВКИН, В.В. (Нg.): 1978, Проблемы учебной лексикографим и обучия лексике, Москва.

ДЕНИСОВ, П.Н.; МОРКОВКИН, В.В. (Нg.): 1977, Проблемы уиебной лексикографим, Москва.

ДЕНИСОВ, П.Н.: 1974, Оџерки по русской лексикологим и уиебной лексикографии, Mockвa.

ДЕНМСОВ, П.Н.; НОВИКОВ, Л.А (Нg.): 1969, Вопросы учебтой лексикографим, Mockвa.

ДУБИЧИНСКИЙ, В.В.: 1998, Теоретинская и практиеская лексикотрафия, WienCharkov.

ЖЕЛТОВЪ, И: 1880, И. Я. Павловскаго руссконымеикій словарь Изданіе второе, истравлен и अамителын дополненое И. Николмемв И Н. Асмусомв. In: Филологинакие записки, Воронеж, 1880, 1, 121-126.

ЖОЛОБОВ, О.Ф.: 1994, О русско-немецком словаре 1771 Г. М. Франзиска Гелтергофa. In: JELITTE, H.; KONOVALOV, V.N.; NIKOLAEV, G.A.; SAFIULLIN, Ja.G. (Hg.): 1994, 211-223.

3АИUЕВА, Т.В.; НАЗАРОВА, И.С.: О четьрехТом-ом словаре русского языкв. In: Сoвременая русская лексикография, 1966, 119-134.

3АЙUЕВА, А.А: 1988, Кнкоторговая деятелыность Гарткнохов и Петербургская академия наук. In: 400 лет книнноо дела в Латви, науио-практиюская кошерения Рита, 15-17 ноября 1988 года, Рита, 42-44.

3АЛИЗНЯі, A. A: 1967, Русское именое словоизменение, Москва.

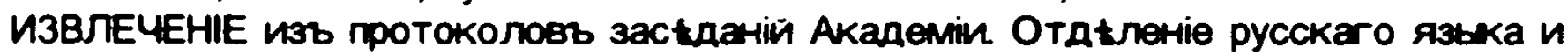
словесности, октябрь 1867 года. In: Записки Императорской Академіи Наук, 12, 1868, 187-195.

ИСТРИНА, Е.С.: 1944, Заметки по двуязыним словарям. In: Известия ОЛЯ СССР, $1944,3,78-97$.

КАНКАВА, М. В.: 1958, В. И. Даль как лексикограф, тт 1-2, Т6илиси.

KACAPEC, Х.: 1958, Введение в современную лексикографио, Москва.

КОВТУН, Л.С.: 1989, Азбуковники XV-XVI в8. (стариая разновидность), Ленинрад.

КОВТУН, Л.С.: 1975, Лексикография в Московской Руси XVI-начала XVII в., Ленинград.

КОВТУН, Л.С.: 1963, Русская лексикография эпохи средневековљя, Лениград.

КУТИНА, Л.Л.; БИРЖАКОВА, Е.Е. (Hg.): 1980, Словари и словарное дело в Россим XVIII. в., Ленитрад.

КУТИНА, ЛЛ:: 1980, Вотросы лексиеской семантики в словаре Академии Россииской (1789-1794rr.). In: КУТИНА, Л.Л.; БИРЖАКОВА, Е.Е. (Hg.): 1980, 70-88.

ЛАРИН, Б.А: 1959, Русско-анлииский словарь-дневник Римарда Днемса 16181619rr., Ленинград.

ЛАРИН, Б.А: 1948, Паринский словарь Московитов, Рита.

ЛУНДЕН, С.С.: 1963, Азбука о голом и небогатом человеке. In: Scando-Slavica, IX, 1963, 169-185.

МЕЛЬЧУК, И.А: 1974, Опыт теории линвистинеских моделей смысл<=>текст. Семантика, синтаксис, Москва.

НИКОЛАЕВ, Г.А.; ТРОШКИНА, Т.П.: 1994, Немеико-русский словарь ХVII века из фондов библиотеки Казанского университета. In: JELITTE, H.; KONOVALOV, V.N.; NIKOLAEV, G.A.; SAFIULLIN, Ja.G. (Hg.): 1994, 149-162.

НИКОЛИЧ, И:: 1843, Опыть пояснения видовь русскихъ глаголовъ, Дерпть.

НIMЧУК, В.В.: 1980, Староукраинська лексикографія в іі з8'язках 3 росіиською та 6ілоруською, Киів. 
ОЖЕГОВ, С.И.: 1952, О трех типах толковых словарей современого русского языка. In: Вопросы Языкознания, 2, 1952, 85-104.

ПАВЛОВСКИЙ, И.Я.: 1844, Руководство Къ географіи Россійской Имперіи, двћ части, Дерпть.

ПАВЛОВСКИЙ, И.Я.: 1843, Пространая географія Россійской Ииперіи, дВћ части, Дерлть .

ПАВЛОВСКИЙ, И.Я.: 1841, Начертаніе географіи Россійской имеріи аля руководства при первоначалыномъ преподаваніи въ уєздныхъ учимщахъ Дерптскаго yuefmaro okpyra, LepnTb.

ПРАВДИН, В.: 1954, Русская филология в Тартуском университете. In: Труды историко-филологинеского факультета, Tallin, 35, 130-164.

CABEЛЬEBA, Е.А.: 1988, Издательская фирма И.Ф. Гарткнохов в Риге и ее публикаum о Росси в XVIII. 8. In: 400 лет кныного дела в Латвм, наунопрактинасая конферениия Рига, 15-17 ноября 1988 года, Рига, 53-55.

СЕНИН, П.И.: 1965, ЗаметкИ о словарях первого 10 летия советской эпохи. In: Филологиеские науки, 8:3, 1965, 150-153.

СЛОВАРЬ, 1859, Полыни Русско-Нtмеикій словарь, составле Иваной Павловскимъ, Рига, 1859 года. In: Морской Сборникъ, XLIV, 5, декабрь, 1859, o. S.

СОРОКОЛЕТОВ, Ф.П.: 1998, История русской лексикографим, Санкт Петербург.

СОРОКОЛЕТОВ, Ф.П.; КУЗНЕЦОВА, О.Д.: 1987, ОчеркИ по русской диалектной лексикографи, Ленингад.

СОРОКОЛЕТОВ, Ф.П.: 1978, Традици русской советской лексикографи. In: Вопросы Языкознания, 3, 1978, 26-42.

СОРОКОЛЕТОВ, Ф.Л.: 1974, Русская лексикография в Академи Наук. In: Вопросы Языкознания, 6, 1974, 19-31.

ФАЛОВСКИЙ, А.: 1991/92, „Ein Rusch Boеck..." руссконемеикий анони словарь parroвoptwk XVI. B. In: Studia Slavica Academiae Scientiarum Hungaricae, 1991/92, 37, 211-217.

ФИЛИН, Ф.П.: 1982, Очерки по теорим языкознания, Москва.

ФЛЕКЕНШТЕЙН, К: 1984, Краткий русско-НемецКий и немецКо-русский словарь Кристофа Uмидта. In: Zeitschrift für Slawistik, 29, 6, 914-920.

ХАЙДАРОВ, Ф.А.: 1994, Идентификация фрасеологиеского состава русского языка по материалам Трехъязыно Петербургского Лексикона 1731 r. In: JELITTE, H.; KONOVALOV, V.N.; NIKOLAEV, G.A.; SAFIULLIN, Ja.G. (Hg.): 1994, 2130.

ЦЕЕЙТ ЛИН, Р.М.: 1958, Краткий очерк историм русской лексикографи, Москва.

ЩЕРБА, Л.В.: 1974, Языковая система и речевая деятелыноть, Летм-трад.

ЩЕРБА, Л.В.: 1974а, Опыт общей теорим лексикографим. In: ЩЕРБА, 1974, 265-304.

ЩЕРБА, Л.В.: 19746, Предисловие к Русско-францускому словарю. In: ЩЕРБА, 1974, 304-312.

ЯГИЧ, В.: 1910, История славанской филологи, Сант Петер6ург.

ЯКИМОВИЧ, Ю.К: 1985, Деятелм русской культуры и словарное дело, Москва. 


\section{Slavistische Beiträge}

Herausgegeben von Peter Rehder

378. Дуличенко, Александр Д.: Этнософиолингвистика «Перестройки» в СССР. Антология запечатленного времени. 1999. VIII, 583 S. 49.08 є. (3-87690-729-2)

379. Kratochvil, Alexander: Mykola Chvyl'ovyj. Eine Studie zu Leben und Werk. 1999. VI, 244 S. $24.54 €$ € (3-87690-736-5)

380. Slavistische Linguistik 1998. Referate des XXIV. Konstanzer Slavistischen Arbeitstreffens, Wien 15.-18.9.98. Herausgegeben von Renate Rathmayr und Wolfgang Weitlaner. 1999. 325 S. $26.59 € .(3-87690-737-3)$

381. Dobrowlanska-Sobczak, Monika Joanna: Das Spiel mit dem Zuschauer. Die Bedeutungsgenerierung im polnischen Bildertheater am Beispiel von "Szczelina“ Leszek Mądziks, "Replika“ Józef Szajnas und „Niech sczezną artyści“ Tadeusz Kantors. 1999. 356 S., zahlr. Abb. $31.70 €$. (3-87690-740-3)

382. Schaeken, Jos, Henrik Birnbaum: Die altkirchenslavische Schriftkultur. Geschichte - Laute und Schriftzeichen - Sprachdenkmäler (mit Textproben, Glossar und Flexionsmustern). Altkirchenslavische Studien II. 1999. 289 S. 24.54 €. (3-87690-741-1)

383. Domblüth, Gesine: „Poststalinizm - postavangardizm“. Das Subjekt und die Welt der Objekte in der postmodemen frühen Lyrik Andrej Voznesenskijs. 1999. 194 S. 21.47 €. (3-87690-742$\mathrm{X})$

384. Bergmann, Martin: Eine diskursanalytische Betrachtung des rok-samizdat in der Sowjetunion und ihren Nachfolgestaaten in der Periode zwischen 1967 und 1994. 1999. 235 S. 24.54 €. (387690-743-8)

385. Sauberer, Gabriele: Die Syntax der „Pis'ma russkogo putesestvennika“ von N. M. Karamzin. 1999. 385 S. 30.68 €. (3-87690-744-6)

386. Lauterbach, Anastassia: Anredeformen im Serbischen um 1800. Die Schauspielbearbeitungen von Joakim Vujic (1772-1847). 1999. 288 S. 24.54 €. (3-87690-751-9)

387. Rippl, Daniela: Žiznetvořestvo oder die Vor-Schrift des Textes. Eine Untersuchung zur Geschlechter-Ethik und Geschlechts-Ästhetik in der russischen Moderne. 1999. 256 S. $24.54 €$. (3-87690-752-7)

388. Poljakov, Fedor B., Carmen Slppl: A. S. Pư̌kin im Übersetzungswerk Henry von Heiselers (1875-1928). Ein europäischer Wirkungsraum der Petersburger Kultur. 1999. 131 S. $18.41 €$. (3-87690-753-5)

389. Betsch, Michael: Diskontinuität und Tradition im System der tschechischen Anredepronomina (1700-1850). 2000. 198 S. $21.47 € .(3-87690-754-3)$

390. Brinkjost, Ulrike: Geschichte und Geschichten. Ästhetischer und historiographischer Diskurs bei N. M. Karamzin. 2000. 225 S. 23.52 €. (3-87690-755-1)

391. Rajewsky, Alice: Changes in the Russian Terminology of Economic Law Since Perestroika. 2000. 208 S. $22.50 €$. (3-87690-757-8)

392. Rybakov, Alexei: Deutsche und russische Literatur an der Schwelle zur Moderne. „Wilhem Meisters Lehrjahre“ und „Eugen Onegin“. Zur Entstehung des modernen Weltbildes. 2000. 251 S. 24.54 €. (3-87690-763-2)

393. Gulawska, Małgorzata: Aspektualität im Polnischen und Deutschen. Eine praktische Untersuchung am Beispiel der Übersetzungen beider Richtungen. 2000. 219 S. 23.52 €. (3-87690764-0)

394. Кондрятенко, Михаил: Лексика народной метеорологии. Опьт сравнительного анализа славянских и немецких наименований природных явлений. 2000. $117 \mathrm{~S} .17 .38 €$. (387690-765-9)

395. Ylli, Xhelal: Das slavische Lehngut im Albanischen. 2. Teil: Ortsnamen. 2000. 280 S. $24.54 €$. (3-87690-772-1) - [1. Teil: Lehnwörter, siehe SB 350, 1997.]

396. Slavistische Linguistik 1999. Referate des XXV. Konstanzer Slavistischen Arbeitstreffens, Konstanz 7.-10.9.1999. Herausgegeben von Walter Breu. 2000. 314 S. 29.65 €. (3-87690774-8)

397. Сологу6, Федор: Двенадцать драм. Составитель Ульрих Штельтнер. 2000. VIII, 366 S. 29.65 €. (3-87690-775-6) - [1 + 2. Bd.: SB 291 (1992) + 343 (1997).]

398. Drews, Peter: Deutsch-polnische Literaturbeziehungen 1800-1850. 2000. 296 S. $24.54 €$. (387690-776-4) 
399. Poljakov, Fedor B., Carmen Sippl: Dramen der russischen Moderne in unbekannten Übersetzungen Henry von Heiselers. 2000. 161 S. 19.43 €. (3-87690-778-0)

400. Patzke, Una: Antonymische Relationen im Text. Zur Neubestimmung einer Kalcoorie unter funktional-kommunikativem Aspekt. 2000. 276 S. 24.54 €. (3-87690-779-9)

401. Notarp, Ulrike: Der Russische Interdiskurs und seine Entwicklung. Eine kultur- und diskurstheoretische Analyse am Material von Schulbüchem (1986-1991 und 1993-1997). 2001. 621 S. 34.77 €. (3-87690-780-2)

402. Soldat, Comelia: Urbild und Abbild. Untersuchungen zu Herrschaft und Weltbild in Altrußland, 11.-16. Jahrhundert. 2001. 265 S. $24.54 €$. (3-87690-81-0)

403. Vintr, Josef: Das Tschechische. Hauptzüge seiner Sprachstruktur in Gegenwar und Geschichte. 2001. 240 S. $20.45 €$. (3-87690-796-9) (= Studienhilfen. 11.)

404. Becker, Joem-Martin: Semantísche Variabilität der russischen politischen Lexik im zwanzigsten Jahrhundert. 2001. 3000 S. $24.54 €$. (3-87690-797-7)

405. Reinkowski, Ljiljana: Syntaktischer Wandel im Kroatischen am Beispiel der Enklitika. 2001. 319 S. $24.54 €$ (3-87690-798-5)

406. Kolchinsky, Irene: The Revival of the Russian Avant-Garde: the Thaw Generation and Beyond. 2001. 206 S. 23.52 є. (3-87690-799-3)

407. Lange, Katrin: Die Glossolalie der Liebe. Geschlechterverhältnisse und Liebesdiskurse in den Texten Valerija Narbokovas. 2001. 204 S. 23.52 €. (3-87690-805-1)

408. Huterer, Andrea: Die Wortbildungslehre in der Anweisung zur Erlernung der SlavonischRußischen Sprache (1705-1729) von Johann Wemer Paus. 2001. 327 S. 26.59. €. (3-87690805-1)

409. Vickery, Walter N.: M. Iu. Lermontov: His Life and Work. 2001. VIII, 422 S. $29.65 \in$. (387690-813-2)

410. Slavistische Linguistik 2000. Referate des XXVI. Konstanzer Slavistischen Arbeitstreffens, Hamburg 26.-28.9.2000. Herausgegeben von Volkmar Lehmann und Jessica Scharnberg. 2001. 277 S. $26.59 \epsilon$. (3-87690-814-0)

411. Berwanger, Katrin: Die szenische Poetik Božena Němcovás. Theatralische Medialität in ihren Briefen, Reiseskizzen und Erzählwerken. 2001. 201 S. 23.52 €. (3-87690-815-9)

412. Świderska, Małgorzata: Studien zur literaturwissenschaftlichen Imagologie. Das literarische Werk F.M. Dostoevskijs aus imagologischer Sicht mit besonderer Berücksichtigung der Darstellung Polens. 2001. 495 S. 29.65 €. (3-87690-816-7)

413. Widera, Steffi: Richard Weiner. Identität und Polarität im Prosafrühwerk. 2001. 296 S. 26.- $€$. (3-87690-818-3)

414. Szucsich, Luka: Nominale Adverbiale im Russischen. Syntax, Semantik und Informationsstruktur. 2002. 255 S. 24.- €. (3-87690-819-1)

415. Breuer, Astrid Yvonne: Asyndese? Zum Problem einer 'negativen' Kategorie. 2002. $291 \mathrm{~S}$. 26.- Є. (3-87690-822-1)

416. Townsend, Charles E., Laura A. Janda: Gemeinslavisch und Slavisch im Vergleich. Einführung in die Entwicklung von Phonologie und Flexion vom Frühurslavischen über das Spätgemeinslavische bis in die slavischen Einzelsprachen. Ubersetzung und Redaktion Peter Rehder. Durchges. Nachdruck 2003 der 1. Aufl. 2002. 237 S. $10 €$. (3-87690-831-0)

417. Stegherr, Marc: Das Russinische. Kulturhistorische und soziolinguistische Aspekte. 2003. XII, 529 S. 58.- €. (3-87690-832-9)

418. Bayer, Lenka: Sprachgebrauch vs. Spracheinstellung im Tschechischen. Eine empirische und soziolinguistische Untersuchung in Westböhmen und Prag. 2003. 328 S. 26.- $€$. (3-87690838-8)

419. Shull, Sarah: The Experience of Space. The Privileged Role of Spatial Prefixation in Czech and Russian. 2003. X. 239 S. 24.- $€$. (3-87690-839-6)

420. Hurtig, Claudia, Taccjana Ramza: Belarussische Grammatik in Tabellen und Übunbgen. Беларуска граматыка у̀ табліцах и практыкаваннях. 2003. 267 S. 20.- €. (3-87690-850-7)

421. Belyavski-Frank, Masha: The Balkan Conditional in South Slavic. A Semantic and Syntactic Study. 2003. IV, X, 310 S. 26.- €. (3-87690-851-5)

422. Slavistische Linguistik 2001. Referate des XXVII. Konstanzer Slavistischen Arbeitstreffens, Frankfurt/Friedrichsdorf 11.-13.9.2001. Herausgegeben von Holger Kuße. 2003. 359 S. 28,€. (3-87690-853-1)

\section{Verlag Otto Sagner • D-80328 München}

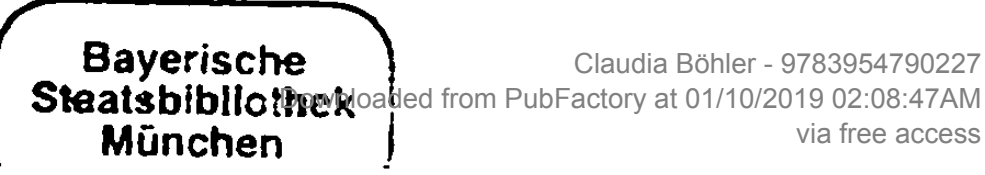

